OAK RIDGE NATIONAL LABORATORY

MARTIN MARUETRA

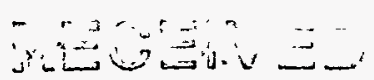

FEB 27198

0 S T 1

Reactor Physics Methods, Models, and Applications Used to Support the Conceptual Design of the Advanced Neutron Source

\author{
J. C. Gehin \\ B. A. Worley \\ J. P. Renier \\ Oak Ridge National Laboratory \\ C. A. Wemple \\ S. N. Jahshan \\ J. M. Ryskamp \\ Idaho National Engineering Laboratory
}

August 1995

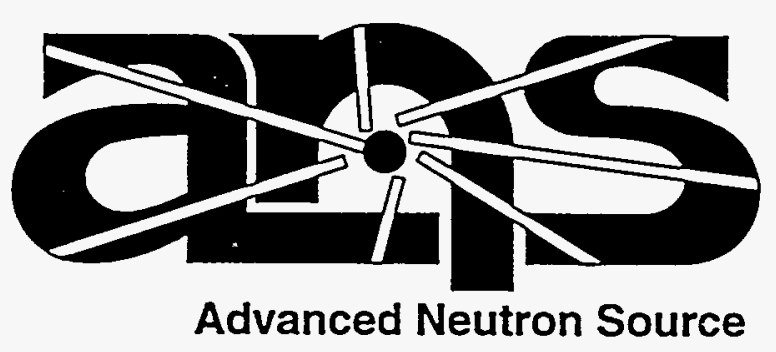

MANAGED BY

MARTIN MARIETTA ENERGY SYSTEMS, INC. FOR THE UNITED STATES DEPARTMENT OF ENERGY 
This report has been reproduced directly from the best available copy.

Available to DOE and DOE contractors from the Office of Scientific and Technical Information, P.O. Box 62, Oak Ridge, TN 37831; prices available from (615) 576-8401, FTS 626-8401.

Available to the public from the National Technical Information Service, U.S. Department of Commerce, 5285 Port Royal Rd., Springfield, VA 22161.

This report was prepared as an account of work sponsored by an agency of the United States Government. Neither the United States Government nor any agency thereof, nor any of their employees, makes any warranty, express or implied, or assumes any legal liability or responsibility for the accuracy, completeness, or usefulness of any information, apparatus, product, or process disclosed, or represents that its use would not infringe privately owned rights. Reference herein to any specific commercial product, process, or service by trade name, trademark, manufacturer, or otherwise, does not necessarily constftute or imply its endorsement, recommendation, or favoring by the United States Government or any agency theresf. The views and opinions of authors expressed herein do not necessarily state or reflect those of the United States Government or any agency thereof. 
This report has been reproduced directly from the best available copy.

Available to DOE and DOE contractors from the Office of Scientific and Technical information. P.O. Box 62, Oak Ridge, TN 37831; prices available from (615) 576-8401, FTS 626-8401.

Available to the public from the National Technical Information Service, U.S. Department of Commerce, 5285 Port Royal Rd., Springfield, VA 22161.

This report was prepared as an account of work sponsored by an agency of the United States Government. Neither the United States Government nor any agency thereof, nor any of their employees, makes any warranty, express or implied, or essumes any legal liability or responsibility for the accuracy, cornpleteness, or usefulness of any information, apparatus, product, or process disclosed, or represents that its use would not infringe privately owned rights. Reference herein to any specific commercial product, process, or service by trade name, trademark, manufacturer, or otherwise, does not necessarily constitute or imply its endorsement, recommendation, or favoring by the United States Government or any agency theresf. The views and opinions of authors expressed herein do not necessarily state or reflect those of the United States Government or any agency thereof. 
Computational Physics and Engineering Division

\title{
REACTOR PHYSICS METHODS, MODELS, AND APPLICATIONS \\ USED TO SUPPORT THE CONCEPTUAL DESIGN OF THE ADVANCED NEUTRON SOURCE
}

\author{
J. C. Gehin \\ B. A. Worley \\ J. P. Renier
}

Oak Ridge National Laboratory

C. A. Wemple

S. N. Jahshan

J. M. Ryskamp

Idaho National Engineering Laboratory

Date Published - August 1995

Prepared by the

OAK RIDGE NATIONAL LABORATORY

Oak Ridge, Tennessee 37831

managed by

LOCKHEED MARTIN ENERGY SYSTEMS, INC.

for the

U.S. DEPARTMENT OF ENERGY

under contract DE-AC05-84OR21400 


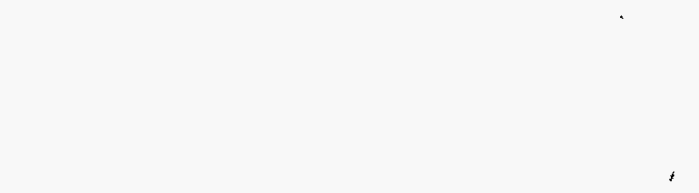




\section{TABLE OF CONTENTS}

LIST OF FIGURES $\ldots \ldots \ldots \ldots \ldots \ldots \ldots \ldots \ldots \ldots \ldots \ldots \ldots \ldots \ldots \ldots$

LIST OF TABLES $\ldots \ldots \ldots \ldots \ldots \ldots \ldots \ldots \ldots \ldots \ldots \ldots \ldots \ldots \ldots \ldots$

ACRONYMS, ABBREVIATIONS AND SYMBOLS $\ldots \ldots \ldots \ldots \ldots \ldots \ldots$

EXECUTIVE SUMMARY $\ldots \ldots \ldots \ldots \ldots \ldots \ldots \ldots \ldots \ldots \ldots \ldots \ldots \ldots$

1. INTRODUCTION $\ldots \ldots \ldots \ldots \ldots \ldots \ldots \ldots \ldots \ldots \ldots \ldots \ldots \ldots \ldots \ldots \ldots \ldots \ldots \ldots$

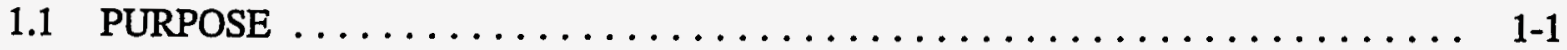

1.2 GENERAL BACKGROUND $\ldots \ldots \ldots \ldots \ldots \ldots \ldots \ldots \ldots \ldots \ldots \ldots \ldots \ldots \ldots \ldots$

1.2.1 ANS Project Technical Objectives ................... 1-1

1.2 .2 ANS Design Goals . . . . . . . . . . . . . . . . . . . . 1-1

1.2.3 Desired Design Features . . . . . . . . . . . . . . . . . 1-1

1.2.4 Selection of the Conceptual Core Design $\ldots \ldots \ldots \ldots \ldots \ldots \ldots \ldots \ldots$

2. CONCEPTUAL CORE DESIGN DESCRIPTION . . . . . . . . . . . . . 2-1

3. COMPUTER CODE DESCRIPTIONS $\ldots \ldots \ldots \ldots \ldots \ldots \ldots \ldots \ldots \ldots \ldots \ldots \ldots$

3.1 CROSS-SECTION PROCESSING CODES $\ldots \ldots \ldots \ldots \ldots \ldots \ldots \ldots \ldots \ldots \ldots \ldots \ldots . \ldots . \ldots . \ldots \ldots$

3.1.1 Codes Used to Create a Master Library .................... 3-1

3.1.2 Codes Used to Produce Few-Group Problem-Dependent

Cross-Section Libraries . . . . . . . . . . . . . . . . . . . . . 3-2

3.2 VENTURE DIFFUSION-THEORY CODE $\ldots \ldots \ldots \ldots \ldots \ldots \ldots \ldots \ldots \ldots \ldots \ldots$ 3-2

3.3 BURNER FUEL DEPLETION CODE $\ldots \ldots \ldots \ldots \ldots \ldots \ldots \ldots \ldots \ldots \ldots \ldots \ldots$

3.4 PDQ DIFFUSION-THEORY CODE $\ldots \ldots \ldots \ldots \ldots \ldots \ldots \ldots \ldots \ldots \ldots \ldots \ldots \ldots \ldots$

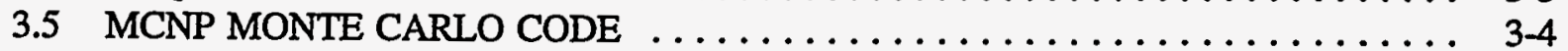

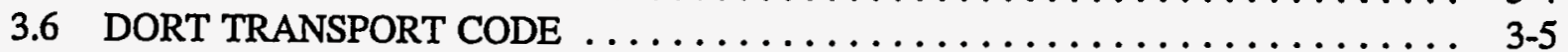

3.7 CONQUEST NODAL KINETICS CODE $\ldots \ldots \ldots \ldots \ldots \ldots \ldots \ldots \ldots \ldots \ldots \ldots$

4. CROSS-SECTION DEVELOPMENT AND VALIDATION . . . . . . . . . . . . 4-1

4.1 CROSS SECTIONS FOR ENERGY GROUP CODES, VENTURE, DORT,

AND KENO $\ldots \ldots \ldots \ldots \ldots \ldots \ldots \ldots \ldots \ldots \ldots \ldots \ldots \ldots \ldots \ldots \ldots$ 4-1

4.1.1 Cross Sections Used in Fuel Cycle Analysis for the Conceptual

Core Design . . . . . . . . . . . . . . . . . . . . . . . 4-1

4.1.2 The ANSL-V Cross-Section Library . . . . . . . . . . . . . . . . . . 4-1

4.2 MCNP CROSS-SECTION DEVELOPMENT AND VALIDATION . . . . . . . . . 4 4-5

4.3 PDQ TRANSPLUTONIUM ISOTOPE PRODUCTION ROD CROSS SECTIONS . . . 4-5

5. TRANSPORT AND DIFFUSION CODES VALIDATION RESULTS $\ldots \ldots \ldots \ldots \ldots \ldots$

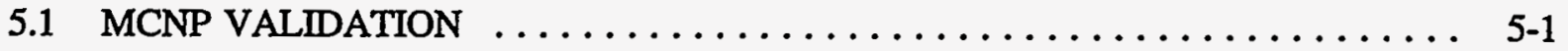

5.2 DORT VALIDATION $\ldots \ldots \ldots \ldots \ldots \ldots \ldots \ldots \ldots \ldots \ldots \ldots \ldots \ldots \ldots \ldots \ldots$

5.3 VENTURE VALIDATION $\ldots \ldots \ldots \ldots \ldots \ldots \ldots \ldots \ldots \ldots \ldots \ldots \ldots \ldots \ldots$

5.4 PDQ VALIDATION $\ldots \ldots \ldots \ldots \ldots \ldots \ldots \ldots \ldots \ldots \ldots \ldots \ldots \ldots \ldots \ldots \ldots \ldots$

5.5 BURNER VALIDATION $\ldots \ldots \ldots \ldots \ldots \ldots \ldots \ldots \ldots \ldots \ldots \ldots \ldots \ldots \ldots$ 
6. MODELING ................................ 6-1

6.1 MCNP MODELING USED IN CONCEPTUAL CORE DESIGN ANALYSIS . . . . . 6-1

6.1.1 MCNP Inner Control Rod Modeling $\ldots \ldots \ldots \ldots \ldots \ldots \ldots \ldots$ 6-1

6.1.2 MCNP Outer Control Rod Modeling $\ldots \ldots \ldots \ldots \ldots \ldots \ldots \ldots \ldots, 6-11$

6.1.3 MCNP Component Modeling $\ldots \ldots \ldots \ldots \ldots \ldots \ldots \ldots \ldots \ldots, 6-13$

6.2 VENTURE/BURNER MODELING AND ANALYSES $\ldots \ldots \ldots \ldots \ldots \ldots \ldots 6-15$

6.2.1 VENTURE Model for Fuel Cycle Analysis . . . . . . . . . . . . 6 6-15

6.2 .2 Fuel Depletion Model . . . . . . . . . . . . . . . . . . . 6-20

6.3 PDQ-7 MODEL FOR FUEL CYCLE ANALYSIS $\ldots \ldots \ldots \ldots \ldots \ldots \ldots \ldots 6-20$

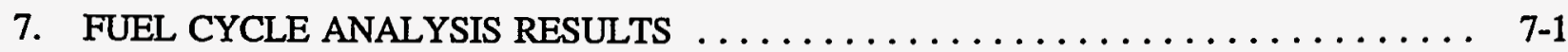

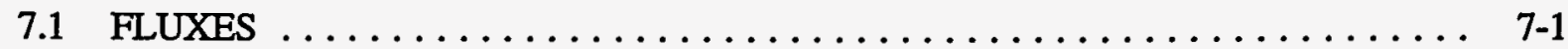

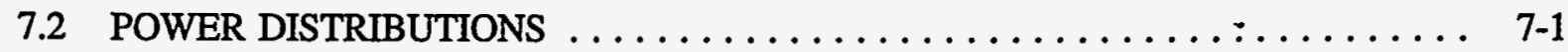

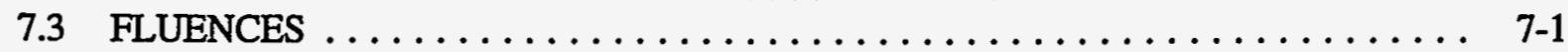

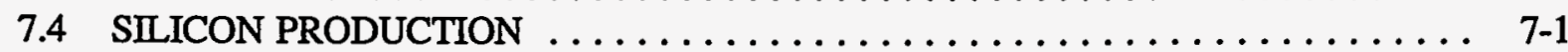

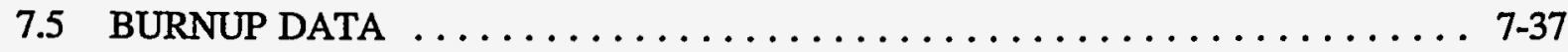

8. COMPONENT REACTIVITIES $\ldots \ldots \ldots \ldots \ldots \ldots \ldots \ldots \ldots \ldots \ldots \ldots \ldots$. 8-1

8.1 BEAM TUBE VARIATION STUDY $\ldots \ldots \ldots \ldots \ldots \ldots \ldots \ldots \ldots \ldots \ldots, 8 \ldots \ldots \ldots$

8.2 COLD SOURCE VARIATION STUDIES $\ldots \ldots \ldots \ldots \ldots \ldots \ldots \ldots \ldots \ldots$. 8 -1

8.3 CORE PRESSURE BOUNDARY TUBE VARIATION STUDIES $\ldots \ldots \ldots \ldots \ldots 8$

9. CONTROL ROD WORTHS $\ldots \ldots \ldots \ldots \ldots \ldots \ldots \ldots \ldots \ldots \ldots \ldots \ldots \ldots$ 9-1

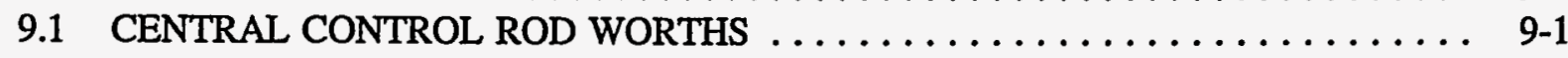

9.2 REFLECTOR SAFETY SHUTDOWN ROD WORTHS $\ldots \ldots \ldots \ldots \ldots \ldots .9 .6$

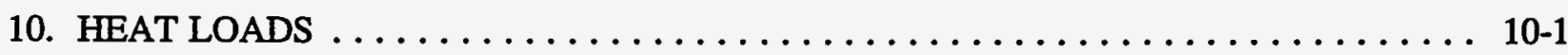

11. SHUTDOWN REACTIVITY MARGINS $\ldots \ldots \ldots \ldots \ldots \ldots \ldots \ldots \ldots \ldots \ldots \ldots \ldots \ldots \ldots \ldots$

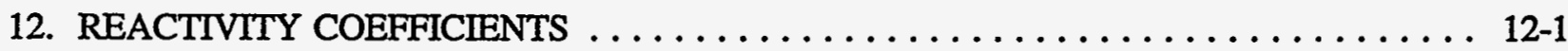

12.1 REACTIVITY EFFECTS OF LIGHT WATER CONTAMINATION $\ldots \ldots \ldots \ldots$ 12-1

12.1.1 Light Water Contamination Studies with MCNP $\ldots \ldots \ldots \ldots \ldots \ldots \ldots$ 12-1

12.1.2 Light Water Contamination Studies with PDQ $\ldots \ldots \ldots \ldots \ldots \ldots \ldots \ldots \ldots \ldots \ldots$

12.2 REACTIVITY EFFECTS OF HEAVY WATER VOIDING . . . . . . . . . 12-19

12.2.1 MCNP Analysis of Heavy Water Voiding . . . . . . . . . . . . 12-19

12.2.2 PDQ Analysis of Heavy Water Voiding Effects on the Core $\ldots \ldots \ldots \ldots \ldots 12-25$

12.2.3 Effects of Heavy Water Voiding on Core Reactivity . . . . . . . . . 12-26

13. MATERIALS IRRADIATION AND ISOTOPE PRODUCTION $\ldots \ldots \ldots \ldots \ldots \ldots$ 13-1

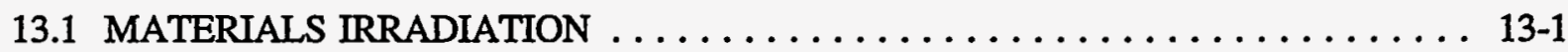

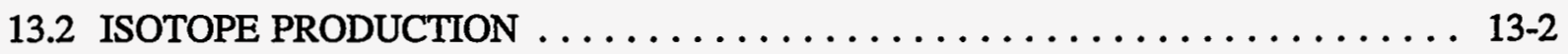

14. REFLECTOR FAST FLUX EXPERIMENTAL FACILITY $\ldots \ldots \ldots \ldots \ldots \ldots \ldots$ 14-1 


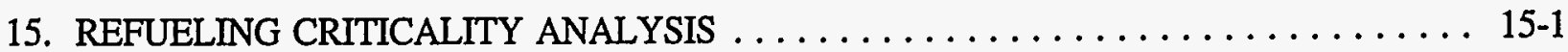

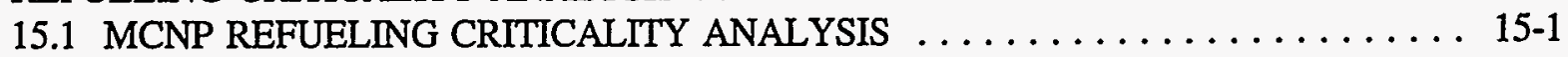

15.2 VENTURE AND KENO REFUELING CRITICALITY ANALYSIS $\ldots \ldots \ldots \ldots 15-5$

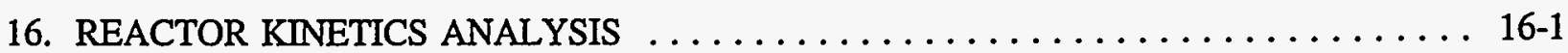

16.1 INTRODUCTION . . . . . . . . . . . . . . . . . . . . . . .

16.2 POINT-KINETICS EQUATIONS WITH DELAYED PHOTONEUTRONS . . . . . 16-1

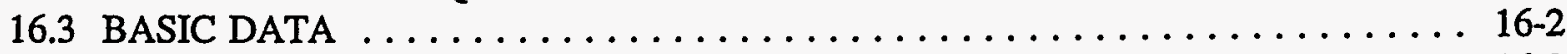

16.3.1 Delayed-Neutron Fractions and Decay Constants $\ldots \ldots \ldots \ldots \ldots \ldots \ldots$ 16-3

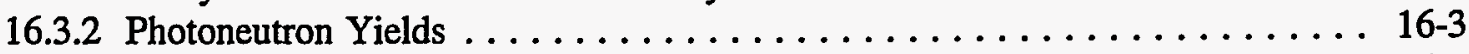

16.3.3 Group Speeds and Energy Boundaries $\ldots \ldots \ldots \ldots \ldots \ldots \ldots \ldots \ldots$ 16-3

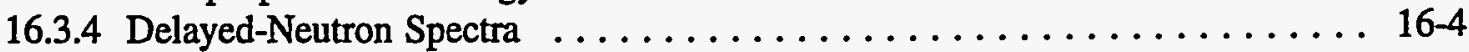

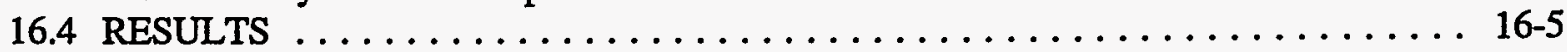

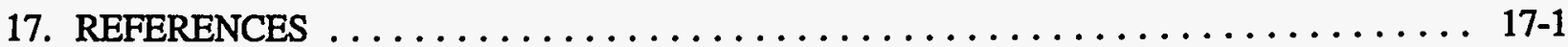




\section{LIST OF FIGURES}

Figure

Page

2.1 General depiction of the ANS fuel element assemblies. . . . . . . . . . . . . 2-2

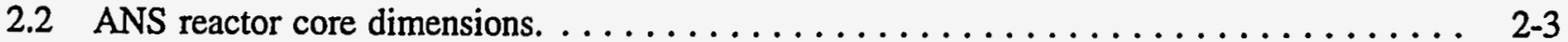

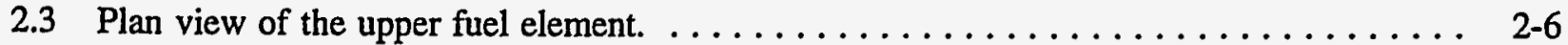

2.4 Plan view of the lower fuel element. $\ldots \ldots \ldots \ldots \ldots \ldots \ldots \ldots \ldots \ldots \ldots \ldots$

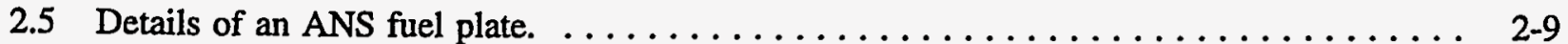

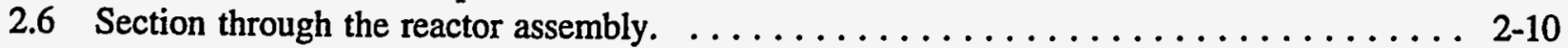

2.7 Elevation view of the inner control rod system. . . . . . . . . . . . . . . . . . $2-12$

2.8 Plan view of the inner control rod system. . . . . . . . . . . . . . . . . 2-13

2.9 Near midplane plan view of the ANS MCNP reactor model showing the radial

location and relative size of short safety rods $A$ through $\mathrm{H} . \ldots \ldots \ldots \ldots \ldots \ldots \ldots$

2.10 Elevation view of the outer control rod system. . . . . . . . . . . . . . . . 2-16

2.11 Elevation view showing the transuranium production rods and the

materials irradiation rods. . . . . . . . . . . . . . . . . . . . . 2-17

2.12 Section of the reactor assembly at core midplane. . . . . . . . . . . . . . $2-18$

5.1 Schematic diagram of the $\mathbb{L L}$ reactor used to construct the simple MCNP model. . . . . . 5-2

6.1 Comparison of the core multiplication factors for varying hafnium absorber thickness in the central control rods. . . . . . . . . . . . . . . . . . . . . . . . . . $6-2$

6.2 Comparison of the core multiplication factors for varying hafnium absorber masses in the central control rods. . . . . . . . . . . . . . . . . . . . . . . .

6.3 Group fluxes for the first $250 \mathrm{~mm}$ of the reflector outside the upper fuel element for the four equivalent control rod models. . . . . . . . . . . . . . . . . .

6.4 Group fluxes for the first $250 \mathrm{~mm}$ of the reflector outside the lower fuel element for the four equivalent control rod models. . . . . . . . . . . . . . . . . . $6-6$

6.5 Group fluxes for the second $250 \mathrm{~mm}$ of the reflector outside the upper fuel element for the four equivalent control rod models. . . . . . . . . . . . . . . . . .

6.6 Group fluxes for the second $250 \mathrm{~mm}$ of the reflector outside the lower fuel element for the four equivalent control rod models.

6.7 Group fluxes inside the upper fuel element for the four equivalent central control rod models.

6.8 Group fluxes inside the lower fuel element for the four equivalent central control rod models. . . . . . . . . . . . . . . . . . . . . . . . . . . . . . . 6-10

6.9 The MCNP model of the ANS reflector components. . . . . . . . . . . . . . 6-14

6.10 Ideal axial power profiles for the ANS CCD. . . . . . . . . . . . . . . . . 6-16

6.11 Uranium-235 atom density contours for the ANS $L 7$ fuel grading. $\ldots \ldots \ldots \ldots \ldots \ldots$ 6 $\ldots \ldots$

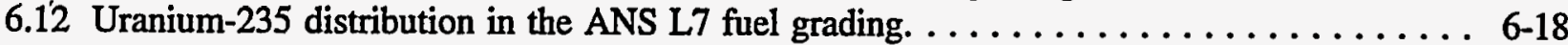

6.13 VENTURE model used in CCD analysis. . . . . . . . . . . . . . . . . . . . . . 6 6-19

6.14 Actinide chains used in the BURNER depletion code for CCD analysis. . . . . . . . . 6-21

6.15 Fission product chains used in the BURNER depletion code for CCD analysis. . . . . 6 6-22

6.16 Critical control rod position throughout the fuel cycle for the ANS CCD. . . . . . . . 6-24

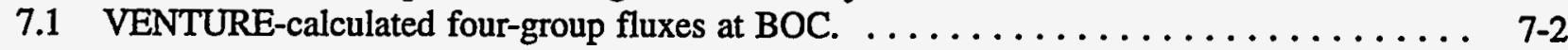

7.2 VENTURE-calculated four-group fluxes at EOC. $\ldots \ldots \ldots \ldots \ldots \ldots \ldots \ldots \ldots \ldots$

7.3 Four-group fluxes for a radial traverse through the upper element at BOC. . . . . . . . . . 7-4

7.4 Four-group fluxes for a radial traverse through the upper element at EOC. . . . . . . 7-5 


\section{LIST OF FIGURES (continued)}

Figure

Page

7.5 Four-group fluxes for an axial traverse through the upper fuel element at BOC. . . . . . 7-6

7.6 Four-group fluxes for an axial traverse through the upper fuel element at EOC. . . . . . 7-7

7.7 Four-group fluxes for a radial traverse through the lower fuel element at BOC. $\ldots \ldots$. . .

7.8 Four-group fluxes for a radial traverse through the lower fuel element at EOC. . . . . . . 7-9

7.9 Four-group fluxes for an axial traverse through the lower fuel element at BOC. . . . . . 7-10

7.10 Four-group fluxes for an axial traverse through the lower fuel element at EOC. . . . . . 7-11

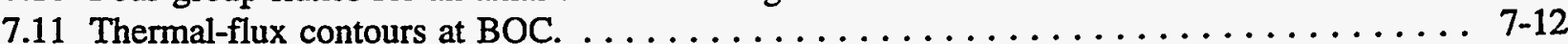

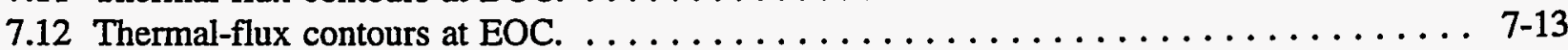

7.13 DORT-calculated flux $(\mathrm{E}>0.1 \mathrm{MeV})$ without photoneutrons. . . . . . . . . $7-14$

7.14 DORT-calculated flux $(\mathrm{E}>0.1 \mathrm{MeV})$ with photoneutrons. . . . . . . . . . 7-15

7.15 DORT-calculated flux $(100 \mathrm{eV}<\mathrm{E}<0.1 \mathrm{MeV})$ without photoneutrons. . . . . . . . 7-16

7.16 DORT-calculated flux $(100 \mathrm{eV}<\mathrm{E}<0.1 \mathrm{MeV})$ with photoneutrons. . . . . . . . . 7-17

7.17 DORT-calculated flux $(0.625 \mathrm{eV}<\mathrm{E}<100 \mathrm{eV})$ without photoneutrons. . . . . . . . 7-18

7.18 DORT-calculated flux $(0.625 \mathrm{eV}<\mathrm{E}<100 \mathrm{eV})$ with photoneutrons. . . . . . . . 7-19

7.19 DORT-calculated flux $(\mathrm{E}<0.625 \mathrm{eV})$ without photoneutrons. $\ldots \ldots \ldots \ldots \ldots \ldots \ldots$

7.20 DORT-calculated flux $(\mathrm{E}<0.625 \mathrm{eV})$ with photoneutrons. . . . . . . . . . . . 7-21

7.21 DORT-calculated fluxes in a radial traverse at core midplane without photoneutrons. . . . 7-22

7.22 DORT-calculated fluxes in a radial traverse at core midplane with photoneutrons. . . . . 7-23

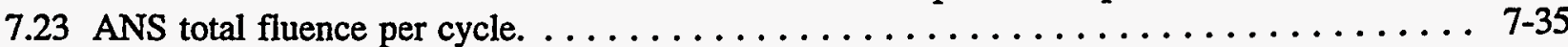

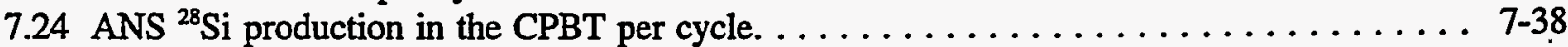

7.25 ANS ${ }^{28} \mathrm{Si}$ production in the reflector vessel wall per cycle. . . . . . . . . . . . 7-39

8.1 Variation in multiplication factor with the CPBT inner wall thicknesses. . . . . . . . 8-6

9.1 MCNP-calculated central control rod bank worth at BOC. . . . . . . . . . . . $9-2$

9.2 PDQ-calculated central control rod bank worth at BOC. . . . . . . . . . . . . . . . $9-4$

9.3 PDQ-calculated central control rod bank worth at EOC. . . . . . . . . . . . . . . $9-5$

10.1 Fission product photon release spectrum for the ANS reactor at 1-d exposure as

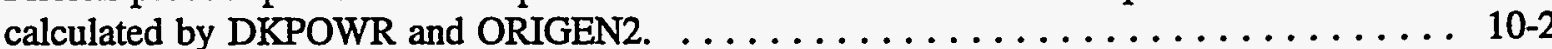

10.2 Fission product photon yield for the ANS reactor at 1-d exposure as calculated by DKPOWR and ORIGEN2. .........................

12.1 Core multiplication factor at $\mathrm{BOC}$ with control rod leading tips at core midplane as a function of molecular percent light water contamination in the central hole $\mathrm{D}_{2} \mathrm{O} . \ldots$

12.2 Core multiplication factor (k-effective) at BOC with control rod leading tips at the top of UFE as a function of molecular percent light water contamination in the

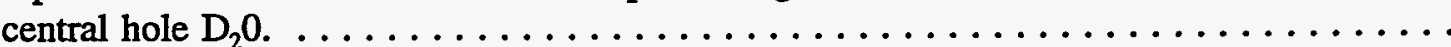

12.3 Core multiplication factor at BOC with control rod leading tips at core midplane as a function of molecular percent light water contamination in the $\mathrm{D}_{2} \mathrm{O}$ between the CPBT and the IT. . . . . . . . . . . . . . . . . . . . . .

12.4 Core multiplication factor at BOC with control rod leading tips at the top of UFE as a function of molecular percent light water contamination in the $\mathrm{D}_{2} \mathrm{O}$ between the CPBT and the IT. . . . . . . . . . . . . . . . . . . . . . . .

12.5 Core multiplication factor at BOC with control rod leading tips at bottom of LFE as a function of molecular percent light water contamination in the $\mathrm{D}_{2} \mathrm{O}$ between the CPBT and the IT. . . . . . . . . . . . . . . . . . . . . . . 


\section{LIST OF FIGURES (continued)}

Figure

12.6 Core multiplication factor at BOC with control rod leading tips at the core midplane as a function of molecular percent light water contamination in the $\mathrm{D}_{2} \mathrm{O}$ inside the CPBT. . . . . . . . . . . . . . . . . . . . . . .

12.7 Core multiplication factor at BOC with control rod leading tips at top of UFE as a function of molecular percent light water contamination in the $\mathrm{D}_{2} 0$ inside the CPBT.

12.8 Core multiplication factor at BOC with control rod leading tips at bottom of LFE as a function of molecular percent light water contamination in the $\mathrm{D}_{2} \mathrm{O}$ inside the CPBT.

12.9 Core multiplication factor at BOC with control rod leading tips at core midplane as a function of molecular percent light water contamination in the $\mathrm{D}_{2} \mathrm{O}$ reflector. . . . 12-12

12.10 Core multiplication factor at BOC with control rod leading tips at top of UFE as a function of molecular percent light water contamination in the $\mathrm{D}_{2} \mathrm{O}$ reflector.

12.11 Core multiplication factor at BOC with control rod leading tips at bottom of LFE as a function of molecular percent light water contamination in the $\mathrm{D}_{2} \mathrm{O}$ reflector.

12.12 PDQ-evaluated core multiplication factor as a function of very small light water contamination in the reflector at BOC. . . . . . . . . . . . . . . . . . . . 12-15

12.13 PDQ-evaluated peak flux in the reflector as a function of very small light water contamination in the reflector at BOC. . . . . . . . . . . . . . . . . 12-16

12.14 The ANS response to a dilute light water ingress inside the CPBT only at BOC and EOC. . . . . . . . . . . . . . . . . . . . . . . . . . . . 12-17

12.15 The ANS response to a dilute light water ingress into the reflector only and into the reflector and the CPBT at EOC.

12.16 Core multiplication factor as a function of $\mathrm{D}_{2} \mathrm{O}$ theoretical density in the central hole.

12.17 Schematic diagram of fuel near fuel regions dried up or voided of $\mathrm{D}_{2} \mathrm{O}$ in the

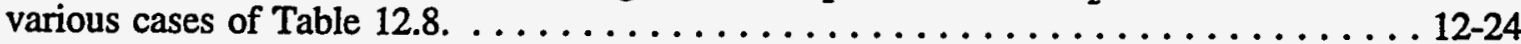

12.18 Void reactivity worth at several time steps in PDQ models V01019-V01024. . . . . . . 12-27

12.19 PDQ-evaluated core multiplication factor as a function of uniform heavy water voiding inside the $C P B T$ with the control rods at core midplane at BOC.

12.20 PDQ-evaluated core multiplication factor as a function of uniform heavy water voiding inside the CPBT with the control rods fully withdrawn at BOC. . . . . . . 12-30

12.21 PDQ-evaluated core multiplication factor as a function of uniform heavy water voiding inside the CPBT with the control rods fully inserted at BOC.

15.1 Front and side views of the two fuel elements in the transfer canal base case. . . . . . 15-2

15.2 Front and side views of the two fuel elements in the transfer canal reduced to

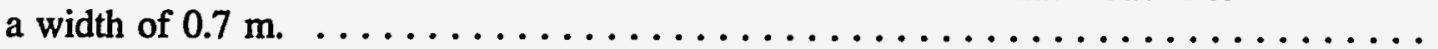

15.3 Top and front views of the two fuel elements during transfer in the long leg of the canal.

15.4 Two fuel elements moved near the top of the reflector tank while control and

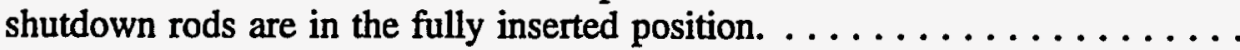

15.5 Schematic of space available for adding absorbers to the upper and lower fuel

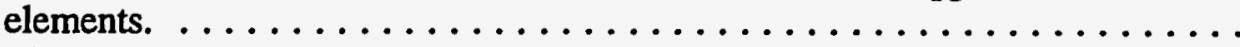

16.1 The prompt-neutron lifetime and effective delayed neutron fraction (including photoneutrons) during the ANS fuel cycle. . . . . . . . . . . . . . . . . 



\section{LIST OF TABLES}

Table

Page

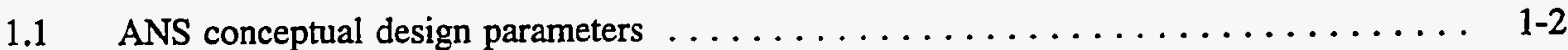

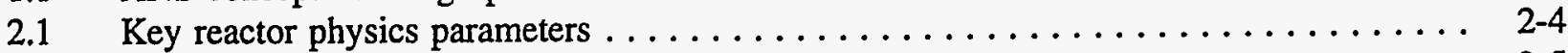

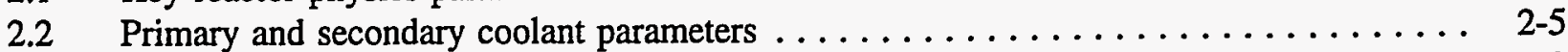

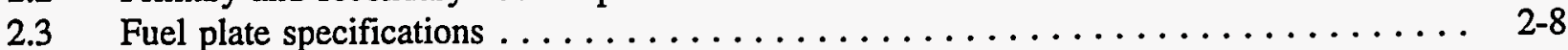

2.4 Inner control rod system specifications $\ldots \ldots \ldots \ldots \ldots \ldots \ldots \ldots \ldots \ldots \ldots \ldots \ldots$

2.5 Outer shutdown rod system specifications $\ldots \ldots \ldots \ldots \ldots \ldots \ldots \ldots \ldots \ldots \ldots \ldots \ldots$

2.6 ANS irradiation facilities . . . . . . . . . . . . . . . . . . . . 2-19

4.1 Core multiplication factor $\left(k_{\text {eff }}\right)$ sensitivities to neutron capture cross sections

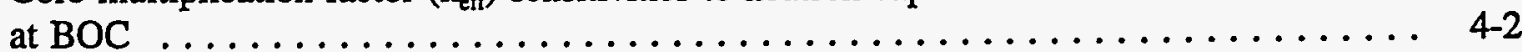

4.2 Core multiplication factor $\left(\mathrm{k}_{\mathrm{eff}}\right)$ sensitivities to neutron transport cross sections

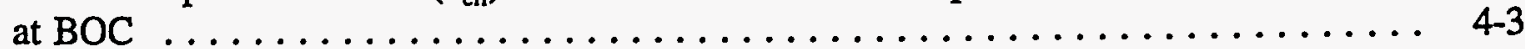

4.3 Core multiplication factor $\left(\mathrm{k}_{\mathrm{eff}}\right)$ sensitivities to neutron total scatter cross sections

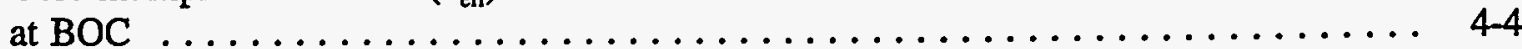

4.4 Core multiplication factor $\left(k_{\text {eff }}\right)$ sensitivities to neutron fission cross section at BOC . . . 4-5

4.5 Nuclides used in the ANS MCNP model . . . . . . . . . . . . . . . . . . 4-6

5.1 MCNP analysis of the ILL simple model (no reflector components) with $\mathrm{P}=57$

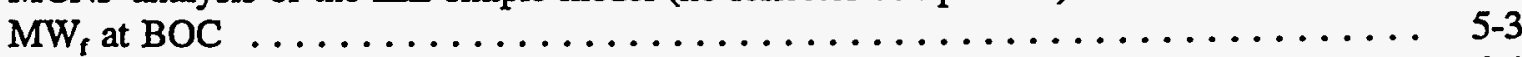

6.1 Absorption rates $\left(\mathrm{s}^{-1}\right)$ in various equivalent single central control rod configurations . . . 6-4

6.2 Energy deposition rates for the outer (fuel) and inner $\left(\mathrm{D}_{2} \mathrm{O}\right)$ sides of the central control rods for the three-rod (ANS629) and four-rod (ANS631) cases with reactor

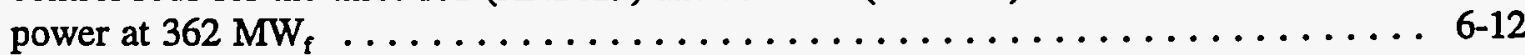

6.3 Thermal flux $(E<0.683 \mathrm{eV})$ in the hafnium portion of the central control rods along the upper fuel element at $\mathrm{BOC}$ and $330 \mathrm{MW}_{\mathrm{f}} \ldots \ldots \ldots \ldots \ldots \ldots \ldots \ldots$

6.4 Control rod positioning relative to midplane as a function of the number of time steps in VENTURE fuel cycle calculation . . . . . . . . . . . . . . . . 6-23

6.5 Power density comparisons against the 16-depletion step fuel cycle calculation . . . . . 6-25

7.1 Key unperturbed flux data as calculated by VENTURE (neutron fluxes) and DORT

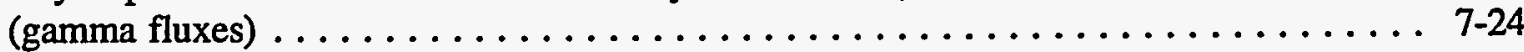

7.2a Relative fission power distribution in upper element at $0.0 \mathrm{~d} \ldots \ldots \ldots \ldots \ldots \ldots . \ldots 7-25$

$7.2 \mathrm{~b}$ Relative fission power distribution in lower element at $0.0 \mathrm{~d} \ldots \ldots \ldots \ldots \ldots \ldots$

7.3a Relative fission power distribution in upper element at $4.25 \mathrm{~d} \ldots \ldots \ldots \ldots \ldots \ldots . \ldots 7-27$

$7.3 \mathrm{~b}$ Relative fission power distribution in lower element at $4.25 \mathrm{~d} \ldots \ldots \ldots \ldots \ldots \ldots .7 .28$

$7.4 \mathrm{a}$ Relative fission power distribution in upper element at $8.5 \mathrm{~d} \ldots \ldots \ldots \ldots \ldots \ldots . . \ldots 7.29$

7.4b Relative fission power distribution in lower element at $8.5 \mathrm{~d} \ldots \ldots \ldots \ldots \ldots \ldots$. . . . . . .

7.5a Relative fission power distribution in upper element at $12.75 \mathrm{~d} \ldots \ldots \ldots \ldots \ldots \ldots$ 7-31

7.5b Relative fission power distribution in lower element at $12.75 \mathrm{~d} \ldots \ldots \ldots \ldots \ldots \ldots$

$7.6 \mathrm{a}$ Relative fission power distribution in upper element at $17 \mathrm{~d} \ldots \ldots \ldots \ldots \ldots \ldots \ldots$

7.6b Relative fission power distribution in lower element at $17 \mathrm{~d} \ldots \ldots \ldots \ldots \ldots \ldots$. $\ldots \ldots$

7.7 Maximum ${ }^{28} \mathrm{Si}$ activation rates in CPBT $\ldots \ldots \ldots \ldots \ldots \ldots \ldots \ldots \ldots \ldots \ldots$

7.8 Maximum ${ }^{28} \mathrm{Si}$ activation rates in reflector vessel $\ldots \ldots \ldots \ldots \ldots \ldots \ldots \ldots \ldots$. $\ldots \ldots 6$

7.9 Maximum cumulative production of ${ }^{28} \mathrm{Si}$ after $17 \mathrm{~d}$ at $330 \mathrm{MW}_{\mathrm{f}} \ldots \ldots \ldots \ldots \ldots \ldots$. . . . . .

7.10 Nuclide inventories (in $\mathrm{kg}$ ) as calculated by VENTURE . . . . . . . . . . . 7-40

8.1 Reactivity impact of various reactor components $\ldots \ldots \ldots \ldots \ldots \ldots \ldots \ldots \ldots . \ldots .1$ 
8.2 Reactivity effects of various beam tube shapes, dimensions, locations, and compositions for the conceptual core at BOC $\ldots \ldots \ldots \ldots \ldots \ldots \ldots \ldots$

8.3 MCNP analysis of the cold source for various accident scenarios at $\mathrm{P}=362 \mathrm{MW}_{\mathrm{f}}$ with the cold source re-entrant cavity always voided $\ldots \ldots \ldots \ldots \ldots \ldots \ldots$

8.4 MCNP analysis of varying the cold source Al-6061 shell thickness at $P=362$ $\mathrm{MW}_{\mathrm{f}}$ with the remainder of the cold source as designed $\ldots \ldots \ldots \ldots \ldots \ldots . \ldots$

8.5 CPBT cases with PDQ-7 models at BOC control rods down to the core midplane . . . . 8-5

9.1 Central control rod bank worth for the three-control rod design at BOC . . . . . . . 9 9-1

9.2 Central control rod bank worths for single-rod-ejection scenarios. All cases are relative to all rods at core midplane (ANS662). $\quad \ldots \ldots \ldots \ldots \ldots \ldots \ldots \ldots$

9.3 Reactivity effects of CPBT failure. CPBT and safety shutdown rods are destroyed; central control rods are inserted as described. . . . . . . . . . . . . . 9-3

9.4 Final location of the short shutdown rods . . . . . . . . . . . . . . . . . $9-6$

9.5 The multiplication factor for several short safety rod positions in ANS with central control rods removed $\ldots \ldots \ldots \ldots \ldots \ldots \ldots \ldots \ldots \ldots \ldots \ldots$

9.6 Reactivity worth of alternative control materials in short $(600-\mathrm{mm})$ safety shutdown rods

9.7 Short safety rod stuck rod worths for the ANS model with central control rods at core midplane. Stuck rods are at $+800 \mathrm{~mm} . \ldots \ldots \ldots \ldots \ldots \ldots \ldots$

9.8 Short safety rod stuck rod worths for the ANS model with central control rods

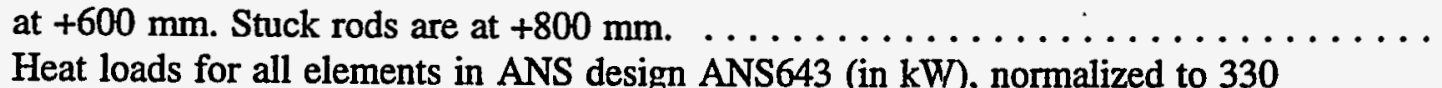

10.1 Heat loads for all elements in ANS design ANS643 (in $\mathrm{kW}$ ), normalized to 330

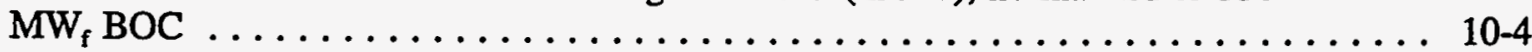

11.1 Core multiplication factor $\left(\mathrm{k}_{\mathrm{eff}}\right)$ after shutdown as a function of cycle time at which reactor trip occurs $\ldots \ldots \ldots \ldots \ldots \ldots \ldots \ldots \ldots \ldots \ldots \ldots \ldots \ldots$

11.2 Core multiplication factor $\left(\mathrm{k}_{\mathrm{eff}}\right)$ after restart from reactor trip, demonstrating the

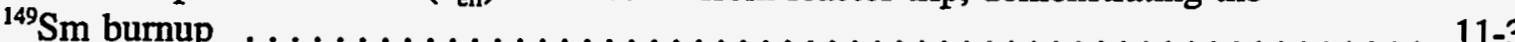

12.1 Reactivity worth of light water contamination in the central hole at BOC with the control rods at the bottom of $\mathrm{LFE} \ldots \ldots \ldots \ldots \ldots \ldots \ldots \ldots \ldots \ldots \ldots \ldots \ldots \ldots$

12.2 Reactivity effect at $\mathrm{BOC}$ of uniform variation in the $\mathrm{D}_{2} \mathrm{O}$ density in the reflector . . . . 12-19

12.3 Reactivity effect at $\mathrm{BOC}$ of decreasing the $\mathrm{D}_{2} \mathrm{O}$ level in the reflector . . . . . . . . . 12-20

12.4 Reactivity effect at $\mathrm{BOC}$ of uniform variation in the $\mathrm{D}_{2} \mathrm{O}$ density in the central hole with the central rods inserted down to core midplane . . . . . . . . . . . . 12-20

12.5 MCNP-evaluated reactivity as a function of $\mathrm{D}_{2} \mathrm{O}$ voiding in the central hole at $\mathrm{BOC} \ldots 12-22$

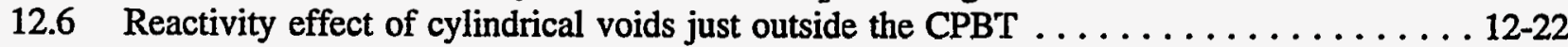

12.7 Evaluation of reactivity worth of uniform reduction of $\mathrm{D}_{2} \mathrm{O}$ density in all components inside the CPBT . . . . . . . . . . . . . . . . . . . . . . . . 12-23

12.8 Evaluation of $\mathrm{D}_{2} \mathrm{O}$ voiding in the fuel and regions near the fuel inside the $\mathrm{CPBT}$ at $\mathrm{BOC}$ with the central control rods inserted down to core midplane . . . . . 12-23

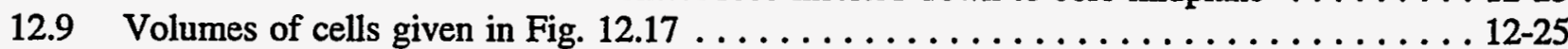

12.10 PDQ calculations of reactivity worth (in $\mathrm{pcm}$ ) of voiding the central hole at various

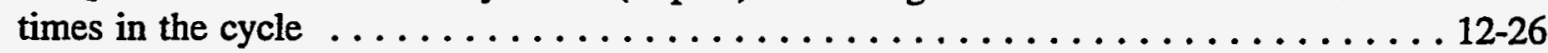

12.11 Effects of heavy water voiding inside the CPBT on core reactivity at BOC . . . . . 12-28

13.1 The impact of fast flux irradiation targets on core reactivity from a base case without targets 


\section{LIST OF TABLES (continued)}

13.2 Production of ${ }^{252} \mathrm{Cf}$ at $330 \mathrm{MW}_{\mathrm{f}}$ in the epithermal and fast regions with exposure-dependent cross sections in the rods

13.3 Production of ${ }^{254} \mathrm{Es}$ at $330 \mathrm{MW}_{\mathrm{f}}$ in the epithermal and fast regions with exposure-dependent cross sections in the rods . . . . . . . . . . . . . . . 13-3

13.4 Production of ${ }^{252} \mathrm{Cf}$ at $330 \mathrm{MW}_{\mathrm{f}}$ in the epithermal and fast regions with exposure-dependent cross sections in the rods . . . . . . . . . . . . . . . . 13-3

13.5 Production of ${ }^{254} \mathrm{Es}$ at $330 \mathrm{MW}_{\mathrm{f}}$ in the epithermal and fast regions with exposure-dependent cross sections in the rods . . . . . . . . . . . . . . . 13-4

14.1 Neutronic results for the fast flux irradiation converter at $\mathrm{BOC}^{a} \ldots \ldots \ldots \ldots \ldots \ldots$

15.1 MCNP-evaluated effective multiplication factors of various fuel transfer cases . . . . . . 15-6

15.2 Criticality $\left(k_{\text {eff }}\right)$ of ANS fuel elements $\ldots \ldots \ldots \ldots \ldots \ldots \ldots \ldots \ldots \ldots \ldots$

15.3 Fuel element criticality $\left(k_{e f f}\right)$ for fresh-fueled elements with BOC burnable poison for fuel loadings for $\mathrm{L} 7$ core $\ldots \ldots \ldots \ldots \ldots \ldots \ldots \ldots \ldots \ldots \ldots \ldots$

16.1 Relative delayed-neutron fractions and decay constants for thermal fission of ${ }^{235} \mathrm{U} \ldots \ldots$. . $16-3$

16.2 Delayed-neutron yields and delay constants for photoneutron production . . . . . . . 16-4

16.3 Spectrum-averaged group speeds and energy-group boundaries . . . . . . . . . . . 16-4

16.4 Energy spectra of delayed-precursor groups $\ldots \ldots \ldots \ldots \ldots \ldots \ldots \ldots \ldots \ldots \ldots \ldots$

16.5 Relative effective delayed-neutron fractions for calculations without photoneutrons at BOC . . . . . . . . . . . . . . . . . . . . . 16-6

16.6 Relative effective delayed-neutron fractions for calculations with

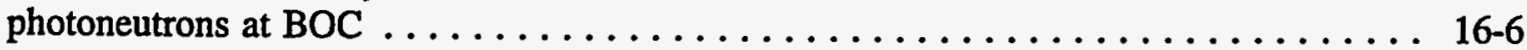


' 


\section{ACRONYMS, ABBREVIATIONS AND SYMBOLS}

ACCD advanced conceptual core design

ANS

Advanced Neutron Source

BOC

CCD

CPBT

DNB

EOC

HFIR

HFP

ILL

INEL

IT

$\mathrm{k}_{\text {eff }}$

LFE

LLNL

MOC

NERSC

beginning of cycle

conceptual core design

core pressure boundary tube

departure from nucleate boiling

end of cycle

High Flux Isotope Reactor

hot full power

Institut Laue-Langevin

Idaho National Engineering Laboratory

inner tube

effective core multiplication factor

lower fuel element

Lawrence Livermore National Laboratory

middle of cycle

NSCANS National Steering Committee for the Advanced Neutron Source

ORNL

pcm

Oak Ridge National Laboratory

UFE

percent mille

upper fuel element 


\section{,}


This report summarizes the neutronics analysis performed during 1991 and 1992 in support of characterization of the conceptual design of the Advanced Neutron Source (ANS). The methods used in the analysis, parametric studies, and key results supporting the design and safety evaluations of the conceptual design are presented. The analysis approach used during the conceptual design phase followed the same approach used in early ANS evaluations: (1) a strong reliance on Monte Carlo theory for beginning-of-cycle reactor performance calculations and (2) a reliance on few-group diffusion theory for reactor fuel cycle analysis and for evaluation of reactor performance at specific time steps over the fuel cycle. The Monte Carlo analysis was carried out using the MCNP continuousenergy code, and the few-group diffusion theory calculations were performed using the VENTURE and PDQ code systems. Validation of these codes for use in ANS analysis was performed during the 1991-1992 time period and is discussed in the report.

The MCNP code was used primarily for its capability to model the reflector components in realistic geometries as well as the inherent circumvention of cross-section processing requirements and use of energy-collapsed cross sections. For these reasons the MCNP code was used almost exclusively for evaluations of reflector component reactivity effects and of heat loads in these components. The code was also used extensively as a benchmark comparison against the diffusion-theory estimates of key reactor parameters such as region fluxes, control rod worths, reactivity coefficients, and material worths. The VENTURE and PDQ codes have been benchmarked extensively and verified over a range of applications for many years and were used to provide independent evaluations of burnup effects, power distributions, and small perturbation worths.

The performance and safety calculations performed over the subject time period are summarized, and key results are provided. The key results include flux and power distributions over the fuel cycle, silicon production rates, fuel burnup rates, component reactivities, control rod worths, component heat loads, shutdown reactivity margins, reactivity coefficients, and isotope production rates. Studies of a reflector fast flux experimental facility, refueling criticality, and reactor kinetics were also performed and are discussed in the report. 



\section{INTRODUCTION}

\subsection{PURPOSE}

The Advanced Neutron Source (ANS) conceptual core nuclear design has evolved as a result of prior design studies, the most relevant of which is the preconceptual design study. ${ }^{1}$ This report provides a description of the neutronics methods used to predict the ANS reactor performance and to document key neutronic analysis results obtained during the conceptual core design (CCD) phase. This report summarizes the neutronics analysis performed during 1991 and 1992 in support of characterization of the conceptual design of the ANS.

\subsection{GENERAL BACKGROUND}

\subsubsection{ANS Project Technical Objectives}

The ANS reactor system is designed to meet three technical objectives: (1) to design and construct the world's highest-flux research reactor for neutron scattering -5 to 10 times the flux of the best existing facilities, (2) to provide isotope production facilities that are as good as or better than those of the High Flux Isotope Reactor (HFIR), and (3) to provide materials irradiation facilities that are as good as or better than those of the HFIR.

\subsubsection{ANS Design Goals}

Minimum performance specifications have been designated to meet the overall project objectives. These design goals designate neutron flux levels over given energy ranges for given experimental sites in the active core and in the reflector. Design goals have been established for five types of experimental facilities: neutron scattering, nuclear and fundamental physics, materials irradiation, isotope production, and materials analysis. Table 1.1 lists the functional requirements for each of the five facilities.

In addition to the experimental facility capability goals just listed, reactor operational and performance goals have also been selected. These additional criteria are to provide: (1) enough excess reactivity to achieve a minimum 17-d full-power fuel cycle, (2) a means to control the excess reactivity throughout the cycle, and (3) sufficient negative reactivity to achieve specified minimum subcriticality levels for all design-basis conditions. Additional design goals not specified as necessary criteria are as follows: (1) to limit nuclear heating of components; (2) to maximize the margin to critical heat flux, fuel temperature limits, and cladding-oxide spallation; (3) to eliminate the potential for positive reactivity effects, particularly coolant voiding; (4) to provide control that is relatively insensitive to spectrum changes; and (5) to design for limiting conditions to occur at beginning of cycle (BOC) so that critical parameters can be validated by tests and measurements such that uncertainties associated with burnup become less important.

\subsubsection{Desired Design Features}

To meet ANS technical objectives and design goals, early analysis performed as part of the preconceptual design activities has shown that several design features are desirable. A short discussion of each of these desirable design features follows. 
Table 1.1. ANS conceptual design parameters

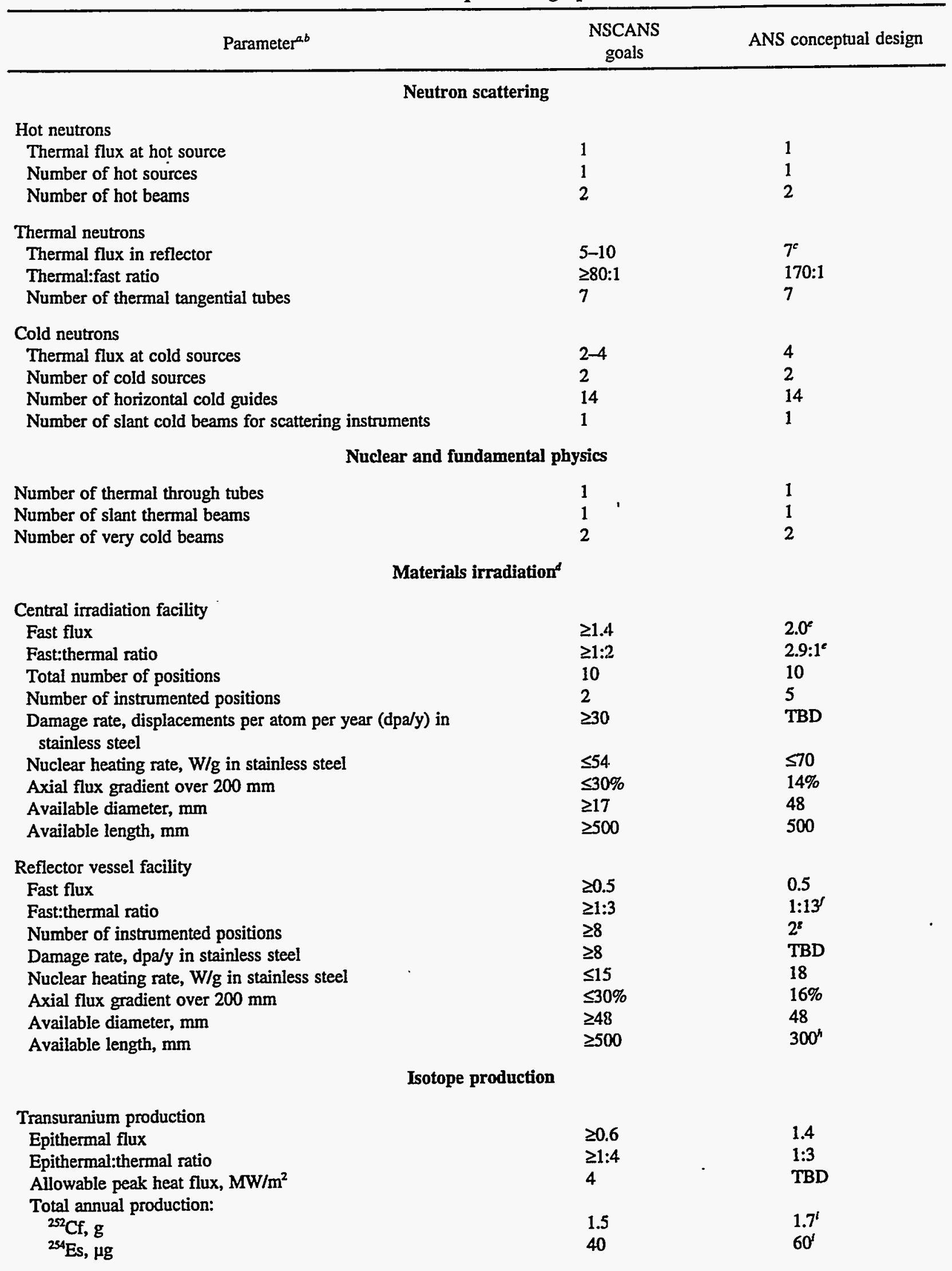


Table 1.1 (continued)

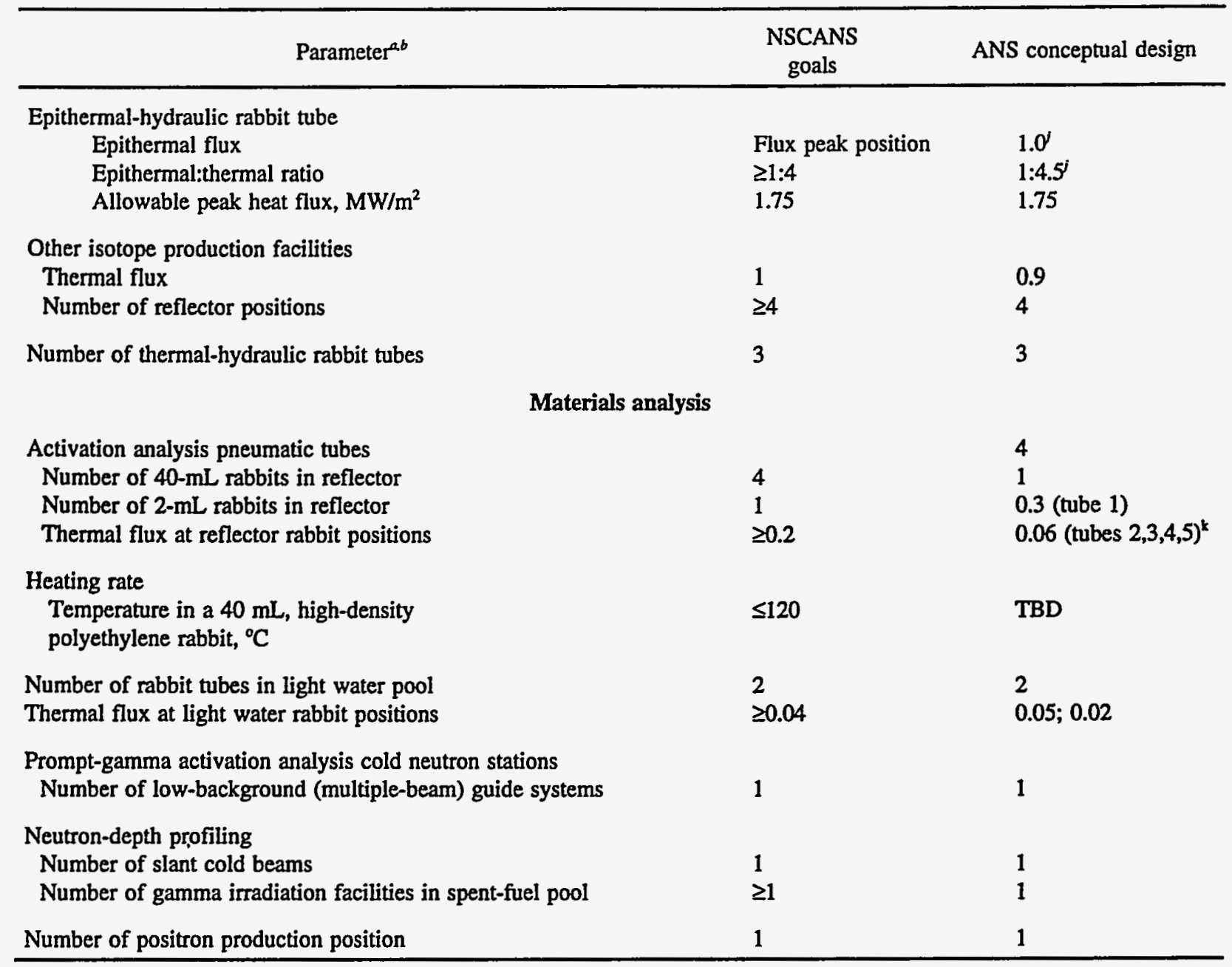

${ }^{a}$ All fluxes in units of $10^{19} \mathrm{~m}^{-2} \cdot \mathrm{s}^{-1}$.

${ }^{b}$ Neutron spectra terms as used in this table are defined as thermal $\leq 0.625 \mathrm{eV}, 0.625 \mathrm{eV} \leq$ epithermal $\leq 100 \mathrm{eV}$, and fast $>0.1 \mathrm{MeV}$. Sources of neutrons for research are classified as ultracold $<25 \mu \mathrm{eV}, 25 \mu \mathrm{eV}<$ very cold $<0.1 \mathrm{meV}, 0.1$ $\mathrm{meV}<$ cold $<5 \mathrm{meV}, 5 \mathrm{meV}<$ thermal $<0.625 \mathrm{eV}, 0.625 \mathrm{eV}<$ hot $<1 \mathrm{eV}$.

EOC value.

'The materials irradiation facilities are intended to replace irradiation facilities in HFIR. ANS cannot meet all these goals because the simultaneous requirements of high fast:thermal flux ratio, high fast flux, and low heating rate are intrinsically incompatible with the physics of an undermoderated core (optimized for neutron-scattering research goals).

Values at $r=160 \mathrm{~mm}$ and BOC. The fast flux increases during the fuel cycle. The fast:thermal ratio decreases to as low as $0.25: 1$ with decreasing radius and burnup.

Best available ratio in reflector vessel.

Access restricted by other facilities in the reflector vessel, partially offset by providing more instrumented positions than required in the central irradiation facility.

hength restricted by outer shutdown rods.

The production number quoted is a preliminary value obtained from two-dimensional neutronic analyses. Possible thermal limitations on pellet loadings have not been evaluated.

'Value at $250 \mathrm{~mm}$ above midplane at midpoint of cycle.

kOptimized for lowest gamma heating, but will need to be located at a higher neutron flux level. 
A reduced moderation of fission neutrons within the core is desirable to allow high neutron leakage to the reflector region, where the beam tubes will be located. The use of heavy water coolant in the primary system reduces the moderation of fission neutrons in the primary core compared to the use of light water and therefore is the coolant of choice. On the average, the number of collisions necessary for fission neutrons to reach thermal energies in heavy water is approximately twice that in light water.

A small core volume increases the ratio of power density to core surface area. Neutrons thermalized in the reflector will have less probability of core reentry for a smaller core surface area, resulting in a higher thermal flux at the beam tube locations (i.e., high neutron efficiency in terms of flux per unit of power).

Heavy water is best suited for the reflector region, in which a high thermal flux is one of the design goals. Thermal neutron absorption in heavy water is less than that in light water by a factor of approximately 600 . In addition, the thermal diffusion length, a measure of the distance a thermal neutron travels before absorption, is about 60 times greater for heavy water than for light water. These factors translate into a much larger volume of high thermal flux in heavy water and result in a larger region within the reflector for placement of beam tubes and cold sources. Solid moderators such as beryllium also have favorable characteristics but have a potential radiation damage problem and cannot accommodate complex experimental equipment as easily as heavy water can.

\subsubsection{Selection of the Conceptual Core Design}

The CCD was chosen based upon a series of studies carried out to identify basic core dimensions and core power for which the predicted reactor performance would meet the technical design goals for neutron energy spectra, flux levels, core lifetime, and core component temperature limits. ${ }^{2,3}$ 


\section{CONCEPTUAL CORE DESIGN DESCRIPTION}

The ANS conceptual core design comprises two fuel elements with fuel plates similar to those of the HFIR. The two elements are fabricated, stored, transported, and loaded in and out of the reactor as two separate elements. The two elements are latched together during loading and remain so during reactor operation. The fuel elements are concentric in the plan view but are displaced axially as shown schematically in Fig. 2.1. The core dimensions are shown in Fig. 2.2, and key design parameters are listed in Tables 2.1 and 2.2. Each fuel element consists of nonfueled cylindrical side plates with involute fuel plates welded into the side plates. Plan views of the upper and lower elements are illustrated in Figs. 2.3 and 2.4. The fuel plate nominal specifications and dimensions are given in Table 2.3. A schematic of an involute plate with radially graded fuel is shown in Fig. 2.5. The layout of the reactor core, the core pressure boundary tube (CPBT), the heavy water reflector tank, and the light water pool are shown schematically in Fig. 2.6.

The primary shutdown system consists of three inner control rods that serve the combined functions of shim control and shutdown under normal and emergency conditions. The control rods are located symmetrically about the core vertical axis in the inner coolant channel. The rods are driven from below the core and always move as a group under normal conditions, but they scram independently when a scram signal is generated. Specifications of the inner control rods are shown in Table 2.4, and the dimensions and location in the core are illustrated in Figs. 2.7 and 2.8.

The secondary reactor shutdown system consists of eight control rods located in the reflector vessel just outside the CPBT. This system serves safety and shutdown functions only and is not used for shimming or regulating functions. The specifications of the outer control rods are listed in Table 2.5. The location of the shutdown rods is shown in Figs. 2.9 and 2.10.

The ANS reactor design must accommodate two in-core experimental facilities and several experimental facilities located in the reflector region. The materials composing these facilities have a negative effect upon total reactivity and must be included in the modeling. An additional consideration is the heat generated in these components as well as in the core and control rod components. The in-core experimental facilities consist of transuranium isotope production rods and materials irradiation positions. The location and dimensions of these two facilities are shown schematically in Figs. 2.3, 2.4 , and 2.11 .

The reflector experimental facilities defined in the modeling of the reactor system are the tangential thermal beam tubes, the thermal beam through-tube, rabbit tubes for light isotope production and transuranium production, pneumatic rabbit tubes for analytical chemistry, slant irradiation tubes, cold source thimbles, and a hot source thimble. A thimble is an indentation in the reflector vessel behind which the cold or hot source is located. A schematic of the external component geometries at the core midplane is shown in Fig. 2.12. The ANS irradiation facilities are summarized in Table 2.6. 


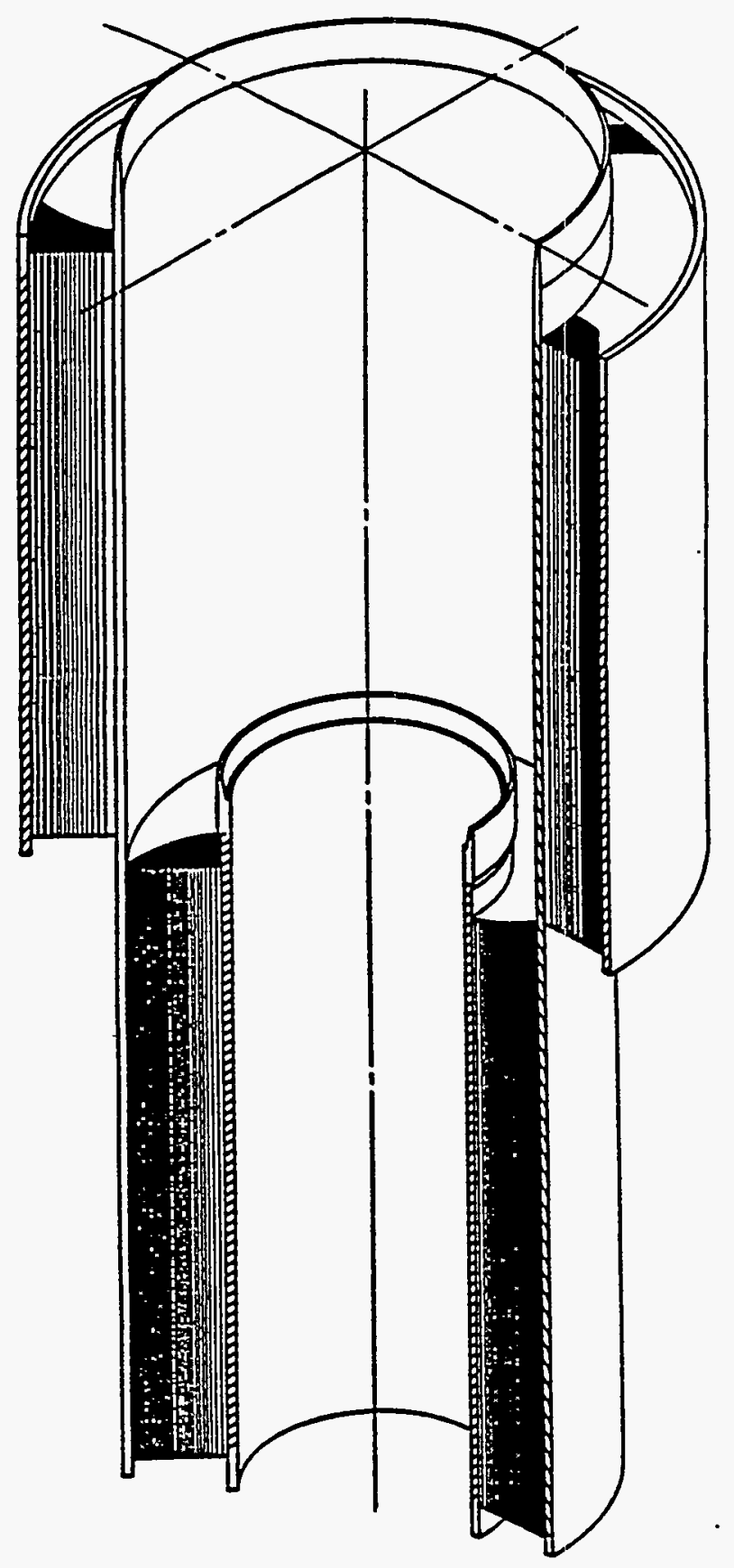

Fig. 2.1. General depiction of the ANS fuel element assemblies. 


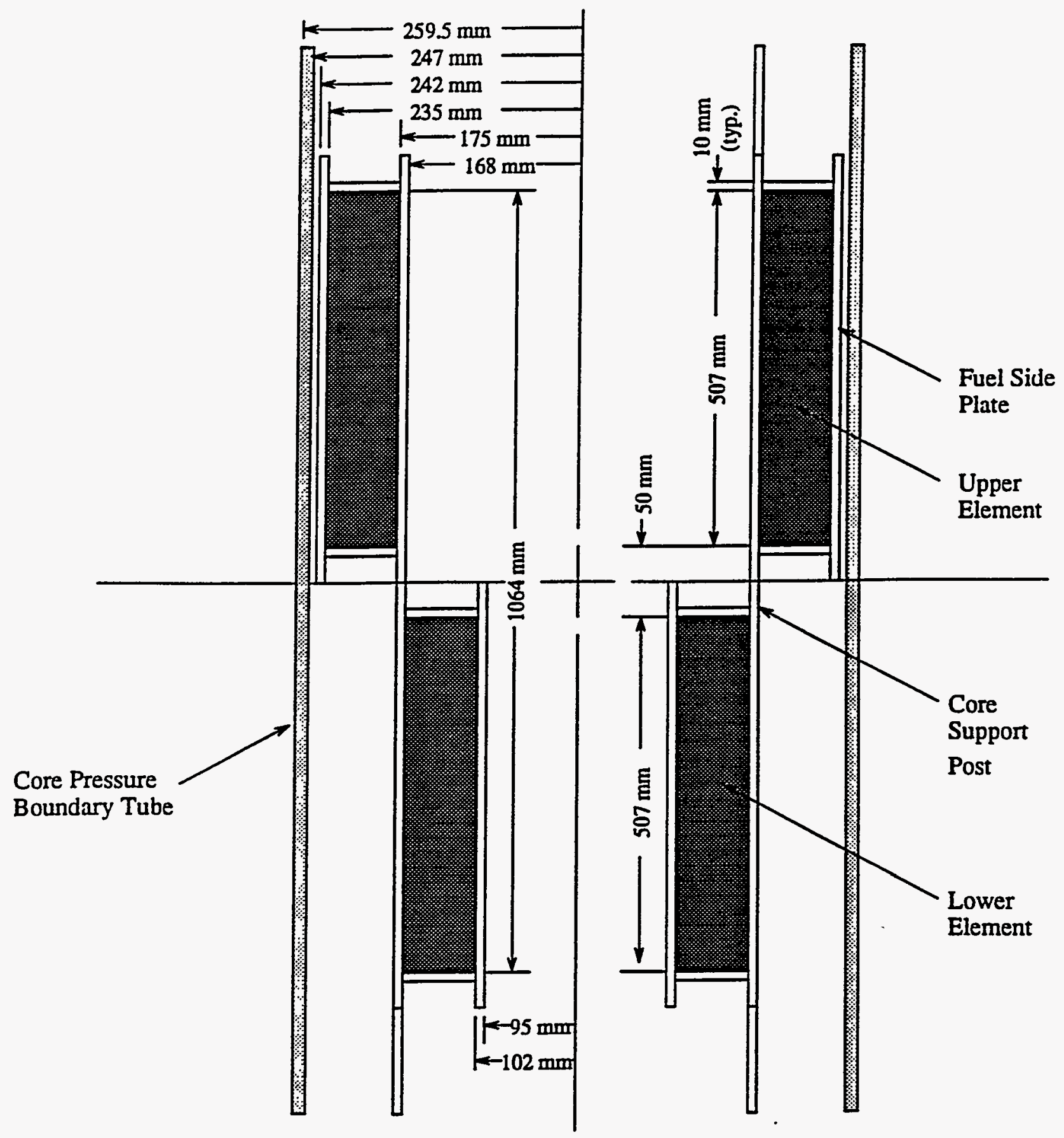

Fig. 2.2. ANS reactor core dimènsions. 
Table 2.1. Key reactor physics parameters

\begin{tabular}{ll}
\hline \multicolumn{1}{c}{ Parameter } & Reference value \\
\hline Reactor power & \\
Deposited in fuel and primary coolant, $\mathrm{MW}$ & 303 \\
Fission, $\mathrm{MW}$ & 330 \\
Core life, full power days & 17 \\
Core average thermal power density, MW/L & 4.5 \\
Ratio of peak to average core thermal power & \\
BOC & 2.31 \\
Middle of cycle & 2.12 \\
EOC & 1.78 \\
Delayed-neutron fraction & 0.008 \\
Prompt-neutron lifetime, $\mathrm{ms}$ & 0.5 \\
Peak reflector thermal flux, $\mathrm{m}^{-2} \cdot \mathrm{s}^{-1}$ & \\
BOC & $7.19 \times 10^{19}$ \\
EOC & $7.40 \times 10^{19}$ \\
Flux efficiency at EOC, $\mathrm{m}^{-2} \cdot \mathrm{s}^{-1} \cdot \mathrm{MW}_{\mathrm{f}}^{-1}$ & $2.24 \times 10^{17}$ \\
Maximum excess reactivity, $\mathrm{pcm}^{a}$ & 31,070 \\
Core fissile loading at BOC, $\mathrm{kg}^{235} \mathrm{U}$ & 15.1 \\
Fuel burnup, $\mathrm{kg}{ }^{235} \mathrm{U}$ & 7.0 \\
Core burnable poison loading, $\mathrm{g}^{10} \mathrm{~B}$ & 13 \\
BOC & $<.06$ \\
EOC &
\end{tabular}

aPotential reactivity of core at $20^{\circ} \mathrm{C}$ without the effects of burnable poison, the CPBT, and experiment facilities. 
Table 2.2. Primary and secondary coolant parameters

\begin{tabular}{|c|c|c|}
\hline Parameter & SI units & English units \\
\hline Core inlet temperature & $45^{\circ} \mathrm{C}$ & $113^{\circ} \mathrm{F}$ \\
\hline Active core bulk outlet temperature & $85^{\circ} \mathrm{C}$ & $185^{\circ} \mathrm{F}$ \\
\hline Hot leg return temperature & $81^{\circ} \mathrm{C}$ & $178^{\circ} \mathrm{F}$ \\
\hline \multicolumn{3}{|l|}{ Primary coolant flow rate } \\
\hline Total (through pump) & $2.01 \mathrm{Mg} / \mathrm{s}$ & $29,100 \mathrm{gal} / \mathrm{min}$ \\
\hline Through active core (fuel) & $1.83 \mathrm{Mg} / \mathrm{s}$ & $26,500 \mathrm{gal} / \mathrm{min}$ \\
\hline Vessel gap and island & $0.18 \mathrm{Mg} / \mathrm{s}$ & $2,600 \mathrm{gal} / \mathrm{min}$ \\
\hline Reactor assembly inlet pressure & $3.5 \mathrm{MPa}$ & 508 psia \\
\hline Fuel inlet pressure & $3.2 \mathrm{MPa}$ & 464 psia \\
\hline Reactor assembly outlet pressure & $1.69 \mathrm{MPa}$ & 245 psia \\
\hline Core pressure drop & $1.51 \mathrm{MPa}$ & 219 psia \\
\hline \multicolumn{3}{|l|}{ Core power } \\
\hline Fission & $330 \mathrm{MW}$ & $1.13 \times 10^{9} \mathrm{Btu} / \mathrm{h}$ \\
\hline Thermal power in active core ${ }^{a}$ & $303 \mathrm{MW}$ & $1.03 \times 10^{9} \mathrm{Btu} / \mathrm{h}$ \\
\hline \multicolumn{3}{|l|}{ Heat carried by primary coolant } \\
\hline Core power to primary coolant & $316 \mathrm{MW}$ & $1.08 \times 10^{9} \mathrm{Btu} / \mathrm{h}$ \\
\hline Pump power to primary coolant & $5.2 \mathrm{MW}$ & $1.77 \times 10^{7} \mathrm{Btu} / \mathrm{h}$ \\
\hline Flow rate & $25 \mathrm{~m} / \mathrm{s}$ & $82 \mathrm{ft} / \mathrm{s}$ \\
\hline Primary loop design temperature & $100^{\circ} \mathrm{C}$ & $212^{\circ} \mathrm{F}$ \\
\hline Primary loop design pressure & $4.0 \mathrm{MPa}$ & $580 \mathrm{psi}$ \\
\hline Primary $\mathrm{pH}$ (deuterium) & $4.5-4.9$ & $4.5-4.9$ \\
\hline Maximum primary tritium concentration & $185,000 \mathrm{MBq} / \mathrm{L}$ & $5 \mathrm{Ci} / \mathrm{L}$ \\
\hline Maximum primary protium concentration & 0.2 at. $\%$ & 0.2 at. $\%$ \\
\hline Secondary supply temperature & $29.4^{\circ} \mathrm{C}$ & $85^{\circ} \mathrm{F}$ \\
\hline Secondary return temperature & $46^{\circ} \mathrm{C}$ & $115^{\circ} \mathrm{F}$ \\
\hline Secondary coolant flow rate & $4.96 \mathrm{~m}^{3} / \mathrm{s}$ & $78,600 \mathrm{gal} / \mathrm{min}$ \\
\hline Secondary maximum operating pressure & $446 \mathrm{kPa}$ & 64.7 psia \\
\hline
\end{tabular}

Fuel plates, end caps, and side plates. 


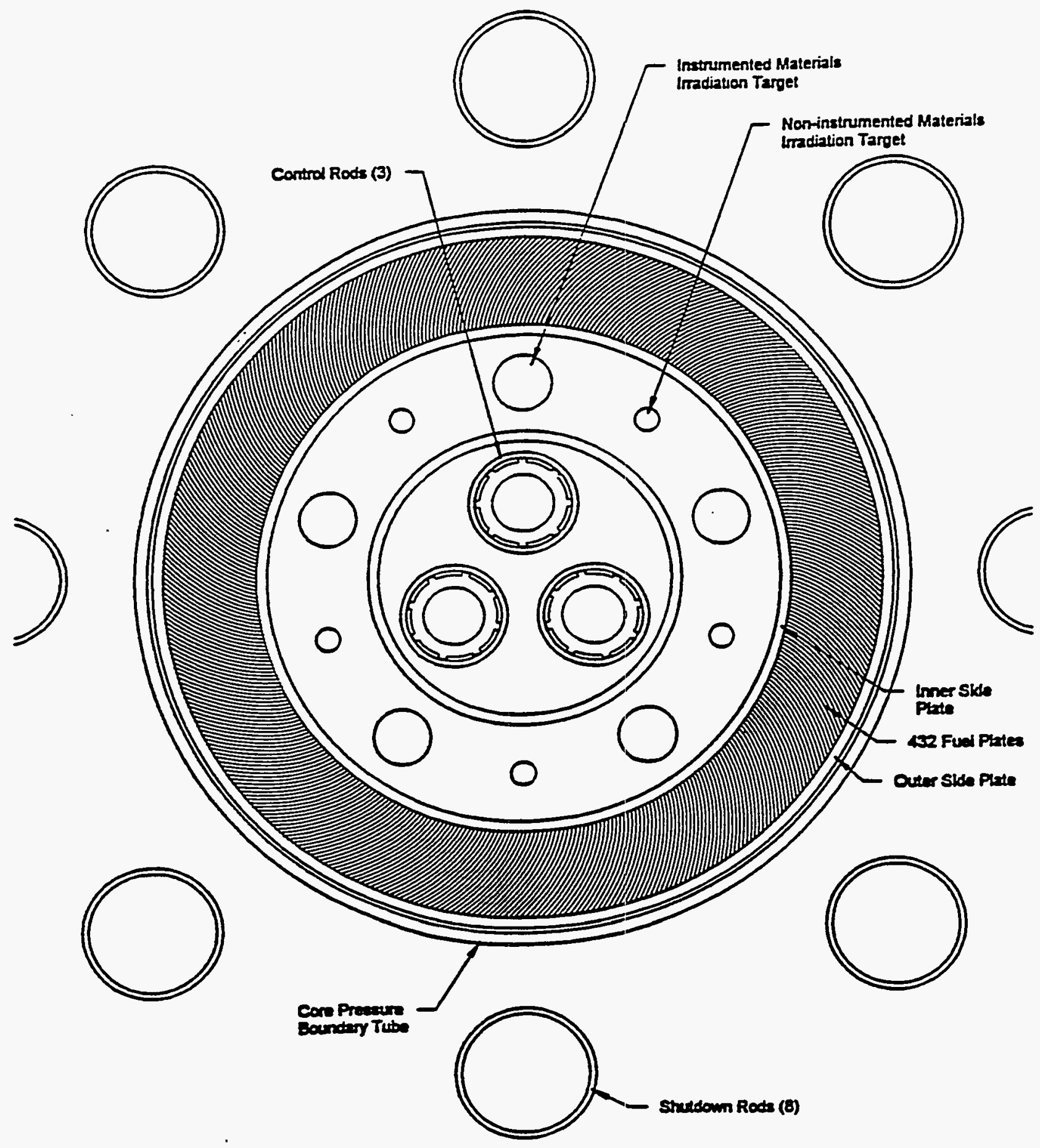

Fig. 2.3. Plan view of the upper fuell element. 


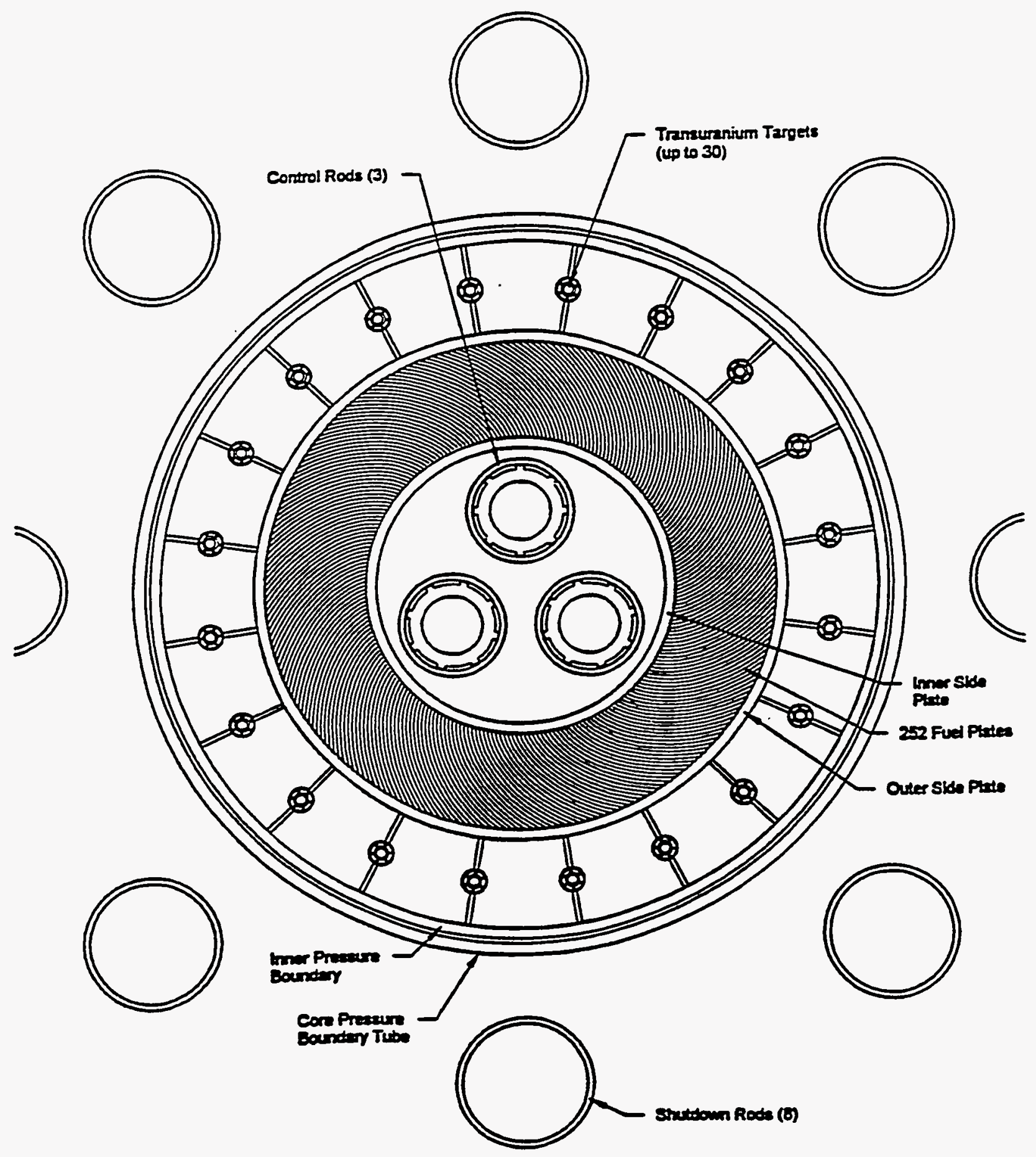

Fig. 2.4. Plan view of the lower fuel element. 
Table 2.3. Fuel plate specifications

Fuel plate thickness, mm

Plate cladding material

Al-6061

Al cladding density, $\mathrm{g} / \mathrm{mL}$

2.6989

Aluminum cladding thickness, mm

0.254

Fuel region filler material

Al-1100

Al filler density, $\mathrm{g} / \mathrm{mL}$

2.6989

$\mathrm{Al}$ filler thickness

Variable

Fuel region materials

$\mathrm{U}_{3} \mathrm{Si}_{2}$ and $\mathrm{Al}$

Fueled region thickness, mm

Variable, $\leq 0.762$

$\mathrm{U}_{3} \mathrm{Si}_{2}$ density, $\mathrm{g} / \mathrm{mL}$

11.9

Uranium enrichment, wt \%

93

$\mathrm{U}_{3} \mathrm{Si}_{2}$ in fuel region, vol \%

11.2

Upper element fueled width (radial), mm

60

Lower element fueled width (radial), mm 66

Upper element fueled length (axial), mm 507

Lower element fueled length (axial), mm

Upper element total width (radial), mm

Lower element total width (radial), mm

Upper element total length (axial), mm

Lower element total length (axial), mm

Number of plates in upper element 


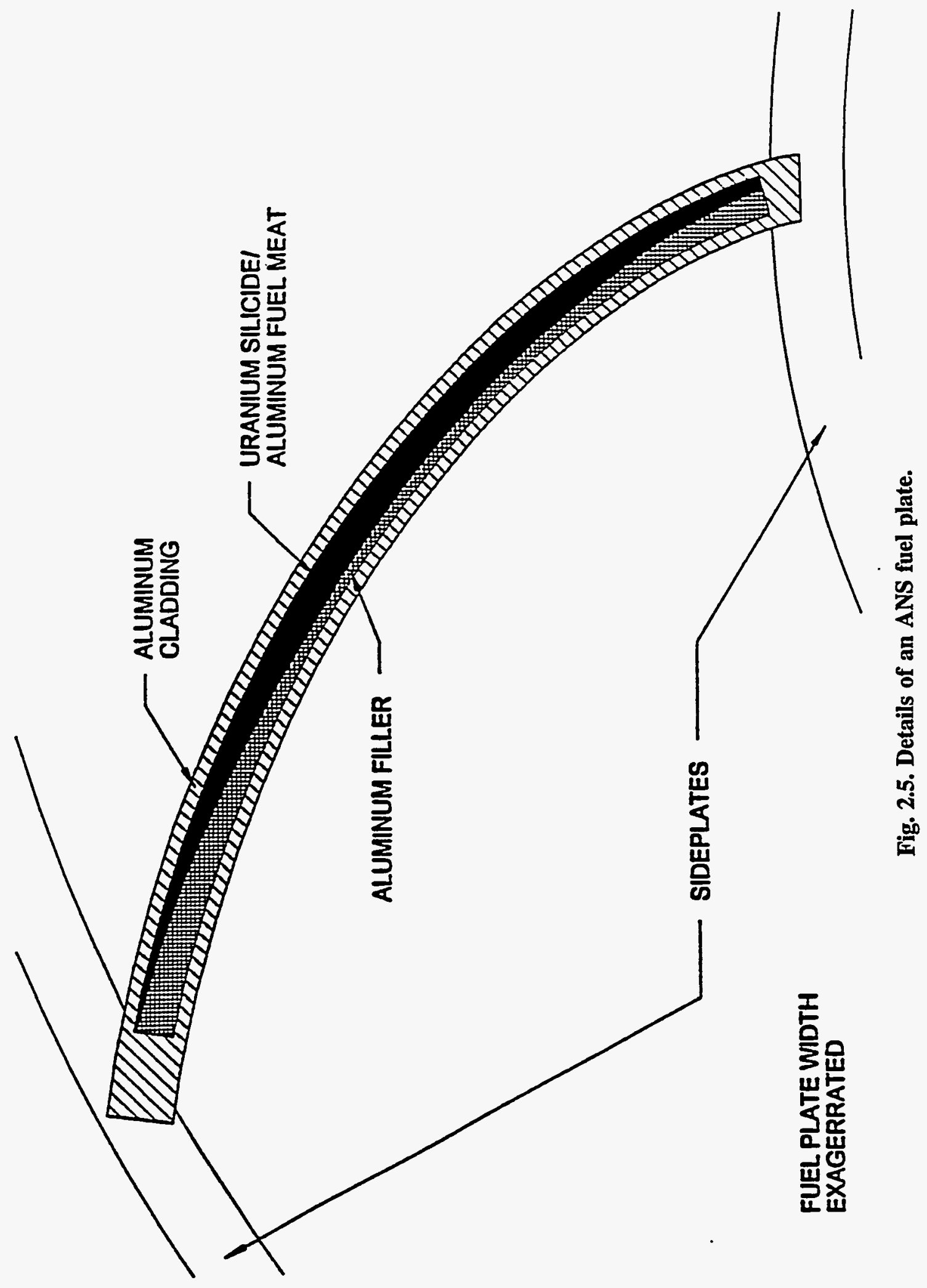




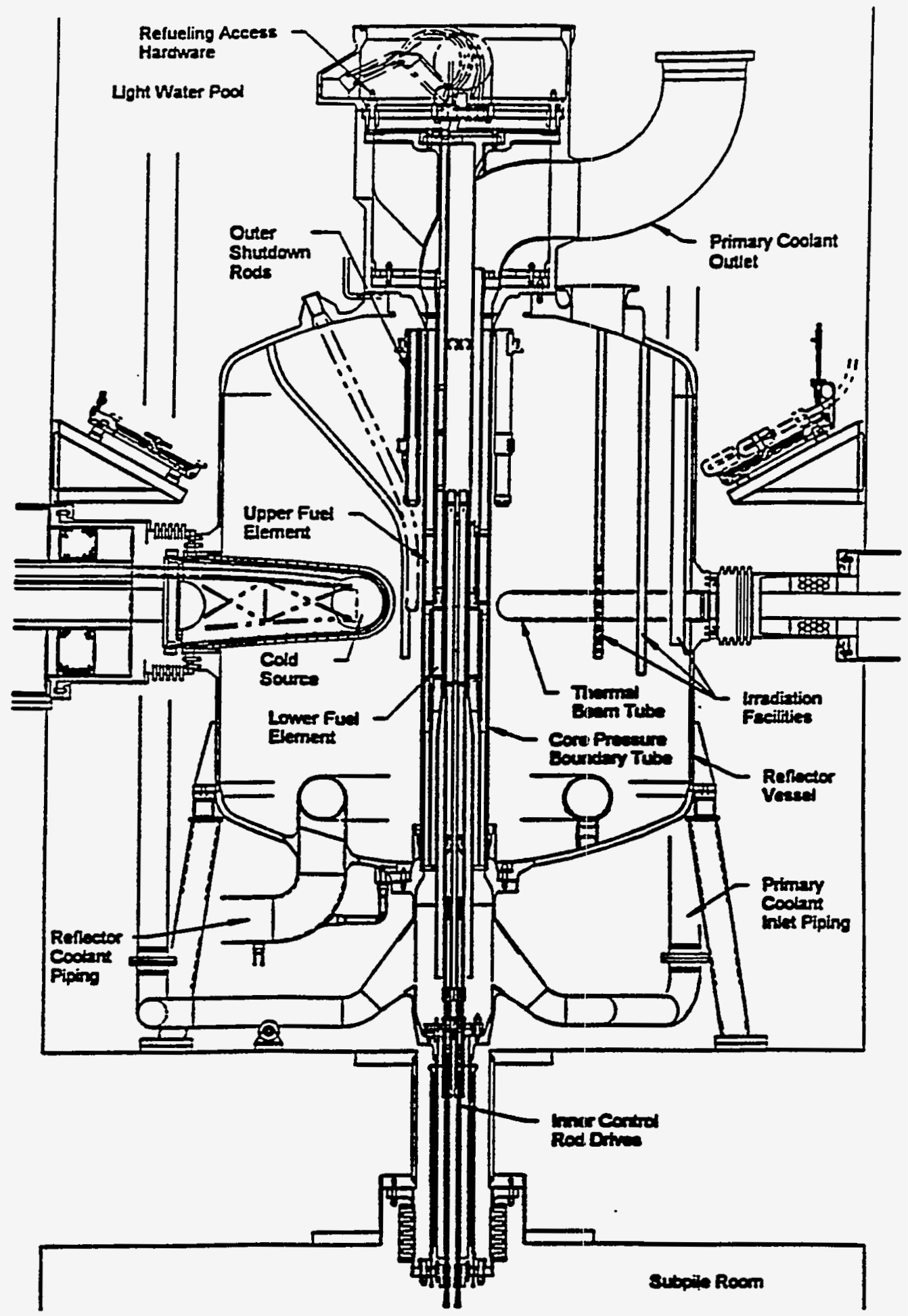

Fig. 2.6. Section through the reactor assembly. 
Table 2.4. Inner control rod system specifications

Number of control rods 3

Central cavity material $\mathrm{D}_{2} \mathrm{O}$

Central cavity inner radius, $\mathrm{mm}$ 22.0

Support ring material Al-6061

Support ring inner radius, $\mathrm{mm}$ 22.0

Support ring outer radius, $\mathrm{mm}$ 28.5

Number of support ring thimbles 8

Thimble material Al-6061

Thimble width, mm 5

Thimble length, $\mathrm{m}$ 1.2

Control ring material Hf, natural

Control ring inner radius, $\mathrm{mm}$ 31.5

Control ring outer radius, $\mathrm{mm}$ 35.5

Active control length, $\mathrm{m}$ 1.2

Upper support ring height (above Hf), $m$ 1.424

Upper support ring inner radius, $\mathrm{mm}^{a}$ 22.0

Upper support ring outer radius, $\mathrm{mm}^{a}$ 35.5

Lower support ring height (below Hf), $m$ 3.80

Lower support ring inner radius, $\mathrm{mm}^{b}$ 17.0

Lower support ring outer radius, $\mathrm{mm}^{b}$ 25.0

${ }^{a} \mathrm{Gap}$ and thimbles identical to active control region.

bInner and outer radii increase to $24.0 \mathrm{~mm}$ and $32.0 \mathrm{~mm}$, respectively, at $\sim 1.8 \mathrm{~m}$ below Hf. 

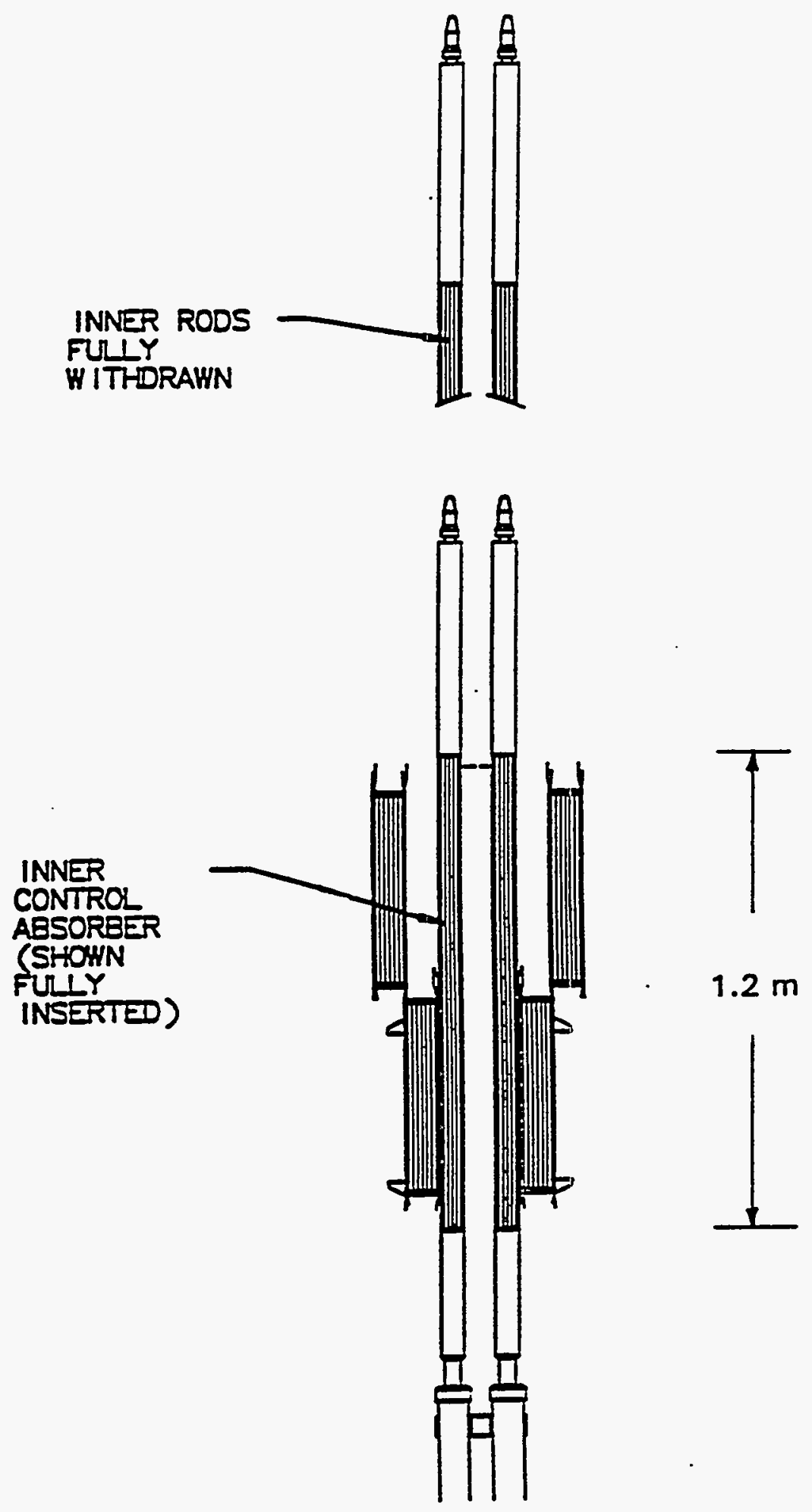

Fig. 2.7. Elevation view of the inner control rod system. 

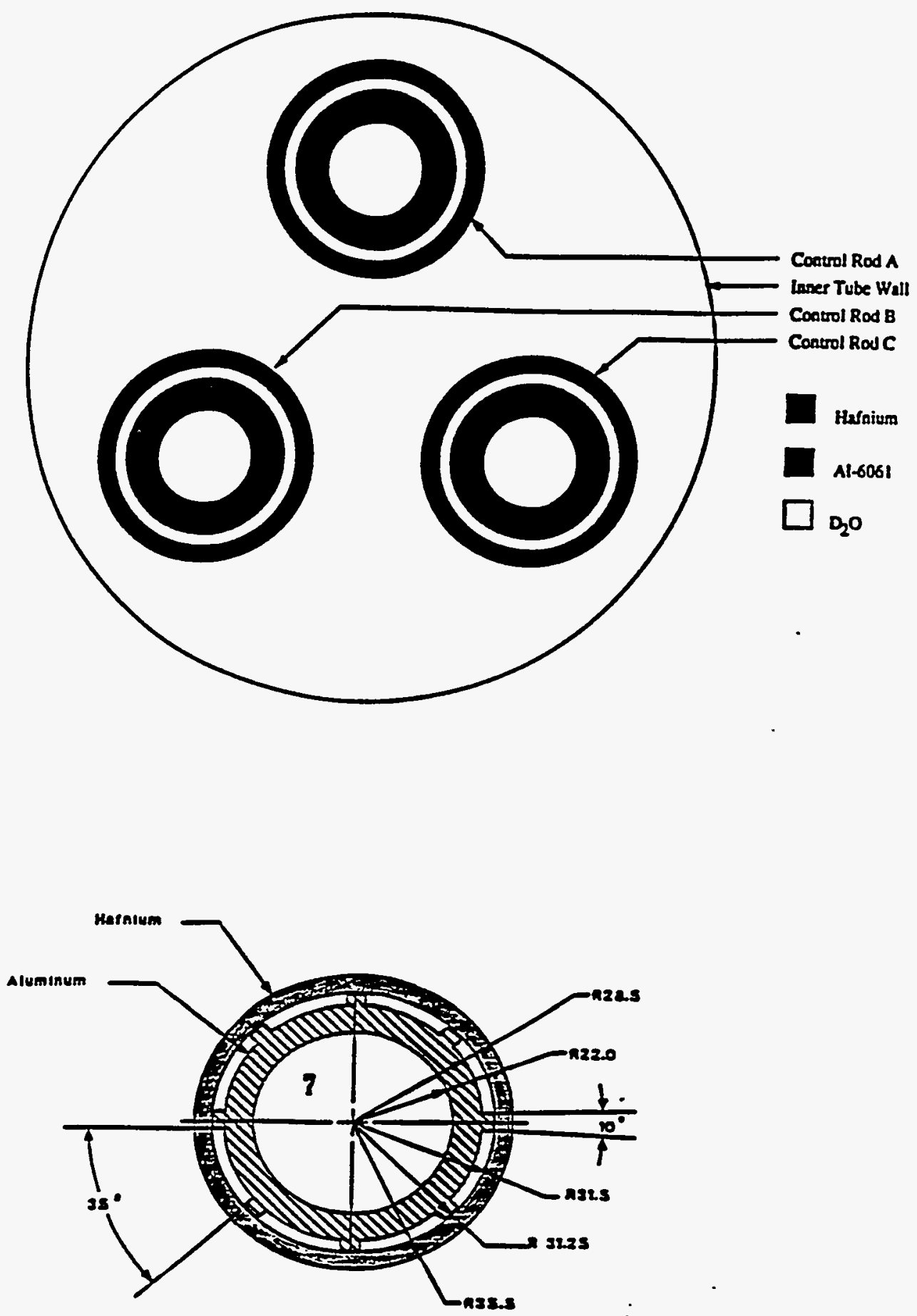

Fig. 2.8. Plan view of the inner control rod system. 
Table 2.5. Outer shutdown rod system specifications

Number of control rods 8

Central cavity material $\mathrm{D}_{2} \mathrm{O}$

Central cavity inner radius, $\mathrm{mm}$ 34.5

Support ring material Al-6061

Support ring inner radius, mm 34.5

Support ring outer radius, $\mathrm{mm}$ 38.5

Control ring material Hf, natural

Control ring inner radius, $\mathrm{mm}$ 38.5

Control ring outer radius, $\mathrm{mm}$ 42.5

Active control length, $\mathrm{m}$

0.6

Control sheath material Al-6061

Control sheath end cap thickness, mm 15

Control sheath inner radius, $\mathrm{mm}^{a}$ 42.5

Control sheath outer radius, $\mathrm{mm}^{a}$ 60.0

Support ring height (above Hf), $m$

0.77

Support ring inner radius (above $\mathrm{Hf}$ ), $\mathrm{mm}$ 34.5

Support ring outer radius (above Hf), mm 42.5

Control sheath height, $\mathrm{m}$ 1.37

${ }^{a}$ Nominal values; see figures of outer control rods. 


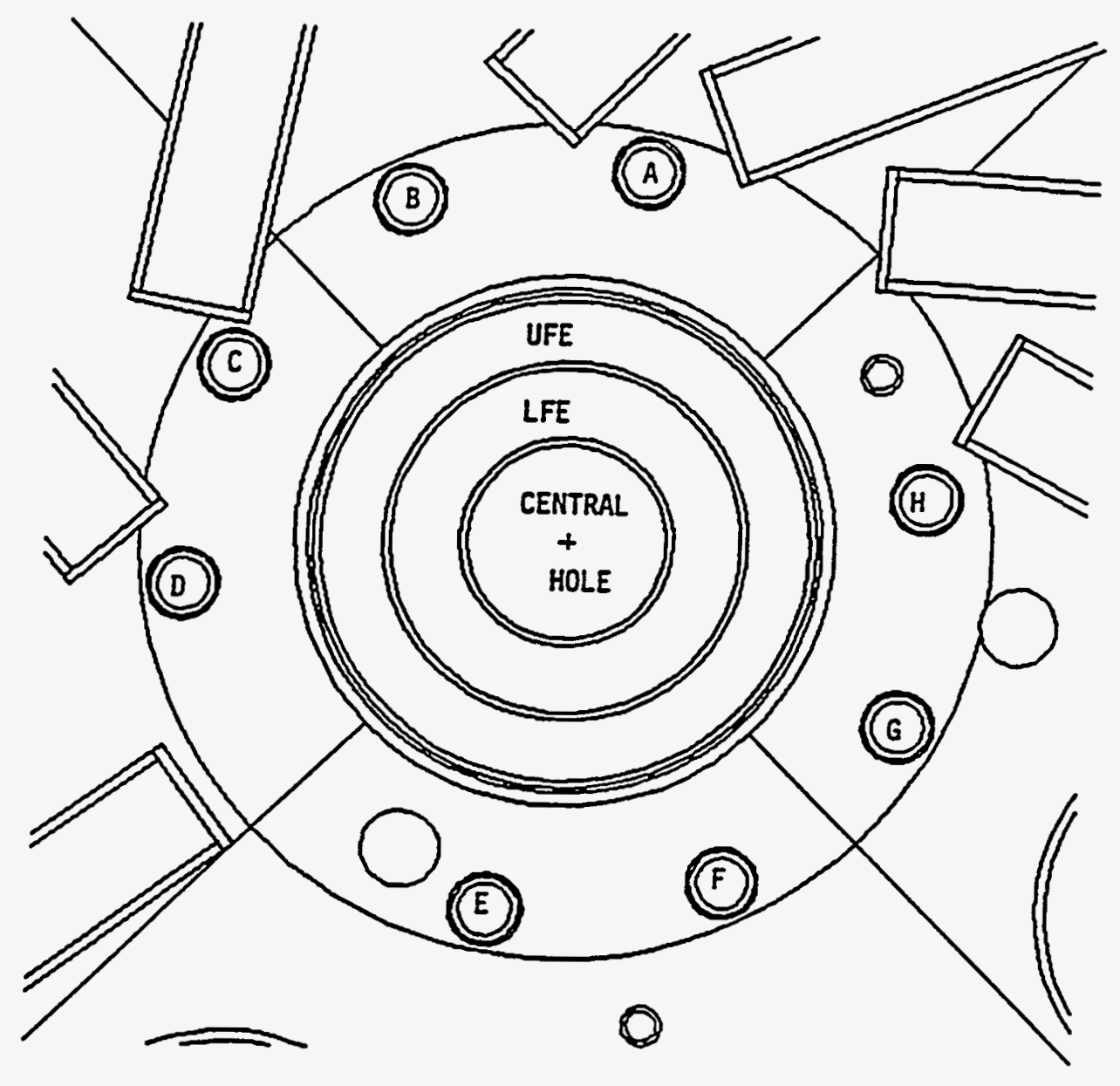

Fig. 2.9. Near midplane plan view of the ANS MCNP reactor model showing the radial location and relative size of short safety rods $A$ through $H$. 


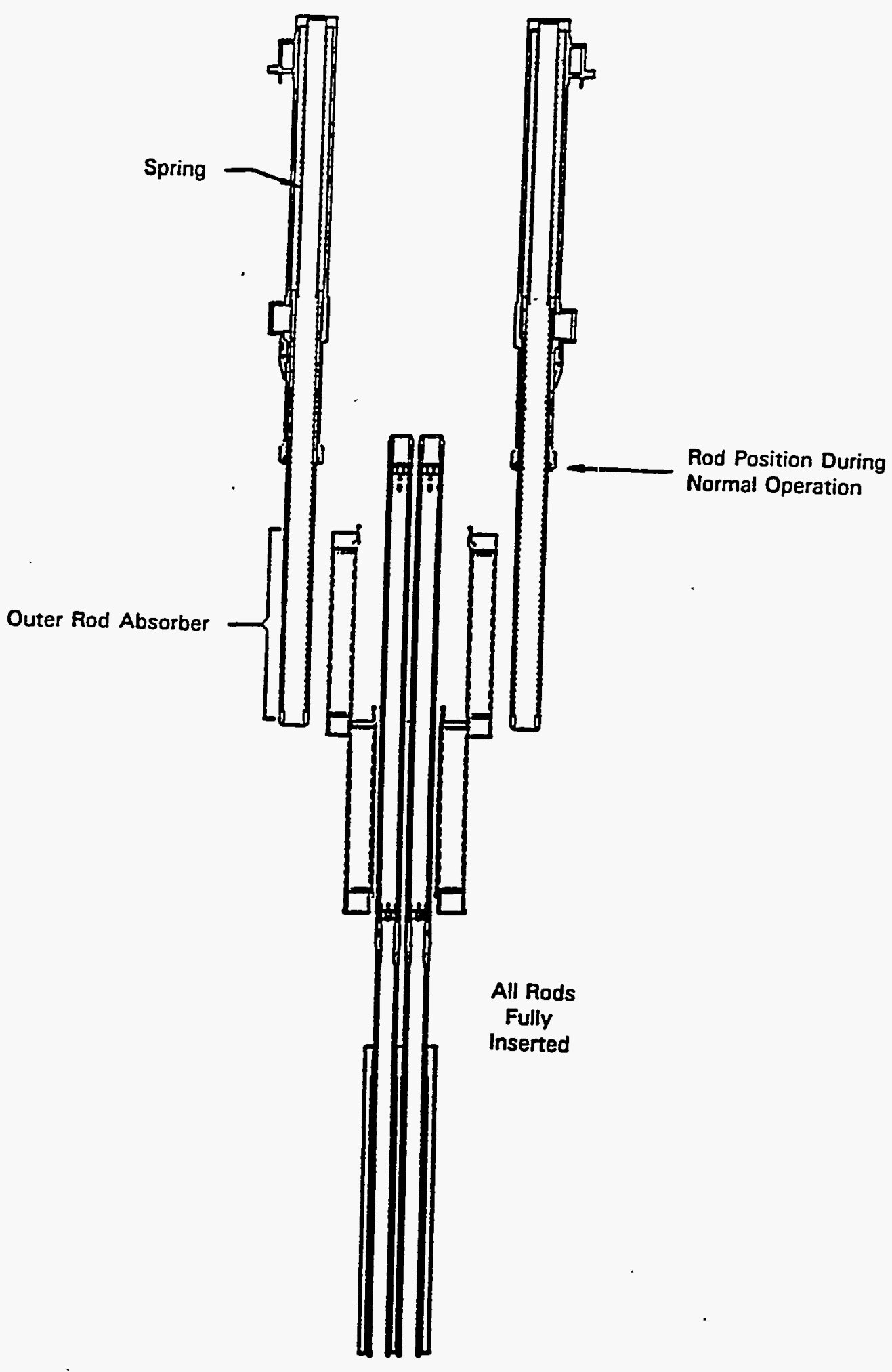

Fig 2.10. Elevation view of the outer control rod system. 


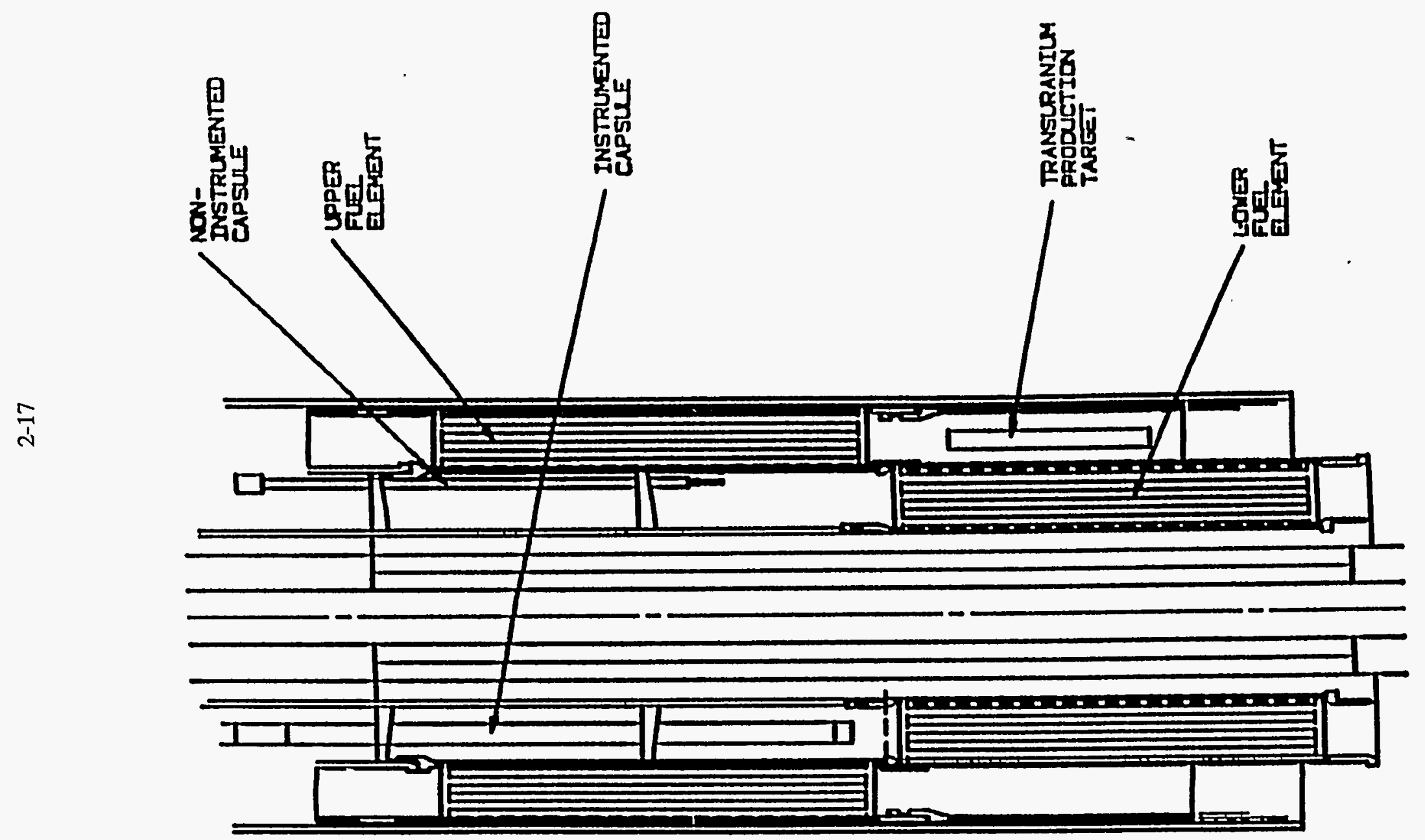




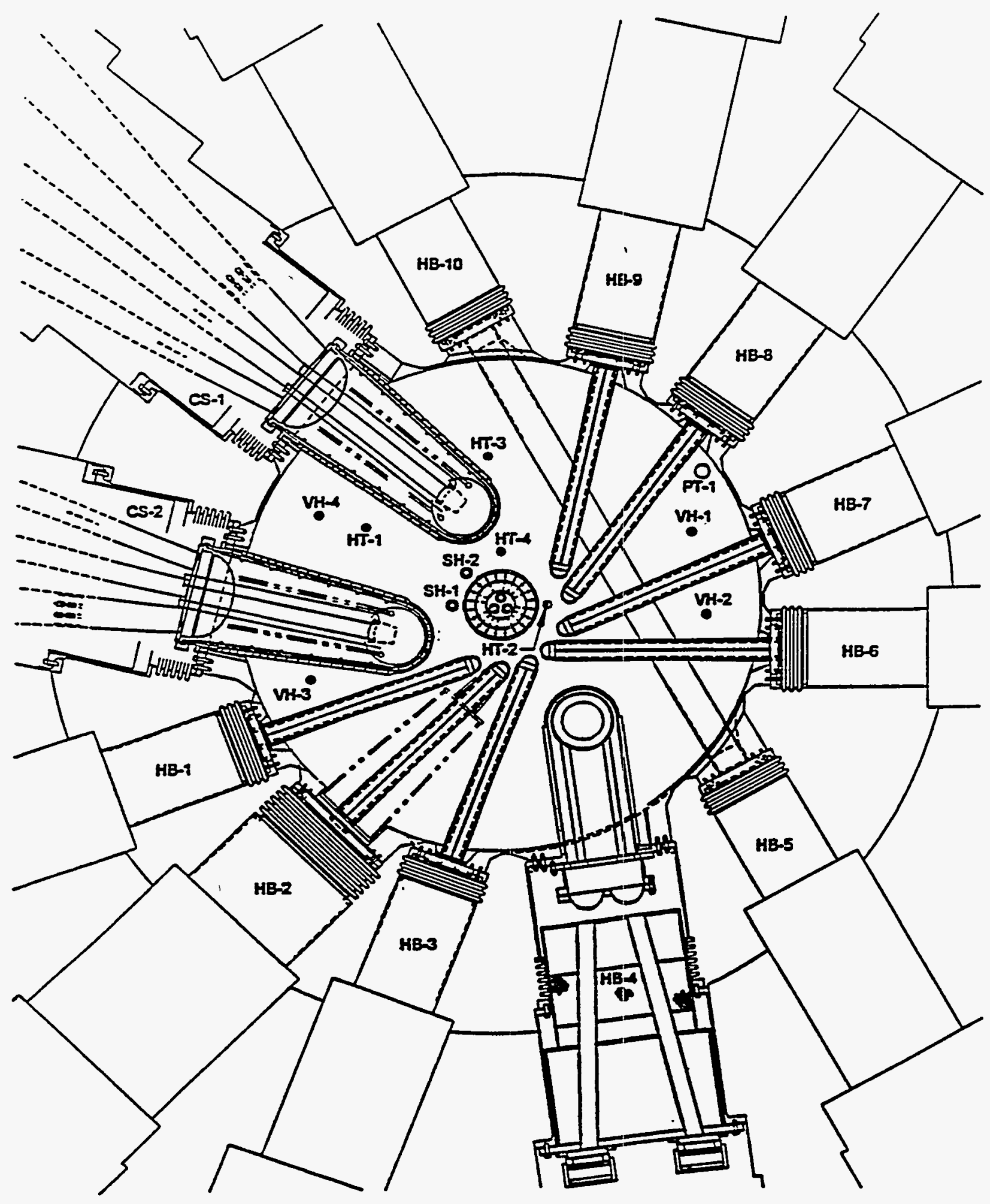

Fig. 2.12. Section of the reactor assembly at core midplane. 
Table 2.6. ANS irradiation facilities

\begin{tabular}{ccc}
\hline Facility & Number & Location \\
\hline \multicolumn{4}{c}{ Transuranium production facilities }
\end{tabular}

In-core irradiation facilities

In-core irradiation targets (up to 30)

Outside lower fuel element

Reflector irradiation facilities

Epithermal hydraulic rabbit tube

HT-2 Reflector

Support facilities

Target handling area

Cask loading area

Hydraulic tube unloading area

Materials irradiation facilities

In-core irradiation facilities

Instrumented irradiation facilities (5)

Noninstrumented irradiation facilities (5)

Inside upper fuel element

Inside upper fuel element

Reflector irradiation facilities

Slant irradiation facility

SH-1 Reflector

Slant irradiation facility

SH-2 Reflector

Support facilities

Upper slant hole facility

Storage pool experiment handling facility

Shielded valve box

Materials irradiation monitoring and control facility

Capsule segmentation and loading cells

Experiment pool

Fuel handling area pool

Reactor building

Isotope production facilities

Reflector irradiation facilities

Hydraulic rabbit tube

HT-1 Reflector

Hydraulic rabbit tube

HT-3 Reflector

Hydraulic rabbit tube

HT-4 Reflector

Vertical irradiation facility

VH-1 Reflector

Vertical irradiation facility

VH-2 Reflector

Vertical irradiation facility

VH-3 Reflector

Vertical irradiation facility

VH-4 Reflector

Support facilities

Rabbit loading and handling facilities

Target handling facilities

\section{Analytical chemistry facilities}

Activation analysis facilities

Pneumatic rabbit tube ( $2 \mathrm{~mL})$

Pneumatic rabbit tube $(40 \mathrm{~mL})$

PT-1 Reflector

PT-2 Reflector

Pneumatic rabbit tube $(40 \mathrm{~mL})$

PT-3 Reflector

Pneumatic rabbit tube $(40 \mathrm{~mL})$

PT-4 Reflector

Pneumatic rabbit tube $(40 \mathrm{~mL})$

PT-5 Reflector

Pneumatic rabbit tube $(120 \mathrm{~mL})$

PF-1 Light water pool

Pneumatic rabbit tube $(120 \mathrm{~mL})$

PF-1 Light water pool 
Table 2.6 (continued)

\begin{tabular}{lll}
\hline \multicolumn{1}{c}{ Facility } & Number & \multicolumn{1}{c}{ Location } \\
\hline Positron facilities & & Reflector (TBD) \\
Krypton irradiation facility & & Second floor, reactor building \\
Positron beam facilities & & \\
Materials analysis facilities & GIF & Spent fuel pool \\
$\gamma$-irradiation facility & & \\
Support facilities & Reactor building \\
NAAF-1 facility & Research support building \\
NAAF-2 facility & \\
\hline
\end{tabular}




\section{COMPUTER CODE DESCRIPTIONS}

The physics analysis of the ANS reactor requires the use of a number of computer codes. This chapter provides a description of the major codes used in evaluation of the ANS conceptual design.

The development of appropriate cross sections is a crucial part of any detailed physics analysis. The cross-section processing codes and various processing options used by the ANS project staff are discussed in Sect. 3.1. The VENTURE diffusion-theory code (discussed in Sect. 3.2) and the BURNER code (discussed in Sect. 3.3) are the major codes used in the conceptual design phase to provide fuel cycle analysis of the ANS reactor core. The PDQ code (discussed in Sect. 3.4) has been used to provide limited parallel evaluations for comparison purposes and to address some special issues.

Both MCNP and DORT have been used to perform transport analyses. The MCNP code (discussed in Sect. 3.5) has been the main reference tool for comparison validation of other models. In the conceptual design analysis, it has been used to perform most of the BOC reactivity evaluations and heat load analyses. The DORT code (discussed in Sect. 3.6) has been used for special analyses such as beam tube, cold source, and shielding evaluations that were not amenable to analysis with the MCNP model. Space-time analyses have been performed using the CONQUEST nodal kinetics code (discussed in Sect. 3.7).

\subsection{CROSS-SECTION PROCESSING CODES}

\subsubsection{Codes Used to Create a Master Library}

Multigroup neutron cross-section libraries were used for fuel cycle calculations in the ANS design analysis. The master library is based upon the ENDF/B-evaluated nuclear data files. ${ }^{4}$ After the choices of the energy group structure and the weighting functions are made, several cross-section processing codes are used to interpret the basic ENDF/B-evaluated nuclear data and to perform the integration over energy to create a master library. An ANS-specific master library, ANSL-V, ${ }^{5}$ was created for fuel cycle analysis. The codes listed in this section are those modules of the SCALE ${ }^{6}$ and AMPX ${ }^{7}$ systems used to create the ANSL-V master library. A brief summary of the functions of each SCALE and/or AMPX code module follows.

The processing codes are used (1) to process an ENDF/B-formatted evaluation with XIACS-77; (2) to perform the first-order data checks by running RADE on the resulting data set, using VASELINE to plot selected cross sections and evaluating the findings; (3) to execute FRESH to adjust thermal-scattering matrices for the heavier materials; (4) to execute COMET to force either the averaged values to agree with the matrix sums or the matrix sums to agree with the average values; (5) to execute RIGEL-UNRESR-TABU sequences to generate Bondarenko factors for unresolved resonance data where applicable; and (6) to execute UNITAB to combine the averaged XIACS-77 data with the Bondarenko factor data. The LAPHNGAS code was used to process data from the ENDF/B-V and LENDL data files into the chosen energy structure. The SMUG code was used (1) to calculate multigroup photon cross sections with transfer coefficients and (2) to process the DLC-99/HUGO photon interaction data to generate multigroup photoelectric and pair-production cross sections. 


\subsubsection{Codes Used to Produce Few-Group Problem-Dependent Cross-Section Libraries}

The master cross-section library, prepared using the codes described in Sect. 3.1.1., needs to be further processed before being used in the neutronics calculations. In particular, the unresolved- and resolved-resonance region cross sections need to be "shielded" to account for the application-dependent fuel temperature and fuel cell densities and dimensions. The computer codes used to perform the resonance shielding calculations are the BONAMI and NITAWL modules of the SCALE or AMPX systems. The shielded cross sections retain the master library group structure (i.e., there is no energy collapsing).

In the ANS applications, BONAMI is used for shielding cross sections in the unresolved resonance range only. BONAMI accesses the master library file that contains Bondarenko factors and performs a resonance self-shielding calculation based on the Bondarenko method. ${ }^{8}$ The Bondarenko method is used for shielding the unresolved resonances in the majority of modern reactor analysis codes. The method has also been shown accurate for most fast reactor applications, which operate in an energy regime where the narrow resonance approximation is apt to be adequate. However, for shielding of the resolved-resonance cross sections in the energy regimes of thermal reactors, more accurate methods are required. One such method is the Nordheim Integral Treatment, ${ }^{9}$ which is used in the NITAWL code for shielding of the resolved-resonance cross sections.

The NITAWL code uses the master cross-section library as input. If the unresolved-resonance cross sections have already been shielded by the BONAMI code, as in ANS applications, only the resolved-resonance cross sections are shielded in NITAWL. NITAWL contains several extensions to the Nordheim calculation: (1) elements containing more than one isotope can be treated,

(2) self-shielding is applied to resonance scattering and the transfer matrices are adjusted, (3) p-wave as well as s-wave levels can be treated, (4) the asymptotic approximation for the flux in the thermal energy range is assumed to have a Maxwellian energy distribution, (5) a refined procedure for generating the energy mesh over which reaction rates are integrated has been developed, and (6) the user has the option of averaging the multigroup constants over the absorber region or with a cellaveraging formulation. Again, the output cross sections retain the master library group structure (i.e., there is no energy collapsing). After performing the resonance analysis, NITAWL combines the shielded cross sections with the fast and thermal data to produce a "working" library organized by the reaction type and scattering expansion order. This working library is compatible with the input requirements of the XSDRNPM and KENO-IV codes.

\subsection{VENTURE DIFFUSION-THEORY CODE}

The VENTURE three-dimensional multigroup diffusion-theory code ${ }^{10}$ is used in combination with the BURNER burnup code to analyze reactor performance over the fuel cycle. VENTURE was developed at Oak Ridge National Laboratory (ORNL) over a 20-year period and has been extensively tested against results from benchmark problems and analytic solutions to the diffusion equation. ${ }^{11}$ The code solves the finite-difference mesh-centered formulation of the neutron diffusion equations in one-, two-, or three-dimensional Cartesian cylindrical, spherical, and triangular geometry for a total of 12 possible modeling options: slab (x), cylinder ( $r$ ), sphere $(s), x-y, r-z$, theta-r, $T$ (equilateral triangle), $H$ (equilateral hexagon), $x-y-z$, theta-r-z, T-z, and $H-z$.

The VENTURE code has the capability to solve the neutronics eigenvalue, adjoint, fixed source, and criticality search problems. The first harmonic of the eigenvalue problem can also be calculated in VENTURE for use in stability analysis. Internal boundary conditions can be defined in terms of the flux-to-current ratio to model control rods or other highly absorbing regions. External boundary options are zero flux, reflected, or extrapolated. A buckling can be input for approximating leakage in dimensions not modeled. Equilibrium xenon can be calculated if desired and included in the neutron 
balance for determining BOC-with-xenon reactivity and flux distributions without performing an explicit exposure calculation using BURNER.

The cross-section file input to VENTURE can contain either macroscopic or microscopic cross sections, although microscopic files are used almost exclusively in this application. The diffusion coefficients can be direction dependent if desired.

Application of VENTURE within CCD of ANS has focused on fuel cycle analysis, design variation studies, perturbation analysis, and calculation of kinetics parameters. Fuel cycle analysis includes determination of fuel loading and burnable poison distributions to meet power density profile goals, calculation of control rod worths over multiple-cycle exposures to determine control rod lifetimes, and calculation of flux and power distributions throughout the core and reflector vessel and into the light water pool. The changes in reactor performance parameters, such as reactivity and peak thermal flux in the reactor, as a function of small design changes have been calculated using VENTURE for cases when Monte Carlo calculations are not feasible because of the poor statistics. VENTURE is also used to solve for the flux and adjoint flux to calculate the effective delayed-neutron fraction and the prompt-neutron lifetime as input to point-kinetics analysis. Finally, the fundamental mode flux and first harmonic flux are calculated in VENTURE to assess reactor stability against power oscillations.

The reactor parameters calculated using VENTURE have been compared with more accurate transport theory results from DORT and MCNP. Validation of the VENTURE modeling of the ANS core is discussed in Sect. 5.3. The design analysis using VENTURE has been for "unperturbed" reactor conditions, meaning that the experimental facilities and components have not been incorporated into the modeling. The reasons are threefold: (1) conclusions for many design trade-off studies are not dependent upon whether perturbed or unperturbed core conditions are modeled, (2) comparisons of achievable thermal flux between ANS and other reactors (Institut Lave-Langevin in particular) should be based on unperturbed conditions because the traditional reportings of achievable flux levels have been for calculations performed without modeling of the experimental facilities, and (3) accurate representation of the experimental component geometries is not possible in existing deterministic neutronics codes (diffusion theory or transport theory). Future design trade-off studies using VENTURE will be performed in which the experimental facilities' effects upon reactivity and power distributions will be incorporated into the modeling based upon comparisons with MCNP Monte Carlo results.

\subsection{BURNER FUEL DEPLETION CODE}

The BURNER fuel depletion code is used in the ANS Project to follow nuclide buildup and depletions over the fuel cycle. BURNER was developed at ORNL as a module to be used in conjunction with the VENTURE diffusion-theory code. Details of the theory and user's manual are contained in Ref. 12. The BURNER code solves explicit chain equations input by the user. Given the cross-section data and fluxes from the VENTURE neutronics calculation, transmutations are calculated. Fission product yield fractions input to BURNER may be incident-energy dependent. Nuclides are exposed to the zone-average flux output from VENTURE. BURNER also has a provision for finescale exposure using mesh-point fluxes rather than zone fluxes. The gamma source and cumulated exposure data can be obtained if desired.

\subsection{PDQ DIFFUSION-THEORY CODE}

PDQ- $7^{13}$ is a general diffusion-theory code with fuel depletion capability. The PDQ-7 model was used to perform the isotope depletion and generation calculations at Idaho National Engineering 
Laboratory (INEL) because MCNP does not have this capability. Thus, the MCNP code was used by INEL to examine core parameters at $\mathrm{BOC}$, while $\mathrm{PDQ}-7$ was used to determine reactor parameters over the entire fuel cycle. As much as possible, the two-dimensional PDQ-7 model is consistent with the three-dimensional MCNP model. Cross sections for the PDQ-7 calculations were obtained by processing 28-group cross-section libraries with the COMBINE ${ }^{14}$ code, using the calculated flux and current spectra from different unit cells as weighting functions. One-dimensional cylindrical transport models were used by INEL in the SCRABL ${ }^{15}$ code to collapse cross sections to four groups.

Reference 16 contains descriptions of the diffusion-theory calculations made with PDQ-7 and the cross-section processing performed to generate the input to PDQ-7.

\subsection{MCNP MONTE CARLO CODE}

Transport calculations were performed using MCNP Version $3 \mathrm{~b}$, a three-dimensional, continuous-energy, coupled neutron-photon Monte Carlo code. MCNP has been developed at the Los Alamos National Laboratory over the past four decades and is one of the most sophisticated Monte Carlo transport codes in general use today. Geometric descriptions are defined by combinatorial geometries, using combinations of two- and three-dimensional surfaces. The code can perform neutral particle transport in either continuous or discrete energy modes, with a variety of physics options available to the user. Tallies of desired output parameters (e.g., flux and current) can be freely defined by the user over any spatial, energy, or angular domain. Various methods of statistical variance reduction are available. Computations may be performed in either the eigenvalue or fixed source mode. More detail is available in the MCNP Code Users Manual. ${ }^{17}$

The MCNP code has been used in the ANS design project to predict criticality, compute reactivity coefficients and effects, calculate component heat loads, and generate limited sets of groupwise cross sections for use in other discrete transport and diffusion codes. ${ }^{18}$ All computations were run using continuous energy cross sections, thus eliminating the need for developing problem-dependent multigroup cross sections as required for analysis using discrete transport and diffusion codes. Consequently, MCNP has been used as a benchmark for other calculations and methods. Computations were run until sufficiently small uncertainties were obtained in the results. For eigenvalue calculations, the statistical uncertainty was less than $0.4 \%$; for other quantities the uncertainty was generally less than $5 \%$ and usually less than $1 \%$. However, when necessary for specific applications, greater or lesser uncertainty was obtained in the results.

Cross sections for MCNP were obtained from the controlled source at the National Energy Research Software Center (NERSC) at Lawrence Livermore National Laboratory (LLNL). These cross sections were processed by various methods from several sources.

The code DKPOWR ${ }^{19}$ computes decay powers, energies, activities, and beta and photon spectra for fission products resulting from fission in light water reactor fuel. The fission-product photon spectra data in DKPOWR were gathered from experimental data compiled for the decay heat power standard ANSI/ANS-5.1-1979. ${ }^{20}$ Further details of this code are available in Ref. 19. It has been assumed that the fission product yields will not be significantly different for heavy water-moderated fuels. Comparison of yields, activities, and total decay powers with results from the ORIGEN2 code, which performs a similar calculation based upon ENDF/B Version 4 data, provides confirmation of this assumption. Details of the ORIGEN2 code are available in Ref. 21.

The MCNP and DKPOWR codes were externally coupled to provide component heat load computations. An initial eigenvalue computation was made with MCNP to calculate the fission, neutron, and prompt-photon heat loads, as well as the fission and aluminum absorption rates in each component of the reactor. The aluminum absorption rates provided a source of photons from the decay of ${ }^{28} \mathrm{Al}$ to ${ }^{28} \mathrm{Si}$ for a fixed source mode computation and the local heat load resulting from the beta particles emitted in this decay. Data on the energetics of this decay were obtained from the 1984 Chart 
of the Nuclides. ${ }^{22}$ An ORIGEN2 model of the ANS was run with a modified one-group library obtained from VENTURE to give the fission rates at each burnup step. Since ORIGEN2 has an ENDF/IV fission product library, it became necessary to use DKPOWR to obtain the correct distribution in the fission production energy and yields between beta and gamma decays. Neither ENDF/IV nor ENDF/V has a sufficiently complete library for the fission product decays, especially for short-lived isotopes, to render a correct result for this problem. DKPOWR (which is based on experimental measurements) was deemed appropriate to obtain the distribution between the beta and gamma decay energies and the gamma yield spectrum. This distribution is important to determine the fraction of the fission-product decay that is deposited locally (beta decay) and the fraction that is deposited elsewhere (gamma decay). The fission rates yielded a source of photons from the decay of fission products and their daughters and also the local heat load from fission-product decay beta particles. This source was evaluated using DKPOWR, which provided the energy split between the photon and beta decays associated with the fission products and daughters.

\subsection{DORT TRANSPORT CODE}

The DORT two-dimensional discrete-ordinates transport code ${ }^{23}$ is used in the CCD of ANS (1) to calculate reactivity and flux and power distributions for detailed design analysis and for benchmarking VENTURE results, (2) to calculate component heating rates, (3) to provide a source distribution for shielding analysis, (4) to carry out detailed shielding analysis, (5) to provide a source distribution for cold source analysis, and (6) to calculate neutron fluxes exiting the beam tubes and guide tubes.

The DORT code, a derivative of the DOT 4 code, ${ }^{24}$ and has been developed at ORNL for more that 20 years, primarily for deep-penetration transport of neutrons and photons. Eigenvalue and criticality search problems can also be solved. DORT can solve both the forward and the adjoint problem. Seven two-dimensional geometries can be modeled: $x-y, r-z, r-$ theta, $180-360^{\circ}$ triangular, $60^{\circ}$ triangular, $90^{\circ}$ triangular, and $120^{\circ}$ triangular. Special remeshing features allow the number of firstdimension mesh intervals to vary with second-dimension indexing. The directional quadrature set can be chosen from an arbitrary number of input sets, the choice varying with spatial position and energy group as desired. A variety of options allows sources to be specified at internal or external boundaries, distributed by space and energy, or determined from an input flux guess.

DORT, like VENTURE, has been used for analysis of ANS "unperturbed" conditions (no experimental facilities modeled). The validation of DORT in ANS core analysis is being performed by a comparison against MCNP results. The validation of the DORT model of the ANS is described in Sect. 5.2.

\subsection{CONQUEST NODAL KUNETICS CODE}

The CONQUEST multigroup nodal kinetics code ${ }^{25}$ is used to perform space-time analyses and to compute the point-kinetics parameters of the ANS. CONQUEST has been developed at the Massachusetts Institute of Technology and at ORNL. The code solves the steady-state and timedependent neutron diffusion equations in $x-y-z$ and $r-z$ geometries, using a polynomial expansion of the transversely integrated fluxes within each node. Second-order polynomial expansions are available for cylindrical geometry, and second- through fourth-order polynomials are available for Cartesian geometries. A mesh-centered finite-difference formulation can also be used. CONQUEST solves the steady-state forward and adjoint eigenvalue problems and can be used as an-alternative to the VENTURE neutronics module. Discontinuity factors can be incorporated to correct for diffusion-theory and cross section-homogenization errors. 
The temporal solution may be performed using the theta method, the improved quasi-static method, or the point-kinetics method. The quasi-static and point-kinetics methods are based on factoring the time-dependent neutron flux into a spatially dependent shape function and a spatially independent amplitude function. Point-kinetics parameters are then defined in terms of the parameters of the nodal model. In many transients the shape function changes more slowly than the amplitude function so that a larger time-step size may be used in the shape function calculation than for the amplitude function calculation. The point-kinetics method assumes that the shape function is constant throughout the transient whereas the quasi-static method periodically computes the shape function using the fully implicit time-differenced equations. Transients may be initiated by material changes (e.g., control rod motions), by using a simple feedback model to change thermal-hydraulic conditions, and by time-varying extraneous neutron sources.

Application of CONQUEST within the conceptual design of the ANS is focused on the analysis of transients, calculation of kinetics parameters (prompt-neutron lifetime and effective delayed-neutron fractions), and the verification of the point-kinetics method used for safety analysis. 


\section{CROSS-SECTION DEVELOPMENT AND VALIDATION}

\subsection{CROSS SECTIONS FOR ENERGY GROUP CODES, VENTURE, DORT, AND KENO}

\subsubsection{Cross Sections Used in Fuel Cycle Analysis for the Conceptual Core Design}

A previously validated thermal reactor library based upon ENDF/B-IV was used for the VENTURE/BURNER fuel cycle analysis. A 27-neutron group AMPX master cross-section library was used in the generation of the neutron cross sections. The BONAMI and NITAWL modules of AMPX were used to perform the resonance calculations for the different regions of the ANS core. One-dimensional $\mathrm{S}_{8} \mathrm{P}_{3}$ transport calculations, using the XSDRNPM module of AMPX, were used to generate zone-weighted few-group cross sections using an equivalent one-dimensional model of the ANS core. The XSDRNPM model contained the central region, an equivalent one-ring regulating control rod, the lower and upper fuel elements, the CPBT, and reflector regions.

The zone-weighted collapsed cross sections were then converted, by using the CONTAC module of AMPX, into CCCC-ISOTXS cross-section files. The CCCC-ISOTXS files were used in the VENTURE multidimensional neutronics calculations. For the CCD fuel cycle analysis, four-energy-group cross sections were used, with recognition that a higher number of energy groups will be required for more detailed design studies beyond the CCD phase.

The relative importance of the basic microscopic cross-section sensitivities upon reactor criticality was assessed by using the VENTURE DEPTH/CHARGE module ${ }^{26}$ to calculate first-order sensitivities. The definition of sensitivities is that a perturbation of $1 \%$ produces a change of $S \%$ in the response [e.g., effective core multiplication factor $\left(\mathrm{k}_{\text {eff }}\right)$, power, flux, and reaction rates], where $S$ is the sensitivity. This method has been used to compute the BOC $\mathrm{k}_{\text {eff }}$ sensitivities to the capture, transport, total scatter, and fission cross sections. The results are presented in Tables $4.1-4.4$. Four different ${ }^{235} \mathrm{U}$ sets are used throughout the elements.

\subsubsection{The ANSL-V Cross-Section Library}

Concurrently with CCD analysis, a 99-energy-group neutron cross-section library was developed specifically for the multigroup neutrons analysis codes used in the ANS project. The development of the ANSL-V library is described in detail in Ref. 5. The ANSL-V 99-group neutron, 44-group gamma cross-section library was developed for neutronics analysis over the range of design and operational options considered for the ANS reactor. The ANSL-V data is processed using BONAMI, NITAWL, and XDRNPM for use in subsequent VENTURE, DORT, or KENO calculations. Initial validation of the ANSL-V library was performed by analysis of a variety of clean critical experiments. Most of the criticals analyzed used highly enriched uranium either as a metal or in light or heavy water solution. The reflected critical had light or heavy water surrounding uranium metal spheres, heavy water surrounding uranium solutions moderated by heavy water, light water surrounding uranium solutions moderated by heavy water, or light water surrounding uranium solutions moderated by light water. Three thermal reactor criticals were also analyzed: BAPL-1 $\left(\mathrm{H}_{2} \mathrm{O}\right.$-moderated uranium oxide lattice), TRX-1 $\left(\mathrm{H}_{2} \mathrm{O}\right.$-moderated $1.31 \mathrm{wt} \%$ enriched uranium metal lattice), and ZEEP-1 $\left(\mathrm{D}_{2} \mathrm{O}\right.$-moderated, natural uranium lattice). A detailed description of the criticals, measured parameters, and calculated parameters using the ANSL-V library is given in Ref. 5. Some discrepancies remain to be resolved, but in general the use of ANSL-V cross sections in analysis of the heavy water criticals showed good agreement with the experimental measurements. The average differences in $\mathrm{k}_{\mathrm{eff}}$ are $0.39 \%$ with a standard deviation of $0.27 \%$ for the lumped criticals and $0.45 \%$ with a standard deviation of $0.46 \%$ for 
Table 4.1. Core multiplication factor $\left(\mathrm{k}_{\mathrm{efr}}\right)$ sensitivities to neutron capture cross sections at $\mathrm{BOC}$

\begin{tabular}{|c|c|c|c|c|c|}
\hline \multirow[b]{2}{*}{ Material } & \multirow[b]{2}{*}{ Location } & \multicolumn{4}{|c|}{ Energy group } \\
\hline & & 1 & 2 & 3 & 4 \\
\hline $\mathrm{Al}$ & CPBT & $-4.98 \times 10^{-5}$ & $-1.02 \times 10^{-3}$ & $-1.64 \times 10^{-3}$ & $-4.59 \times 10^{-2}$ \\
\hline${ }^{235} \mathrm{U}$ & Core $x s-4^{a}$ & $-1.59 \times 10^{-4}$ & $-3.87 \times 10^{-3}$ & $-1.01 \times 10^{-2}$ & $-4.21 \times 10^{-2}$ \\
\hline${ }^{235} \mathrm{U}$ & Core $x s-3^{a}$ & $-1.82 \times 10^{-4}$ & $-4.20 \times 10^{-3}$ & $-1.05 \times 10^{-2}$ & $-2.32 \times 10^{-2}$ \\
\hline${ }^{235} \mathrm{U}$ & Core Xs- $1^{a}$ & $-1.40 \times 10^{-4}$ & $-3.69 \times 10^{-3}$ & $-9.21 \times 10^{-3}$ & $-1.78 \times 10^{-2}$ \\
\hline${ }^{235} \mathrm{U}$ & Core $x s-2^{a}$ & $-1.65 \times 10^{-4}$ & $-3.94 \times 10^{-3}$ & $-9.69 \times 10^{-3}$ & $-1.57 \times 10^{-2}$ \\
\hline $\mathrm{Al}$ & Core & $-9.34 \times 10^{-5}$ & $-1.50 \times 10^{-3}$ & $-1.84 \times 10^{-3}$ & $-1.27 \times 10^{-2}$ \\
\hline D & Reflector & $-3.85 \times 10^{-6}$ & $-4.29 \times 10^{-6}$ & $-4.38 \times 10^{-5}$ & $-9.14 \times 10^{-3}$ \\
\hline $\mathrm{Al}$ & Control & $-1.74 \times 10^{-5}$ & $-3.81 \times 10^{-4}$ & $-5.18 \times 10^{-4}$ & $-4.86 \times 10^{-3}$ \\
\hline $\mathrm{Mn}$ & CPBT & $-3.36 \times 10^{-7}$ & $-1.02 \times 10^{-4}$ & $-7.38 \times 10^{-5}$ & $-1.99 \times 10^{-3}$ \\
\hline $\mathrm{Fe}$ & CPBT & $-1.80 \times 10^{-6}$ & $-2.42 \times 10^{-5}$ & $-6.26 \times 10^{-5}$ & $-1.77 \times 10^{-3}$ \\
\hline 0 & Reflector & $-1.11 \times 10^{-8}$ & $-7.40 \times 10^{-7}$ & $-8.57 \times 10^{-6}$ & $-1.59 \times 10^{-3}$ \\
\hline${ }^{234} \mathrm{U}$ & Core & $-1.15 \times 10^{-5}$ & $-2.56 \times 10^{-4}$ & $-3.17 \times 10^{-3}$ & $-1.13 \times 10^{-3}$ \\
\hline $\mathrm{Al}$ & Reflector vessel & $-1.85 \times 10^{-19}$ & $-5.08 \times 10^{-14}$ & $-1.15 \times 10^{-7}$ & $-6.48 \times 10^{-4}$ \\
\hline $\mathrm{Zr}$ & Control & $-2.24 \times 10^{-5}$ & $-4.39 \times 10^{-4}$ & $-3.57 \times 10^{-5}$ & $-4.37 \times 10^{-4}$ \\
\hline $\mathrm{Cr}$ & CPBT & $-9.37 \times 10^{-7}$ & $-9.11 \times 10^{-6}$ & $-1.52 \times 10^{-5}$ & $-4.32 \times 10^{-4}$ \\
\hline $\mathrm{Fe}$ & Core & $-2.84 \times 10^{-6}$ & $-2.81 \times 10^{-5}$ & $-5.83 \times 10^{-5}$ & $-4.16 \times 10^{-4}$ \\
\hline Mn & Core & $-3.96 \times 10^{-7}$ & $-8.52 \times 10^{-5}$ & $-5.11 \times 10^{-5}$ & $-3.45 \times 10^{-4}$ \\
\hline $\mathrm{Si}$ & Core & $-8.65 \times 10^{-6}$ & $-1.95 \times 10^{-5}$ & $-3.35 \times 10^{-5}$ & $-3.28 \times 10^{-4}$ \\
\hline $\mathrm{Mn}$ & Control & $-1.28 \times 10^{-7}$ & $-4.67 \times 10^{-5}$ & $-2.52 \times 10^{-5}$ & $-2.44 \times 10^{-4}$ \\
\hline $\mathrm{Fe}$ & Control & $-6.70 \times 10^{-7}$ & $-1.01 \times 10^{-5}$ & $-2.13 \times 10^{-5}$ & $-2.16 \times 10^{-4}$ \\
\hline Hf & Control & $-1.00 \times 10^{-4}$ & $-5.64 \times 10^{-3}$ & $-3.20 \times 10^{-3}$ & $-1.81 \times 10^{-4}$ \\
\hline${ }^{238} U$ & Core & $-2.30 \times 10^{-5}$ & $-7.66 \times 10^{-4}$ & $-4.26 \times 10^{-3}$ & $-1.64 \times 10^{-4}$ \\
\hline $\mathrm{D}$ & Control & $-7.68 \times 10^{-7}$ & $-7.31 \times 10^{-7}$ & $-5.24 \times 10^{-6}$ & $-6.90 \times 10^{-5}$ \\
\hline $\mathrm{Cr}$ & Control & $-3.19 \times 10^{-7}$ & $-3.60 \times 10^{-6}$ & $-5.25 \times 10^{-6}$ & $-5.30 \times 10^{-5}$ \\
\hline $\mathrm{Cr}$ & Core & $-7.96 \times 10^{-7}$ & $-5.57 \times 10^{-6}$ & $-7.25 \times 10^{-6}$ & $-5.13 \times 10^{-5}$ \\
\hline $\mathrm{D}$ & Core & $-2.01 \times 10^{-6}$ & $-8.44 \times 10^{-7}$ & $-4.76 \times 10^{-6}$ & $-3.41 \times 10^{-5}$ \\
\hline Mn & Reflector vessel & $-1.24 \times 10^{-21}$ & $-6.90 \times 10^{-15}$ & $-2.20 \times 10^{-9}$ & $-2.85 \times 10^{-5}$ \\
\hline${ }^{236} \mathrm{U}$ & Core & $-4.65 \times 10^{-6}$ & $-7.74 \times 10^{-5}$ & $-6.88 \times 10^{-4}$ & $-2.59 \times 10^{-5}$ \\
\hline $\mathrm{Fe}$ & Reflector vessel & $-6.50 \times 10^{-21}$ & $-1.46 \times 10^{-15}$ & $-1.87 \times 10^{-9}$ & $-2.53 \times 10^{-5}$ \\
\hline $\mathrm{Cr}$ & Reflector vessel & $-3.08 \times 10^{-21}$ & $-4.98 \times 10^{-16}$ & $-4.61 \times 10^{-10}$ & $-6.19 \times 10^{-6}$ \\
\hline 0 & Core & $-4.53 \times 10^{-9}$ & $-1.09 \times 10^{-7}$ & $-8.40 \times 10^{-7}$ & $-6.01 \times 10^{-6}$ \\
\hline${ }^{10} \mathrm{~B}$ & Endcaps & $-2.78 \times 10^{-9}$ & $-1.48 \times 10^{-7}$ & $-1.17 \times 10^{-6}$ & $-5.14 \times 10^{-6}$ \\
\hline${ }^{11} B$ & Endcaps & $-5.44 \times 10^{-10}$ & $-1.98 \times 10^{-8}$. & $-5.13 \times 10^{-8}$ & $-2.92 \times 10^{-7}$ \\
\hline $\mathrm{C}$ & Endcaps & $-3.48 \times 10^{-10}$ & $-1.59 \times 10^{-9}$ & $-1.12 \times 10^{-8}$ & $-6.31 \times 10^{-8}$ \\
\hline
\end{tabular}

Indicates ${ }^{235} \mathrm{U}$ cross-section zone in core region. 
4-3

Table 4.2. Core multiplication factor $\left(k_{e f f}\right)$ sensitivities to neutron transport cross sections at BOC

\begin{tabular}{|c|c|c|c|c|c|}
\hline \multirow[b]{2}{*}{ Material } & \multirow[b]{2}{*}{ Location } & \multicolumn{4}{|c|}{ Energy group } \\
\hline & & 1 & 2 & 3 & 4 \\
\hline $\mathrm{D}$ & Reflector & $2.31 \times 10^{-2}$ & $3.92 \times 10^{-2}$ & $2.56 \times 10^{-2}$ & $2.05 \times 10^{-2}$ \\
\hline${ }^{235} \mathrm{U}$ & Core $x s-4^{a}$ & $6.75 \times 10^{-5}$ & $1.23 \times 10^{-4}$ & $3.83 \times 10^{-5}$ & $-1.32 \times 10^{-2}$ \\
\hline 0 & Reflector & $1.48 \times 10^{-2}$ & $3.17 \times 10^{-2}$ & $2.19 \times 10^{-2}$ & $1.04 \times 10^{-2}$ \\
\hline $\mathrm{D}$ & Core & $3.24 \times 10^{-3}$ & $3.05 \times 10^{-3}$ & $7.41 \times 10^{-4}$ & $-1.03 \times 10^{-2}$ \\
\hline $\mathrm{Al}$ & CPBT & $4.45 \times 10^{-3}$ & $5.08 \times 10^{-3}$ & $2.44 \times 10^{-3}$ & $-6.38 \times 10^{-3}$ \\
\hline 0 & Core & $2.04 \times 10^{-3}$ & $2.16 \times 10^{-3}$ & $5.78 \times 10^{-4}$ & $-5.34 \times 10^{-3}$ \\
\hline${ }^{10} \mathrm{~B}$ & Endcaps & $1.86 \times 10^{-6}$ & $4.51 \times 10^{-6}$ & $4.29 \times 10^{-5}$ & $4.38 \times 10^{-3}$ \\
\hline Al & Core & $3.14 \times 10^{-3}$ & $2.88 \times 10^{-3}$ & $3.62 \times 10^{-4}$ & $-3.51 \times 10^{-3}$ \\
\hline Hf & Control & $9.34 \times 10^{-5}$ & $3.83 \times 10^{-4}$ & $2.65 \times 10^{-3}$ & $2.98 \times 10^{-3}$ \\
\hline${ }^{235} \mathrm{U}$ & Core $x s-3^{a}$ & $3.54 \times 10^{-5}$ & $1.05 \times 10^{-4}$ & $9.22 \times 10^{-5}$ & $-2.65 \times 10^{-3}$ \\
\hline${ }^{235} \mathrm{U}$ & Core $x s-1^{a}$ & $1.25 \times 10^{-5}$ & $6.92 \times 10^{-5}$ & $6.07 \times 10^{-5}$ & $-1.80 \times 10^{-3}$ \\
\hline $\mathrm{Al}$ & Control & $1.02 \times 10^{-4}$ & $9.79 \times 10^{-4}$ & $1.47 \times 10^{-3}$ & $-9.42 \times 10^{-4}$ \\
\hline $\mathrm{D}$ & Control & $2.57 \times 10^{-5}$ & $2.05 \times 10^{-3}$ & $2.22 \times 10^{-3}$ & $2.29 \times 10^{-4}$ \\
\hline $\mathrm{Fe}$ & CPBT & $1.57 \times 10^{-5}$ & $3.49 \times 10^{-5}$ & $7.36 \times 10^{-5}$ & $-1.97 \times 10^{-4}$ \\
\hline $\mathrm{Si}$ & Core & $9.35 \times 10^{-5}$ & $5.63 \times 10^{-5}$ & $4.55 \times 10^{-5}$ & $-1.58 \times 10^{-4}$ \\
\hline${ }^{235} \mathrm{U}$ & Core $x s-2^{a}$ & $1.85 \times 10^{-5}$ & $8.86 \times 10^{-5}$ & $1.06 \times 10^{-4}$ & $-1.09 \times 10^{-4}$ \\
\hline $\mathrm{Fe}$ & Core & $9.23 \times 10^{-6}$ & $2.11 \times 10^{-5}$ & $8.96 \times 10^{-6}$ & $-8.93 \times 10^{-5}$ \\
\hline $\mathrm{Al}$ & Reflector vessel & $2.52 \times 10^{-16}$ & $2.58 \times 10^{-12}$ & $5.53 \times 10^{-7}$ & $8.92 \times 10^{-5}$ \\
\hline${ }^{11} \mathrm{~B}$ & Endcaps & $6.62 \times 10^{-6}$ & $7.66 \times 10^{-6}$ & $2.27 \times 10^{-6}$ & $3.55 \times 10^{-5}$ \\
\hline${ }^{234} \mathrm{U}$ & Core & $1.82 \times 10^{-6}$ & $3.97 \times 10^{-6}$ & $7.93 \times 10^{-6}$ & $-3.44 \times 10^{-5}$ \\
\hline $\mathbf{M n}$ & CPBT & $3.91 \times 10^{-6}$ & $4.72 \times 10^{-5}$ & $3.97 \times 10^{-6}$ & $-3.23 \times 10^{-5}$ \\
\hline $\mathrm{Fe}$ & Control & $3.72 \times 10^{-7}$ & $5.90 \times 10^{-6}$ & $4.43 \times 10^{-5}$ & $-2.89 \times 10^{-5}$ \\
\hline${ }^{238} U$ & Core & $7.73 \times 10^{-6}$ & $2.22 \times 10^{-5}$ & $1.44 \times 10^{-5}$ & $-2.74 \times 10^{-5}$ \\
\hline $\mathrm{Cr}$ & CPBT & $4.96 \times 10^{-6}$ & $1.06 \times 10^{-5}$ & $8.59 \times 10^{-6}$ & $-2.54 \times 10^{-5}$ \\
\hline $\mathrm{Zr}$ & Control & $-8.47 \times 10^{-6}$ & $7.96 \times 10^{-5}$ & $1.07 \times 10^{-4}$ & $-1.96 \times 10^{-5}$ \\
\hline $\mathrm{C}$ & Endcaps & $2.17 \times 10^{-6}$ & $2.26 \times 10^{-6}$ & $6.72 \times 10^{-7}$ & $1.05 \times 10^{-5}$ \\
\hline $\mathrm{Mn}$ & Core & $1.71 \times 10^{-6}$ & $2.40 \times 10^{-5}$ & $3.39 \times 10^{-7}$ & $-9.48 \times 10^{-6}$ \\
\hline $\mathrm{Cr}$ & Core & $1.49 \times 10^{-6}$ & $3.13 \times 10^{-6}$ & $5.28 \times 10^{-7}$ & $-5.62 \times 10^{-6}$ \\
\hline $\mathrm{Mn}$ & Control & $9.36 \times 10^{-8}$ & $7.07 \times 10^{-6}$ & $2.29 \times 10^{-6}$ & $-4.42 \times 10^{-6}$ \\
\hline $\mathrm{Cr}$ & Control & $1.19 \times 10^{-7}$ & $1.64 \times 10^{-6}$ & $5.18 \times 10^{-6}$ & $-3.64 \times 10^{-6}$ \\
\hline $\mathrm{Fe}$ & Reflector vessel & $8.95 \times 10^{-19}$ & $2.54 \times 10^{-14}$ & $1.75 \times 10^{-8}$ & $2.65 \times 10^{-6}$ \\
\hline${ }^{236} \mathrm{U}$ & Core & $6.80 \times 10^{-7}$ & $1.87 \times 10^{-6}$ & $1.92 \times 10^{-6}$ & $-2.19 \times 10^{-6}$ \\
\hline $\mathrm{Mn}$ & Reflector vessel & $2.24 \times 10^{-19}$ & $4.21 \times 10^{-14}$ & $8.95 \times 10^{-10}$ & $4.14 \times 10^{-7}$ \\
\hline $\mathrm{Cr}$ & Reflector vessel & $2.87 \times 10^{-19}$ & $7.37 \times 10^{-15}$ & $2.05 \times 10^{-9}$ & $3.35 \times 10^{-7}$ \\
\hline
\end{tabular}

Indicates ${ }^{235} \mathrm{U}$ cross-section zone in core region. 
Table 4.3. Core multiplication factor $\left(k_{e f f}\right)$ sensitivities to neutron total scatter cross sections at BOC

\begin{tabular}{|c|c|c|c|c|c|}
\hline \multirow[b]{2}{*}{ Material } & \multirow[b]{2}{*}{ Location } & \multicolumn{4}{|c|}{ Energy group } \\
\hline & & 1 & 2 & 3 & 4 \\
\hline $\mathrm{D}$ & Reflector & $4.12 \times 10^{-2}$ & $8.20 \times 10^{-2}$ & $5.33 \times 10^{-2}$ & $2.05 \times 10^{-2}$ \\
\hline $\mathrm{D}$ & Core & $1.69 \times 10^{-2}$ & $1.64 \times 10^{-2}$ & $1.68 \times 10^{-2}$ & $-1.04 \times 10^{-2}$ \\
\hline 0 & Reflector & $1.67 \times 10^{-2}$ & $3.64 \times 10^{-2}$ & $2.57 \times 10^{-2}$ & $1.03 \times 10^{-2}$ \\
\hline $\mathrm{Al}$ & CPBT & $5.47 \times 10^{-3}$ & $5.30 \times 10^{-3}$ & $2.64 \times 10^{-3}$ & $-5.88 \times 10^{-3}$ \\
\hline 0 & Core & $3.08 \times 10^{-3}$ & $3.34 \times 10^{-3}$ & $2.10 \times 10^{-3}$ & $-5.50 \times 10^{-3}$ \\
\hline $\mathrm{Al}$ & Core & $5.58 \times 10^{-3}$ & $3.30 \times 10^{-3}$ & $9.29 \times 10^{-4}$ & $-3.39 \times 10^{-3}$ \\
\hline${ }^{235} \mathrm{U}$ & Core $x s-4^{a}$ & $5.91 \times 10^{-5}$ & $6.67 \times 10^{-5}$ & $1.43 \times 10^{-5}$ & $-3.12 \times 10^{-3}$ \\
\hline $\mathrm{Al}$ & Control & $5.87 \times 10^{-4}$ & $1.08 \times 10^{-3}$ & $1.57 \times 10^{-3}$ & $-8.80 \times 10^{-4}$ \\
\hline${ }^{235} \mathrm{U}$ & Core $\mathrm{xs}-3^{a}$ & $3.75 \times 10^{-5}$ & $6.25 \times 10^{-5}$ & $2.34 \times 10^{-5}$ & $-8.75 \times 10^{-4}$ \\
\hline${ }^{10} \mathrm{~B}$ & Endcaps & $1.55 \times 10^{-6}$ & $-9.49 \times 10^{-7}$ & $1.22 \times 10^{-5}$ & $5.13 \times 10^{-4}$ \\
\hline${ }^{235} \mathrm{U}$ & Core Xs- $1^{a}$ & $1.79 \times 10^{-5}$ & $4.42 \times 10^{-5}$ & $1.87 \times 10^{-5}$ & $-3.21 \times 10^{-4}$ \\
\hline D & Control & $5.41 \times 10^{-3}$ & $1.18 \times 10^{-2}$ & $1.12 \times 10^{-2}$ & $1.84 \times 10^{-4}$ \\
\hline $\mathrm{Fe}$ & CPBT & $1.66 \times 10^{-5}$ & $3.81 \times 10^{-5}$ & $7.62 \times 10^{-5}$ & $-1.77 \times 10^{-4}$ \\
\hline Hf & Control & $6.04 \times 10^{-5}$ & $2.31 \times 10^{-4}$ & $1.03 \times 10^{-3}$ & $1.75 \times 10^{-4}$ \\
\hline $\mathrm{Si}$ & Core & $1.03 \times 10^{-4}$ & $7.19 \times 10^{-5}$ & $6.48 \times 10^{-5}$ & $-1.57 \times 10^{-4}$ \\
\hline $\mathrm{Fe}$ & Core & $1.11 \times 10^{-5}$ & $2.62 \times 10^{-5}$ & $1.65 \times 10^{-5}$ & $-8.49 \times 10^{-5}$ \\
\hline $\mathrm{Al}$ & Reflector vessel & $2.55 \times 10^{-16}$ & $2.57 \times 10^{-12}$ & $5.64 \times 10^{-7}$ & $7.83 \times 10^{-5}$ \\
\hline${ }^{11} \mathrm{~B}$ & Endcaps & $7.25 \times 10^{-6}$ & $6.57 \times 10^{-6}$ & $-6.63 \times 10^{-6}$ & $3.55 \times 10^{-5}$ \\
\hline${ }^{235} \mathrm{U}$ & Core $x s-2^{a}$ & $2.42 \times 10^{-5}$ & $6.00 \times 10^{-5}$ & $2.83 \times 10^{-5}$ & $-2.63 \times 10^{-5}$ \\
\hline $\mathrm{Fe}$ & Control & $8.55 \times 10^{-7}$ & $7.79 \times 10^{-6}$ & $4.60 \times 10^{-5}$ & $-2.58 \times 10^{-5}$ \\
\hline${ }^{238} \mathrm{U}$ & Core & $1.02 \times 10^{-5}$ & $2.00 \times 10^{-5}$ & $6.80 \times 10^{-6}$ & $-2.50 \times 10^{-5}$ \\
\hline $\mathrm{Zr}$ & Control & $5.86 \times 10^{-7}$ & $8.51 \times 10^{-5}$ & $1.17 \times 10^{-4}$ & $-2.12 \times 10^{-5}$ \\
\hline $\mathrm{Cr}$ & CPBT & $5.44 \times 10^{-6}$ & $1.10 \times 10^{-5}$ & $8.77 \times 10^{-6}$ & $-2.02 \times 10^{-5}$ \\
\hline${ }^{234} \mathrm{U}$ & Core & $2.25 \times 10^{-6}$ & $3.29 \times 10^{-6}$ & $1.83 \times 10^{-6}$ & $-1.23 \times 10^{-5}$ \\
\hline C & Endcaps & $2.38 \times 10^{-6}$ & $1.92 \times 10^{-6}$ & $-1.94 \times 10^{-6}$ & $1.05 \times 10^{-5}$ \\
\hline Mn & CPBT & $4.36 \times 10^{-6}$ & $4.68 \times 10^{-5}$ & $2.80 \times 10^{-6}$ & $-7.69 \times 10^{-6}$ \\
\hline $\mathrm{Cr}$ & Core & $2.00 \times 10^{-6}$ & $3.44 \times 10^{-6}$ & $9.66 \times 10^{-7}$ & $-4.84 \times 10^{-6}$ \\
\hline $\mathbf{M n}$ & Core & $2.38 \times 10^{-6}$ & $2.41 \times 10^{-5}$ & $3.72 \times 10^{-7}$ & $-2.99 \times 10^{-6}$ \\
\hline $\mathrm{Cr}$ & Control & $3.91 \times 10^{-7}$ & $1.88 \times 10^{-6}$ & $5.29 \times 10^{-6}$ & $-2.83 \times 10^{-6}$ \\
\hline $\mathrm{Fe}$ & Reflector vessel & $8.95 \times 10^{-19}$ & $2.52 \times 10^{-14}$ & $1.73 \times 10^{-8}$ & $2.22 \times 10^{-6}$ \\
\hline${ }^{236} U$ & Core & $9.36 \times 10^{-7}$ & $1.66 \times 10^{-6}$ & $5.89 \times 10^{-7}$ & $-1.73 \times 10^{-6}$ \\
\hline Mn & Control & $3.40 \times 10^{-7}$ & $7.09 \times 10^{-6}$ & $1.54 \times 10^{-6}$ & $-5.47 \times 10^{-7}$ \\
\hline $\mathrm{Cr}$ & Reflector vessel & $2.88 \times 10^{-19}$ & $7.32 \times 10^{-15}$ & $1.99 \times 10^{-9}$ & $2.30 \times 10^{-7}$ \\
\hline $\mathrm{Mn}$ & Reflector vessel & $2.26 \times 10^{-19}$ & $4.15 \times 10^{-14}$ & $5.62 \times 10^{-10}$ & $-6.49 \times 10^{-8}$ \\
\hline
\end{tabular}

Indicates ${ }^{235} \mathrm{U}$ cross-section zone in core region. 
Table 4.4. Core multiplication factor $\left(\mathrm{k}_{\mathrm{eff}}\right)$ sensitivities to neutron fission cross section at BOC

\begin{tabular}{clcccc}
\hline & & \multicolumn{4}{c}{ Energy group } \\
\cline { 3 - 6 } Material & Location & \multicolumn{1}{c}{1} & 2 & 3 & 4 \\
\hline${ }^{235} \mathrm{U}$ & Core xs-4 $^{a}$ & $2.16 \times 10^{-3}$ & $1.08 \times 10^{-2}$ & $1.76 \times 10^{-2}$ & $9.86 \times 10^{-2}$ \\
${ }^{235} \mathrm{U}$ & Core xs-3 $^{a}$ & $2.47 \times 10^{-3}$ & $1.16 \times 10^{-2}$ & $1.74 \times 10^{-2}$ & $4.54 \times 10^{-2}$ \\
${ }^{235} \mathrm{U}$ & Core xs-1 $^{a}$ & $1.87 \times 10^{-3}$ & $1.01 \times 10^{-2}$ & $1.52 \times 10^{-2}$ & $3.60 \times 10^{-2}$ \\
${ }^{235} \mathrm{U}$ & Core xs-2 $^{a}$ & $2.23 \times 10^{-3}$ & $1.08 \times 10^{-2}$ & $1.57 \times 10^{-2}$ & $2.91 \times 10^{-2}$ \\
${ }^{234} \mathrm{U}$ & Core & $8.09 \times 10^{-5}$ & $2.83 \times 10^{-6}$ & $1.20 \times 10^{-6}$ & $1.64 \times 10^{-6}$ \\
${ }^{236} \mathrm{U}$ & Core & $1.43 \times 10^{-5}$ & $1.21 \times 10^{-6}$ & $6.53 \times 10^{-6}$ & $7.40 \times 10^{-8}$ \\
${ }^{238} \mathrm{U}$ & Core & $9.37 \times 10^{-5}$ & $6.29 \times 10^{-8}$ & $4.12 \times 10^{-9}$ & $1.14 \times 10^{-10}$ \\
\hline
\end{tabular}

${ }^{\circ}$ Indicates ${ }^{235} \mathrm{U}$ cross-section zone in core region.

the solution criticals. Future validation of the ANSL-V library will be performed by comparison against numerical continuous-energy Monte Carlo benchmark results and by use of the library in analysis of ANS critical experiments.

\subsection{MCNP CROSS-SECTION DEVELOPMENT AND VALIDATION}

The MCNP continuous-energy cross sections used for the ANS design project were processed from evaluated data files, generally using the $\mathrm{NJOY}^{27}$ nuclear data processing code. The cross sections were converted to a linear-linear interpolation scheme. Resonances and, if applicable, thermal scattering matrices were Doppler-broadened to the appropriate temperature, generally $300-\mathrm{K}$, output in the Los Alamos ACE format, then converted to the MCNP export cross-section file format. Most of the isotopes used for these analyses were developed from ENDF/B-V, which contains the most-updated MCNP-format cross sections. A few were processed from ENDL-85 data, which were evaluated at LLNL. A list of the nuclides used for the MCNP analyses of the ANS conceptual core design is given in Table 4.5.

The cross-section sets supplied with MCNP, as well as those acquired later from the NERSC, were included in the software configuration control package and are subject to configuration control along with the quality assurance version of MCNP. Verification of MCNP was performed as part of the software quality assurance plan for MCNP3b at INEL. A set of standard MCNP benchmark calculations, many of which are models of existing experimental facilities, was run using a subset of the cross sections mentioned previously.

\subsection{PDQ TRANSPLUTONIUM ISOTOPE PRODUCTION ROD CROSS SECTIONS}

Nuclides used for depletion analysis in the transplutonium production rods were processed from ENDF/B-V cross-section data using the codes ETOP- $15^{28}$ and FLANGE. ${ }^{29}$ These codes produce, respectively, fast-energy-range and thermal-energy-range fine-group cross-section libraries for use in the spectrum code COMBINE/PC. The COMBINE code was then used to calculate a core spectrum for a representative BOC core composition. The leakage spectrum from this core composition was then used to collapse the fine-group cross sections in the transplutonium production rods for compositions at several times during a normal irradiation cycle. These compositions had been calculated from a 
Table 4.5. Nuclides used in the ANS MCNP model

\begin{tabular}{llll}
\hline Nuclide & Identifier & Library & Origin \\
\hline${ }^{1} \mathrm{H}$ & $1001.50 \mathrm{c}$ & rmccs2 & ENDF/B-V \\
${ }^{2} \mathrm{H}$ & $1002.55 \mathrm{c}$ & rmccs2 & ENDF/B-V \\
${ }^{10} \mathrm{~B}$ & $5010.50 \mathrm{c}$ & rmccs2 & ENDF/B-V \\
${ }^{16} \mathrm{O}$ & $8016.50 \mathrm{c}$ & rmccs2 & ENDF/B-V \\
$\mathrm{Mg}$ & $12000.50 \mathrm{c}$ & endf5u2 & ENDF/B-V \\
${ }^{27} \mathrm{Al}$ & $13027.50 \mathrm{c}$ & rmccs2 & ENDF/B-V \\
$\mathrm{Si}$ & $14000.50 \mathrm{c}$ & endf5p2 & ENDF/B-V \\
$\mathrm{Ti}$ & $22000.50 \mathrm{c}$ & endf5u2 & ENDF/B-V \\
$\mathrm{Cr}$ & $24000.50 \mathrm{c}$ & rmccs2 & ENDF/B-V \\
${ }^{55} \mathrm{Mn}$ & $25055.50 \mathrm{c}$ & endf5u2 & ENDF/B-V \\
$\mathrm{Fe}$ & $26000.55 \mathrm{c}$ & rmccs2 & ENDF/B-V \\
$\mathrm{Cu}$ & $29000.55 \mathrm{c}$ & rmccs2 & ENDF/B-V \\
$\mathrm{Zr}$ & $40000.35 \mathrm{c}$ & endl852 & ENDL-V \\
$\mathrm{Sn}$ & $50000.35 \mathrm{c}$ & endl852 & ENDL-V \\
$\mathrm{Hf}$ & $72000.35 \mathrm{c}$ & endl852 & ENDL-V \\
$\mathrm{W}$ & $74000.55 \mathrm{c}$ & endf5u2 & ENDF/B-V \\
$\mathrm{Pb}$ & $82000.50 \mathrm{c}$ & rmccs2 & ENDF/B-V \\
${ }^{235 \mathrm{U}}$ & $92235.50 \mathrm{c}$ & rmccs2 & ENDF/B-V \\
${ }^{238} \mathrm{U}$ & $92238.50 \mathrm{c}$ & rmccs2 & ENDF/B-V \\
\hline
\end{tabular}

standard PDQ depletion case with BOC group constants in the transplutonium rods. The PDQ group constant input required is a fit of a third-order polynomial to the time dependence. Only a subset of the entire burnup chain in the transplutonium rods required time-dependent group constants: ${ }^{241} \mathrm{Pu}$, ${ }^{242} \mathrm{Pu},{ }^{241} \mathrm{Am},{ }^{243} \mathrm{Am},{ }^{244} \mathrm{Cm},{ }^{249} \mathrm{Bk},{ }^{250} \mathrm{Cf}$, and ${ }^{251} \mathrm{Cf}$. These group constants were then used to deplete the rods over several core cycles to determine the effects of using time-dependent group constants in the transplutonium rods. 


\section{TRANSPORT AND DIFFUSION CODES VALMATION RESULTS}

\subsection{MCNP VALIDATION}

To validate the MCNP code fully, it was decided that a known reactor design similar to that of the ANS reactor should be modeled. This process would allow comparisons to known experimental results and provide for a higher degree of confidence in the MCNP calculations for ANS. Therefore, a series of increasingly complex models was developed for the ILL reactor, located in Grenoble, France. This section follows the development of these models.

A simple model of the ILL research reactor using the MCNP Monte Carlo code was developed in March 1991. The model was based upon information obtained from a lecture series given at ORNL by Drs. H. Reutler and A. Stroemich in $19899^{30}$ This simple model consisted of a 95-mm-radius central hole with a 10 -mm-thick control shroud at $60 \mathrm{~mm}$, a 50-mm-thick, aluminum-clad, single-enrichment fuel zone, and a 1.32-m-thick reflector pool. The model used cylindrical geometry, with seven compositions representing the (1) core, (2) reflector, (3) central hole, (4) lower, (5) upper fuel endplates, (6) fuel side plates, and (7) control rod. A representation of the model is shown in Fig. 5.1. This figure does not show the fine spatial structure employed in the fuel and reflector regions to calculate the neutron flux more accurately.

The information used to construct the ILL model contained several rather gross approximations. First, the ${ }^{238} U$ content of the fuel was ignored. Second, the structures in the side plates, despite containing a 4-mm-thick Zircaloy shroud, were approximated as aluminum and heavy water only. Third, it was assumed, for lack of concrete information, that no internal structures existed in either the central hole or the reflector.

This early simple model was used to evaluate the core eigenvalue and central control shroud worth in the ILL model. It was also used to determine the peak thermal flux for the ILL reactor. All these results revealed the need for a more refined model because the evaluations were not comparable with those given by Reutler and Stroemlich. ${ }^{30}$

A new model for the $\mathrm{IL}$ reactor was constructed in August 1991 to perform more detailed analyses and to provide a better basis for comparison with the ANS simple model results. This model included the ${ }^{238} U$ in the fuel mixture, the trace metals used to alloy the aluminum structural components, a pure-nickel control shroud with the exact ILL control shroud geometry, $5.77 \mathrm{~g}$ of ${ }^{10} \mathrm{~B}$ split equally between the upper and lower fuel endplates, and the final ILL core specifications. The final core design provided for a single fuel element $800-\mathrm{mm}$ high and $55-\mathrm{mm}$ thick, with a central hole radius of $140 \mathrm{~mm}$. This height does not include the 30 -mm-thick fuel endplates at the top and bottom of the fuel assembly. The control shroud consists of two annular tubes, the outer tube being $1055 \mathrm{~mm}$ long and the inner tube $450 \mathrm{~mm}$ long. Both tubes have a common lower surface. The outer diameter of the outer tube is $253.6 \mathrm{~mm}$. At normal startup position, the shroud is withdrawn $230 \mathrm{~mm}$ from the core. $^{30}$ This model is of the same level of complexity as the ANS simple model.

A series of MCNP analysis runs were performed to compare the results of the new simple model with the previous results determined by Reutler and Stroemlich. The base case was determined to be the simple model with the shroud at startup position and the boron present in the endplates. Subsequent cases included the simple model with the control shroud removed, with the shroud fully inserted, with only the boron removed, and with both the boron and shroud removed, with safety shutdown rods inserted, and with safety shutdown rods withdrawn to $+800 \mathrm{~mm}$. The results of these cases are shown in Table 5.1. 


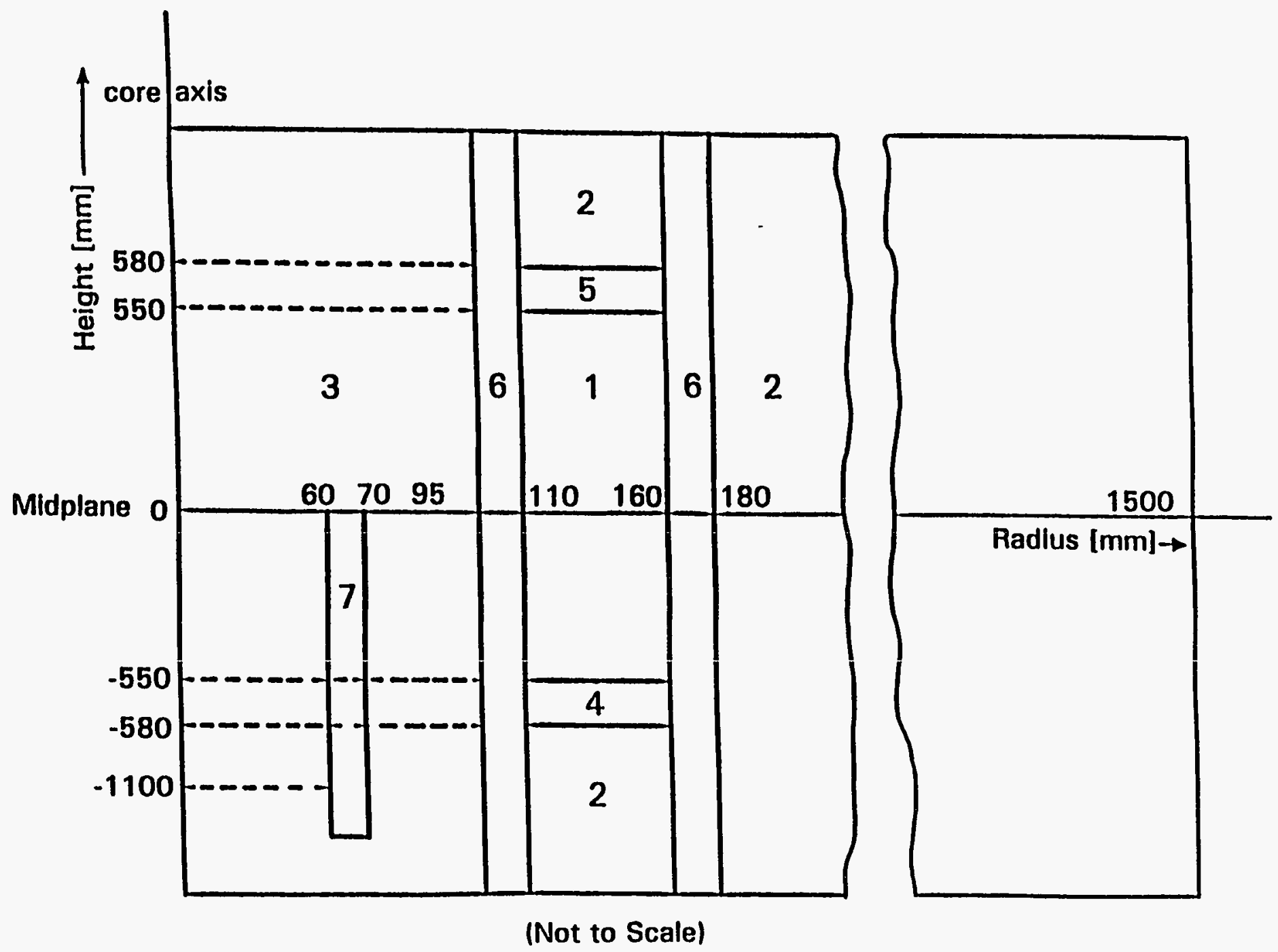

Fig. 5.1. Schematic diagram of the ILL reactor used to construct the simple MCNP model. Source: Fig. 2.1 in Ref. 30. 
Table 5.1. MCNP analysis of the ILL simple model (no reflector components) with $P=57 \mathrm{MW}_{\mathrm{f}}$ at $\mathrm{BOC}$

\begin{tabular}{lllc}
\hline Identifier & \multicolumn{1}{c}{ Case } & \multicolumn{1}{c}{$\mathrm{k}_{\text {eff }}$} & $\begin{array}{c}\text { Peak thermal flux } \\
\left(10^{19} \mathrm{~m}^{-2} \cdot \mathrm{s}^{-1}\right)\end{array}$ \\
\hline ILL021 & $\begin{array}{l}\text { Base case-pure Ni control shroud, } 2.885 \mathrm{~g}^{10} \mathrm{~B} \\
\text { in each fuel endplate }\end{array}$ & $1.0617 \pm 0.0022$ & 1.6104 \\
ILL022 & ILL021 with control shroud removed & $1.1895 \pm 0.0021$ & 1.6952 \\
ILL023 & ILL021 with control shroud fully inserted & $1.0002 \pm 0.0032$ & 1.6811 \\
ILL024 & ILL021 with ${ }^{10} \mathrm{~B}$ removed & $1.1150 \pm 0.0025$ & 1.5044 \\
ILL025 & ILL021 with ${ }^{10} \mathrm{~B}$ and control shroud removed & $1.2540 \pm 0.0020$ & 1.3136 \\
ILL027 & ILL021 with safety shutdown rods inserted & $0.6817 \pm 0.0048$ & \\
ILL028 & IIL021 with safety shutdown rods withdrawn to & $1.0629 \pm 0.0029$ & \\
& +800 mm & &
\end{tabular}

The reactivity worths (in pcm) calculated from the data in Table 5.1 show good agreement with Reutler's figures (shown in parenthesis:

$$
\begin{array}{lrl}
\text { Control shroud } & 17,333(17,300) \\
\text { Boron in endplates } & 4,898(4,500) \\
\text { Safety shutdown rods } & 44,420(34,685)
\end{array}
$$

However, some significant discrepancies did appear. First, the MCNP calculations resulted in an eigenvalue that was $3 \%$ lower than that reported by $\operatorname{Reutler}^{30}$ for the unpoisoned core. Also, the MCNP results were $3 \%$ higher than Reutler's for the fully poisoned core, where it was reported that the core was " 3100 pcm subcritical" with the shroud "fully inserted." This discrepancy was partially explained by differences in the modeling of full insertion and led to further refinements in the model.

In November 1991, the MCNP model of the ILL reactor was modified to include the five safety shutdown rods in the reflector, the Zircaloy and stainless steel chimney above the core, and the two flow-dispersion plates below the core. This model was used to compute the bank worth of the safety shutdown rods and the fluxes, absorption rates, and energy deposition rates in the chimney and flow-dispersion plates.

The safety shutdown rod bank worth was calculated at 44,420 percent mille (pcm). The core eigenvalue with the rod bank inserted was $0.6817 \pm 0.0048$, whereas the core eigenvalue with the bank withdrawn was $1.0629 \pm 0.0029$. The flux calculations were made with the safety rod bank fully withdrawn to $800 \mathrm{~mm}$ above the core midplane, thus giving a conservative value for the neutron flux seen by these components at or near cycle startup.

The tally normalization factor is given by the following formula:

$$
P_{n}=\frac{P \times y}{Q \times k \times C Q},
$$

where

$P=$ reactor power in $\mathrm{W}(57 \mathrm{MW})$,

$v=$ average neutron release per fission, 
$Q=$ recoverable energy release per fission $(202.47 \mathrm{MeV})$,

$k=$ core eigenvalue,

$C Q=$ conversion factor from $\mathrm{MeV}$ to $\mathrm{J}\left(1.602 \times 10^{-13} \mathrm{~J} / \mathrm{MeV}\right)$.

The flux calculation case was run for several hundred cycles to achieve good statistics. For the flux values in the chimney, the statistical error was generally less than $10 \%$, with the most accurate values in the Zircaloy section and the larger cells having smaller errors. In the flow-dispersion plates, the statistical error was generally less than $15 \%$, with the error increasing with increasing radius. The statistical errors in the upper plate were slightly smaller than those in the lower plate.

The actions described above completed the modeling of the ILL reactor. No additional expansion of this model is anticipated because of the lack of further data. However, extremely detailed physical and experimental data (known as the FOEHN critical experiments) are available for the ILL critical assembly at the Centre d'Etudes Nucleaires, Cadarache, France. For this reason, the analysis of FOEHN critial experiments will be used as a primary validation of MCNP for the analysis of the ANS. $^{31}$

\subsection{DORT VALIDATION}

The use of DORT with ANSL-V multigroup cross sections will be validated against MCNP results for the advanced conceptual core design (ACCD) phase. The comparisons against MCNP will be used primarily to assess the validity of the multigroup cross sections and the modeling of the inner control rod system, the outer control rod system, the materials irradiation and isotope production facilities, and the reflector components.

\subsection{VENTURE VALIDATION}

VENTURE-calculated core physics parameters have been compared with those from DORT using consistent few-group cross sections. ${ }^{32}$ The results indicate that significant transport effects must be accounted for near the core reflector interface and that small mesh sizes are needed to represent the flux gradients accurately. A rigorous comparison of VENTURE models against DORT-validated models will be performed in the ACCD phase. During this phase, an evaluation will be made of whether the DORT model or VENTURE nodal modules with discontinuity factors should be used in fuel cycle analysis beyond ACCD.

\subsection{PDQ VALIDATION}

As part of the software quality assurance plan for the MCNP code, a set of cases was run comparing MCNP and PDQ eigenvalues, peak fluxes, and four-group flux traces in both the core and reflector.

Several differences in the ANS reactor models, which are important to future comparisons of these codes, are discussed here. In addition to the differences imposed by the varied natures of the codes involved, two important physical model differences must be pointed out. First, the central control rods are modeled explicitly in MCNP, but PDQ has smeared the central control rods over the entire central hole area. A variety of different effects are thus introduced; the primary difference is in the control rod bank worth and absorption rate. The second physical difference is in the height of the heavy water reflector vessel. The vessel in the PDQ model is $6.6 \mathrm{~cm}$ taller than that in the MCNP model, a result 
of changes in the design that had not been incorporated in the PDQ model. This second difference should not significantly affect the PDQ results.

\subsection{BURNER VALIDATION}

The BURNER code calculates material depletion and buildup for all the important nuclides contributing to fuel depletion, control material burnup, material activation, buildup and decay of fission products, silicon production in aluminum, burnable poison depletion, and other specific nuclide changes of interest.

The accuracy in the solution to the nuclide chain equations has been extensively tested and verified for the BURNER code (Ref. 12). Verification that the nuclide chain equations have been properly developed for the ANS is described in Ref. 33. The development of lumped fission product materials that properly account for the nuclides not explicitly represented is summarized in Ref. 34 . 



\section{MODELING}

\subsection{MCNP MODELING USED IN CONCEPTUAL CORE DESIGN ANALYSIS}

\subsubsection{MCNP Inner Control Rod Modeling}

Two physical models have existed for the central control rods in the conceptual design. The first contained four rods of $1200 \mathrm{~mm}$ active length at a radius of $64 \mathrm{~mm}$ from the core centerline, with a rod radius of $27 \mathrm{~mm}$ each. The other model contained three rods of $1200 \mathrm{~mm}$ active length at a radius of $52 \mathrm{~mm}$ from the core centerline, with a rod radius of $35.5 \mathrm{~mm}$ each. Both designs had the control rods driven from below the reactor and withdrawn upwardly from the core throughout the fuel cycle. The control material for both was a hafnium annulus, $6 \mathrm{~mm}$ thick for the four-rod design and $4 \mathrm{~mm}$ thick for the three-rod design.

Various trade-off and parametric studies for the design with four central control rods have been performed using the MCNP model. A study of varying the absorber thickness, shown in Figs. 6.1 and 6.2 , demonstrated that hafnium absorber greater than $2 \mathrm{~mm}$ thick made little difference in the core eigenvalue. There was less than $3 \%$ difference in eigenvalue between the 2-mm-thick and the 9-mmthick hafnium absorbers. However, these two absorber thicknesses result in considerably different lifetimes for the control rods in the core. The thinner absorber rods would burn out faster and thus need to be replaced more frequently. At the conclusion of the CCD study, a 4-mm thickness was chosen as the baseline design.

Differences in modeling techniques for the central control rods were also analyzed. Specifically, several methods for computing a single equivalent control rod were examined to model the central control rods in the ANS r-z models. Two separate models were considered in MCNP: an annular heterogeneous control rod and a cylindrical homogeneous control rod. The heterogeneous model conserved the volumes of the rod structural materials, using the inner heavy water radius to achieve the appropriate physics characteristics. The homogeneous model utilized two variations: (1) fixing an outer radius and varying the hafnium density and (2) preserving the smeared densities while varying the outer control rod radius. In all three cases, the goal was to match as closely as possible the core eigenvalue, the total hafnium absorption rate in the rod, the group-wise absorption rate in the rod, the spectrum in the reflector outside the fuel elements, and the spectrum in the fuel elements themselves.

The eigenvalue and absorption rate results for the final control rod configurations are shown in Table 6.1. All the total absorption rates and eigenvalues are identical within the MCNP statistics. However, the heterogeneous control rod model provided the closest group-wise absorption rates, with nearly all groups within $2-3 \%$ of the base case model with explicit rods. The homogeneous model with the increased hafnium density (1.5 times the smeared base-model density) provided the worst comparison, with the unmodified homogeneous model between the two. Thus, for evaluation of the control rod hafnium depletion and isotope production rates, the heterogeneous control rod model should be used because it preserves the neutron spectrum and the reaction rates.

Figures 6.3 and 6.4 show the 25 -group neutron fluxes for the four cases in the first $25 \mathrm{~cm}$ of the reflector outside the upper and lower fuel assemblies, respectively. Figures 6.5 and 6.6 show similar group fluxes for the second $25 \mathrm{~cm}$ of the reflector, and Figs. 6.7 and 6.8 for the fuel elements themselves. In all cases, the group fluxes in the reflector and fuel elements are identical within the MCNP statistics.

These results show that the specifics of the central control rod do not influence the performance of the reflector region in the ANS reactor because the neutron mean free path is too short to penetrate deeply into the highly enriched fuel elements. The reflector peak flux and group fluxes are influenced only by the leakage spectrum from the individual fuel elements, not by neutrons streaming from the 


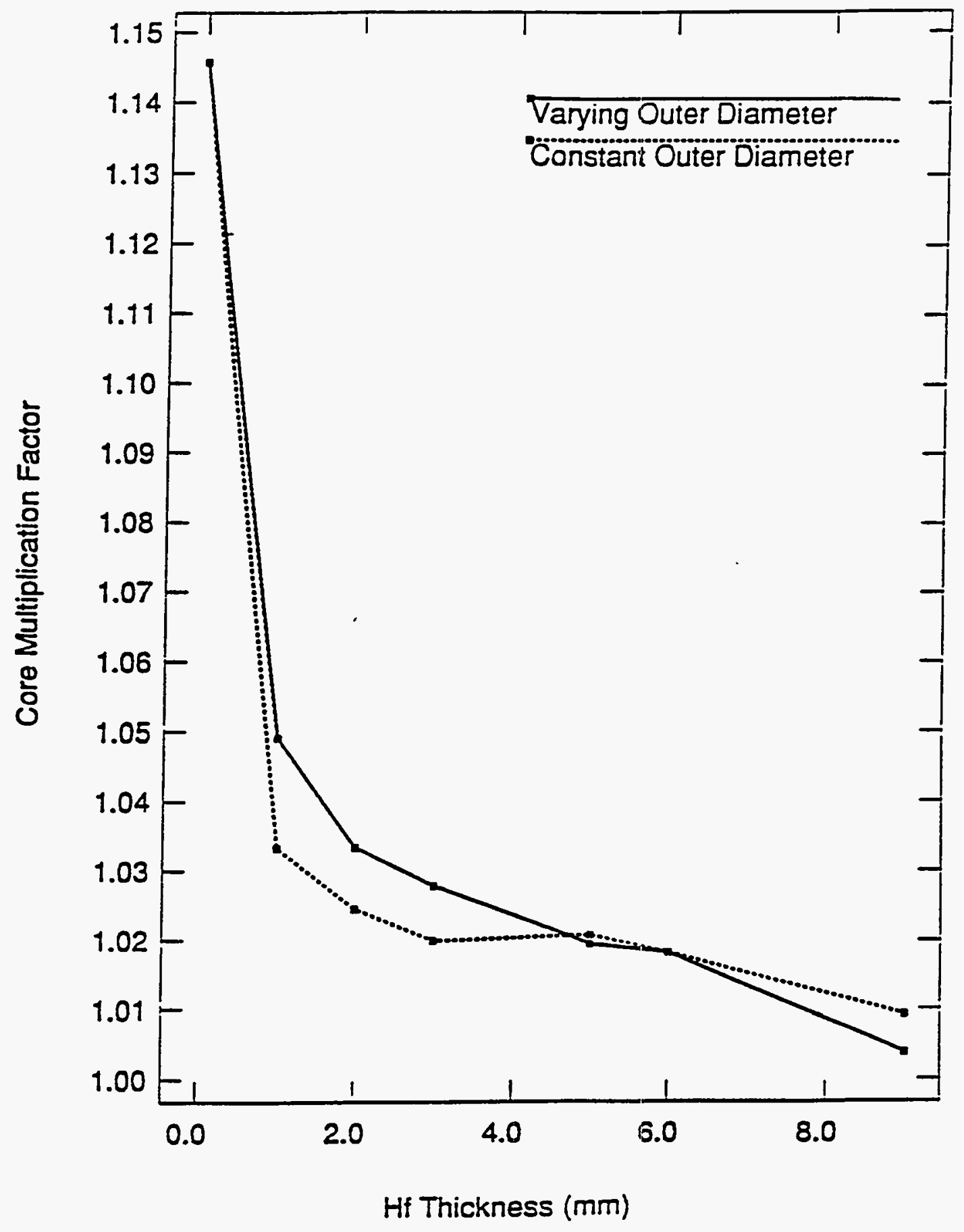

Fig. 6.1. Comparison of the core multiplication factors for varying hafnium absorber thickness in the central control rods. 


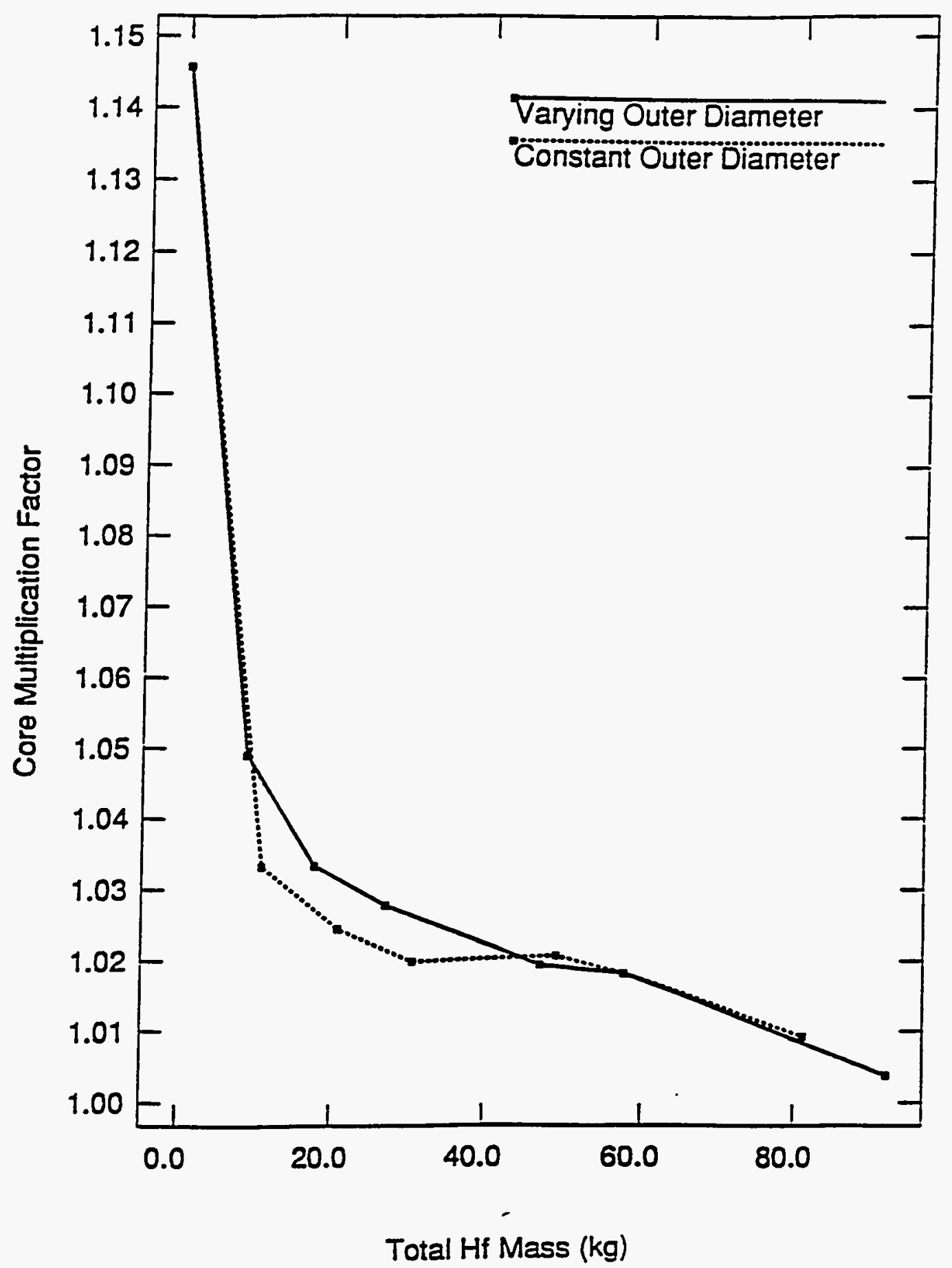

Fig. 6.2. Comparison of the core multiplication factors for varying hafnium absorber masses in the central control rods. 
Table 6.1. Absorption rates $\left(\mathrm{s}^{-1}\right)$ in various equivalent single central control rod configurations

\begin{tabular}{|c|c|c|c|c|}
\hline $\begin{array}{l}\text { Upper energy } \\
\text { (eV) }\end{array}$ & $\begin{array}{l}\text { Base case }^{a} \\
\text { ANS642 }\end{array}$ & $\begin{array}{l}\text { Heterogeneous } \\
\text { ANS651 }\end{array}$ & $\begin{array}{l}\text { Homogeneous } \\
\text { ANK554 }\end{array}$ & $\begin{array}{c}\text { Densified } \\
\text { homogeneous } \\
\text { ANX546 }\end{array}$ \\
\hline 0.500 & $1.654 \times 10^{17}$ & $1.525 \times 10^{17}$ & $1.462 \times 10^{17}$ & $1.246 \times 10^{17}$ \\
\hline 0.100 & $1.414 \times 10^{17}$ & $1.390 \times 10^{17}$ & $1.172 \times 10^{17}$ & $1.198 \times 10^{17}$ \\
\hline 0.414 & $2.118 \times 10^{17}$ & $2.041 \times 10^{17}$ & $1.841 \times 10^{17}$ & $1.695 \times 10^{17}$ \\
\hline 0.683 & $6.360 \times 10^{16}$ & $6.372 \times 10^{16}$ & $6.229 \times 10^{16}$ & $4.988 \times 10^{16}$ \\
\hline 2.38 & $1.971 \times 10^{17}$ & $1.959 \times 10^{17}$ & $1.835 \times 10^{17}$ & $1.648 \times 10^{17}$ \\
\hline 3.93 & $8.032 \times 10^{16}$ & $8.232 \times 10^{16}$ & $8.827 \times 10^{16}$ & $7.061 \times 10^{16}$ \\
\hline 17.6 & $2.245 \times 10^{17}$ & $2.203 \times 10^{17}$ & $2.440 \times 10^{17}$ & $2.113 \times 10^{17}$ \\
\hline 101.3 & $2.232 \times 10^{17}$ & $2.223 \times 10^{17}$ & $2.712 \times 10^{17}$ & $2.347 \times 10^{17}$ \\
\hline 582.9 & $2.373 \times 10^{17}$ & $2.422 \times 10^{17}$ & $2.592 \times 10^{17}$ & $2.700 \times 10^{17}$ \\
\hline $5.53 \times 10^{3}$ & $2.331 \times 10^{17}$ & $2.500 \times 10^{17}$ & $2.490 \times 10^{17}$ & $3.132 \times 10^{17}$ \\
\hline $1.83 \times 10^{5}$ & $8.904 \times 10^{16}$ & $8.856 \times 10^{16}$ & $8.372 \times 10^{16}$ & $1.319 \times 10^{17}$ \\
\hline $8.21 \times 10^{5}$ & $4.813 \times 10^{15}$ & $4.790 \times 10^{15}$ & $4.038 \times 10^{15}$ & $7.083 \times 10^{15}$ \\
\hline $6.07 \times 10^{6}$ & $1.855 \times 10^{15}$ & $1.786 \times 10^{15}$ & $1.943 \times 10^{15}$ & $2.999 \times 10^{15}$ \\
\hline $1.70 \times 10^{7}$ & $9.037 \times 10^{13}$ & $1.162 \times 10^{14}$ & $2.024 \times 10^{14}$ & $2.132 \times 10^{14}$ \\
\hline Totals & $1.874 \times 10^{18}$ & $1.867 \times 10^{18}$ & $1.895 \times 10^{18}$ & $1.871 \times 10^{18}$ \\
\hline $\mathbf{k}_{\mathrm{eff}}$ & 1.0145 & 1.0160 & 1.0142 & 1.0160 \\
\hline
\end{tabular}

${ }^{\circ}$ The base case has four control rods. 


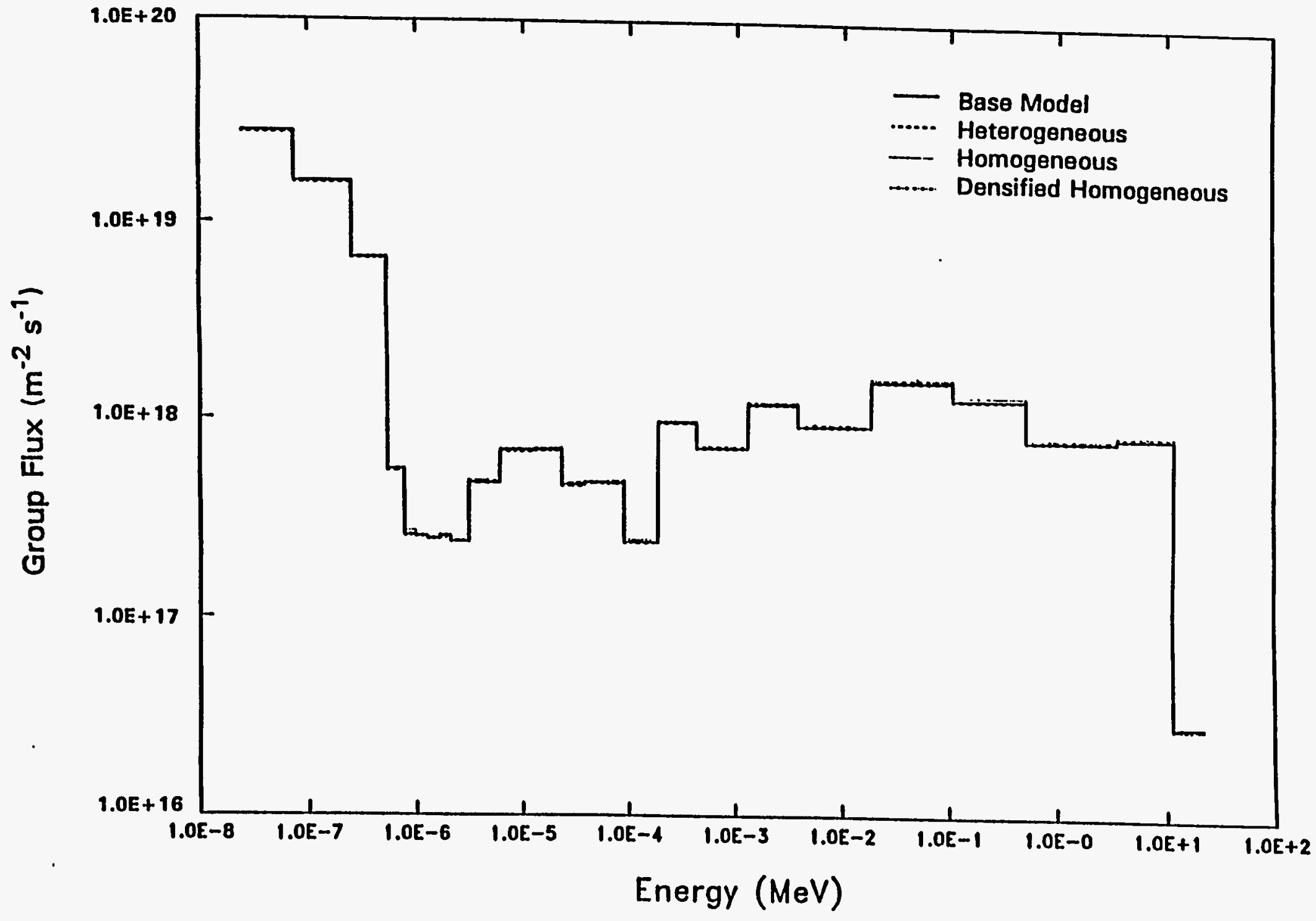

Fig. 6.3. Group fluxes for the first $250 \mathrm{~mm}$ of the reflector outside the upper fuel element for the four equivalent control rod models. 


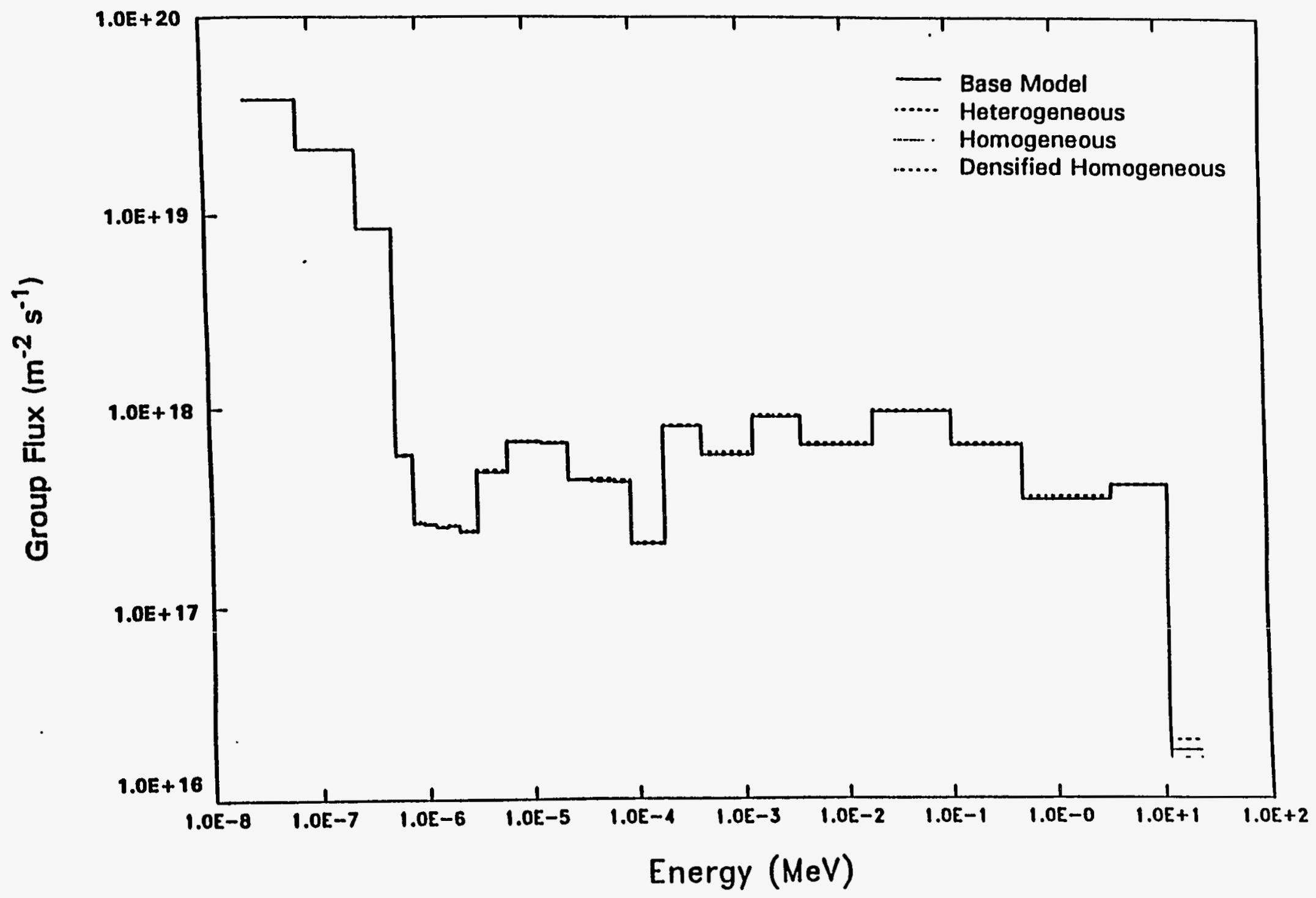

Fig. 6.4. Group fluxes for the first $250 \mathrm{~mm}$ of the reflector outside the lower fuel element for the four equivalent control rod models. 


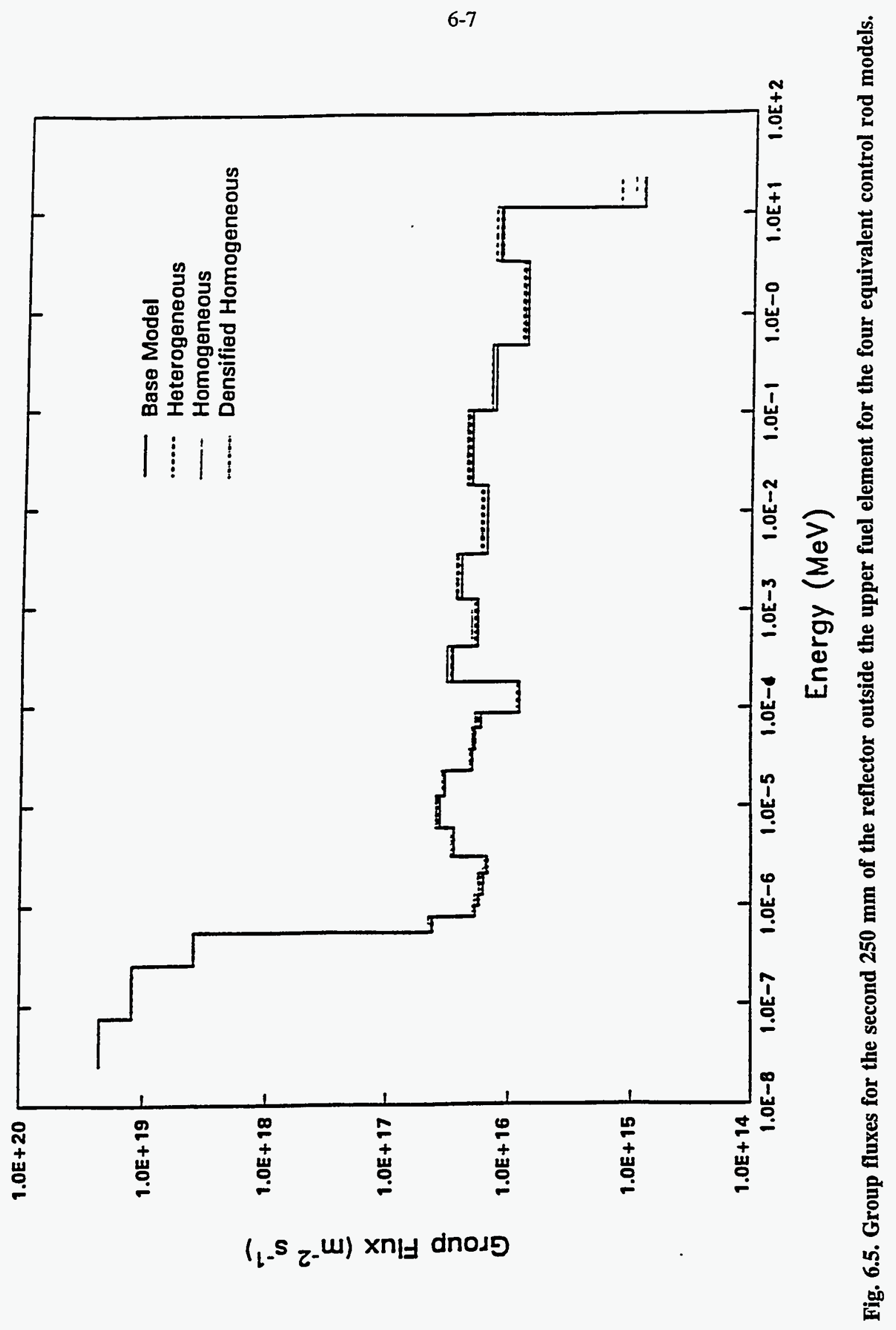




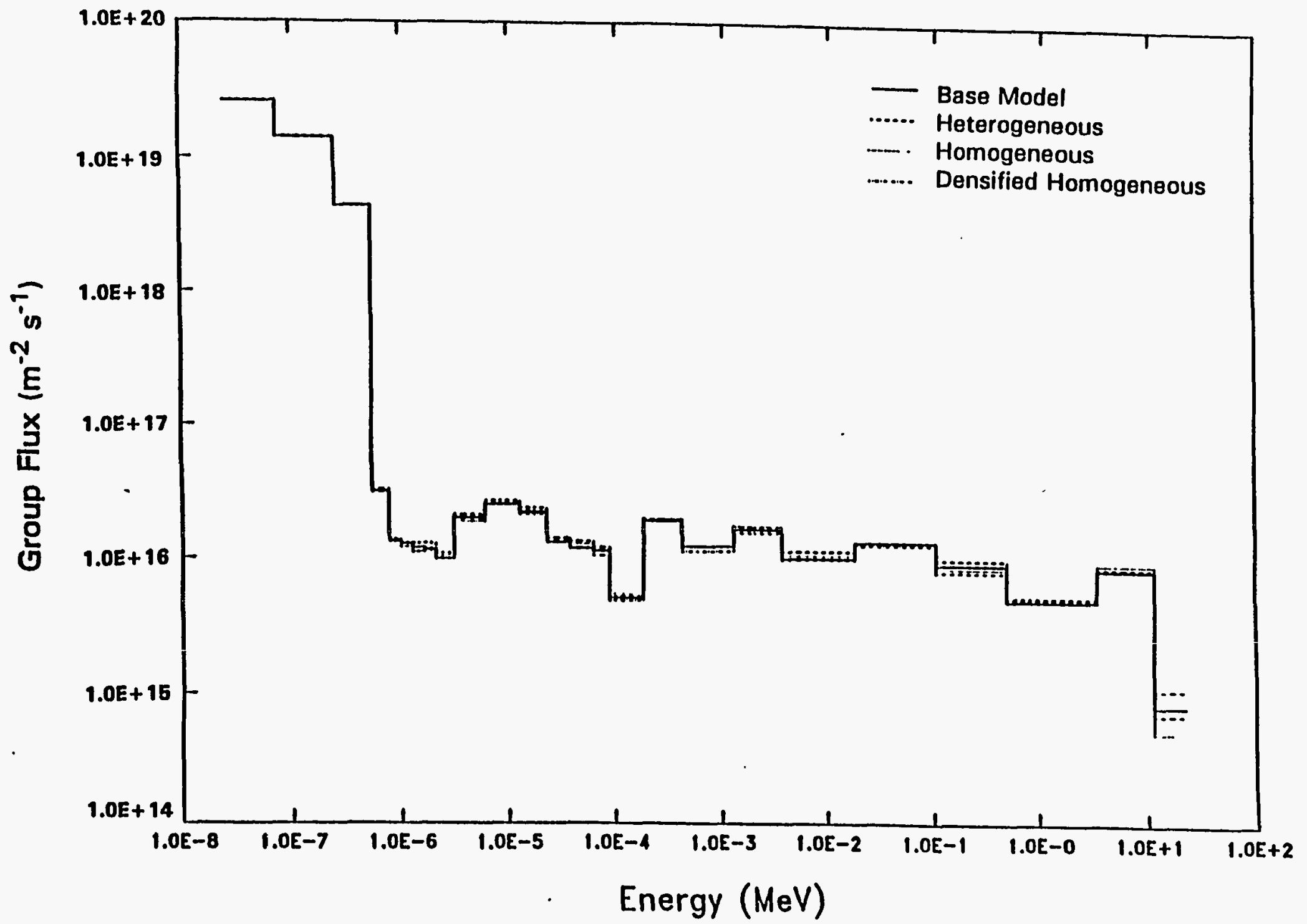

Fig. 6.6. Group fluxes for the second $250 \mathrm{~mm}$ of the reflector outside the lower fuel element for the four equivalent control rod models. 


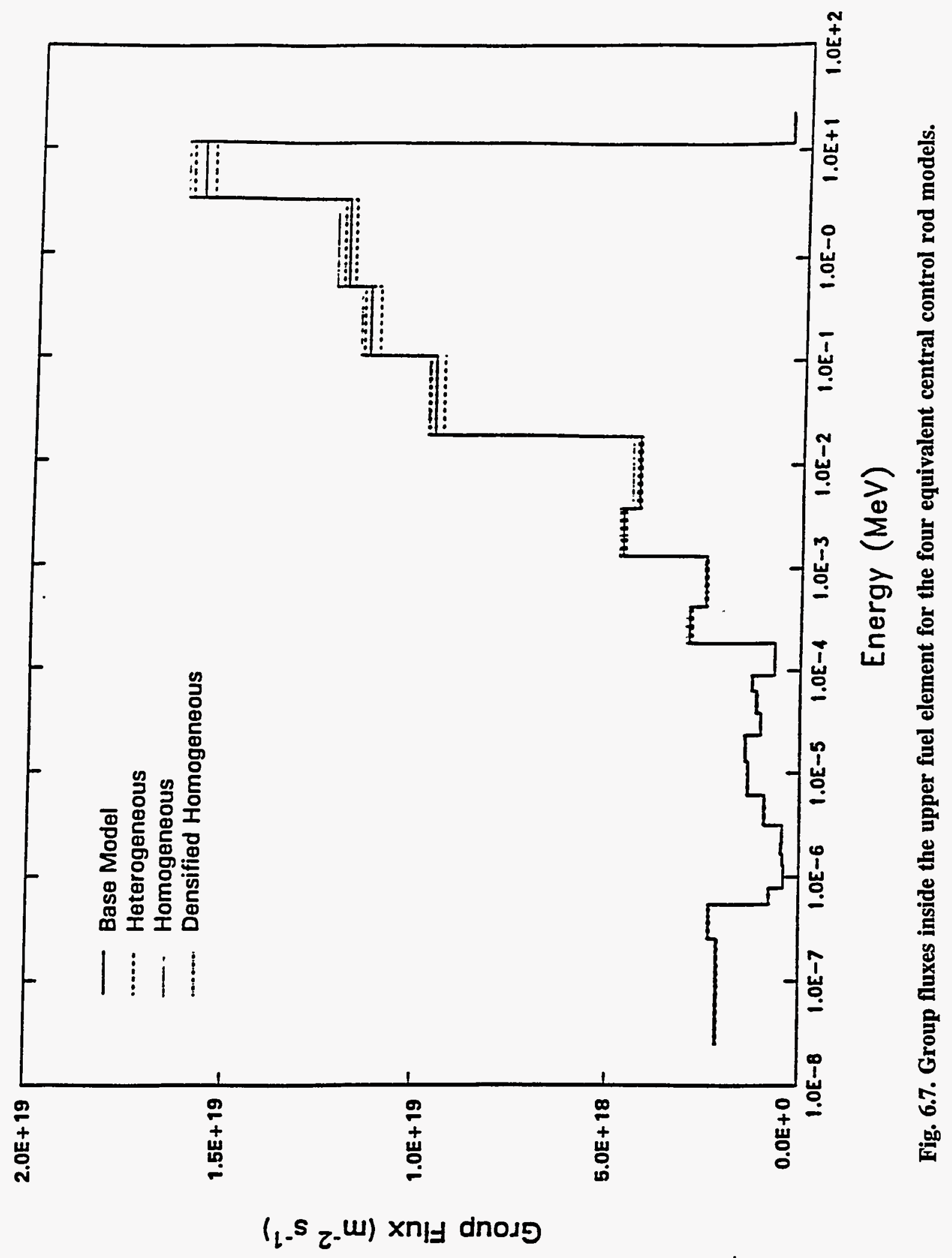




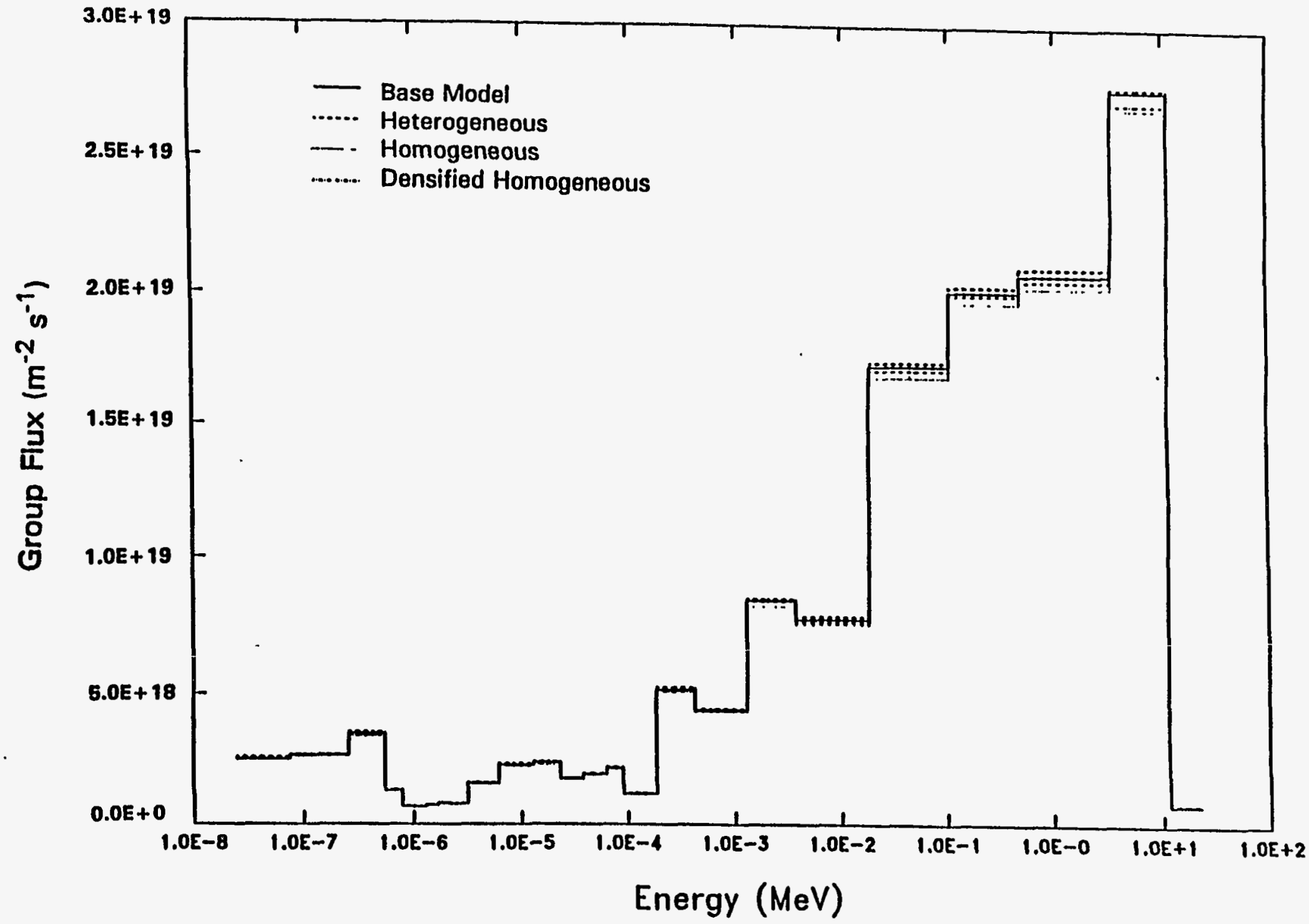

Fig. 6.8. Group fluxes inside the lower fuel element for the four equivalent central control rod models. 
central flux trap. Otherwise, significant deviations would occur in the reflector group fluxes, caused by the differences in the control rod group absorption rates.

The fuel group fluxes exhibit some small deviation in the fast groups. This variation results from the differences in the central control rod configurations, where the fuel elements provide an absorption barrier between the central control rods and the reflector. The deviations in the central control rod group absorption rates are hidden from the reflector by the fuel elements. The differences in the thermal absorption rates, and thus the thermal flux, are the primary driving force behind these deviations. The thermal neutrons, with their short mean free path, are unable to penetrate deeply into the fuel elements and thus are able to influence only the fuel group fluxes. A slight difference in the spatial distribution of the fission rate results from the deviations in the control rod absorption rates and produces the small differences in the fuel group fluxes.

Heat load results for the central control rod designs were also examined. Variations in the hafnium cross-section set used for control rod cases were examined and show no significant change in core eigenvalue or hafnium absorption rate. Large differences were noted in the heat load in the control rods, however, as a result of differences in the methods used to account for photons produced by neutron-matter interactions between the cross-section sets. One set did not include explicit photon-production data and thus assumed that this photon energy was all deposited locally. This conservative approximation results in greatly overestimated heat loads. The other hafnium cross-section set did contain these data and thus was able to transport correctly the photons produced by neutron interactions with hafnium. The calculated heat load in the control rod hafnium was thus reduced by approximately one-third.

Differences between the heat loads of the inner side (facing the central hole) and outer side (facing the fuel) of the central control rods were also considered. This study was performed for both the four-rod and the three-rod case. To perform the study, the central control rods in the ANS MCNP model were divided along their $z$-axes, and both neutron and photon energy deposition tallies were taken in each half. The results, summarized in Table 6.2, show that there is a significant amount of shielding through the control rods, which is more pronounced for neutrons than for photons. The neutron heating rates are about $30 \%$ greater on the outer side of the control rods than on the inner side, whereas the photon heating rates are about $20 \%$ greater. This trend agrees well with the physical properties of the radiation types present because photons are more penetrating than neutrons and thus are less susceptible to severe shielding effects. The heavy neutron shielding is also consistent with the results of the neutron flux studies of the control rods, shown in Table 6.3.

\subsubsection{MCNP Outer Control Rod Modeling}

The outer control rods in the MCNP model were modeled explicitly as eight cylindrical rods placed outside of the CPBT. The outer control rods incorporated into the MCNP model of the ANS reactor were at a radius of $369 \mathrm{~mm}$ from the core centerline and were $35 \mathrm{~mm}$ in radius. They consisted of a 25 -mm-radius central hole filled with heavy water, a 7-mm-thick support structure of Al-6061, and a 3-mm-thick section of hafnium absorber. A cross-sectional diagram of the outer control rods is shown in Fig. 2.9. The absorber region was $600 \mathrm{~mm}$ in length, and the rods were inserted from the top of the reactor. Above the absorber region, the rods were composed of a 25 -mm-radius central hole filled with heavy water and a 10-mm-thick support structure region.

Various design changes were made in the outer control rods during the development of the reactor design. Initially, the outer control rods were inserted from the bottom of the reactor and were 1200 $\mathrm{mm}$ in length. However, as studies showed that this was an excessive amount of control material, the rods were shortened, with little impact on the core reactivity. In the current-ANS design, the outer control rods are inserted from above the core. Different absorber materials were examined, with the results presented in Sect. 9.2. 
Table 6.2. Energy deposition rates for the outer (fuel) and inner $\left(\mathrm{D}_{2} \mathrm{O}\right)$ sides of the central control rods for the three-rod (ANS629) and four-rod (ANS631) cases with reactor power at $362 \mathrm{MW}$,

\begin{tabular}{|c|c|c|c|c|c|c|c|c|c|}
\hline \multirow{2}{*}{ Case } & \multirow{2}{*}{ Rod } & \multicolumn{2}{|c|}{$\begin{array}{l}\text { Outer heating rate } \\
\qquad(\mathrm{kW})\end{array}$} & \multicolumn{2}{|c|}{$\begin{array}{l}\text { Inner heating rate } \\
(\mathrm{kW})\end{array}$} & \multicolumn{2}{|c|}{$\begin{array}{l}\text { Total heating rate } \\
(\mathrm{kW})\end{array}$} & \multicolumn{2}{|c|}{$\begin{array}{l}\text { Difference }^{a} \\
\quad(\%)\end{array}$} \\
\hline & & Neutron $^{b}$ & Photon & Neutron $^{b}$ & Photon & Neutron $^{b}$ & Photon & Neutron ${ }^{b}$ & Photon \\
\hline \multirow[t]{3}{*}{ ANS629 } & 1 & 519.8 & 85.2 & 365.5 & 70.5 & 885.3 & 155.7 & 29.7 & 17.3 \\
\hline & 2 & 533.9 & 84.7 & 355.3 & 66.8 & 889.2 & 151.5 & 33.4 & 21.1 \\
\hline & 3 & 539.8 & 82.5 & 355.3 & 64.1 & 895.1 & 146.6 & 34.2 & 22.3 \\
\hline \multirow[t]{4}{*}{ ANS631 } & 1 & 445.4 & 64.3 & 311.0 & 47.3 & 756.5 & 111.5 & 30.2 & 26.4 \\
\hline & 2 & 452.2 & 64.0 & 325.8 & 51.4 & 777.9 & 115.4 & 28.0 & 19.7 \\
\hline & 3 & 446.8 & 62.9 & 315.7 & 49.2 & 762.5 & 112.0 & 29.3 & 21.8 \\
\hline & 4 & 448.2 & 67.3 & 309.6 & 45.4 & 757.7 & 112.9 & 30.9 & 32.5 \\
\hline
\end{tabular}

"The difference between the outer and inner heating rates, as a percentage of the outer heating rate.

${ }^{b}$ The neutron heating rates include the photon that is assumed to be deposited locally in the $(\mathrm{n}, \gamma)$ reaction in Hf. 
Table 6.3. Thermal flux $(\mathrm{E}<0.683 \mathrm{eV})$ in the hafnium portion of the central control rods along the upper fuel element at $\mathrm{BOC}$ and $330 \mathrm{MW}$,

\begin{tabular}{cccc}
\hline \multirow{2}{*}{$\begin{array}{c}\text { Position of hafnium above } \\
\text { core midplane } \\
(\mathrm{mm})\end{array}$} & \multicolumn{3}{c}{$\begin{array}{c}\text { Thermal neutron flux } \\
\left(10^{18} \mathrm{~m}^{-2} \cdot \mathrm{s}^{-1}\right)\end{array}$} \\
\cline { 2 - 4 } & $\begin{array}{c}\text { Facing } \\
\text { fuel }\end{array}$ & $\begin{array}{c}\text { Facing } \\
\text { centerline }\end{array}$ & Overall \\
\hline $600-480$ & 0.947 & 0.566 & 0.7540 \\
$480-360$ & 0.994 & 0.655 & 0.8243 \\
$360-240$ & 1.175 & 0.757 & 0.9661 \\
$240-120$ & 1.224 & 0.848 & 1.036 \\
$120-0$ & 1.664 & 1.404 & 1.534 \\
Average & 1.201 & 0.845 & 1.023 \\
\hline
\end{tabular}

No outer control rods were included in the two-dimensional PDQ-7 model because no suitable homogenization was performed. Future models may include the outer control rods if necessary for burnup and depletion studies.

\subsubsection{MCNP Component Modeling}

All known reflector components were modeled explicitly in the MCNP model of the ANS reactor. The known components are seven beam tubes, one through-tube, one large slant-beam tube, four hydraulic tubes, two slant tubes, four isotope-production facilities, two cold sources with associated cold guide tubes, and five pneumatic rabbit tubes. Figure 6.9 shows the reflector components in the ANS MCNP model (for the 1992 conceptual design).

Some approximations are made in the modeling of some ellipsoidal components. The endcaps on all tubes are modeled as cylindrical plugs in the tube ends, not as the hemispherical shells actually used in the design drawings. This approximation was made to simplify the modeling effort and has no significant effect on the resulting calculations. Also, the slant tubes and two slanted hydraulic tubes are not modeled exactly as designed. These components slant towards the core, then curve to a vertical orientation near the core. In the ANS MCNP model, these tubes are modeled by slanting linearly from top to bottom, with no curved section. This approximation was made because final specifications for these components were not yet available.

The PDQ model of the ANS reactor includes no components outside the CPBT except for the reflector vessel walls and heavy water. However, future work is planned to homogenize the reflector components and reflector heavy water to produce the correct BOC core eigenvalue in PDQ, resulting in more accurate burnup studies and allowing better approximation of the central control rod positions during the exposure cycle.

Several components were not fully developed in the MCNP model for CCD. These components are the hot source in the reflector, which at the time of these studies had not been fully developed, and the transplutonium production and material irradiation facilities outside the fuel elements. The final specifications of these facilities were not known at the time of these studies. However, a homogenized 


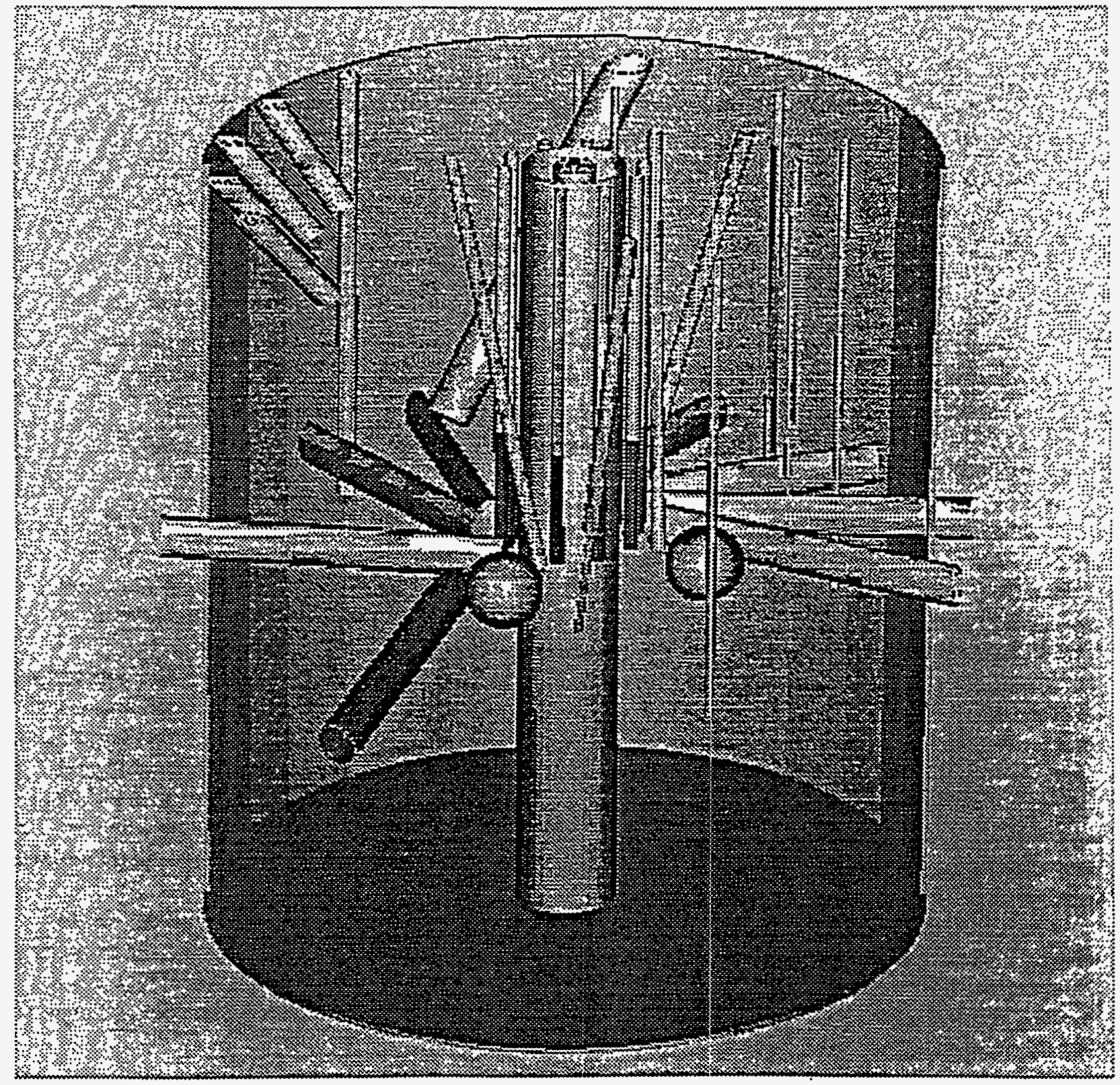

Fig. 6.9. The MCNP model of the ANS reflector components. 
model representative of proposed facilities has been included in the PDQ diffusion model to perform burnup and trade-off studies on various loadings and exposure histories.

\subsection{VENTURE/BURNER MODELING AND ANALYSES}

\subsubsection{VENTURE Model for Fuel Cycle Analysis}

The VENTURE model for ANS fuel cycle analysis is an r-z representation of the core with the central control rods modeled as an equivalent single rod. The outer control rods, the reflector components, irradiation facilities, and materials irradiation facilities were not modeled for the CCD fuel cycle analysis. Future fuel cycle analysis will incorporate these components and facilities into the model.

The optimal core power distribution for the ANS core is that distribution resulting in the maximum core power that can be achieved without occurrence of incipient boiling, without exceeding centerline fuel temperature limits, and without exceeding the temperature drop limit across the oxide layer. The centerline fuel temperature limit is determined by fuel-swelling considerations, and the limit on the temperature drop across the oxide film is determined by spallation considerations. Optimizing for incipient boiling requires that the normalized axial power profile at any radial position within the core that maximizes power output be one for which the onset of incipient boiling will occur at each axial position simultaneously. The ideal axial profile for maximizing the output power without exceeding the centerline fuel temperature limit is one that forces the centerline fuel temperature to be at the maximum limit at every axial position. The ideal axial power profile for prevention of spallation is one that forces the temperature drop across the oxide film to be at the allowable limit at every axial position. These ideal power profiles for incipient boiling and centerline fuel temperature are shown in Fig. 6.10 and represent the optimal axial power profile at any radial position at any time in the fuel cycle. The ideal profile for the oxide spallation criterion is very similar to the centerline fuel temperature profile. One additional goal is that the limiting condition for total core power take place at BOC so that startup testing of the initial core can be used to validate predictions of the worst conditions to be expected at any point in the fuel cycle and so that uncertainties in burnup analysis are not important.

The slight difference between ideal power profiles for incipient boiling and those for centerline fuel temperature and temperature drop across the oxide film is indicative of the range of axial power profiles desired. The actual ideal profile is the weighted average of the three that will result in the maximum achievable power without exceeding any of the three limits. In reality, none of the profiles can be achieved at all radial positions at all times during the fuel cycle. The profiles shown in Fig. 6.10 provide a goal.

The power distribution is controlled by grading the fuel in both the axial and radial directions. For $C C D$, the fuel was graded by axial and radial variation of the fuel thickness within the fuel meat. The minimum and maximum allowable fuel meat thicknesses were fixed by fuel plate manufacturing considerations.

The fuel grading for CCD is shown in Figs. 6.11 and 6.12. A number of fuel gradings were examined, and the reference fuel grading used for the CCD analysis is referred to as L-7.

The VENTURE model used in the fuel cycle analysis of CCD is shown schematically in Fig. 6.13. The accuracy in the calculation of the power distribution depends upon the number of fuel material zones and the mesh size used in the VENTURE model. Because the fuel grading in the ANS core varies continuously both radially and axially, a large number of material zones are required for accurate approximation of the fuel grading. The calculations of power density for CCD have been carried out using 598 material zones, and the power density is calculated for 1656 meshes within each element ( 24 radial and 69 axial zones). The mesh sizes vary both within and outside the fueled regions, with mesh interval widths as small as $2.5 \mathrm{~mm}$ near core-reflector boundaries. 


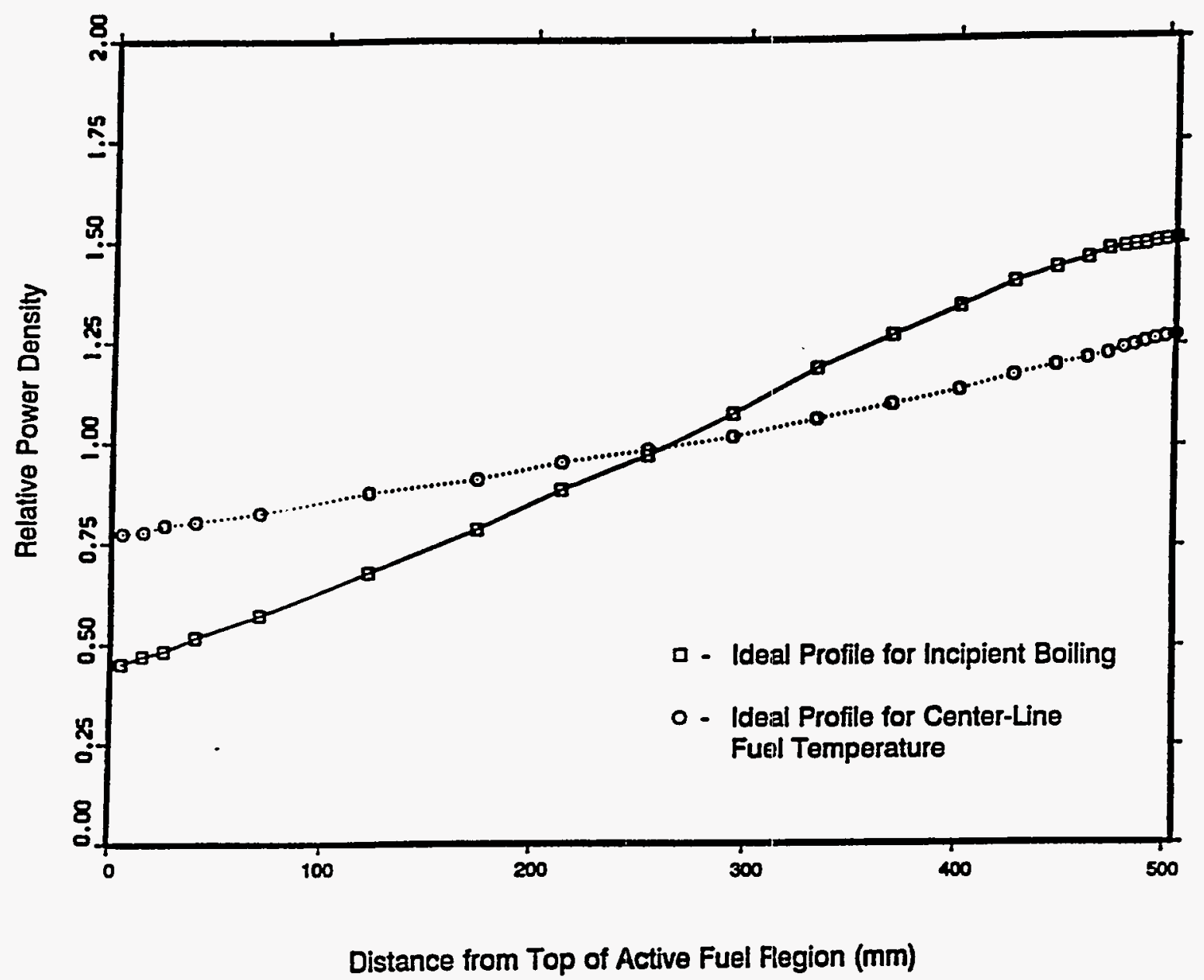

Fig. 6.10. Ideal axial power profiles for the ANS CCD. 


\section{ANS ${ }^{235} \mathrm{U}$ Atom Density \\ (L7 Fuel Grading)}
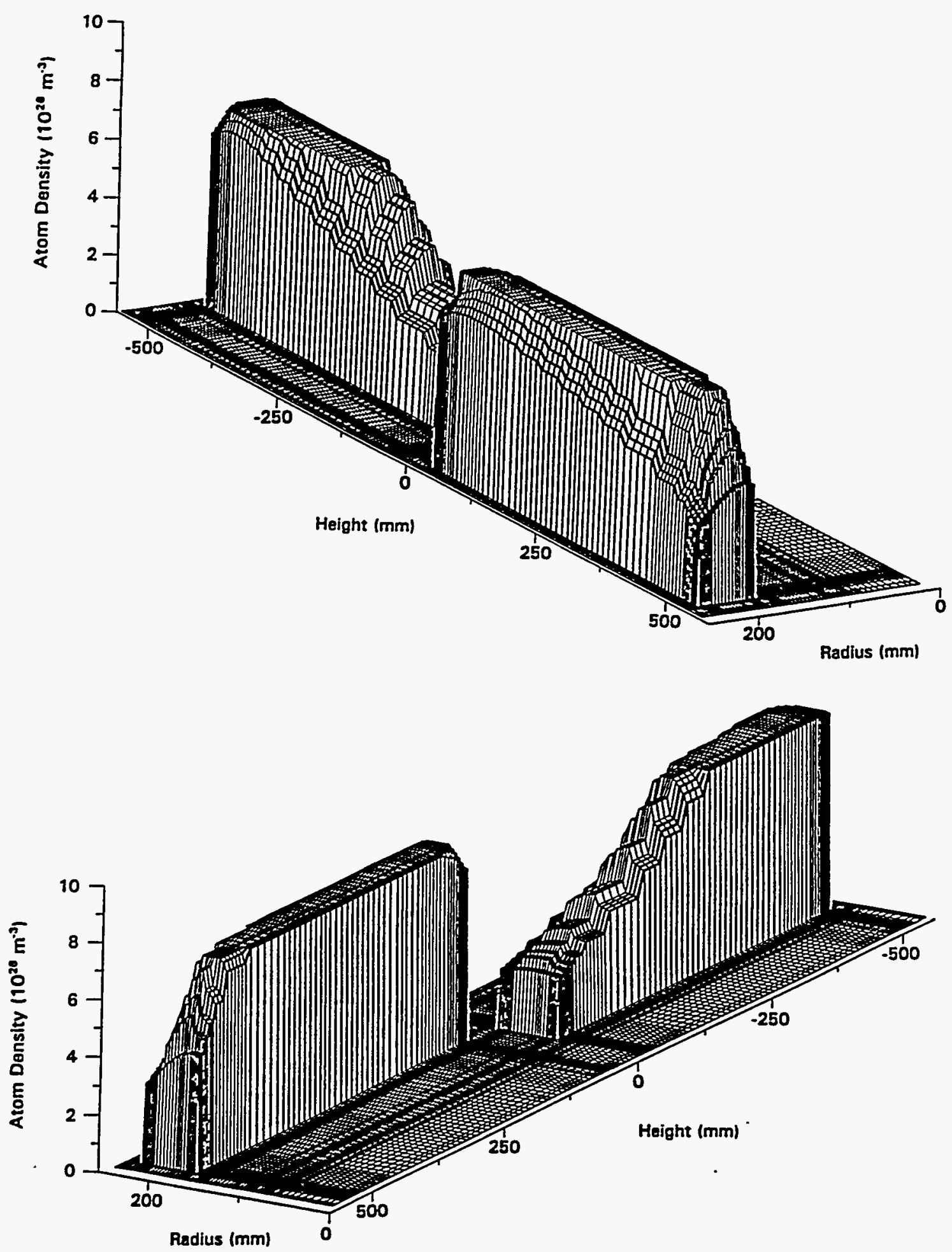

Fig. 6.11. Uranium-235 atom density contours for the ANS L7 fuel grading. 

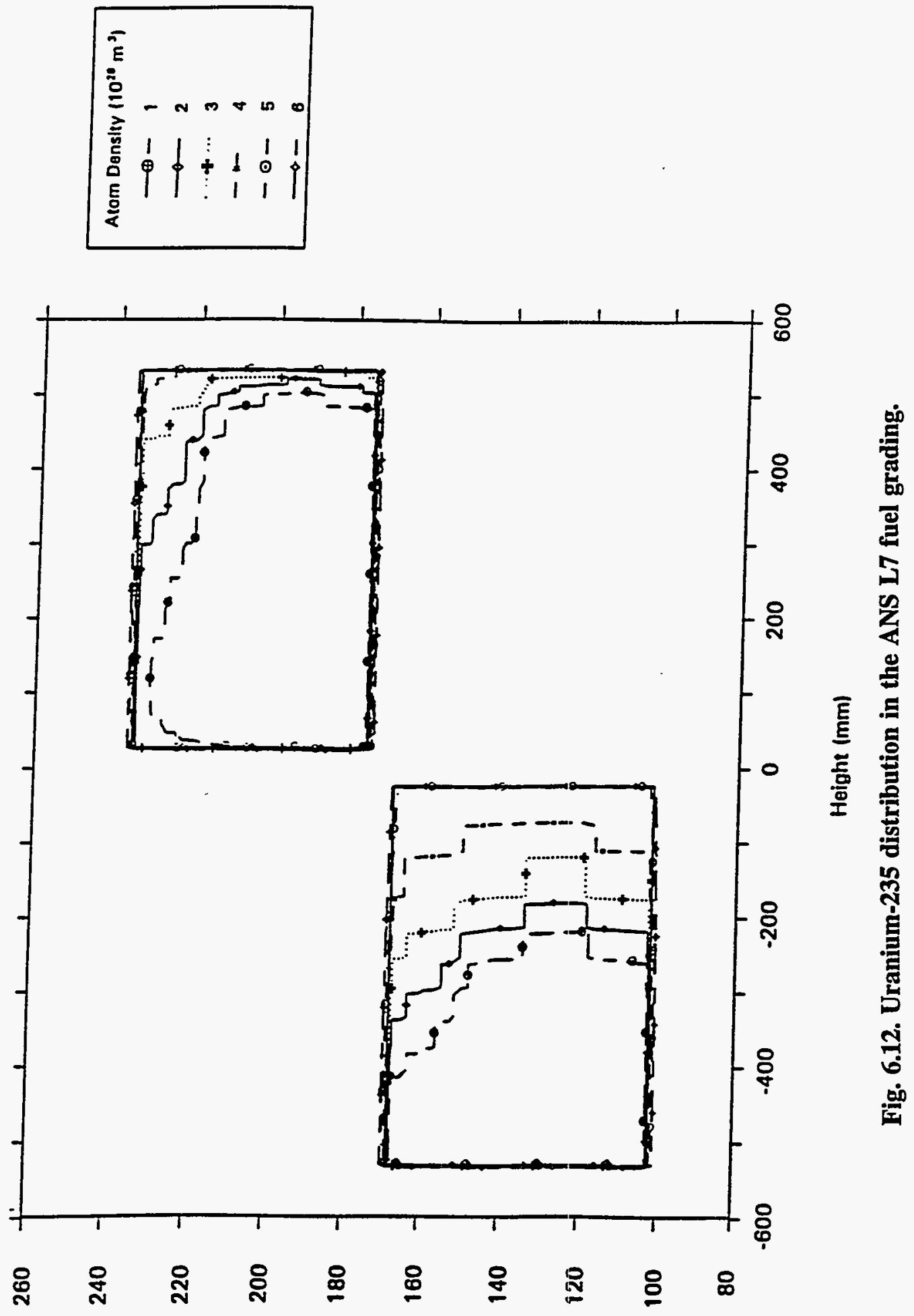

(uu) sn!pey 


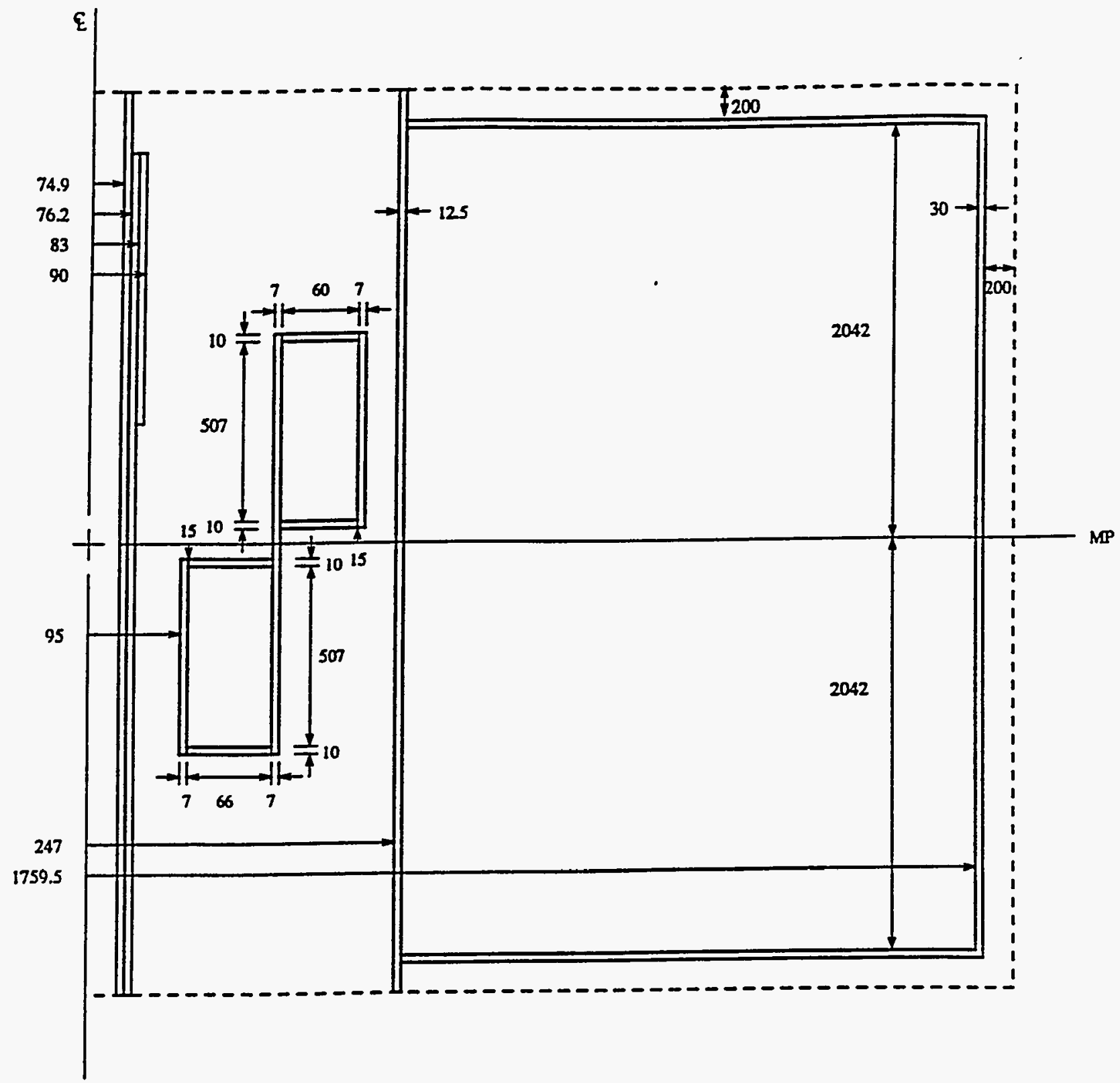

(dimensions in millimeters, not to seale)

Fig. 6.13. VENTURE model used in CCD analysis. 


\subsubsection{Fuel Depletion Model}

The fuel cycle analysis for the CCD design was performed using five depletion steps. The VENTURE code was used to calculate zone-averaged fluxes at $0,1.0,4.25,8.50,12.75$, and $17.0 \mathrm{~d}$ over the 17-d fuel cycle. The ${ }^{135} \mathrm{Xe}$ density in each fuel zone was iteratively adjusted to the equilibrium xenon associated with the zone-averaged flux using the VENTURE equilibrium-xenon option.

The BURNER code was used to calculate new nuclide densities using the burnup chains shown in Figs. 6.14 and 6.15. Each BURNER depletion step used the VENTURE-calculated zone fluxes at the beginning of the step, with the flux renormalized to the total reactor power twice during each depletion step.

The inner control rods were not depleted during the 17-d cycle for the CCD analysis. The control rod position for each VENTURE calculation was chosen a priori based upon pre-CCD analysis. Table 6.4 shows results using a recently developed control rod positioning module in VENTURE called CTRLPOS..$^{35}$ The L7 fuel cycle was analyzed with $5,7,9$, and 16 depletion steps (in all cases, equilibrium xenon was included after $1 \mathrm{~d}$ ). The 5-step case represents 4.25 -d steps, the 9-step case represents $2.125-\mathrm{d}$ steps and the 16-step case represents $1.0625-\mathrm{d}$ steps. The critical rod positions and $\mathrm{k}_{\text {eff }}$ values given in Table 6.4 are shown in Fig. 6.16. The control rod position was adjusted until $k_{\text {eff }}$ was within $0.1 \%$ of criticality. Power density comparisons with the 16-step case were performed, and the results are presented in Table 6.5.

These results indicate that the control rod position can be predicted accurately by using seven depletion steps. More steps are required in the first half of the cycle in order to deplete accurately the burnable absorber in the end caps. Note that the 16-step case indicated that the rod must be inserted 7 $\mathrm{mm}$ at $3.2 \mathrm{~d}$ because the burnable absorber burns out faster than the fuel. This effect does not appear in calculations with larger depletion steps. The power density comparisons indicate that at least nine depletion steps are required to obtain accurate results ( $0.8 \%$ average error, $3.0 \%$ maximum error).

\subsection{PDQ-7 MODEL FOR FUEL CYCLE ANALYSIS}

The PDQ-7 model is two-dimensional ( $\mathrm{r}-\mathrm{z}$ ) with four-group diffusion theory. The fuel was modeled with 160 regions ( 80 in each element). The mesh structure was examined and modified to account for the steep flux gradients near the fuel/water interface. The materials irradiation and transplutonium production targets were modeled as smeared rings. The control rods in the central hole were smeared throughout this region, and the homogeneous cross sections were adjusted to match reaction rates computed with transport theory. Several sets of cross sections were provided for important nuclides to account properly for the spatial variation in the flux-weighting spectrum. 


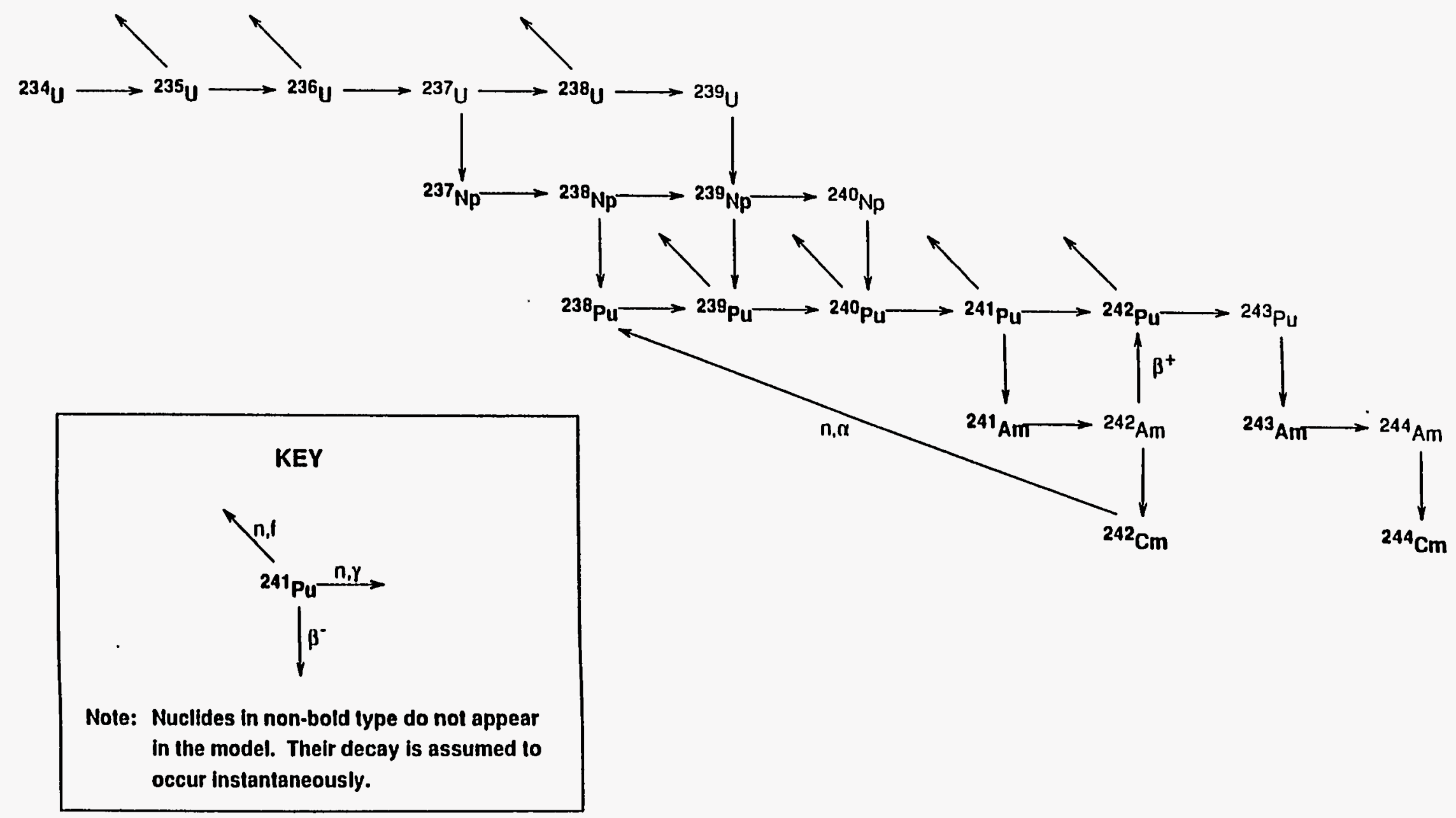

Fig. 6.14. Actinide chains used in the BURNER depletion code for CCD analysis. 

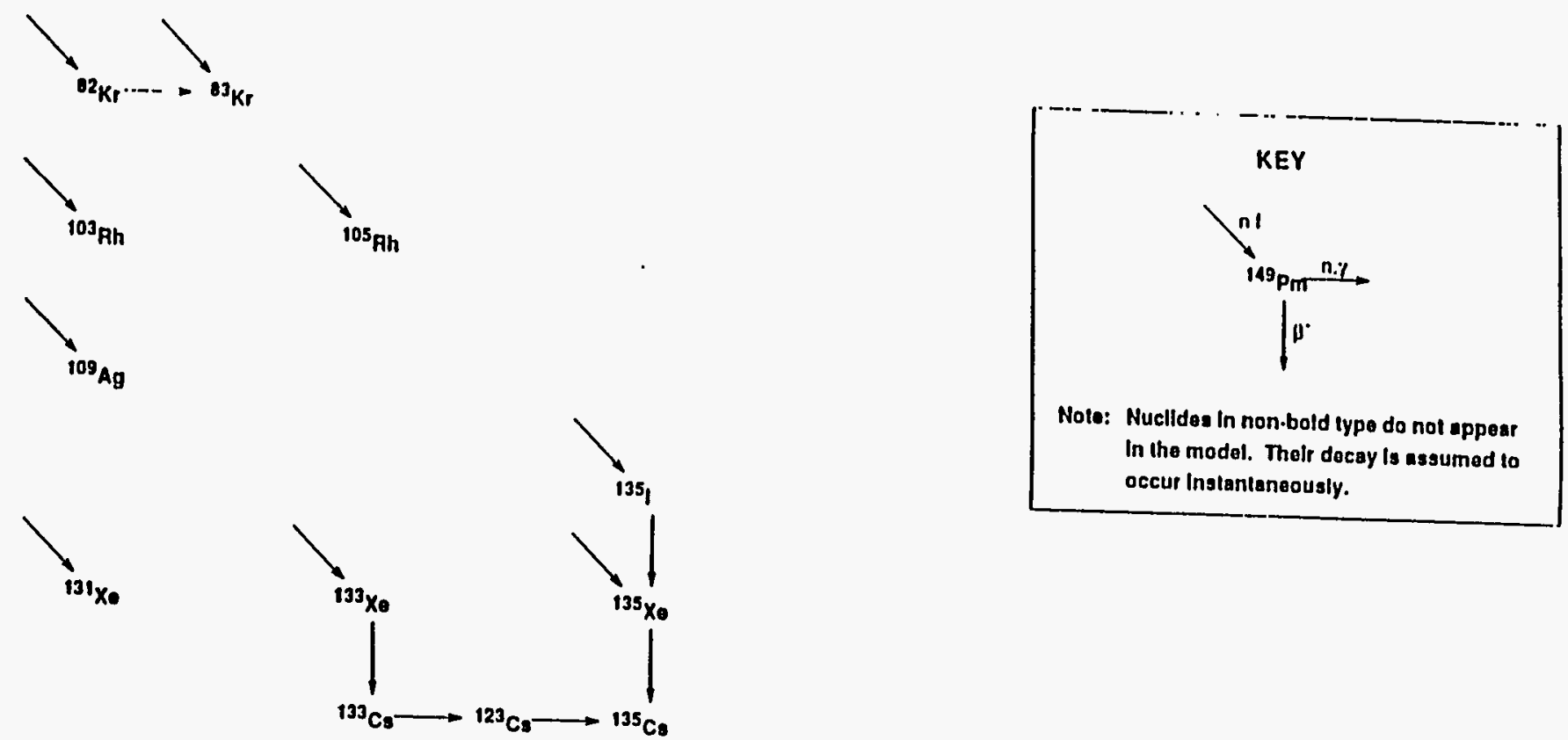

${ }^{\prime} x_{0}$
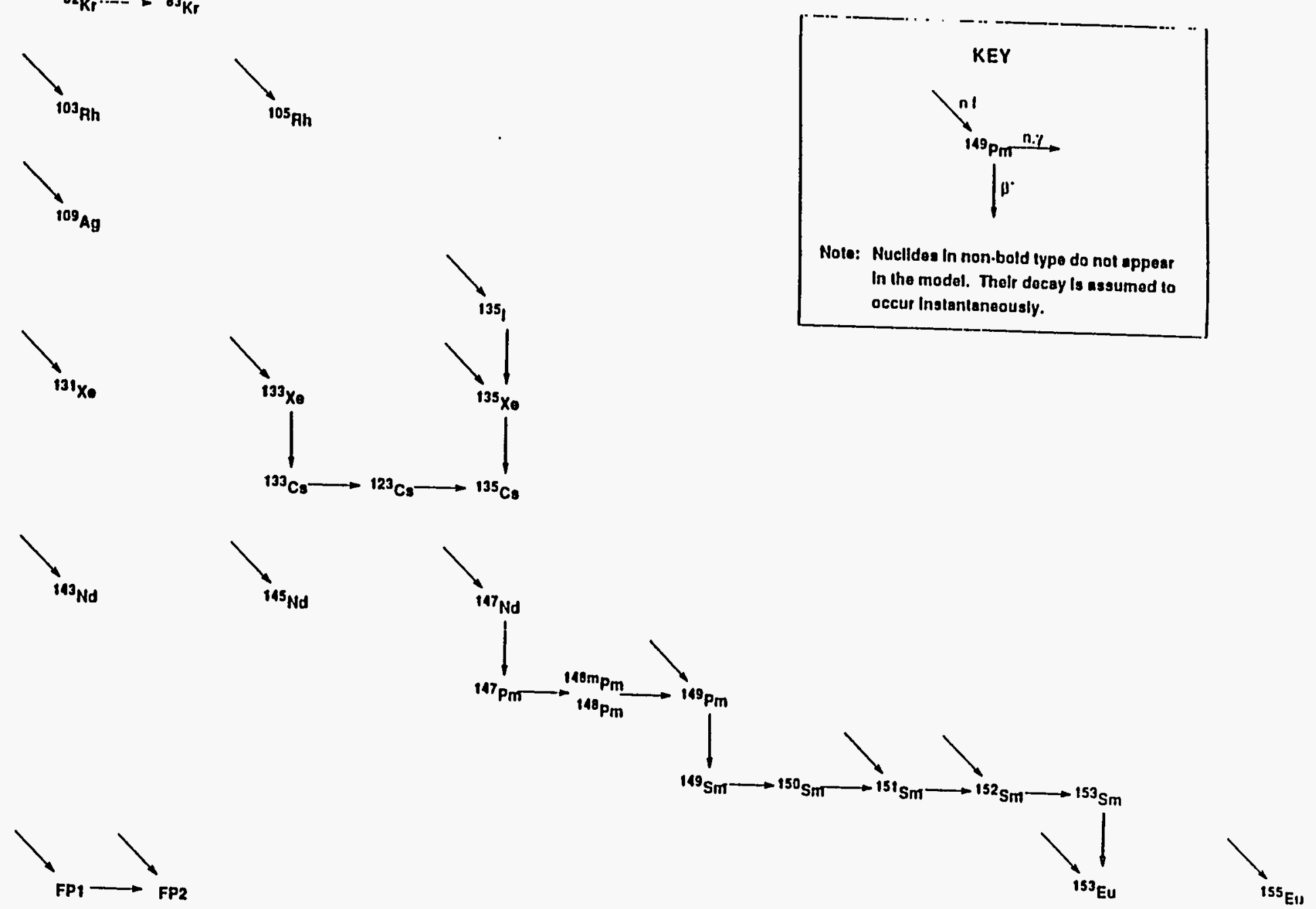

Fig. 6.15. Fission product chains used in the BURNER depletion code for CCD analysis. 
Table 6.4. Control rod positioning relative to midplane as a function of the number of time steps in VENTURE fuel cycle calculation

\begin{tabular}{|c|c|c|c|c|c|c|c|c|}
\hline \multirow[b]{2}{*}{$\begin{array}{l}\text { Time } \\
\text { (d) }\end{array}$} & \multicolumn{2}{|c|}{5 Steps } & \multicolumn{2}{|c|}{7 Steps } & \multicolumn{2}{|c|}{9 Steps } & \multicolumn{2}{|c|}{16 Steps } \\
\hline & $\begin{array}{c}\text { Position } \\
\text { (mm) }\end{array}$ & $\mathrm{k}_{\mathrm{eff}}$ & $\begin{array}{l}\text { Position } \\
\text { (mm) }\end{array}$ & $k_{\text {eff }}$ & $\begin{array}{c}\text { Position } \\
\text { (mm) }\end{array}$ & $k_{\text {eff }}$ & $\begin{array}{c}\text { Position } \\
\text { (mm) }\end{array}$ & $k_{\text {efr }}$ \\
\hline 0.0000 & -120.4 & 1.0002 & -120.4 & 1.0002 & -120.4 & 1.0002 & -120.4 & 1.0002 \\
\hline 1.0000 & 68.9 & 1.0000 & 68.9 & 1.0000 & 68.9 & 1.0000 & 68.9 & 1.0000 \\
\hline 2.1250 & & & 76.9 & 1.0002 & 76.9 & 1.0002 & 76.9 & 1.0002 \\
\hline 3.1875 & & & & & & & 76.9 & 1.0009 \\
\hline 4.2500 & 91.0 & 1.0004 & 76.9 & 1.0004 & 76.9 & 1.0004 & 69.8 & 0.9999 \\
\hline 5.3125 & & & & & & & 69.8 & 0.9992 \\
\hline 6.3750 & & & 87.7 & 0.9991 & 87.7 & 0.9991 & 80.1 & 0.9992 \\
\hline 7.4375 & & & & & & & 101.4 & 1.0008 \\
\hline 8.5000 & 138.3 & 0.9990 & 123.6 & 0.9991 & 123.6 & 0.9991 & 120.6 & 1.0004 \\
\hline 9.5625 & & & & & & & 145.0 & 0.9998 \\
\hline 10.6250 & & & & & 180.8 & 1.0002 & 177.2 & 0.9997 \\
\hline 11.6875 & & & & & & & 217.5 & 1.0001 \\
\hline 12.7500 & 266.8 & 0.9998 & 271.4 & 1.0006 & 269.7 & 1.0009 & 266.6 & 1.0007 \\
\hline 13.8125 & & & & & & & 316.6 & 0.9995 \\
\hline 14.8750 & & & & & 370.5 & 1.0002 & 368.8 & 0.9994 \\
\hline 15.9375 & & & & & & & 432.9 & 0.9995 \\
\hline 17.0000 & 481.2 & 1.0002 & 483.7 & 1.0008 & 482.7 & 1.0009 & 481.3 & 1.0002 \\
\hline
\end{tabular}




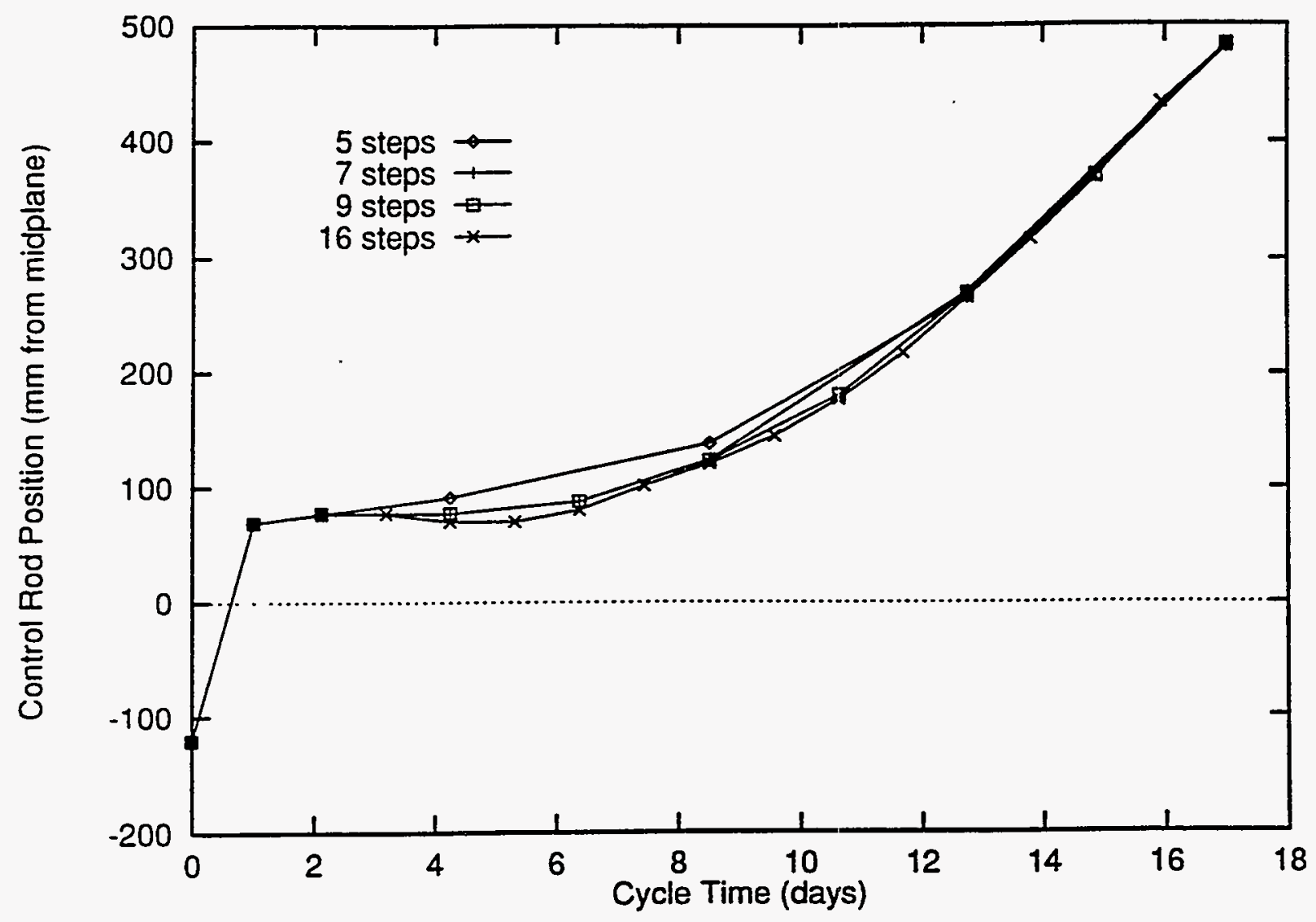

Fig. 6.16. Critical control rod position throughout the fuel cycle for the ANS CCD. 
Table 6.5. Power density comparisons against the 16-depletion step fuel cycle calculation

\begin{tabular}{|c|c|c|c|c|c|c|c|c|c|}
\hline \multirow[b]{2}{*}{$\begin{array}{l}\text { Time } \\
\text { (d) }\end{array}$} & \multicolumn{3}{|c|}{5 Depletion steps } & \multicolumn{3}{|c|}{7 depletion steps } & \multicolumn{3}{|c|}{9 Depletion steps } \\
\hline & $\begin{array}{c}\text { Average } \\
\text { difference }^{a} \\
(\%)\end{array}$ & $\begin{array}{l}\text { Maximum } \\
\text { absolute } \\
\text { difference }^{b} \\
(\%)\end{array}$ & $\begin{array}{c}\text { Maximum } \\
\text { power } \\
\text { difference }^{c} \\
(\%)\end{array}$ & $\begin{array}{c}\text { Average } \\
\text { difference }^{a} \\
(\%)\end{array}$ & $\begin{array}{l}\text { Maximum } \\
\text { absolute } \\
\text { difference }^{b} \\
(\%)\end{array}$ & $\begin{array}{c}\text { Maximum } \\
\text { power } \\
\text { difference }^{c} \\
(\%)\end{array}$ & $\begin{array}{c}\text { Average } \\
\text { difference }^{a} \\
(\%)\end{array}$ & $\begin{array}{c}\text { Maximum } \\
\text { absolute } \\
\text { difference }^{b} \\
(\%)\end{array}$ & $\begin{array}{c}\text { Maximum } \\
\text { power } \\
\text { difference }^{c} \\
(\%)\end{array}$ \\
\hline 4.25 & 0.91 & 4.66 & 1.51 & 0.33 & 1.81 & 0.54 & 0.33 & 1.81 & 0.54 \\
\hline 8.50 & 0.75 & 3.10 & 2.86 & 0.16 & 1.10 & 1.10 & 0.16 & 1.10 & 1.10 \\
\hline 12.75 & 0.80 & 7.90 & 3.03 & 0.92 & 4.90 & 1.91 & 0.38 & 2.58 & 0.95 \\
\hline 17.00 & 1.87 & 8.11 & 3.08 & 2.07 & 6.01 & 3.47 & 0.80 & 2.99 & 1.02 \\
\hline
\end{tabular}

in

${ }^{a}$ Average absolute difference between power densities.

${ }^{6}$ Maximum absolute difference between power densities.

Difference between maximum power densities. 


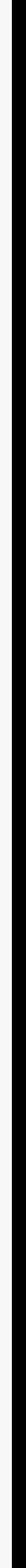




\section{FUEL CYCLE ANALYSIS RESULTS}

\subsection{FLUXES}

The VENTURE-calculated four-group fluxes at BOC and end of cycle (EOC) are illustrated in Figs. 7.1 and 7.2. The group boundaries of the four energy groups are $0.0 \mathrm{eV}, 0.650 \mathrm{eV}, 100 \mathrm{eV}, 0.15$ $\mathrm{MeV}$, and $20 \mathrm{MeV}$. Subsequent analysis has shown that the calculated thermal group flux $<1 \%$ above that for a $0.625-\mathrm{eV}$ cutoff, but the calculated fast flux is $5 \%$ less than that for a $0.1-\mathrm{MeV}$ cutoff. The flux shifts from the lower to the upper fuel element over the 17-d fuel cycle as the control rod is withdrawn. Radial and axial traverses of the four-group fluxes through the midpoint of each fuel element at BOC and EOC, shown in Figs. 7.3-7.10, are indicative of the spectrum differences between fuel elements as well as between BOC and EOC within each element. Contour maps of the thermal flux at BOC and EOC throughout the reflector are shown in Figs. 7.11 and 7.12.

A 39-group DORT fixed-source problem using cycle-averaged fission rates from the VENTURE fuel cycle calculation was subsequently performed to determine the flux spectrum throughout the reflector and to determine the contribution of photoneutrons to the flux distributions. The collapsed four-group flux contours with and without photoneutrons are shown in Figs. 7.13-7.20. The impact of accounting for photoneutrons can be seen clearly by comparing the radial traverses in Fig. 7.21 to those presented in Fig. 7.22.

The key flux data for meeting National Steering Committee for the Advanced Neutron Source goals as calculated by VENTURE and DORT are listed in Table 7.1.

\subsection{POWER DISTRIBUTIONS}

The power distribution has been calculated at five time steps over the 17-d fuel cycle. The resulting power densities within each element at each of the five time steps are listed in Tables 7.2-7.6.

\subsection{FLUENCES}

The neutron fluence levels at the end of each cycle are calculated based on the VENTURE four-group fluxes. The thermal fluence contours at the end of a single 17-d cycle is shown in Fig. 7.23.

\subsection{SILICON PRODUCTION}

The CPBT and reflector vessel material properties depend upon the accumulated silicon content within the Al-6061 material, and thus the peak activation rates of ${ }^{28} \mathrm{Si}$ in the CPBT and the reflector vessel have been calculated over the $17-\mathrm{d}$ cycle. The silicon atoms are produced by the ${ }^{27} \mathrm{Al}(\mathrm{n}, \gamma){ }^{28} \mathrm{Al}$ reaction and subsequent beta decay to ${ }^{28} \mathrm{Si}$ with a 2.24 -min half-life. The neutron absorption in ${ }^{27} \mathrm{Al}$ is a function of the neutron spectrum and flux level.

Synopses of the results are shown in Tables 7.7 and 7.8. Table 7.7 displays the maximum ${ }^{28} \mathrm{Si}$ production rates in the CPBT at BOC, middle of cycle (MOC), and EOC at hot full power (HFP) operation for four energy group ranges. Group 1 represents the fast neutron energy range, groups 2 and 3 the epithermal range, and group 4 represents the thermal neutron range. Note that these 

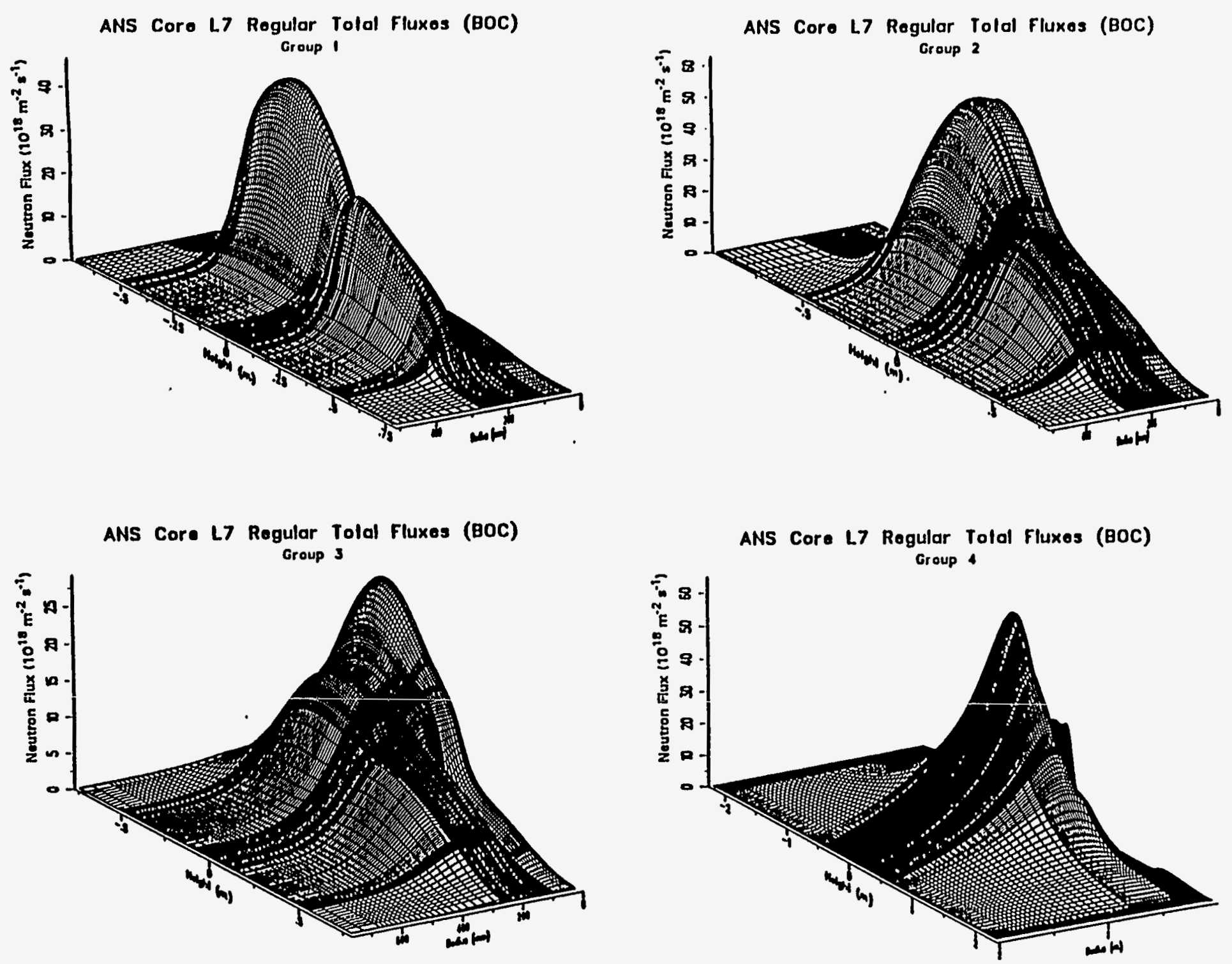

Fig. 7.1. VENTURE-calculated four-group fluxes at BOC. 

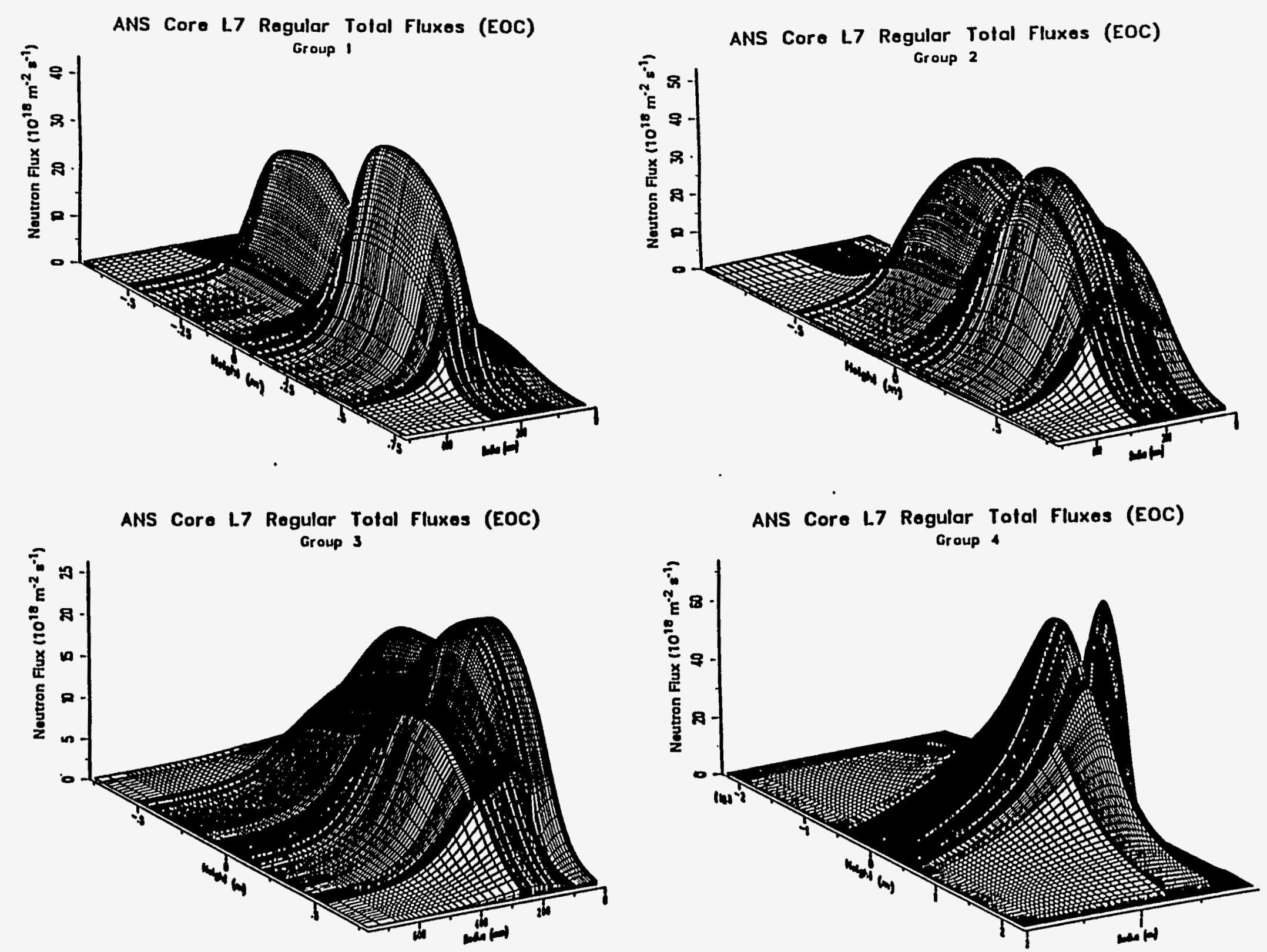

Fig. 7.2. VENTURE-calculated four-group fluxes at EOC. 

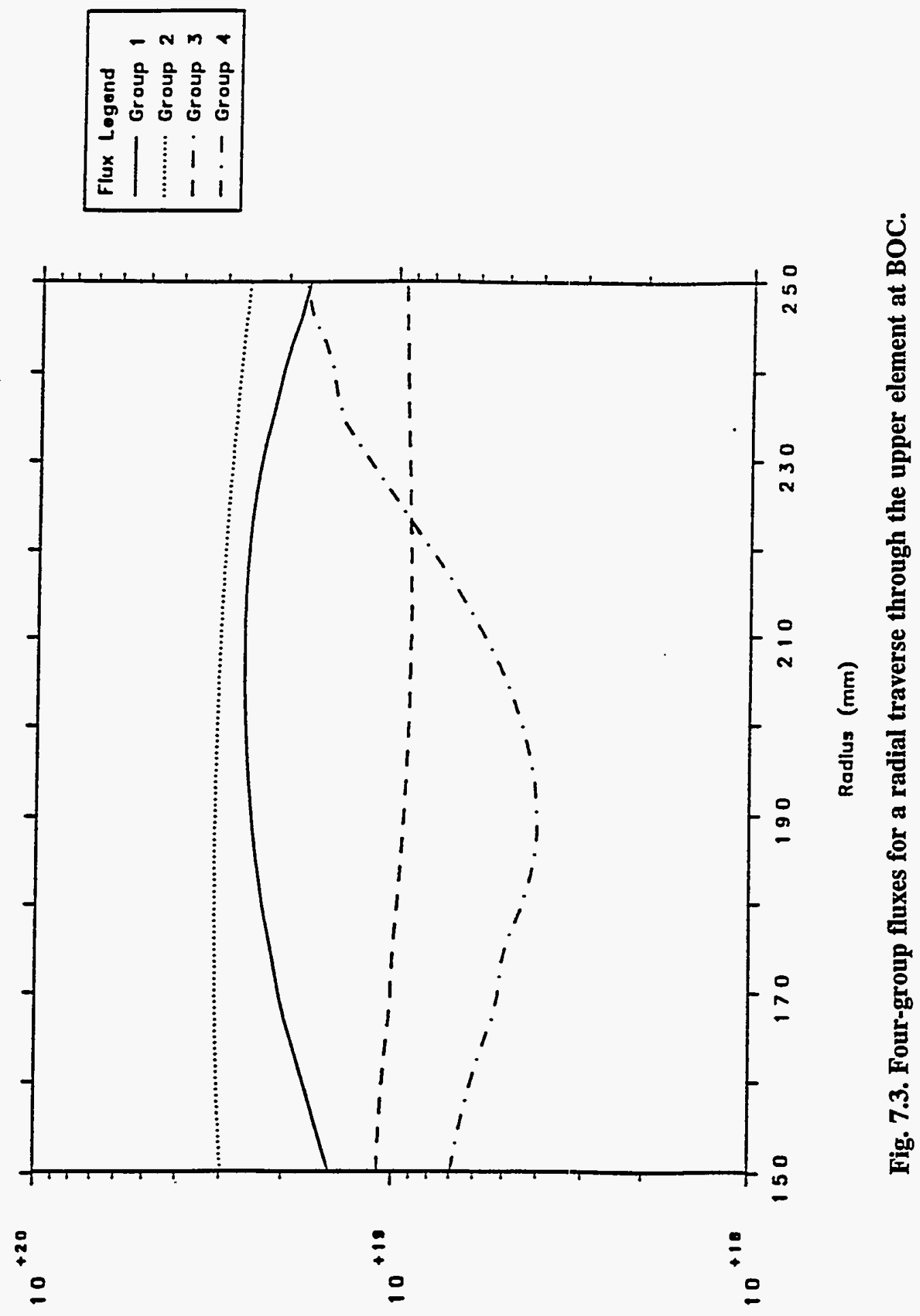

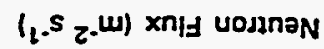




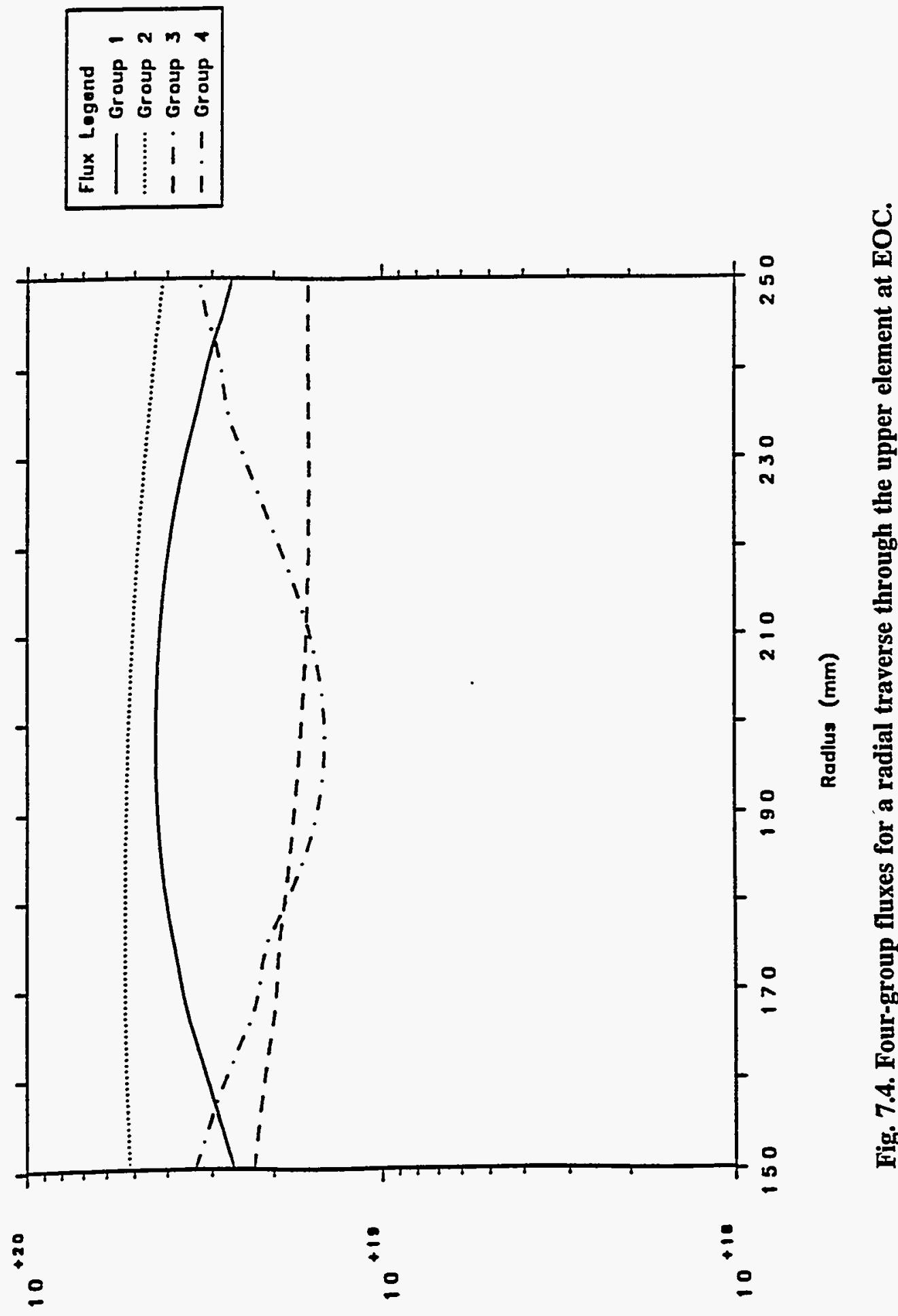

$l_{1}, 5 z^{-}(w)$ xn!J uonnan 


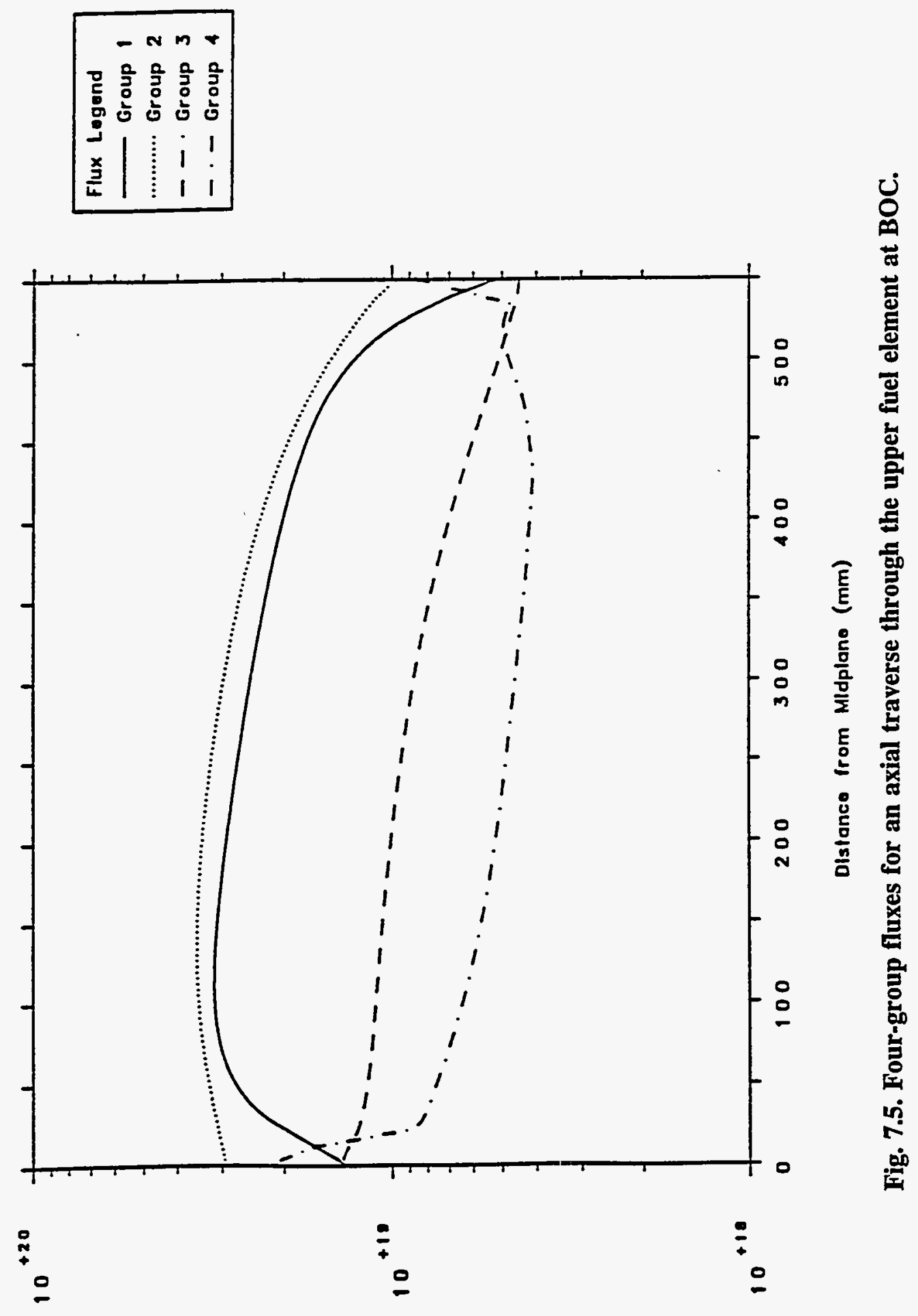

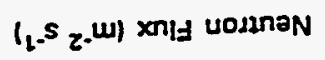




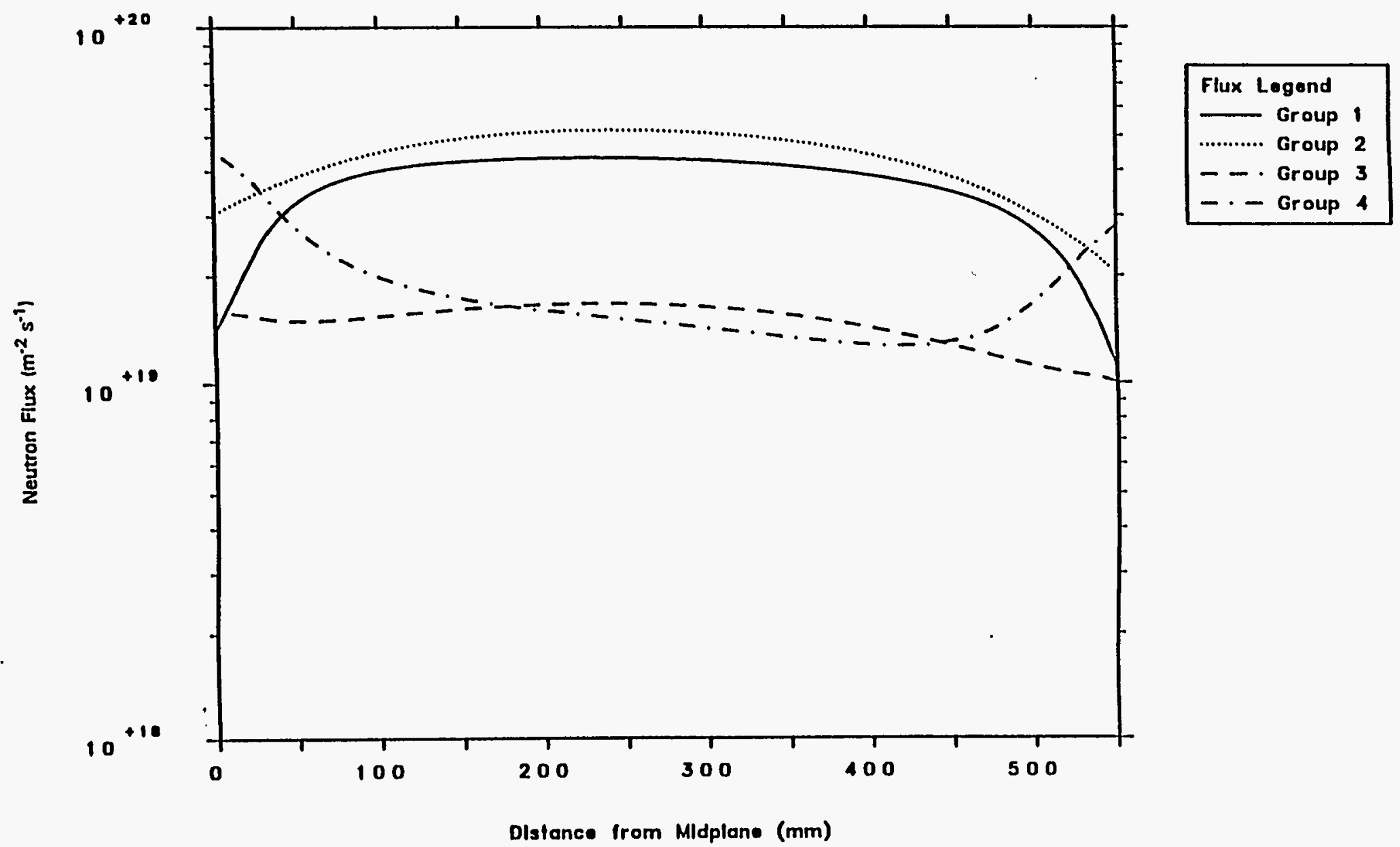

Fig. 7.6. Four-group fluxes for an axial traverse through the upper fuel element at EOC. 


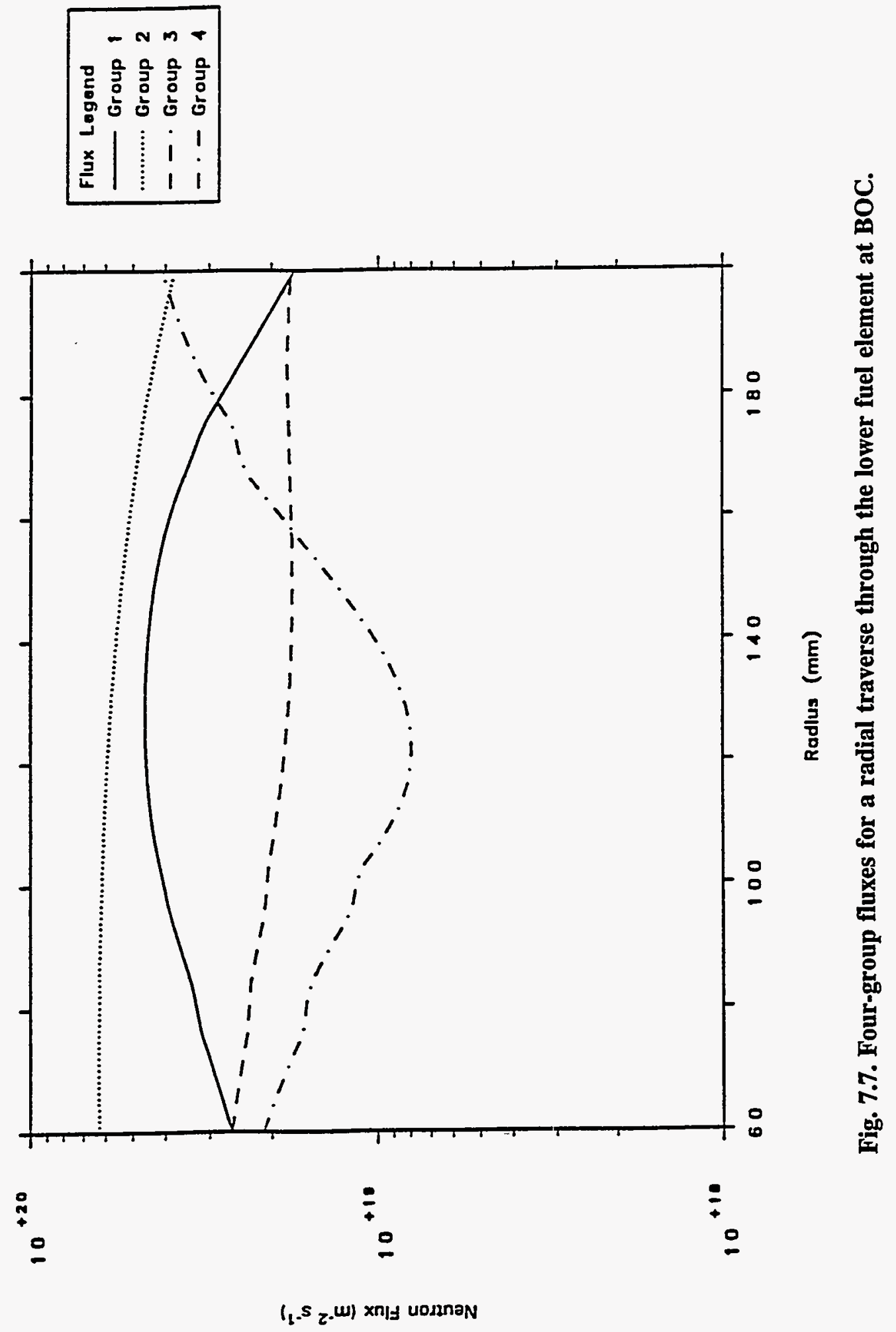




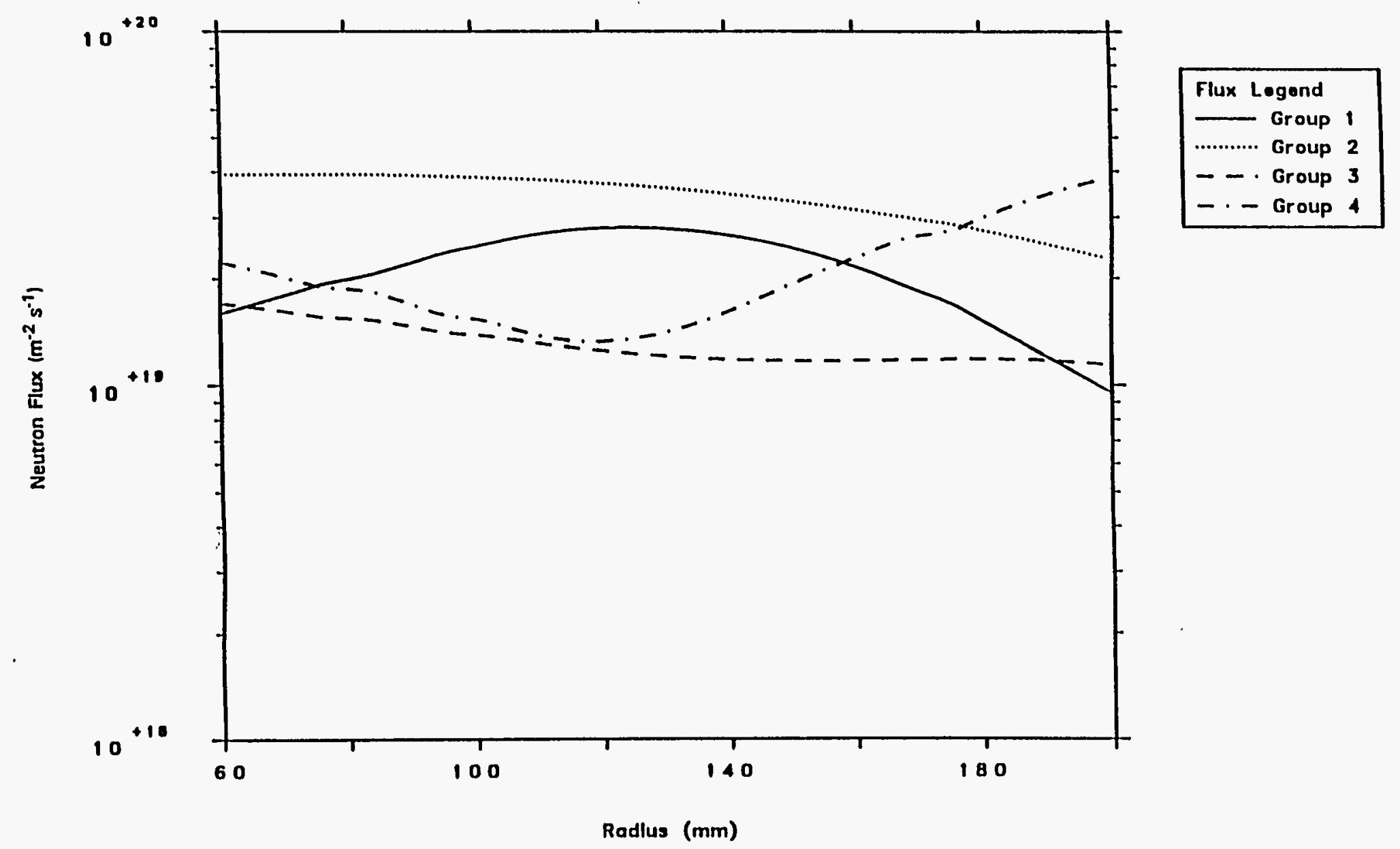

Fig. 7.8. Four-group fluxes for a radial traverse through the lower fuel element at EOC. 


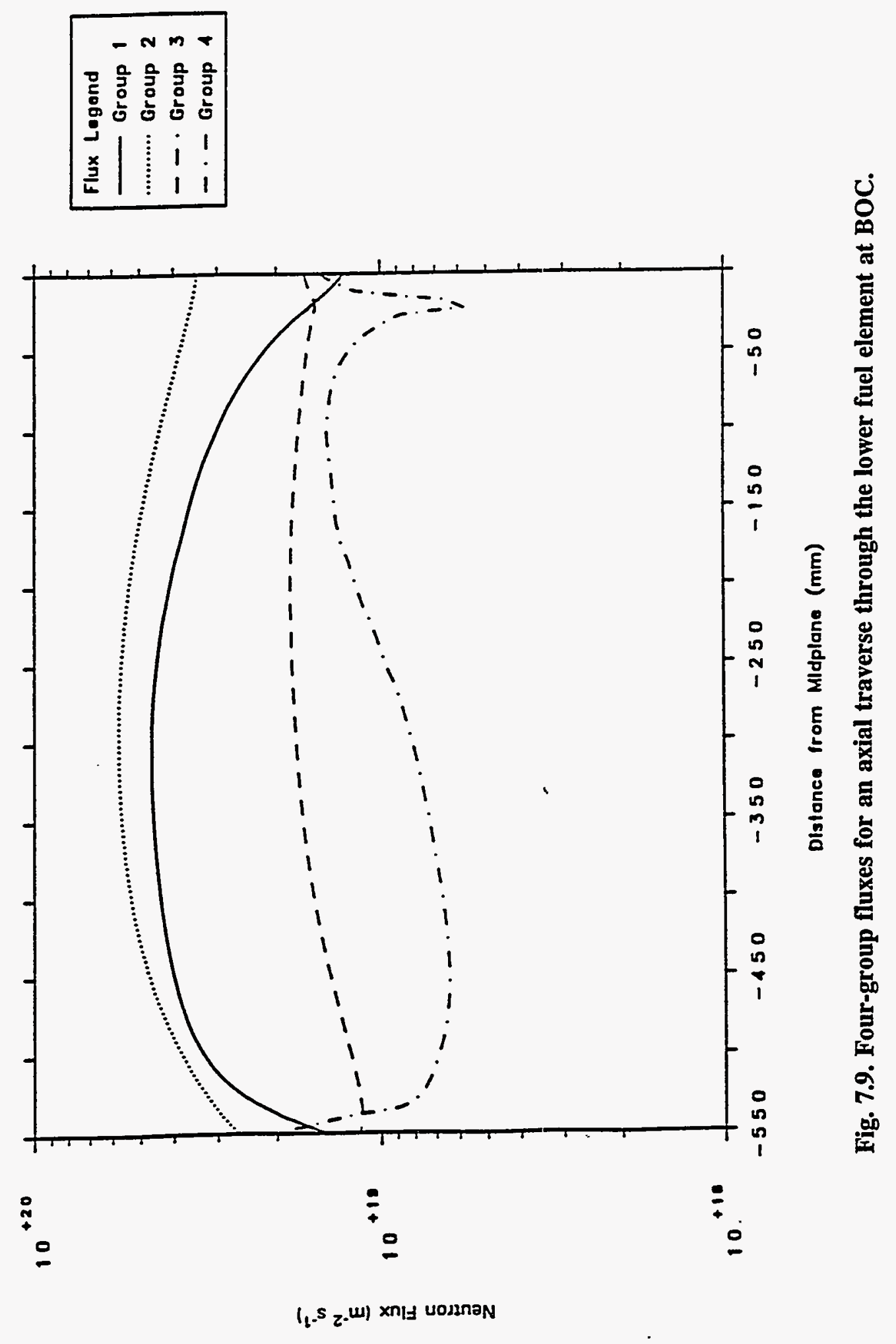




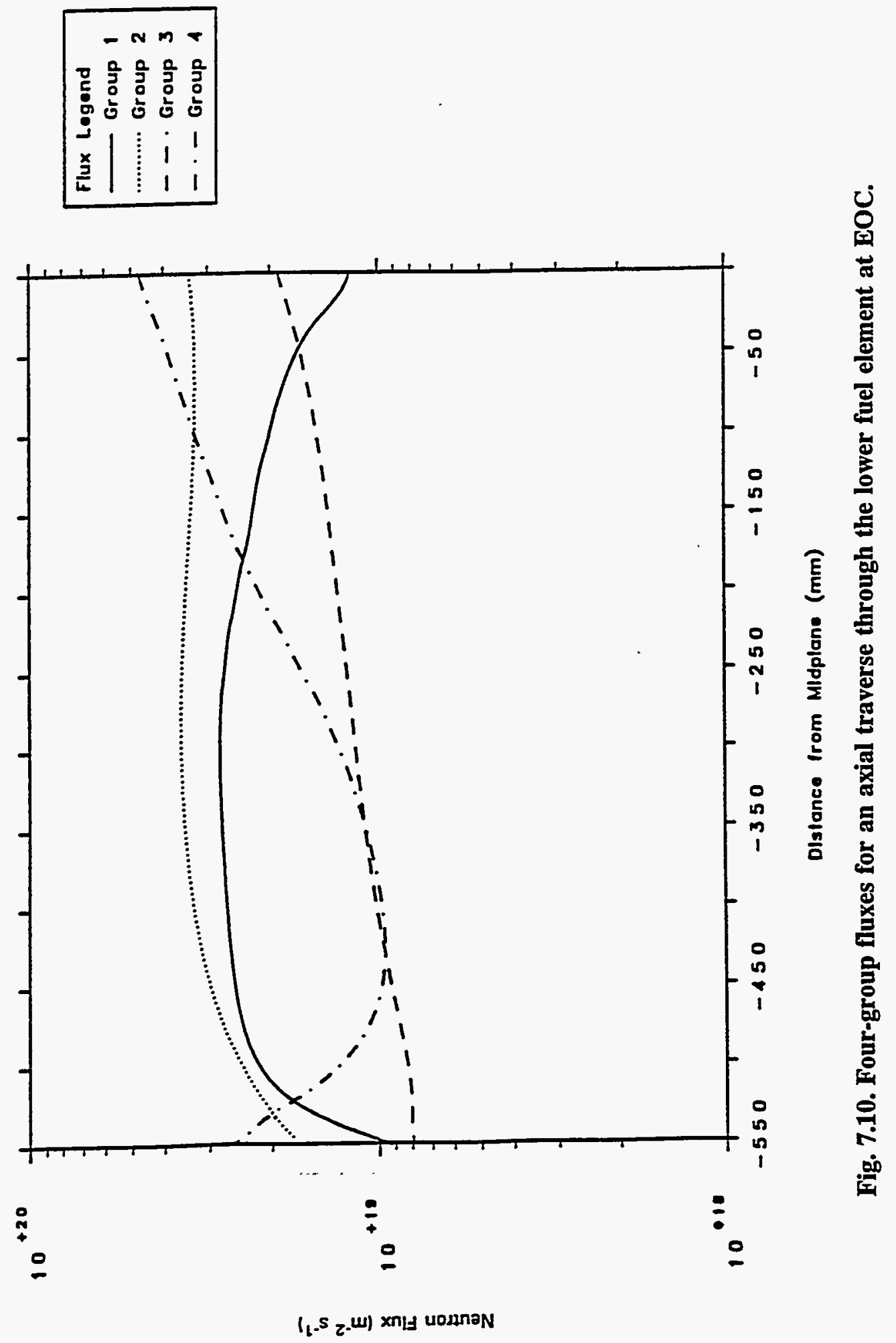



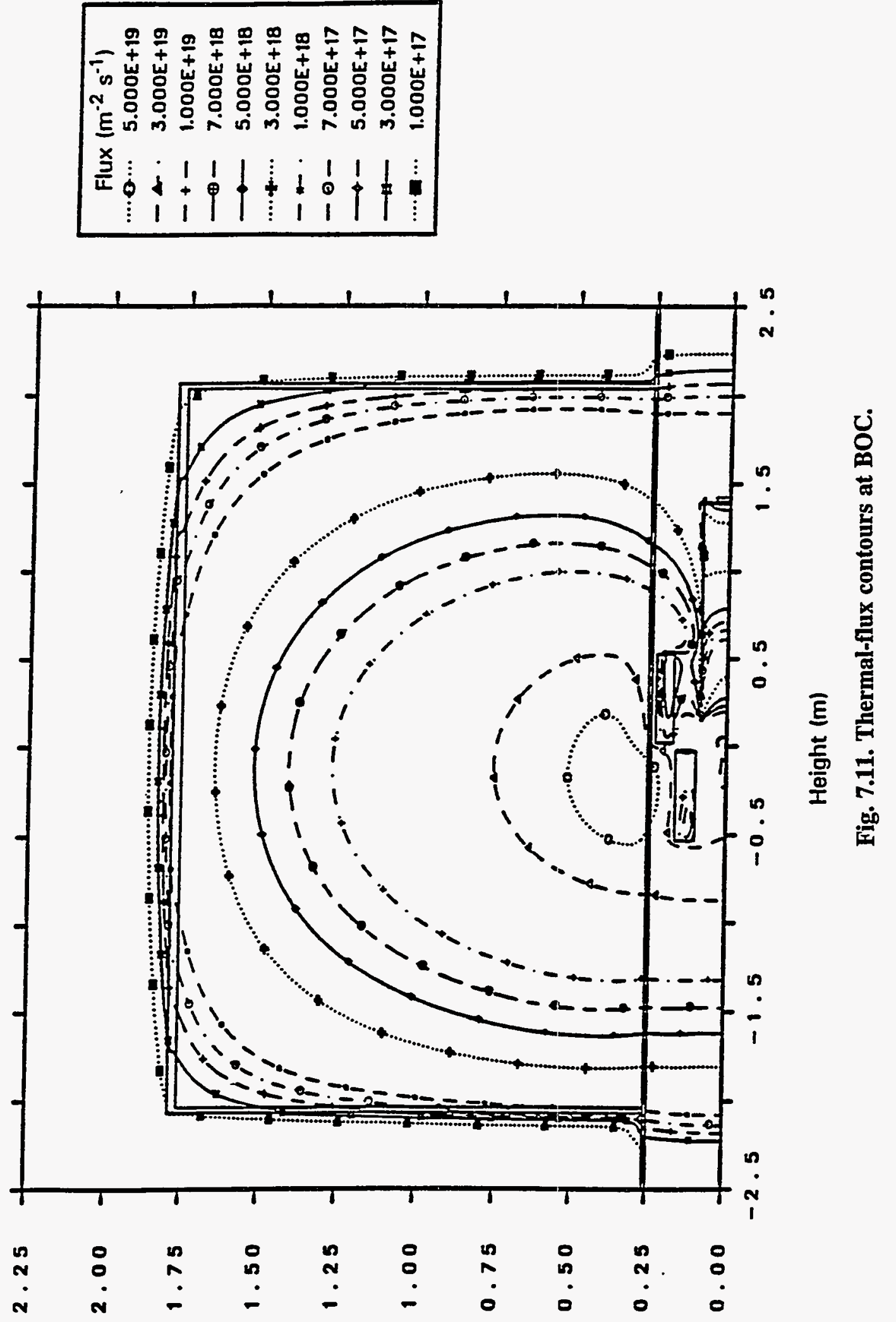

(w) sn!pey 


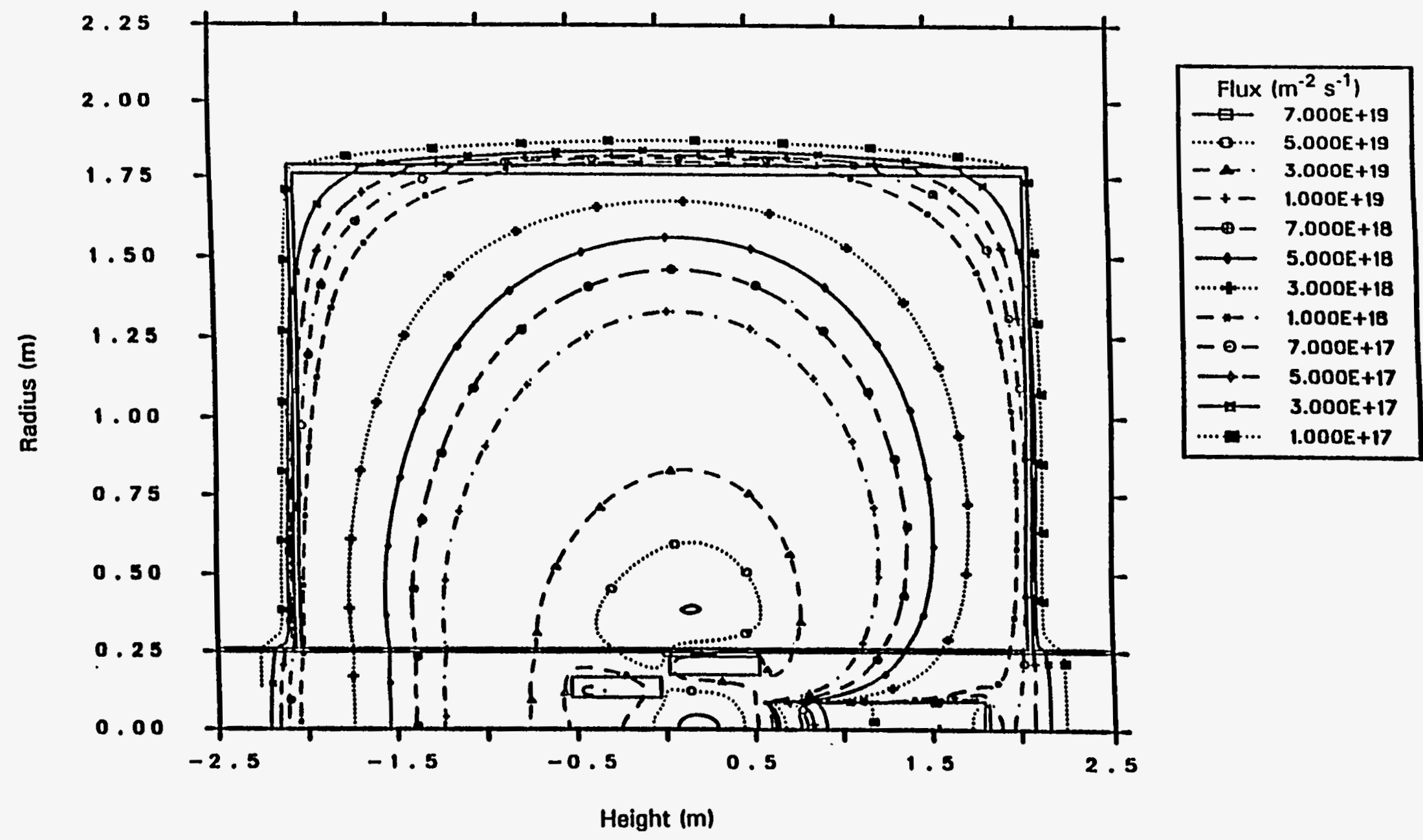

Fig. 7.12. Thermal-flux contours at EOC. 


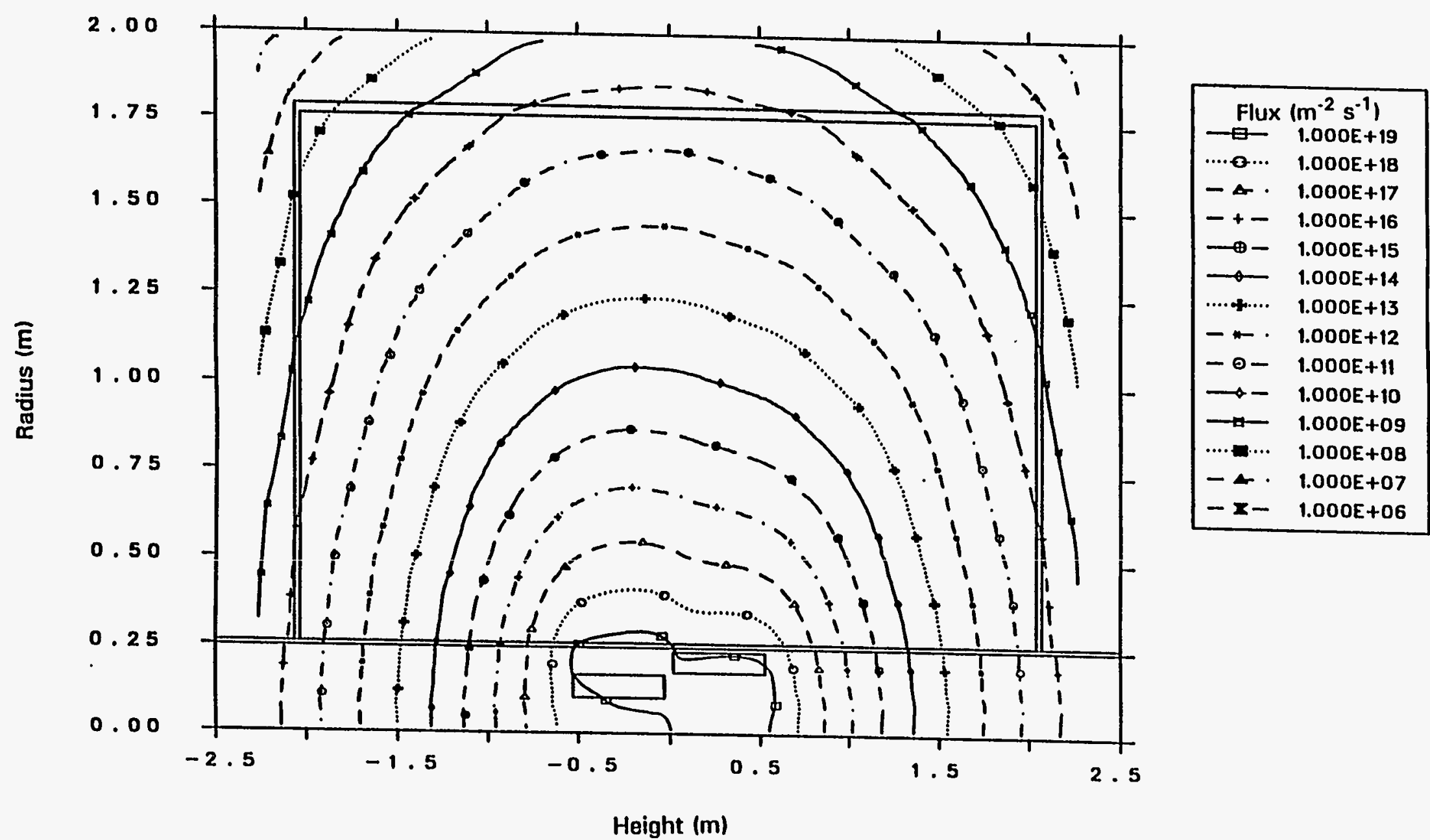

Fig. 7.13. DORT-calculated flux $(\mathrm{E}>0.1 \mathrm{MeV})$ without photoneutrons. 

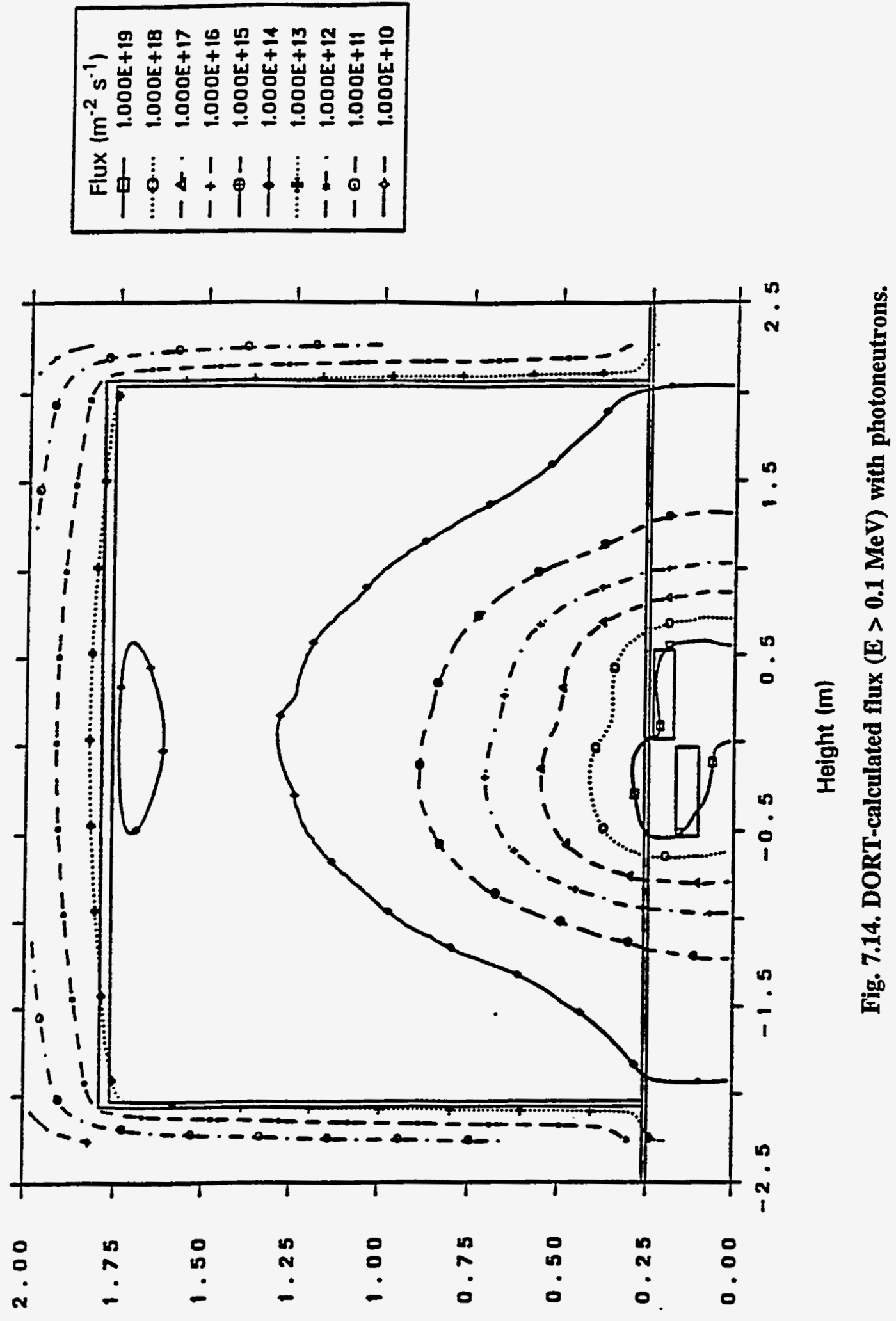

(w) sn!pey 


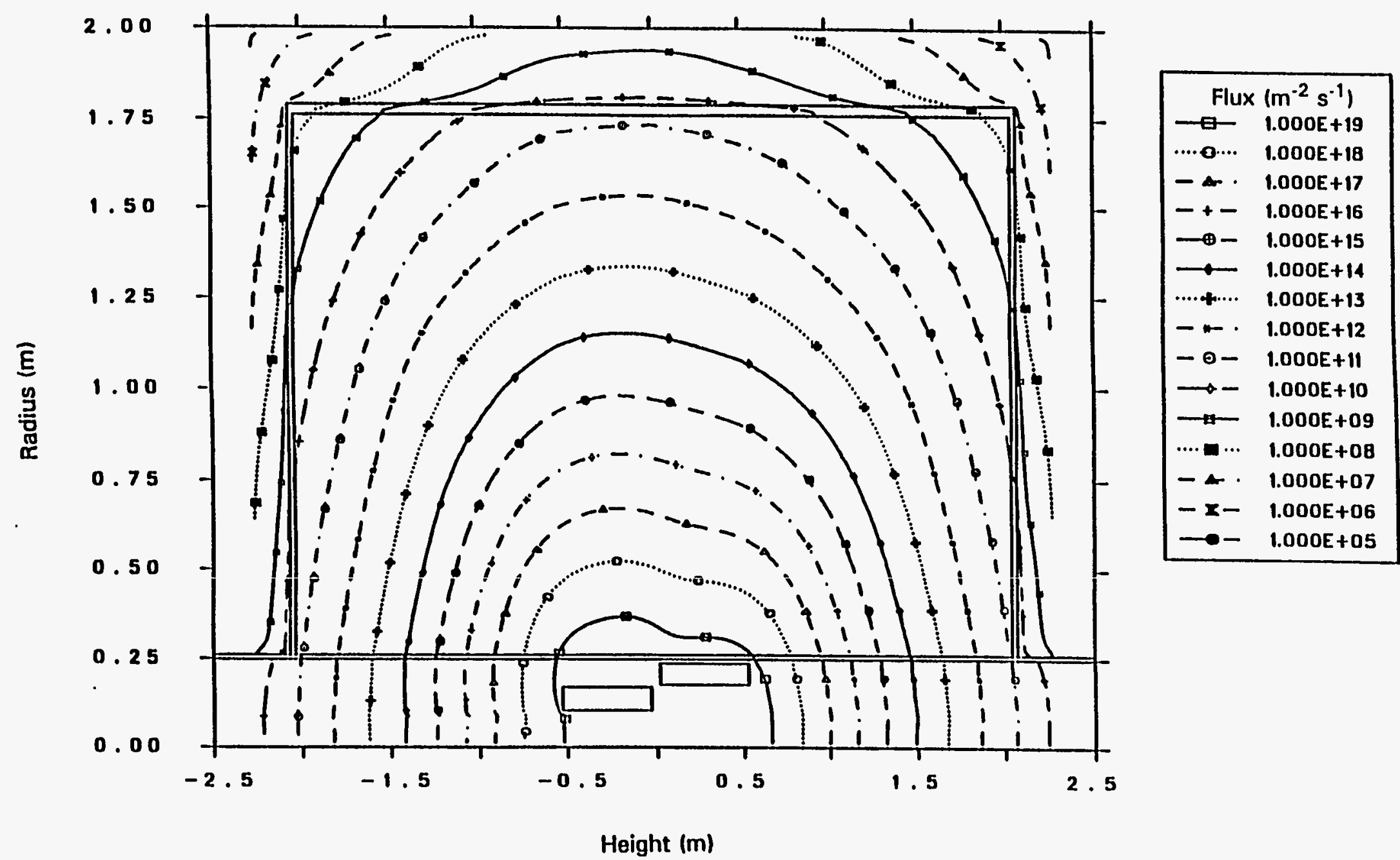

Fig. 7.15. DORT-calculated flux $(100 \mathrm{eV}<\mathrm{E}<0.1 \mathrm{MeV})$ without photoneutrons. 


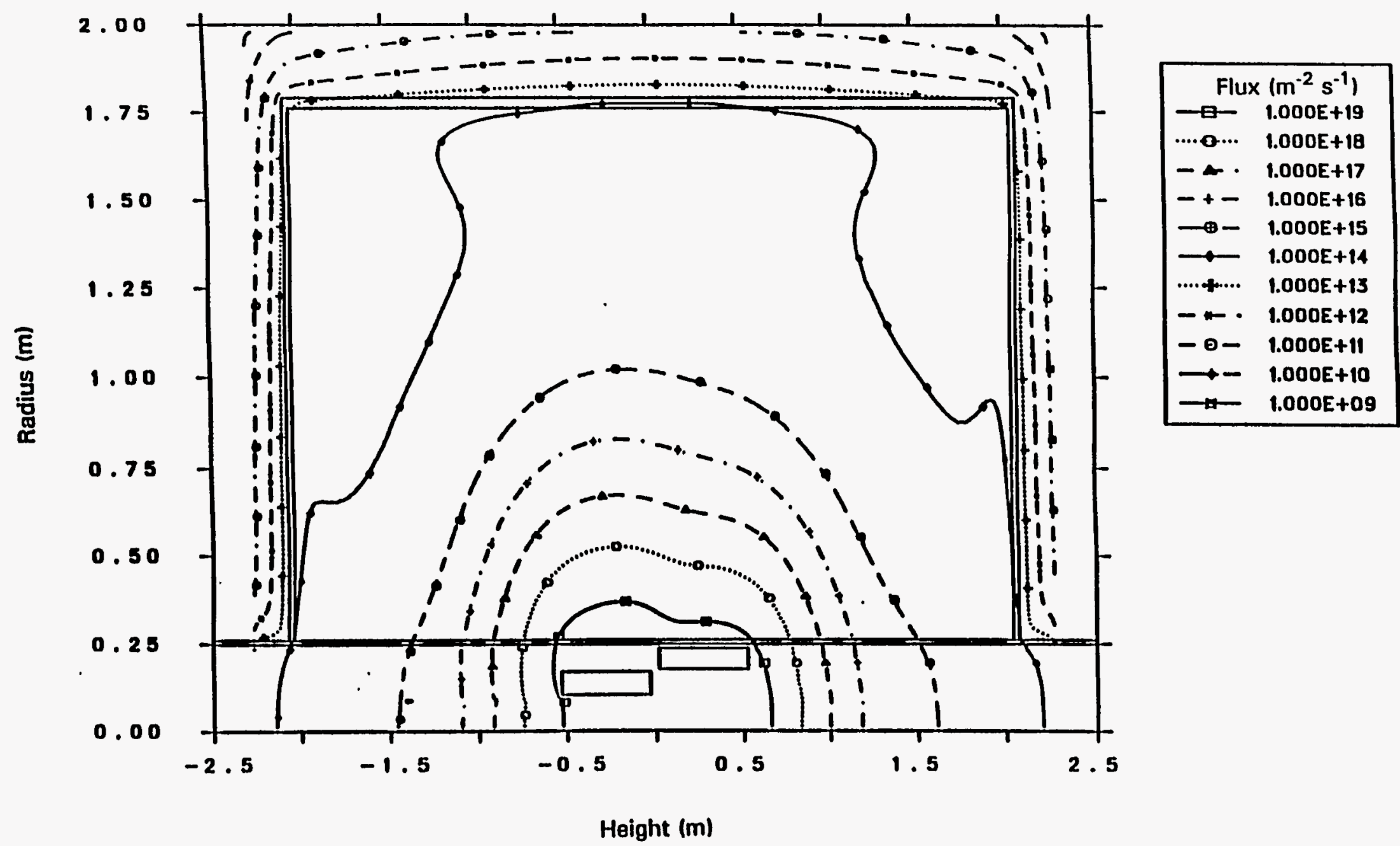

Fig. 7.16. DORT-calculated flux $(100 \mathrm{eV}<\mathrm{E}<0.1 \mathrm{MeV})$ with photoneutrons. 


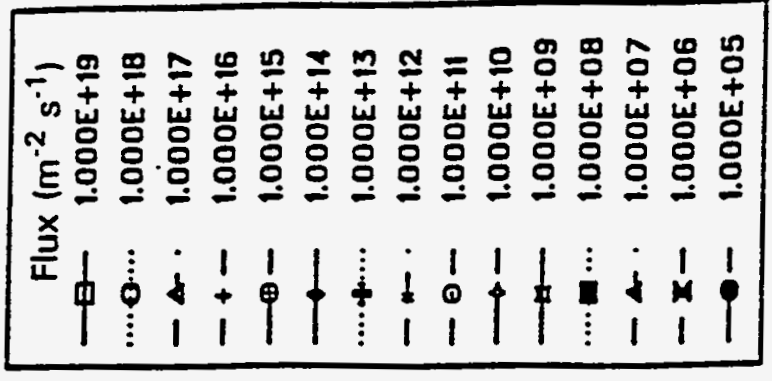

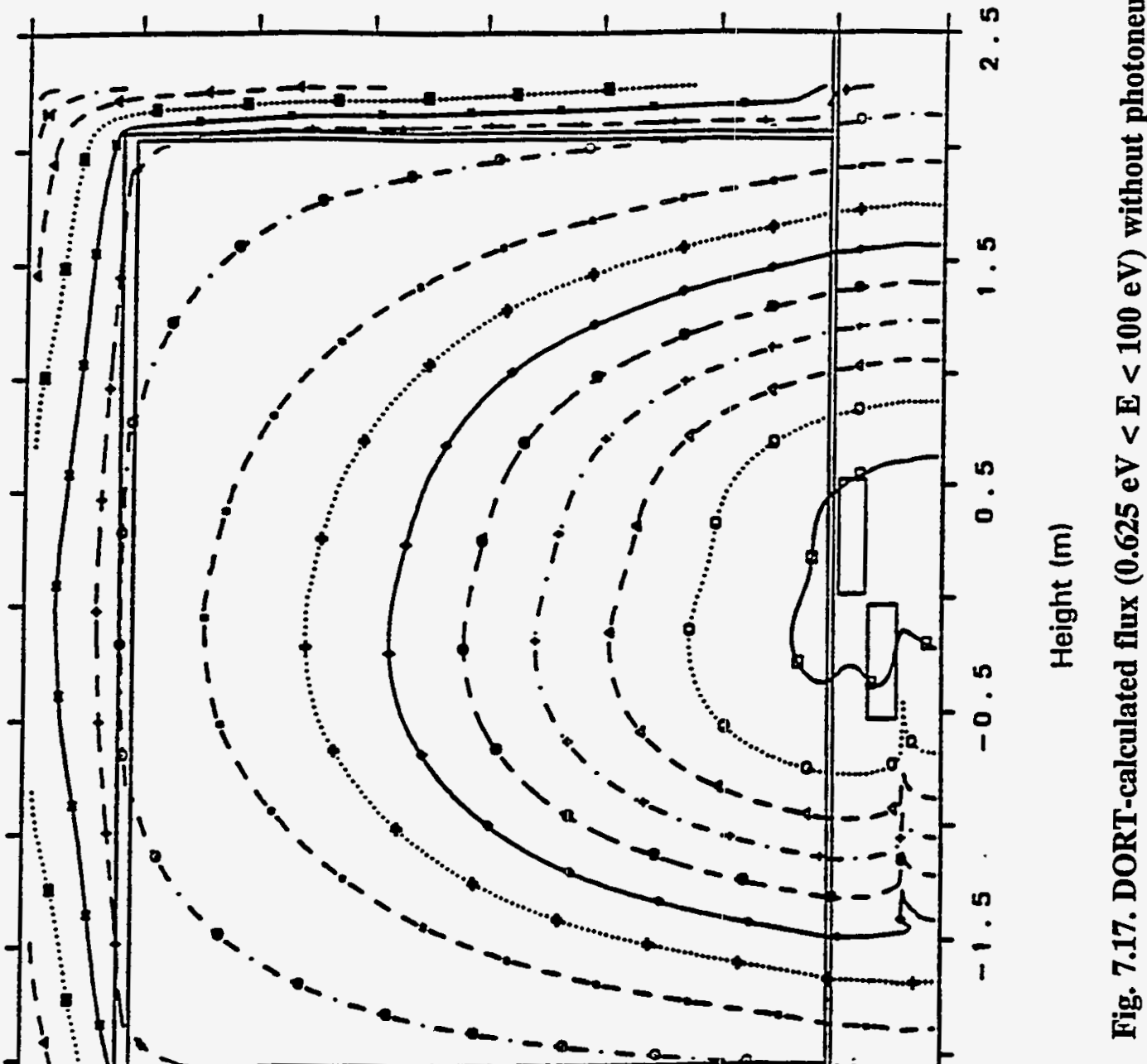

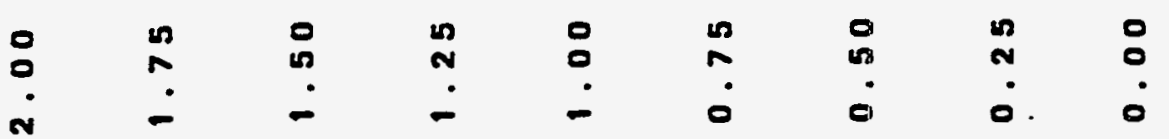

(w) sntpey 


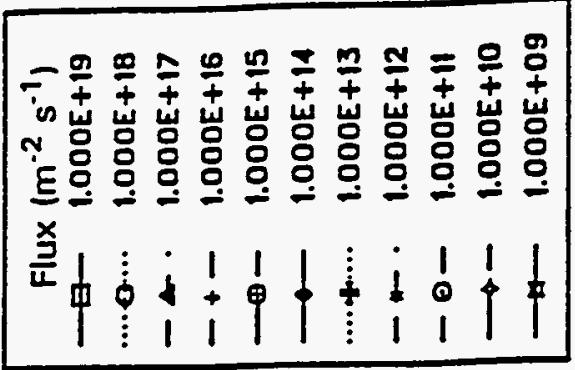

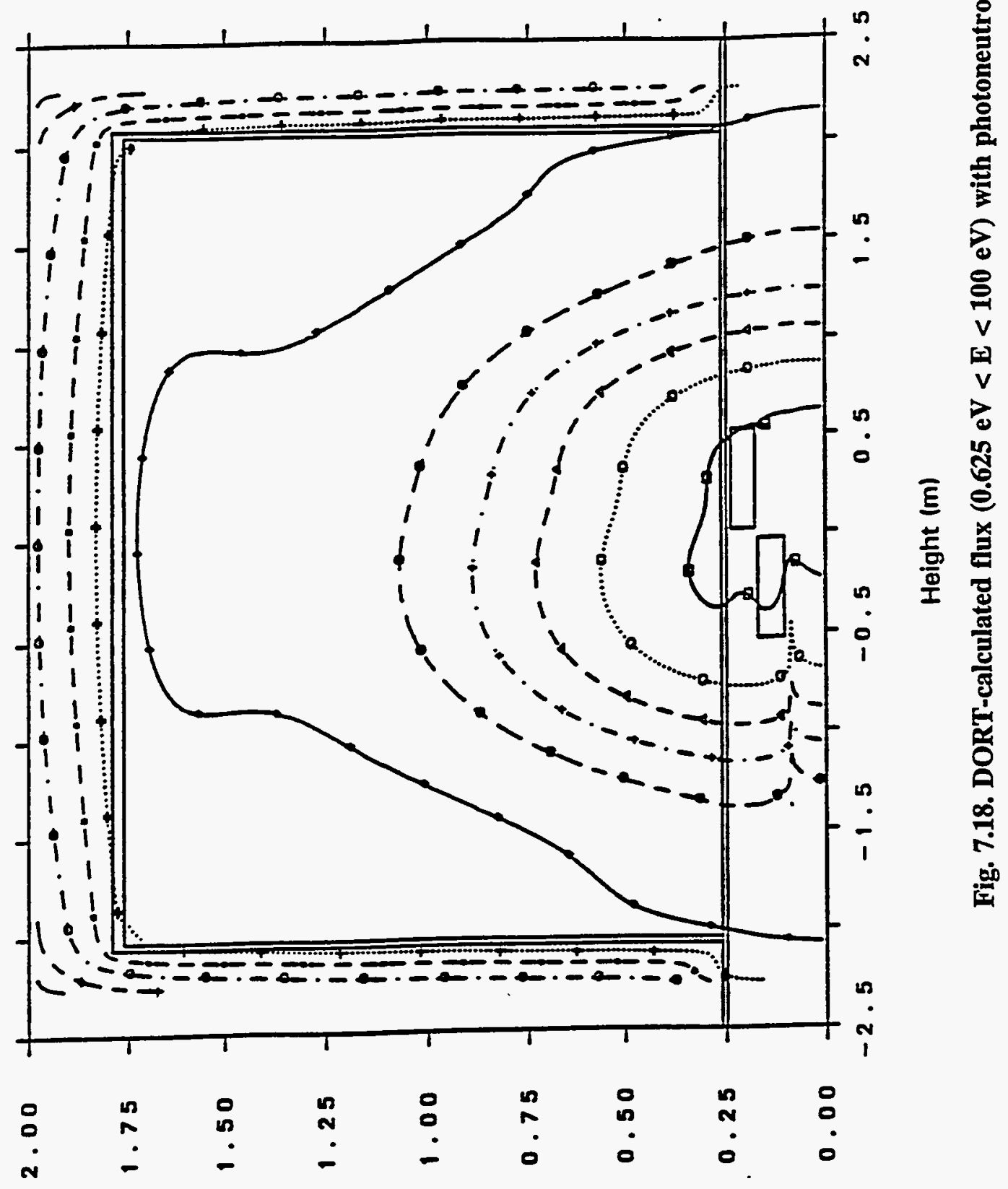

(w) sn!pey 


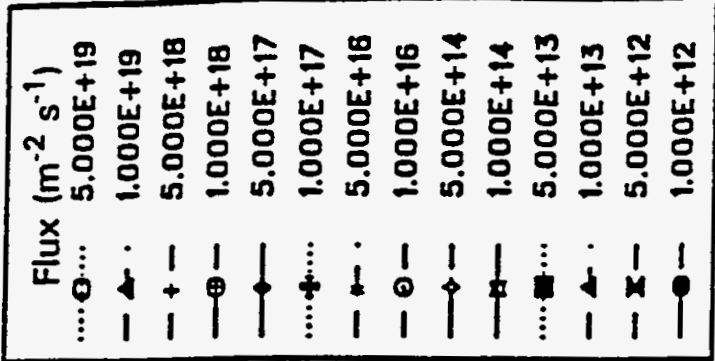

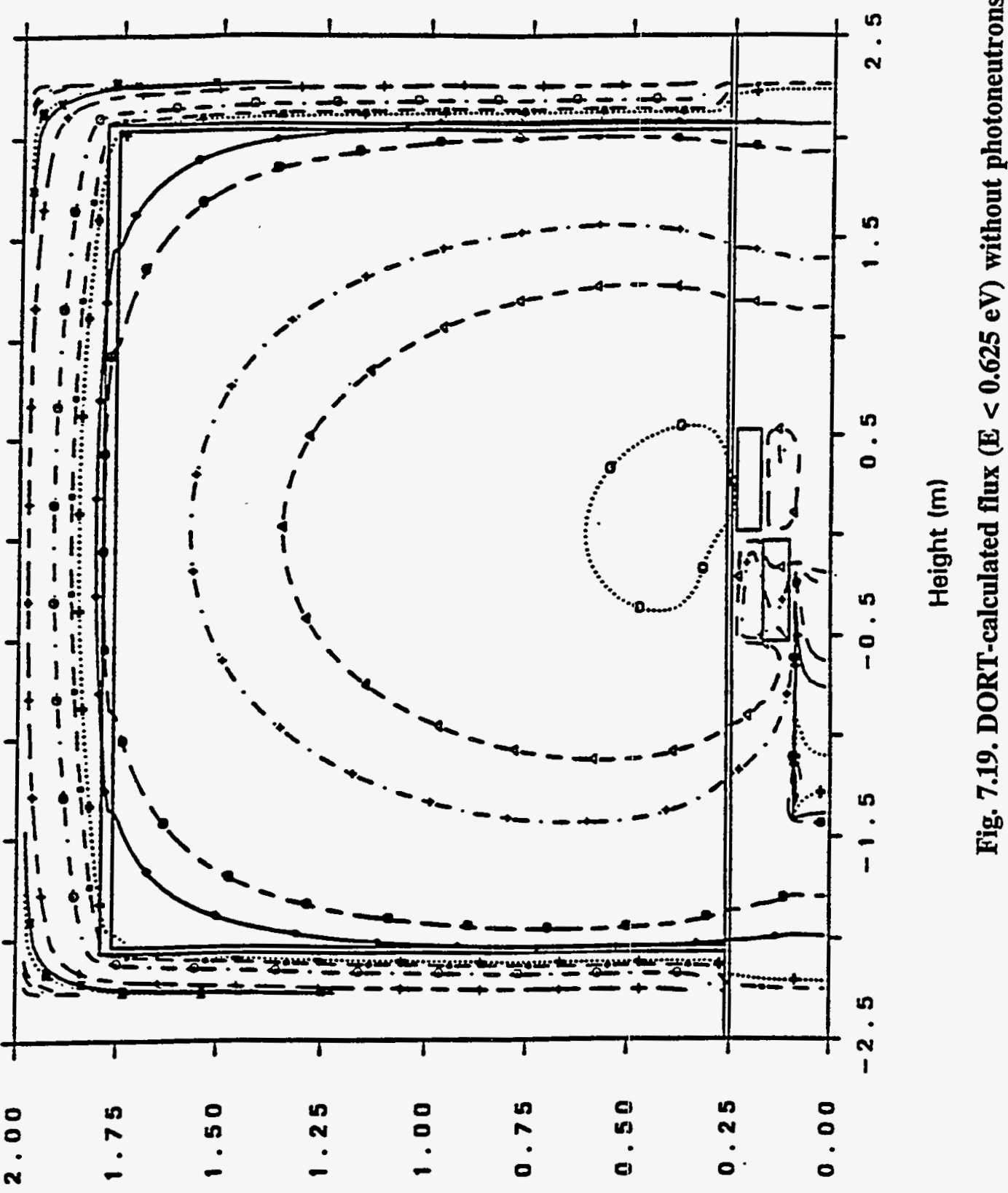

(w) sn!̣pey 


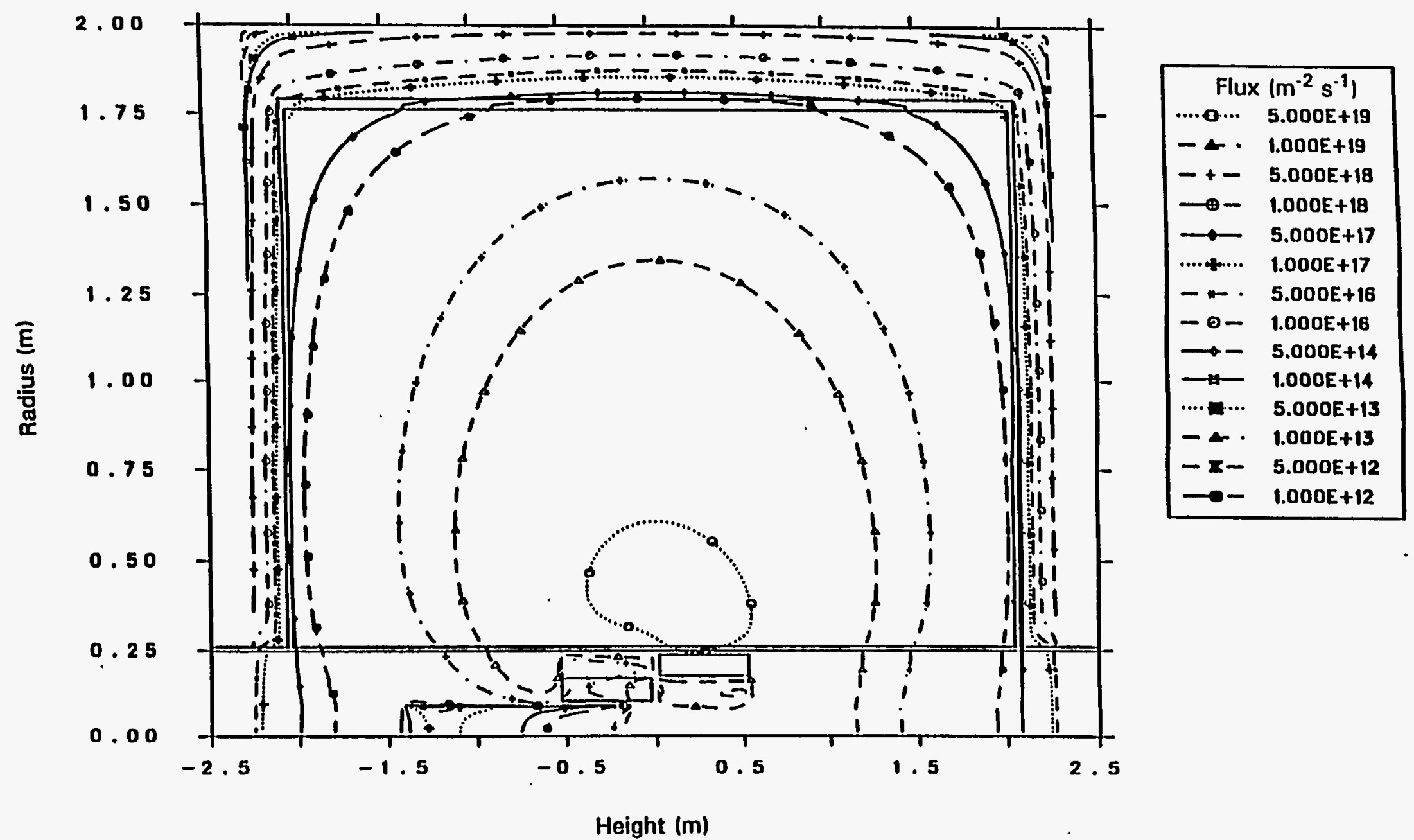

Fig. 7.20. DORT-calculated flux $(E<0.625 \mathrm{eV})$ with photoneutrons. 


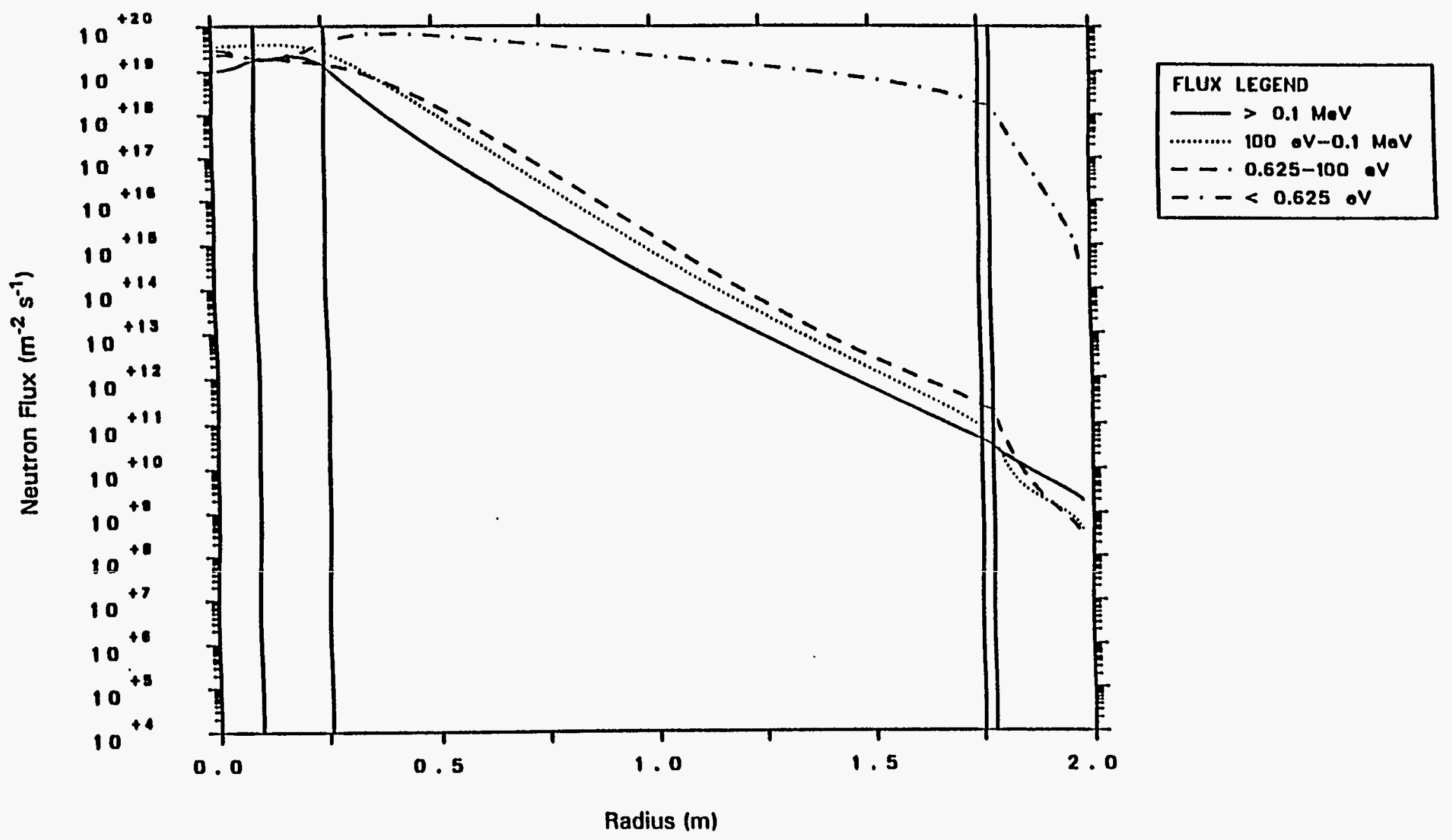

Fig. 7.21. DORT-calculated fluxes in a radial traverse at core midplane without photoneutrons. 

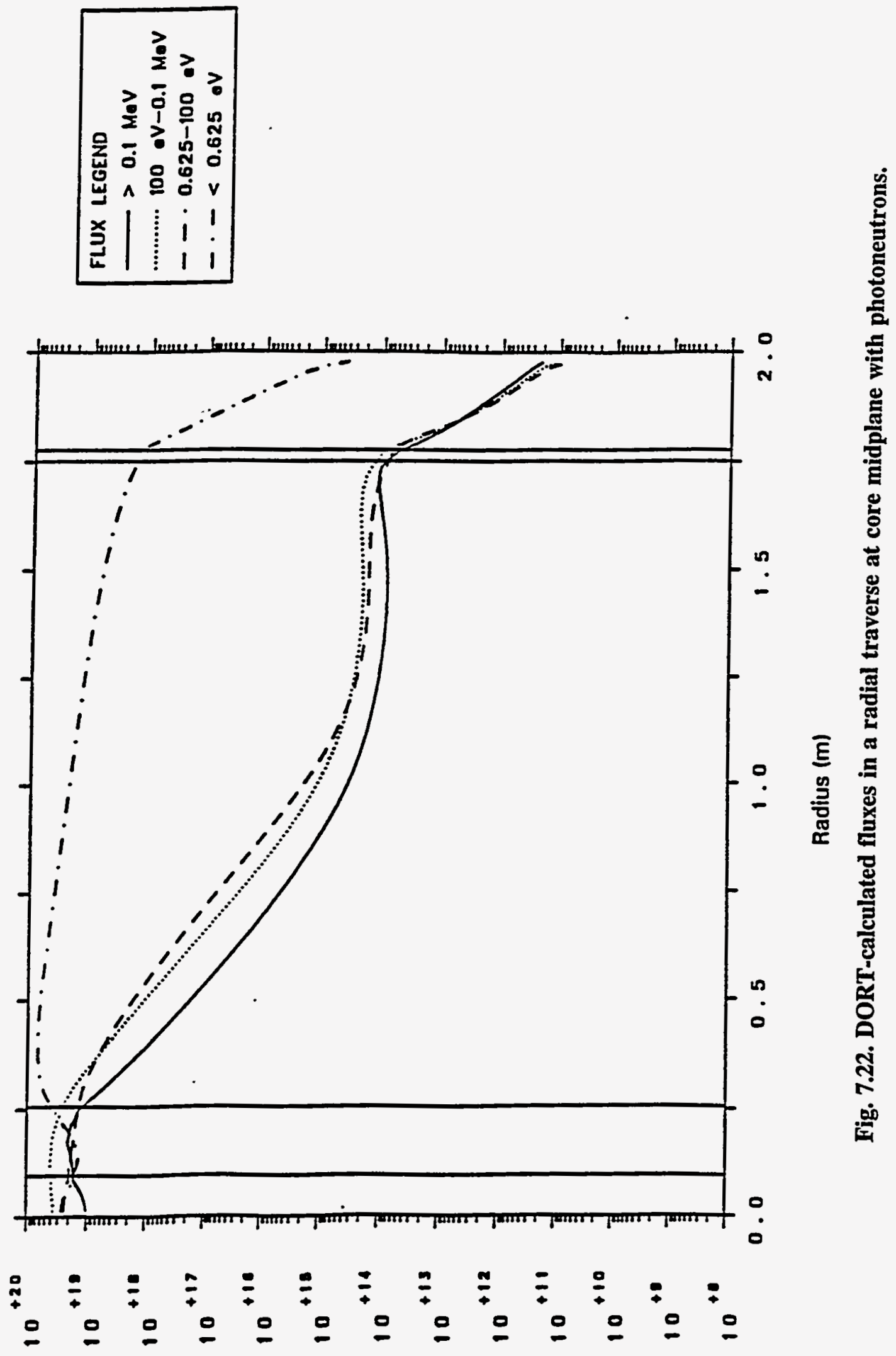

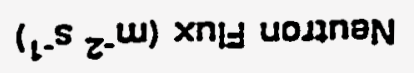


Table 7.1. Key unperturbed flux data as calculated by VENTURE (neutron fluxes) and DORT (gamma fluxes)

\begin{tabular}{|c|c|c|c|c|c|c|c|}
\hline & \multicolumn{4}{|c|}{ Beginning of cycle } & \multirow{2}{*}{\multicolumn{3}{|c|}{$\begin{array}{l}\text { End of cycle } \\
\text { neutron flux } \\
\left(10^{19} \mathrm{~m}^{-2} \cdot \mathrm{s}^{-1}\right)\end{array}$}} \\
\hline & \multicolumn{3}{|c|}{$\begin{array}{l}\text { Neutron flux } \\
\left(10^{19} \mathrm{~m}^{-2} \cdot \mathrm{s}^{-1}\right)\end{array}$} & \multirow{2}{*}{$\begin{array}{l}\text { Gamma flux } \\
\left(10^{19} \mathrm{~m}^{-2} \cdot \mathrm{s}^{-1}\right)\end{array}$} & & & \\
\hline & Fast $^{a}$ & Epithermal $^{b}$ & Thermal $^{c}$ & & Fast $^{a}$ & Epithermal $^{b}$ & Thermal $^{c}$ \\
\hline \multicolumn{8}{|l|}{ Fixed irradiation facilities } \\
\hline In-core & 1.2 & 1.0 & 0.7 & 11.4 & 2.0 & 2.4 & 4.2 \\
\hline Reflector vessel slant tubes (SH-1, SH-2) & 0.3 & 0.7 & 4.1 & 6.5 & 0.4 & 1.1 & 6.4 \\
\hline Transuranium production positions & 2.0 & 1.8 & 3.9 & 12.5 & 1.1 & 1.2 & 3.8 \\
\hline Reflector vessel production (VT-1) & & & 0.7 & 0.04 & & & 0.8 \\
\hline \multicolumn{8}{|l|}{ Rabbit tubes } \\
\hline Epithermal isotope production & 0.5 & 0.86 & 3.6 & 7.2 & 0.8 & 1.4 & 5.8 \\
\hline Materials analysis (40 mL \#1) (PT-1) & & & 0.3 & 0.04 & & & 0.3 \\
\hline Materials analysis (40 mL \#2-5) (PT-2) & & & 0.05 & & & & 0.07 \\
\hline Light water pool rabbit (\#1) (PF-1) & & & 0.05 & 0.04 & & & 0.05 \\
\hline Light water pool rabbit (\#2) (PF-2) & & & 0.02 & 0.04 & & & 0.03 \\
\hline \multicolumn{8}{|l|}{ Components (typical) } \\
\hline CPBT & 1.1 & 1.2 & 3.4 & 19.0 & 1.1 & 1.3 & 5.0 \\
\hline Beam tube nose & 0.02 & 0.3 & 5.5 & 3.6 & 0.03 & 0.3 & 6.6 \\
\hline Cold source vessel & & 0.1 & 5.0 & 5.2 & & 0.2 & 6.1 \\
\hline Reflector vessel wall (midplane) & & & 0.2 & & & & 0.2 \\
\hline
\end{tabular}

${ }^{\sigma} \mathrm{E}>0.1 \mathrm{MeV}$.

${ }^{b} 0.625 \mathrm{eV}<\mathrm{E}<100 \mathrm{eV}$.

$\mathrm{E}<0.625 \mathrm{eV}$. 
Table 7.2a. Relative fission power distribution in upper element at $0.0 \mathrm{~d}^{a}$

\begin{tabular}{|c|c|c|c|c|c|c|c|c|c|c|c|c|c|}
\hline \multirow{2}{*}{$\begin{array}{c}\text { Distance from top } \\
\text { of element } \\
(\mathrm{mm})\end{array}$} & \multicolumn{13}{|c|}{ Radial distance (in $\mathrm{mm}$ ) within element } \\
\hline & 1.88 & 5.63 & 9.38 & 13.13 & 18.75 & 26.25 & 33.75 & 39.38 & 43.12 & 46.88 & 50.62 & 54.38 & 58.12 \\
\hline 5.00 & 0.45 & 0.42 & 0.40 & 0.39 & 0.40 & 0.41 & 0.44 & 0.45 & 0.48 & 0.52 & 0.55 & 0.59 & 0.63 \\
\hline 15.00 & 0.47 & 0.46 & 0.45 & 0.44 & 0.44 & 0.45 & 0.48 & 0.49 & 0.51 & 0.57 & 0.60 & 0.63 & 0.66 \\
\hline 25.00 & 0.50 & 0.49 & 0.49 & 0.48 & 0.49 & 0.50 & 0.53 & 0.53 & 0.55 & 0.61 & 0.64 & 0.67 & 0.70 \\
\hline 40.00 & 0.54 & 0.54 & 0.54 & 0.54 & 0.55 & 0.56 & 0.59 & 0.59 & 0.61 & 0.66 & 0.69 & 0.72 & 0.75 \\
\hline 70.00 & 0.61 & 0.61 & 0.60 & 0.59 & 0.55 & 0.60 & 0.68 & 0.67 & 0.69 & 0.76 & 0.79 & 0.82 & 0.86 \\
\hline 121.75 & 0.71 & 0.67 & 0.65 & 0.63 & 0.59 & 0.64 & 0.75 & 0.82 & 0.84 & 0.93 & 0.97 & 1.01 & 1.06 \\
\hline 173.50 & 0.77 & 0.72 & 0.69 & 0.68 & 0.63 & 0.68 & 0.79 & 0.86 & 0.95 & 1.05 & 1.10 & 1.16 & 1.23 \\
\hline 213.50 & 0.83 & 0.78 & 0.74 & 0.73 & 0.67 & 0.72 & 0.83 & 0.91 & 1.00 & 1.16 & 1.22 & 1.29 & 1.36 \\
\hline 253.50 & 0.89 & 0.83 & 0.80 & 0.77 & 0.71 & 0.76 & 0.87 & 0.95 & 1.04 & 1.26 & 1.33 & 1.41 & 1.50 \\
\hline 293.50 & 0.97 & 0.90 & 0.86 & 0.83 & 0.75 & 0.80 & 0.91 & 0.99 & 1.09 & 1.36 & 1.44 & 1.53 & 1.64 \\
\hline 333.50 & 1.07 & 0.99 & 0.94 & 0.90 & 0.80 & 0.84 & 0.95 & 1.03 & 1.13 & 1.46 & 1.55 & 1.65 & 1.78 \\
\hline 369.38 & 1.19 & 1.10 & 1.03 & 0.97 & 0.85 & 0.89 & 0.99 & 1.07 & 1.18 & 1.55 & 1.65 & 1.76 & 1.91 \\
\hline 401.13 & 1.31 & 1.19 & 1.11 & 1.04 & 0.90 & 0.93 & 1.04 & 1.12 & 1.22 & 1.62 & 1.73 & 1.87 & 2.02 \\
\hline 427.00 & 1.39 & 1.26 & 1.17 & 1.09 & 0.95 & 0.97 & 1.08 & 1.16 & 1.27 & 1.68 & 1.80 & 1.95 & 2.12 \\
\hline 447.00 & 1.46 & 1.33 & 1.23 & 1.15 & 0.99 & 1.01 & 1.13 & 1.22 & 1.33 & 1.74 & 1.87 & 2.03 & 2.21 \\
\hline 462.00 & 1.49 & 1.36 & 1.25 & 1.17 & 1.01 & 1.03 & 1.15 & 1.24 & 1.36 & 1.75 & 1.89 & 2.06 & 2.25 \\
\hline 472.00 & 1.51 & 1.40 & 1.30 & 1.21 & 1.04 & 1.06 & 1.19 & 1.29 & 1.41 & 1.78 & 1.93 & 2.11 & 2.32 \\
\hline 479.50 & 1.50 & 1.42 & 1.32 & 1.23 & 1.05 & 1.08 & 1.21 & 1.31 & 1.44 & 1.78 & 1.94 & 2.13 & 2.34 \\
\hline 484.50 & 1.51 & 1.42 & 1.34 & 1.24 & 1.07 & 1.09 & 1.22 & 1.33 & 1.46 & 1.79 & 1.95 & 2.15 & 2.37 \\
\hline 489.50 & 1.52 & 1.42 & 1.35 & 1.27 & 1.09 & 1.11 & 1.25 & 1.35 & 1.49 & 1.79 & 1.97 & 2.17 & 2.41 \\
\hline 494.50 & 1.53 & 1.42 & 1.34 & 1.27 & 1.11 & 1.13 & 1.26 & 1.37 & 1.50 & 1.78 & 1.97 & 2.19 & 2.44 \\
\hline 499.50 & 1.55 & 1.42 & 1.33 & 1.25 & 1.23 & 1.25 & 1.36 & 1.44 & 1.55 & 1.75 & 1.95 & 2.19 & 2.47 \\
\hline 504.50 & 1.55 & 1.40 & 1.30 & 1.22 & 1.20 & 1.22 & 1.33 & 1.40 & 1.51 & 1.71 & 1.91 & 2.16 & 2.49 \\
\hline
\end{tabular}

${ }^{a}$ Average power density of element: $4.169 \mathrm{MW} / \mathrm{L}$ 
Table 7.2b. Relative fission power distribution in lower element at $0.0 \mathrm{~d}^{a}$

\begin{tabular}{|c|c|c|c|c|c|c|c|c|c|c|c|c|c|}
\hline \multirow{2}{*}{$\begin{array}{l}\text { Distance from top } \\
\text { of element } \\
\text { (mm) }\end{array}$} & \multicolumn{13}{|c|}{ Radial distance (in $\mathrm{mm}$ ) within element } \\
\hline & 2.06 & 6.19 & 10.31 & 14.44 & 20.62 & 28.88 & 37.12 & 43.31 & 47.44 & 51.56 & 55.69 & 59.81 & 63.94 \\
\hline 5.00 & 0.48 & 0.45 & 0.42 & 0.39 & 0.39 & 0.37 & 0.39 & 0.40 & 0.42 & 0.45 & 0.48 & 0.52 & 0.5 \\
\hline 15.00 & 0.51 & 0.49 & 0.47 & 0.45 & 0.42 & 0.42 & 0.43 & 0.45 & 0.46 & 0.52 & 0.55 & 0.58 & 0.6 \\
\hline 25.00 & 0.55 & 0.53 & 0.51 & 0.50 & 0.47 & 0.47 & 0.49 & 0.50 & 0.52 & 0.58 & 0.61 & 0.64 & 0.6 \\
\hline 40.00 & 0.60 & 0.58 & 0.57 & 0.56 & 0.53 & 0.54 & 0.56 & 0.57 & 0.59 & 0.66 & 0.69 & 0.73 & 0.7 \\
\hline 70.00 & 0.70 & 0.68 & 0.66 & 0.65 & 0.62 & 0.64 & 0.66 & 0.68 & 0.70 & 0.79 & 0.83 & 0.87 & 0.9 \\
\hline 121.75 & 0.86 & 0.84 & 0.82 & 0.80 & 0.77 & 0.78 & 0.81 & 0.82 & 0.84 & 0.95 & 1.00 & 1.05 & 1.1 \\
\hline 173.50 & 1.02 & 0.98 & 0.96 & 0.94 & 0.90 & 0.92 & 0.95 & 0.96 & 0.99 & 1.11 & 1.16 & 1.22 & 1.3 \\
\hline 213.50 & 1.13 & 1.09 & 1.06 & 1.03 & 0.99 & 1.00 & 1.04 & 1.04 & 1.07 & 1.21 & 1.27 & 1.34 & 1.4 \\
\hline 253.50 & 1.22 & 1.17 & 1.13 & 1.09 & 0.97 & 1.02 & 1.11 & 1.11 & 1.14 & 1.29 & 1.36 & 1.44 & 1.5 \\
\hline 293.50 & 1.29 & 1.17 & 1.09 & 1.02 & 0.90 & 0.94 & 1.05 & 1.14 & 1.20 & 1.34 & 1.43 & 1.53 & 1.6 \\
\hline 333.50 & 1.23 & 1.12 & 1.03 & 0.97 & 0.85 & 0.88 & 0.98 & 1.06 & 1.16 & 1.40 & 1.49 & 1.59 & 1.7 \\
\hline 369.38 & 1.18 & 1.07 & 0.99 & 0.92 & 0.81 & 0.82 & 0.92 & 0.99 & 1.08 & 1.42 & 1.51 & 1.63 & 1.7 \\
\hline 401.12 & 1.15 & 1.04 & 0.95 & 0.88 & 0.77 & 0.78 & 0.87 & 0.94 & 1.02 & 1.37 & 1.53 & 1.65 & 1.8 \\
\hline 427.00 & 1.14 & 1.02 & 0.93 & 0.86 & 0.75 & 0.75 & 0.83 & 0.89 & 0.98 & 1.31 & 1.49 & 1.65 & 1.8 \\
\hline 447.00 & 1.17 & 1.04 & 0.95 & 0.86 & 0.74 & 0.74 & 0.81 & 0.87 & 0.96 & 1.28 & 1.46 & 1.65 & 1.8 \\
\hline 462.00 & 1.19 & 1.06 & 0.96 & 0.87 & 0.74 & 0.73 & 0.80 & 0.87 & 0.95 & 1.27 & 1.45 & 1.65 & 1.8 \\
\hline 472.00 & 1.24 & 1.10 & 0.99 & 0.89 & 0.76 & 0.74 & 0.81 & 0.87 & 0.95 & 1.28 & 1.47 & 1.65 & 1.8 \\
\hline 479.50 & 1.27 & 1.12 & 1.00 & 0.90 & 0.76 & 0.74 & 0.81 & 0.87 & 0.95 & 1.29 & 1.48 & 1.65 & 1.8 \\
\hline 484.50 & 1.30 & 1.14 & 1.02 & 0.92 & 0.77 & 0.75 & 0.82 & 0.88 & 0.96 & 1.30 & 1.49 & 1.65 & 1.8 \\
\hline 489.50 & 1.34 & 1.17 & 1.05 & 0.94 & 0.79 & 0.76 & 0.82 & 0.88 & 0.97 & 1.31 & 1.49 & 1.65 & 1.8 \\
\hline 494.50 & 1.39 & 1.20 & 1.07 & 0.95 & 0.80 & 0.76 & 0.83 & 0.89 & 0.97 & 1.33 & 1.47 & 1.64 & 1.8 \\
\hline 499.50 & 1.47 & 1.26 & 1.12 & 1.00 & 0.95 & 0.91 & 0.98 & 1.05 & 1.15 & 1.31 & 1.45 & 1.63 & 1.8 \\
\hline 504.50 & 1.51 & 1.29 & 1.14 & 1.03 & 0.98 & 0.94 & 1.01 & 1.06 & 1.13 & 1.26 & 1.41 & 1.60 & 1.8 \\
\hline
\end{tabular}

\footnotetext{
${ }^{a}$ Average power density of element: $5.871 \mathrm{MW} / \mathrm{L}$.
} 
Table 7.3a. Relative fission power distribution in upper element at $4.25 \mathrm{~d}^{\boldsymbol{z}}$

\begin{tabular}{|c|c|c|c|c|c|c|c|c|c|c|c|c|c|}
\hline \multirow{2}{*}{$\begin{array}{l}\text { Distance from top } \\
\text { of element } \\
\text { (mm) }\end{array}$} & \multicolumn{13}{|c|}{ Radial distance (in mm) within element } \\
\hline & 1.88 & 5.62 & 9.38 & 13.12 & 18.75 & 26.25 & 33.75 & 39.38 & 43.12 & 46.88 & 50.62 & 54.38 & 58.12 \\
\hline 5.00 & 0.51 & 0.49 & 0.49 & 0.48 & 0.49 & 0.50 & 0.52 & 0.52 & 0.53 & 0.56 & 0.58 & 0.60 & 0.62 \\
\hline 15.00 & 0.52 & 0.52 & 0.51 & 0.51 & 0.51 & 0.52 & 0.54 & 0.54 & 0.55 & 0.59 & 0.61 & 0.63 & 0.65 \\
\hline 25.00 & 0.54 & 0.54 & 0.53 & 0.53 & 0.54 & 0.56 & 0.58 & 0.57 & 0.58 & 0.62 & 0.64 & 0.66 & 0.67 \\
\hline 40.00 & 0.57 & 0.57 & 0.57 & 0.57 & 0.58 & 0.60 & 0.62 & 0.61 & 0.63 & 0.67 & 0.68 & 0.70 & 0.71 \\
\hline 70.00 & 0.63 & 0.62 & 0.61 & 0.61 & 0.56 & 0.62 & 0.70 & 0.68 & 0.69 & 0.74 & 0.76 & 0.78 & 0.80 \\
\hline 121.75 & 0.69 & 0.65 & 0.63 & 0.62 & 0.58 & 0.63 & 0.74 & 0.81 & 0.82 & 0.89 & 0.91 & 0.94 & 0.97 \\
\hline 173.50 & 0.74 & 0.70 & 0.67 & 0.66 & 0.62 & 0.67 & 0.77 & 0.84 & 0.93 & 1.00 & 1.04 & 1.07 & 1.11 \\
\hline 213.50 & 0.80 & 0.75 & 0.72 & 0.71 & 0.65 & 0.71 & 0.81 & 0.89 & 0.97 & 1.10 & 1.14 & 1.18 & 1.22 \\
\hline 253.50 & 0.86 & 0.81 & 0.77 & 0.75 & 0.70 & 0.75 & 0.86 & 0.93 & 1.02 & 1.20 & 1.24 & 1.29 & 1.34 \\
\hline 293.50 & 0.94 & 0.88 & 0.84 & 0.81 & 0.74 & 0.79 & 0.90 & 0.97 & 1.06 & 1.29 & 1.34 & 1.40 & 1.46 \\
\hline 333.50 & 1.06 & 0.98 & 0.93 & 0.89 & 0.80 & 0.84 & 0.95 & 1.02 & 1.12 & 1.40 & 1.46 & 1.52 & 1.58 \\
\hline 369.38 & 1.19 & 1.10 & 1.03 & 0.98 & $0.86^{\circ}$ & 0.90 & 1.00 & 1.08 & 1.17 & 1.49 & 1.56 & 1.63 & 1.70 \\
\hline 401.13 & 1.32 & 1.21 & 1.13 & 1.06 & 0.93 & 0.96 & 1.06 & 1.14 & 1.23 & 1.58 & 1.65 & 1.73 & 1.81 \\
\hline 427.00 & 1.43 & 1.31 & 1.22 & 1.14 & 1.00 & 1.02 & 1.13 & 1.20 & 1.30 & 1.65 & 1.73 & 1.81 & 1.90 \\
\hline 447.00 & 1.54 & 1.41 & 1.32 & 1.23 & 1.08 & 1.09 & 1.20 & 1.28 & 1.39 & 1.74 & 1.81 & 1.90 & 1.99 \\
\hline 462.00 & 1.58 & 1.46 & 1.37 & 1.28 & 1.12 & 1.13 & 1.25 & 1.33 & 1.43 & 1.75 & 1.84 & 1.93 & 2.02 \\
\hline 472.00 & 1.65 & 1.56 & 1.46 & 1.38 & 1.20 & 1.22 & 1.34 & 1.42 & 1.53 & 1.83 & 1.91 & 2.01 & 2.10 \\
\hline 479.50 & 1.66 & 1.60 & 1.51 & 1.43 & 1.24 & 1.27 & 1.39 & 1.47 & 1.57 & 1.85 & 1.93 & 2.03 & 2.12 \\
\hline 484.50 & 1.69 & 1.62 & 1.57 & 1.48 & 1.29 & 1.32 & 1.44 & 1.52 & 1.63 & 1.88 & 1.97 & 2.06 & 2.15 \\
\hline 489.50 & 1.73 & 1.67 & 1.63 & 1.58 & 1.38 & 1.42 & 1.54 & 1.62 & 1.72 & 1.94 & 2.02 & 2.11 & 2.20 \\
\hline 494.50 & 1.77 & 1.71 & 1.67 & 1.64 & 1.46 & 1.51 & 1.63 & 1.71 & 1.80 & 1.98 & 2.06 & 2.15 & 2.23 \\
\hline 499.50 & 1.81 & 1.76 & 1.73 & 1.71 & 1.71 & 1.77 & 1.85 & 1.88 & 1.94 & 2.04 & 2.11 & 2.19 & 2.27 \\
\hline 504.50 & 1.85 & 1.82 & 1.80 & 1.78 & 1.80 & 1.85 & 1.94 & 1.96 & 2.01 & 2.11 & 2.17 & 2.24 & 2.31 \\
\hline
\end{tabular}

${ }^{a}$ Average power density of element: $4.295 \mathrm{MW} / \mathrm{L}$. 
Table 7.3b. Relative fission power distribution in lower element at $4.25 \mathrm{~d}^{a}$

\begin{tabular}{|c|c|c|c|c|c|c|c|c|c|c|c|c|c|}
\hline \multirow{2}{*}{$\begin{array}{l}\text { Distance from top } \\
\text { of element } \\
\text { (mm) }\end{array}$} & \multicolumn{13}{|c|}{ Radial distance (in $\mathrm{mm}$ ) within element } \\
\hline & 2.06 & 6.19 & 10.31 & 14.44 & 20.62 & 28.88 & 37.12 & 43.31 & 47.44 & 51.56 & 55.69 & 59.81 & 63.94 \\
\hline 5.00 & 0.54 & 0.52 & 0.51 & 0.49 & 0.49 & 0.48 & 0.49 & 0.50 & 0.52 & 0.54 & 0.56 & 0.58 & 0.60 \\
\hline 15.00 & 0.56 & 0.54 & 0.53 & 0.52 & 0.50 & 0.50 & 0.52 & 0.52 & 0.53 & 0.58 & 0.59 & 0.61 & 0.63 \\
\hline 25.00 & 0.58 & 0.57 & 0.56 & 0.55 & 0.54 & 0.54 & 0.55 & 0.56 & 0.57 & 0.61 & 0.63 & 0.65 & 0.66 \\
\hline 40.00 & 0.62 & 0.61 & 0.60 & 0.60 & 0.58 & 0.59 & 0.60 & 0.61 & 0.62 & 0.67 & 0.68 & 0.70 & 0.72 \\
\hline 70.00 & 0.70 & 0.69 & 0.68 & 0.68 & 0.66 & 0.66 & 0.68 & 0.69 & 0.70 & 0.75 & 0.77 & 0.79 & 0.81 \\
\hline 121.75 & 0.85 & 0.83 & 0.82 & 0.82 & 0.80 & 0.81 & 0.82 & 0.82 & 0.83 & 0.89 & 0.90 & 0.92 & 0.94 \\
\hline 173.50 & 0.97 & 0.96 & 0.94 & 0.93 & 0.92 & 0.93 & 0.95 & 0.95 & 0.96 & 1.02 & 1.04 & 1.06 & 1.08 \\
\hline 213.50 & 1.07 & 1.05 & 1.03 & 1.02 & 1.00 & 1.02 & 1.04 & 1.03 & 1.04 & 1.12 & 1.14 & 1.16 & 1.19 \\
\hline 253.50 & 1.15 & 1.13 & 1.10 & 1.08 & 0.98 & 1.03 & 1.11 & 1.10 & 1.12 & 1.20 & 1.23 & 1.26 & 1.28 \\
\hline 293.50 & 1.22 & 1.13 & 1.06 & 1.01 & 0.90 & 0.95 & 1.06 & 1.13 & 1.18 & 1.26 & 1.30 & 1.34 & 1.38 \\
\hline 333.50 & 1.17 & 1.08 & 1.01 & 0.96 & 0.85 & 0.89 & 0.99 & 1.07 & 1.16 & 1.33 & 1.38 & 1.42 & 1.46 \\
\hline 369.38 & 1.14 & 1.05 & 0.98 & 0.92 & 0.82 & 0.84 & 0.94 & 1.00 & 1.09 & 1.37 & 1.42 & 1.48 & 1.53 \\
\hline 401.12 & 1.14 & 1.04 & 0.96 & 0.90 & 0.80 & 0.81 & 0.90 & 0.96 & 1.04 & 1.35 & 1.47 & 1.53 & 1.59 \\
\hline 427.00 & 1.18 & 1.07 & 0.99 & 0.91 & 0.80 & 0.80 & 0.88 & 0.94 & 1.02 & 1.32 & 1.46 & 1.57 & 1.63 \\
\hline 447.00 & 1.24 & 1.13 & 1.04 & 0.95 & 0.83 & 0.82 & 0.90 & 0.96 & 1.03 & 1.33 & 1.48 & 1.61 & 1.68 \\
\hline 462.00 & 1.28 & 1.16 & 1.07 & 0.98 & 0.85 & 0.84 & 0.92 & 0.97 & 1.05 & 1.36 & 1.50 & 1.64 & 1.71 \\
\hline 472.00 & 1.37 & 1.24 & 1.14 & 1.05 & 0.91 & 0.90 & 0.97 & 1.02 & 1.10 & 1.41 & 1.56 & 1.68 & 1.75 \\
\hline 479.50 & 1.41 & 1.28 & 1.18 & 1.09 & 0.94 & 0.93 & 1.00 & 1.05 & 1.13 & 1.45 & 1.59 & 1.69 & 1.76 \\
\hline 484.50 & 1.46 & 1.33 & 1.23 & 1.14 & 0.98 & 0.97 & 1.04 & 1.09 & 1.17 & 1.49 & 1.63 & 1.71 & 1.78 \\
\hline 489.50 & 1.53 & 1.40 & 1.31 & 1.22 & 1.05 & 1.04 & 1.11 & 1.16 & 1.23 & 1.56 & 1.68 & 1.75 & 1.82 \\
\hline 494.50 & 1.60 & 1.47 & 1.38 & 1.30 & 1.13 & 1.12 & 1.18 & 1.23 & 1.30 & 1.64 & 1.71 & 1.78 & 1.84 \\
\hline 499.50 & 1.70 & 1.59 & 1.51 & 1.44 & 1.42 & 1.41 & 1.49 & 1.54 & 1.62 & 1.70 & 1.76 & 1.81 & 1.87 \\
\hline 504.50 & 1.78 & 1.71 & 1.65 & 1.60 & 1.58 & 1.58 & 1.65 & 1.68 & 1.71 & 1.77 & 1.81 & 1.85 & 1.90 \\
\hline
\end{tabular}

${ }^{a}$ Average power density of element: $5.698 \mathrm{MW} / \mathrm{L}$. 
Table 7.4a. Relative fission power distribution in upper element at $8.5 \mathrm{~d}^{a}$

\begin{tabular}{|c|c|c|c|c|c|c|c|c|c|c|c|c|c|}
\hline \multirow{2}{*}{$\begin{array}{l}\text { Distance from top } \\
\text { of element } \\
\text { (mm) }\end{array}$} & \multicolumn{13}{|c|}{ Radial distance (in $\mathrm{mm}$ ) within element } \\
\hline & 1.88 & 5.62 & 9.38 & 13.12 & 18.75 & 26.25 & 33.75 & 39.38 & 43.12 & 46.88 & 50.62 & 54.38 & 58.12 \\
\hline 5.00 & 0.55 & 0.56 & 0.56 & 0.57 & 0.58 & 0.59 & 0.59 & 0.58 & 0.58 & 0.58 & 0.58 & 0.58 & 0.58 \\
\hline 15.00 & 0.56 & 0.57 & 0.57 & 0.57 & 0.59 & 0.59 & 0.60 & 0.58 & 0.58 & 0.60 & 0.60 & 0.60 & 0.60 \\
\hline 25.00 & 0.58 & 0.58 & 0.58 & 0.59 & 0.60 & 0.61 & 0.62 & 0.60 & 0.60 & 0.62 & 0.62 & 0.62 & 0.62 \\
\hline 40.00 & 0.61 & 0.61 & 0.61 & 0.62 & 0.63 & 0.64 & 0.65 & 0.63 & 0.63 & 0.65 & 0.65 & 0.65 & 0.65 \\
\hline 70.00 & 0.65 & 0.65 & 0.64 & 0.64 & 0.59 & 0.65 & 0.71 & 0.69 & 0.69 & 0.71 & 0.71 & 0.71 & 0.71 \\
\hline 121.75 & 0.68 & 0.65 & 0.63 & 0.62 & 0.59 & 0.64 & 0.74 & 0.79 & 0.80 & 0.83 & 0.84 & 0.84 & 0.85 \\
\hline 173.50 & 0.73 & 0.70 & 0.68 & 0.67 & 0.62 & 0.67 & 0.77 & 0.83 & 0.90 & 0.94 & 0.95 & 0.95 & 0.96 \\
\hline 213.50 & 0.79 & 0.75 & 0.73 & 0.72 & 0.67 & 0.72 & 0.82 & 0.87 & 0.95 & 1.03 & 1.04 & 1.05 & 1.05 \\
\hline 253.50 & 0.87 & 0.83 & 0.80 & 0.78 & 0.72 & 0.76 & 0.86 & 0.92 & 0.99 & 1.12 & 1.13 & 1.14 & 1.14 \\
\hline 293.50 & 0.98 & 0.93 & 0.89 & 0.86 & 0.78 & 0.82 & 0.92 & 0.97 & 1.05 & 1.22 & 1.23 & 1.24 & 1.24 \\
\hline 333.50 & 1.14 & 1.07 & 1.01 & 0.97 & 0.86 & 0.89 & 0.98 & 1.04 & 1.11 & 1.33 & 1.34 & 1.35 & 1.35 \\
\hline 369.38 & 1.30 & 1.21 & 1.14 & 1.08 & 0.95 & 0.97 & 1.05 & 1.11 & 1.18 & 1.43 & 1.44 & 1.44 & 1.45 \\
\hline 401.13 & 1.43 & 1.33 & 1.25 & 1.18 & 1.04 & 1.04 & 1.13 & 1.18 & 1.25 & 1.52 & 1.53 & 1.54 & 1.53 \\
\hline 427.00 & 1.54 & 1.44 & 1.36 & 1.28 & 1.12 & 1.12 & 1.20 & 1.25 & 1.32 & 1.60 & 1.60 & 1.61 & 1.60 \\
\hline 447.00 & 1.67 & 1.57 & 1.48 & 1.40 & 1.23 & 1.22 & 1.30 & 1.35 & 1.42 & 1.68 & 1.68 & 1.68 & 1.67 \\
\hline 462.00 & 1.71 & 1.62 & 1.54 & 1.45 & 1.28 & 1.27 & 1.35 & 1.40 & 1.47 & 1.69 & 1.70 & 1.70 & 1.68 \\
\hline 472.00 & 1.79 & 1.75 & 1.66 & 1.59 & 1.40 & 1.39 & 1.47 & 1.52 & 1.58 & 1.77 & 1.77 & 1.76 & 1.74 \\
\hline 479.50 & 1.81 & 1.79 & 1.72 & 1.64 & 1.45 & 1.45 & 1.53 & 1.57 & 1.63 & 1.78 & 1.78 & 1.77 & 1.74 \\
\hline 484.50 & 1.84 & 1.82 & 1.79 & 1.72 & 1.52 & 1.52 & 1.60 & 1.64 & 1.70 & 1.82 & 1.81 & 1.79 & 1.76 \\
\hline 489.50 & 1.89 & 1.88 & 1.87 & 1.84 & 1.63 & 1.65 & 1.72 & 1.75 & 1.80 & 1.87 & 1.86 & 1.83 & 1.79 \\
\hline 494.50 & 1.92 & 1.92 & 1.93 & 1.92 & 1.74 & 1.76 & 1.83 & 1.85 & 1.89 & 1.91 & 1.89 & 1.85 & 1.81 \\
\hline 499.50 & 1.96 & 1.98 & 1.99 & 1.99 & 2.01 & 2.03 & 2.03 & 1.98 & 1.96 & 1.96 & 1.92 & 1.88 & 1.82 \\
\hline 504.50 & 2.00 & 2.03 & 2.06 & 2.07 & 2.09 & 2.10 & 2.10 & 2.05 & 2.03 & 2.01 & 1.97 & 1.91 & 1.84 \\
\hline
\end{tabular}

${ }^{a}$ Average power distance of element: $4.548 \mathrm{MW} / \mathrm{L}$. 
Table 7.4b. Relative fission power distribution in lower element at $8.5 \mathrm{~d}^{a}$

\begin{tabular}{|c|c|c|c|c|c|c|c|c|c|c|c|c|c|}
\hline \multirow{2}{*}{$\begin{array}{l}\text { Distance from top } \\
\text { of element } \\
\text { (mm) }\end{array}$} & \multicolumn{13}{|c|}{ Radial distance (in $\mathrm{mm}$ ) within element } \\
\hline & 2.06 & 6.19 & 10.31 & 14.44 & 20.62 & 28.88 & 37.12 & 43.31 & 47.44 & 51.56 & 55.69 & 59.81 & 63.94 \\
\hline 5.00 & 0.66 & 0.67 & 0.68 & 0.68 & 0.69 & 0.69 & 0.68 & 0.68 & 0.67 & 0.67 & 0.66 & 0.65 & 0.64 \\
\hline 15.00 & 0.67 & 0.67 & 0.68 & 0.68 & 0.67 & 0.67 & 0.67 & 0.66 & 0.66 & 0.67 & 0.66 & 0.65 & 0.65 \\
\hline 25.00 & 0.68 & 0.68 & 0.68 & 0.68 & 0.68 & 0.68 & 0.68 & 0.67 & 0.67 & 0.67 & 0.67 & 0.66 & 0.65 \\
\hline 40.00 & 0.71 & 0.71 & 0.71 & 0.70 & 0.70 & 0.70 & 0.70 & 0.69 & 0.68 & 0.69 & 0.68 & 0.67 & 0.67 \\
\hline 70.00 & 0.77 & 0.77 & 0.77 & 0.76 & 0.76 & 0.76 & 0.76 & 0.74 & 0.74 & 0.73 & 0.73 & 0.72 & 0.71 \\
\hline 121.75 & 0.87 & 0.88 & 0.88 & 0.88 & 0.87 & 0.87 & 0.87 & 0.85 & 0.84 & 0.84 & 0.83 & 0.81 & 0.80 \\
\hline 173.50 & 0.96 & 0.97 & 0.97 & 0.97 & 0.98 & 0.98 & 0.98 & 0.95 & 0.94 & 0.94 & 0.92 & 0.91 & 0.89 \\
\hline 213.50 & 1.04 & 1.05 & 1.06 & 1.06 & 1.06 & 1.07 & 1.07 & 1.03 & 1.02 & 1.02 & 1.01 & 0.99 & 0.96 \\
\hline 253.50 & 1.11 & 1.12 & 1.12 & 1.11 & 1.03 & 1.08 & 1.14 & 1.10 & 1.09 & 1.10 & 1.09 & 1.07 & 1.04 \\
\hline 293.50 & 1.17 & 1.11 & 1.07 & 1.03 & 0.94 & 0.99 & 1.09 & 1.14 & 1.16 & 1.17 & 1.16 & 1.14 & 1.12 \\
\hline 333.50 & 1.12 & 1.06 & 1.01 & 0.98 & 0.88 & 0.93 & 1.02 & 1.07 & 1.14 & 1.24 & 1.24 & 1.22 & 1.19 \\
\hline 369.38 & 1.09 & 1.03 & 0.98 & 0.94 & 0.85 & 0.88 & 0.97 & 1.02 & 1.09 & 1.30 & 1.29 & 1.28 & 1.26 \\
\hline 401.12 & 1.11 & 1.04 & 0.98 & 0.93 & 0.83 & 0.86 & 0.94 & 0.99 & 1.05 & 1.29 & 1.35 & 1.34 & 1.32 \\
\hline 427.00 & 1.15 & 1.08 & 1.02 & 0.96 & 0.86 & 0.86 & 0.94 & 0.99 & 1.05 & 1.29 & 1.37 & 1.40 & 1.38 \\
\hline 447.00 & 1.23 & 1.15 & 1.09 & 1.03 & 0.91 & 0.91 & 0.98 & 1.02 & 1.08 & 1.33 & 1.41 & 1.46 & 1.44 \\
\hline 462.00 & 1.27 & 1.19 & 1.13 & 1.07 & 0.94 & 0.94 & 1.01 & 1.05 & 1.11 & 1.36 & 1.44 & 1.49 & 1.46 \\
\hline 472.00 & 1.36 & 1.29 & 1.22 & 1.16 & 1.03 & 1.02 & 1.09 & 1.13 & 1.18 & 1.43 & 1.51 & 1.54 & 1.51 \\
\hline 479.50 & 1.39 & 1.33 & 1.27 & 1.21 & 1.07 & 1.07 & 1.13 & 1.17 & 1.22 & 1.47 & 1.54 & 1.55 & 1.51 \\
\hline 484.50 & 1.44 & 1.38 & 1.32 & 1.27 & 1.12 & 1.12 & 1.19 & 1.22 & 1.27 & 1.52 & 1.58 & 1.56 & 1.53 \\
\hline 489.50 & 1.51 & 1.45 & 1.41 & 1.37 & 1.22 & 1.22 & 1.28 & 1.31 & 1.35 & 1.60 & 1.63 & 1.60 & 1.55 \\
\hline 494.50 & 1.56 & 1.52 & 1.49 & 1.46 & 1.31 & 1.32 & 1.37 & 1.39 & 1.43 & 1.67 & 1.66 & 1.62 & 1.57 \\
\hline 499.50 & 1.64 & 1.63 & 1.62 & 1.60 & 1.61 & 1.63 & 1.68 & 1.70 & 1.72 & 1.73 & 1.69 & 1.64 & 1.58 \\
\hline 504.50 & 1.70 & 1.73 & 1.75 & 1.75 & 1.77 & 1.80 & 1.84 & 1.82 & 1.80 & 1.78 & 1.73 & 1.67 & 1.60 \\
\hline
\end{tabular}

\footnotetext{
${ }^{a}$ Average power density of element: 5.347 MW/L.
} 
Table 7.5a. Relative fission power distribution in upper element at $12.75 \mathrm{~d}^{a}$

\begin{tabular}{|c|c|c|c|c|c|c|c|c|c|c|c|c|c|}
\hline \multirow{2}{*}{$\begin{array}{c}\text { Distance from top } \\
\text { of element } \\
\text { (mm) }\end{array}$} & \multicolumn{13}{|c|}{ Radial distance (in $\mathrm{mm}$ ) within element } \\
\hline & 1.88 & 5.62 & 9.38 & 13.12 & 18.75 & 26.25 & 33.75 & 39.38 & 43.12 & 46.88 & 50.62 & 54.38 & 58.12 \\
\hline 5.00 & 0.59 & 0.61 & 0.62 & 0.63 & 0.64 & 0.64 & 0.63 & 0.60 & 0.59 & 0.58 & 0.56 & 0.55 & 0.53 \\
\hline 15.00 & 0.61 & 0.62 & 0.63 & 0.63 & 0.65 & 0.65 & 0.64 & 0.61 & 0.60 & 0.59 & 0.57 & 0.56 & 0.55 \\
\hline 25.00 & 0.62 & 0.63 & 0.64 & 0.64 & 0.66 & 0.66 & 0.65 & 0.62 & 0.61 & 0.60 & 0.59 & 0.58 & 0.56 \\
\hline 40.00 & 0.65 & 0.66 & 0.67 & 0.68 & 0.69 & 0.69 & 0.69 & 0.65 & 0.64 & 0.63 & 0.62 & 0.61 & 0.59 \\
\hline 70.00 & 0.70 & 0.71 & 0.70 & 0.70 & 0.65 & 0.70 & 0.75 & 0.71 & 0.70 & 0.69 & 0.68 & 0.66 & 0.65 \\
\hline 121.75 & 0.76 & 0.73 & 0.70 & 0.69 & 0.64 & 0.69 & 0.77 & 0.81 & 0.81 & 0.80 & 0.79 & 0.77 & 0.76 \\
\hline 173.50 & 0.86 & 0.82 & 0.79 & 0.76 & 0.70 & 0.74 & 0.82 & 0.86 & 0.91 & 0.91 & 0.89 & 0.87 & 0.85 \\
\hline 213.50 & 1.01 & 0.95 & 0.90 & 0.86 & 0.77 & 0.80 & 0.87 & 0.91 & 0.96 & 0.99 & 0.97 & 0.95 & 0.92 \\
\hline 253.50 & 1.17 & 1.09 & 1.03 & 0.97 & 0.86 & 0.87 & 0.93 & 0.97 & 1.01 & 1.08 & 1.06 & 1.02 & 0.99 \\
\hline 293.50 & 1.32 & 1.23 & 1.15 & 1.08 & 0.95 & 0.94 & 0.99 & 1.02 & 1.06 & 1.17 & 1.14 & 1.10 & 1.06 \\
\hline 333.50 & 1.42 & 1.32 & 1.25 & 1.17 & 1.02 & 1.00 & 1.05 & 1.07 & 1.11 & 1.26 & 1.22 & 1.17 & 1.12 \\
\hline 369.38 & 1.48 & 1.39 & 1.31 & 1.23 & 1.08 & 1.05 & 1.10 & 1.12 & 1.16 & 1.33 & 1.28 & 1.23 & 1.18 \\
\hline 401.13 & 1.51 & 1.43 & 1.36 & 1.29 & 1.14 & 1.11 & 1.15 & 1.17 & 1.21 & 1.38 & 1.33 & 1.28 & 1.22 \\
\hline 427.00 & 1.55 & 1.48 & 1.42 & 1.34 & 1.20 & 1.16 & 1.21 & 1.23 & 1.26 & 1.42 & 1.37 & 1.31 & 1.25 \\
\hline 447.00 & 1.61 & 1.55 & 1.49 & 1.43 & 1.28 & 1.25 & 1.29 & 1.30 & 1.33 & 1.47 & 1.41 & 1.34 & 1.27 \\
\hline 462.00 & 1.60 & 1.56 & 1.52 & 1.46 & 1.31 & 1.28 & 1.32 & 1.33 & 1.36 & 1.45 & 1.39 & 1.33 & 1.25 \\
\hline 472.00 & 1.64 & 1.64 & 1.60 & 1.55 & 1.40 & 1.38 & 1.41 & 1.41 & 1.43 & 1.48 & 1.42 & 1.35 & 1.26 \\
\hline 479.50 & 1.62 & 1.65 & 1.63 & 1.58 & 1.43 & 1.41 & 1.44 & 1.44 & 1.46 & 1.47 & 1.40 & 1.33 & 1.25 \\
\hline 484.50 & 1.62 & 1.65 & 1.66 & 1.62 & 1.48 & 1.46 & 1.49 & 1.48 & 1.49 & 1.47 & 1.40 & 1.33 & 1.24 \\
\hline 489.50 & 1.64 & 1.67 & 1.70 & 1.69 & 1.55 & 1.54 & 1.56 & 1.54 & 1.55 & 1.48 & 1.41 & 1.33 & 1.24 \\
\hline 494.50 & 1.64 & 1.68 & 1.71 & 1.72 & 1.61 & 1.60 & 1.62 & 1.60 & 1.58 & 1.48 & 1.41 & 1.32 & 1.23 \\
\hline 499.50 & 1.62 & 1.67 & 1.70 & 1.71 & 1.72 & 1.71 & 1.66 & 1.57 & 1.52 & 1.47 & 1.40 & 1.31 & 1.22 \\
\hline 504.50 & 1.61 & 1.65 & 1.68 & 1.70 & 1.70 & 1.68 & 1.63 & 1.55 & 1.50 & 1.45 & 1.38 & 1.30 & 1.21 \\
\hline
\end{tabular}

${ }^{a}$ Average power density of element: $5.143 \mathrm{MW} / \mathrm{L}$. 
Table 7.5b. Relative fission power distribution in lower element at $\mathbf{1 2 . 7 5} \mathrm{d}^{a}$

\begin{tabular}{|c|c|c|c|c|c|c|c|c|c|c|c|c|c|}
\hline \multirow{2}{*}{$\begin{array}{l}\text { Distance from top } \\
\text { of element } \\
(\mathrm{mm})\end{array}$} & \multicolumn{13}{|c|}{ Radial distance (in $\mathrm{mm}$ ) within element } \\
\hline & 2.06 & 6.19 & 10.31 & 14.44 & 20.62 & 28.88 & 37.12 & 43.31 & 47.44 & 51.56 & 55.69 & 59.81 & 63.94 \\
\hline 5.00 & 0.69 & 0.72 & 0.74 & 0.76 & 0.77 & 0.77 & 0.76 & 0.74 & 0.72 & 0.70 & 0.67 & 0.64 & 0.61 \\
\hline 15.00 & 0.71 & 0.72 & 0.74 & 0.75 & 0.78 & 0.78 & 0.77 & 0.75 & 0.73 & 0.68 & 0.66 & 0.63 & 0.61 \\
\hline 25.00 & 0.72 & 0.73 & 0.74 & 0.75 & 0.78 & 0.78 & 0.76 & 0.74 & 0.72 & 0.68 & 0.65 & 0.63 & 0.61 \\
\hline 40.00 & 0.74 & 0.75 & 0.76 & 0.77 & 0.80 & 0.79 & 0.77 & 0.75 & 0.73 & 0.68 & 0.66 & 0.63 & 0.61 \\
\hline 70.00 & 0.81 & 0.82 & 0.83 & 0.83 & 0.86 & 0.85 & 0.83 & 0.79 & 0.77 & 0.71 & 0.69 & 0.66 & 0.63 \\
\hline 121.75 & 0.92 & 0.93 & 0.94 & 0.95 & 0.98 & 0.97 & 0.94 & 0.89 & 0.87 & 0.80 & 0.76 & 0.73 & 0.69 \\
\hline 173.50 & 0.99 & 1.01 & 1.03 & 1.04 & 1.07 & 1.07 & 1.04 & 0.98 & 0.95 & 0.88 & 0.84 & 0.79 & 0.75 \\
\hline 213.50 & 1.07 & 1.10 & 1.13 & 1.14 & 1.17 & 1.17 & 1.13 & 1.06 & 1.03 & 0.96 & 0.91 & 0.86 & 0.81 \\
\hline 253.50 & 1.13 & 1.16 & 1.19 & 1.20 & 1.13 & 1.18 & 1.21 & 1.13 & 1.10 & 1.04 & 0.99 & 0.93 & 0.87 \\
\hline 293.50 & 1.17 & 1.14 & 1.12 & 1.10 & 1.02 & 1.07 & 1.15 & 1.17 & 1.16 & 1.10 & 1.05 & 1.00 & 0.93 \\
\hline 333.50 & 1.10 & 1.07 & 1.05 & 1.03 & 0.95 & 0.99 & 1.07 & 1.10 & 1.15 & 1.18 & 1.13 & 1.07 & 1.00 \\
\hline 369.38 & 1.06 & 1.03 & 1.00 & 0.98 & 0.90 & 0.94 & 1.02 & 1.05 & 1.09 & 1.24 & 1.19 & 1.13 & 1.05 \\
\hline 401.12 & 1.07 & 1.03 & 1.00 & 0.97 & 0.88 & 0.91 & 0.99 & 1.02 & 1.06 & 1.24 & 1.25 & 1.19 & 1.11 \\
\hline 427.00 & 1.11 & 1.07 & 1.04 & 1.00 & 0.91 & 0.92 & 0.99 & 1.02 & 1.06 & 1.24 & 1.27 & 1.24 & 1.16 \\
\hline 447.00 & 1.17 & 1.13 & 1.10 & 1.06 & 0.96 & 0.97 & 1.04 & 1.06 & 1.10 & 1.28 & 1.31 & 1.29 & 1.21 \\
\hline 462.00 & 1.19 & 1.16 & 1.13 & 1.09 & 0.99 & 1.00 & 1.06 & 1.09 & 1.13 & 1.30 & 1.32 & 1.31 & 1.22 \\
\hline 472.00 & 1.26 & 1.23 & 1.21 & 1.18 & 1.07 & 1.08 & 1.14 & 1.16 & 1.19 & 1.35 & 1.37 & 1.33 & 1.24 \\
\hline 479.50 & 1.27 & 1.25 & 1.24 & 1.21 & 1.11 & 1.12 & 1.17 & 1.18 & 1.21 & 1.37 & 1.38 & 1.33 & 1.23 \\
\hline 484.50 & 1.30 & 1.29 & 1.27 & 1.25 & 1.15 & 1.16 & 1.21 & 1.22 & 1.25 & 1.40 & 1.40 & 1.33 & 1.23 \\
\hline 489.50 & 1.34 & 1.34 & 1.33 & 1.32 & 1.22 & 1.24 & 1.28 & 1.29 & 1.30 & 1.45 & 1.42 & 1.34 & 1.24 \\
\hline 494.50 & 1.36 & 1.37 & 1.38 & 1.38 & 1.28 & 1.30 & 1.34 & 1.34 & 1.35 & 1.48 & 1.42 & 1.33 & 1.23 \\
\hline 499.50 & 1.40 & 1.43 & 1.45 & 1.46 & 1.48 & 1.51 & 1.53 & 1.52 & 1.51 & 1.48 & 1.41 & 1.32 & 1.23 \\
\hline 504.50 & 1.41 & 1.47 & 1.50 & 1.52 & 1.54 & 1.57 & 1.59 & 1.55 & 1.51 & 1.46 & 1.39 & 1.31 & 1.21 \\
\hline
\end{tabular}

${ }^{a}$ Average power density of element: $4.527 \mathrm{MW} / \mathrm{L}$. 
Table 7.6a. Relative fission power distribution in upper element at $17 \mathbf{d}^{\mathbf{a}}$

\begin{tabular}{|c|c|c|c|c|c|c|c|c|c|c|c|c|c|}
\hline \multirow{2}{*}{$\begin{array}{l}\text { Distance from top } \\
\text { of element } \\
\text { (mm) }\end{array}$} & \multicolumn{13}{|c|}{ Radial distance (in $\mathrm{mm}$ ) within element } \\
\hline & 1.88 & 5.62 & 9.38 & 13.12 & 18.75 & 26.25 & 33.75 & 39.38 & 43.12 & 46.88 & 50.62 & 54.38 & 58.12 \\
\hline 5.00 & 0.83 & 0.84 & 0.84 & 0.84 & 0.83 & 0.79 & 0.74 & 0.69 & 0.66 & 0.63 & 0.60 & 0.57 & 0.53 \\
\hline 15.00 & 0.89 & 0.89 & 0.89 & 0.88 & 0.88 & 0.84 & 0.79 & 0.74 & 0.70 & 0.65 & 0.62 & 0.58 & 0.55 \\
\hline 25.00 & 0.95 & 0.95 & 0.94 & 0.92 & 0.91 & 0.87 & 0.82 & 0.76 & 0.72 & 0.67 & 0.64 & 0.60 & 0.57 \\
\hline 40.00 & 1.04 & 1.04 & 1.03 & 1.00 & 0.98 & 0.93 & 0.87 & 0.80 & 0.76 & 0.71 & 0.67 & 0.64 & 0.60 \\
\hline 70.00 & 1.19 & 1.18 & 1.14 & 1.08 & 0.94 & 0.95 & 0.96 & 0.87 & 0.83 & 0.78 & 0.74 & 0.70 & 0.66 \\
\hline 121.75 & 1.35 & 1.25 & 1.17 & 1.09 & 0.95 & 0.92 & 0.96 & 0.97 & 0.92 & 0.86 & 0.81 & 0.77 & 0.73 \\
\hline 173.50 & 1.39 & 1.29 & 1.21 & 1.12 & 0.98 & 0.95 & 0.97 & 0.98 & 1.01 & 0.94 & 0.88 & 0.83 & 0.78 \\
\hline 213.50 & 1.41 & 1.31 & 1.23 & 1.15 & 1.01 & 0.97 & 0.99 & 1.00 & 1.02 & 0.98 & 0.93 & 0.87 & 0.81 \\
\hline 253.50 & 1.40 & 1.31 & 1.24 & 1.16 & 1.02 & 0.98 & 1.00 & 1.00 & 1.02 & 1.02 & 0.96 & 0.90 & 0.83 \\
\hline 293.50 & 1.37 & 1.30 & 1.23 & 1.16 & 1.03 & 0.99 & 1.01 & 1.01 & 1.02 & 1.06 & 0.99 & 0.92 & 0.85 \\
\hline 333.50 & 1.32 & 1.27 & 1.22 & 1.15 & 1.03 & 0.99 & 1.01 & 1.01 & 1.02 & 1.08 & 1.01 & 0.94 & 0.86 \\
\hline 369.38 & 1.27 & 1.24 & 1.20 & 1.15 & 1.04 & 1.00 & 1.02 & 1.02 & 1.03 & 1.10 & 1.02 & 0.95 & 0.87 \\
\hline 401.13 & 1.24 & 1.21 & 1.19 & 1.15 & 1.05 & 1.02 & 1.03 & 1.03 & 1.04 & 1.11 & 1.03 & 0.95 & 0.87 \\
\hline 427.00 & 1.21 & 1.20 & 1.19 & 1.16 & 1.07 & 1.04 & 1.06 & 1.05 & 1.05 & 1.10 & 1.02 & 0.94 & 0.85 \\
\hline 447.00 & 1.21 & 1.21 & 1.21 & 1.18 & 1.10 & 1.08 & 1.09 & 1.08 & 1.08 & 1.10 & 1.01 & 0.93 & 0.84 \\
\hline 462.00 & 1.18 & 1.19 & 1.19 & 1.17 & 1.10 & 1.08 & 1.09 & 1.07 & 1.07 & 1.05 & 0.97 & 0.89 & 0.80 \\
\hline 472.00 & 1.16 & 1.21 & 1.22 & 1.21 & 1.14 & 1.13 & 1.13 & 1.11 & 1.09 & 1.04 & 0.96 & 0.88 & 0.79 \\
\hline 479.50 & 1.13 & 1.19 & 1.21 & 1.20 & 1.14 & 1.13 & 1.13 & 1.10 & 1.09 & 1.00 & 0.93 & 0.85 & 0.76 \\
\hline .484 .50 & 1.11 & 1.17 & 1.21 & 1.20 & 1.15 & 1.14 & $1: 14$ & 1.11 & 1.09 & 0.98 & 0.91 & 0.83 & 0.74 \\
\hline 489.50 & 1.09 & 1.15 & 1.20 & 1.22 & 1.18 & 1.16 & 1.15 & 1.12 & 1.10 & 0.97 & 0.89 & 0.81 & 0.73 \\
\hline 494.50 & 1.07 & 1.12 & 1.17 & 1.20 & 1.18 & 1.17 & 1.16 & 1.12 & 1.09 & 0.93 & 0.86 & 0.79 & 0.71 \\
\hline 499.50 & 1.02 & 1.07 & 1.11 & 1.13 & 1.15 & 1.13 & 1.08 & 1.00 & 0.95 & 0.90 & 0.83 & 0.76 & 0.69 \\
\hline 504.50 & 0.99 & 1.03 & 1.05 & 1.07 & 1.08 & 1.06 & 1.01 & 0.94 & 0.90 & 0.85 & 0.80 & 0.73 & 0.67 \\
\hline
\end{tabular}

${ }^{a}$ Average power density of element: $5.998 \mathrm{MW} / \mathrm{L}$. 
Table 7.6b. Relative fission power distribution in lower element at $17 \mathbf{d}^{a}$

\begin{tabular}{|c|c|c|c|c|c|c|c|c|c|c|c|c|c|}
\hline \multirow{2}{*}{$\begin{array}{c}\text { Distance from top } \\
\text { of element } \\
\text { (mm) }\end{array}$} & \multicolumn{13}{|c|}{ Radial distance (in $\mathrm{mm}$ ) within element } \\
\hline & 2.06 & 6.19 & 10.31 & 14.44 & 20.62 & 28.88 & 37.12 & 43.31 & 47.44 & 51.56 & 55.69 & 59.81 & 63.94 \\
\hline 5.00 & 0.59 & 0.62 & 0.64 & 0.66 & 0.68 & 0.68 & 0.67 & 0.65 & 0.63 & 0.60 & 0.58 & 0.55 & 0.51 \\
\hline 15.00 & 0.62 & 0.64 & 0.66 & 0.68 & 0.76 & 0.76 & 0.74 & 0.72 & 0.69 & 0.59 & 0.57 & 0.54 & 0.51 \\
\hline 25.00 & 0.64 & 0.66 & 0.68 & 0.69 & 0.77 & 0.76 & 0.74 & 0.72 & 0.69 & 0.59 & 0.57 & 0.54 & 0.51 \\
\hline 40.00 & 0.68 & 0.70 & 0.72 & 0.73 & 0.80 & 0.79 & 0.77 & 0.73 & 0.71 & 0.60 & 0.57 & 0.54 & 0.51 \\
\hline 70.00 & 0.77 & 0.79 & 0.81 & 0.82 & 0.89 & 0.87 & 0.84 & 0.79 & 0.76 & 0.64 & 0.61 & 0.57 & 0.53 \\
\hline 121.75 & 0.91 & 0.94 & 0.97 & 0.98 & 1.05 & 1.03 & 0.98 & 0.91 & 0.87 & 0.74 & 0.69 & 0.64 & 0.59 \\
\hline 173.50 & 1.01 & 1.05 & 1.09 & 1.11 & 1.18 & 1.16 & 1.09 & 1.01 & 0.96 & 0.82 & 0.76 & 0.70 & 0.64 \\
\hline 213.50 & 1.11 & 1.16 & 1.21 & 1.24 & 1.30 & 1.28 & 1.21 & 1.11 & 1.05 & 0.91 & 0.84 & 0.77 & 0.70 \\
\hline 253.50 & 1.17 & 1.24 & 1.29 & 1.32 & 1.27 & 1.31 & 1.31 & 1.19 & 1.13 & 0.99 & 0.91 & 0.83 & 0.75 \\
\hline 293.50 & 1.21 & 1.21 & 1.21 & 1.20 & 1.14 & 1.18 & 1.24 & 1.23 & 1.19 & 1.06 & 0.98 & 0.90 & 0.81 \\
\hline 333.50 & 1.13 & 1.12 & 1.12 & 1.11 & 1.05 & 1.09 & 1.15 & 1.16 & 1.18 & 1.14 & 1.06 & 0.97 & 0.87 \\
\hline 369.38 & 1.07 & 1.07 & 1.06 & 1.05 & 0.98 & 1.02 & 1.09 & 1.10 & 1.12 & 1.20 & 1.12 & 1.02 & 0.92 \\
\hline 401.12 & 1.07 & 1.05 & 1.04 & 1.02 & 0.95 & 0.99 & 1.06 & 1.07 & 1.10 & 1.21 & 1.18 & 1.08 & 0.98 \\
\hline 427.00 & 1.10 & 1.09 & 1.07 & 1.06 & 0.98 & 1.00 & 1.06 & 1.07 & 1.10 & 1.21 & 1.20 & 1.13 & 1.01 \\
\hline 447.00 & 1.14 & 1.14 & 1.13 & 1.11 & 1.03 & 1.05 & 1.11 & 1.11 & 1.13 & 1.24 & 1.23 & 1.17 & 1.05 \\
\hline 462.00 & 1.14 & 1.14 & 1.14 & 1.13 & 1.05 & 1.07 & 1.12 & 1.13 & 1.15 & 1.25 & 1.23 & 1.17 & 1.05 \\
\hline 472.00 & 1.18 & 1.20 & 1.20 & 1.20 & 1.12 & 1.14 & 1.18 & 1.18 & 1.19 & 1.28 & 1.26 & 1.18 & 1.05 \\
\hline 479.50 & 1.18 & 1.20 & 1.21 & 1.21 & 1.14 & 1.16 & 1.20 & 1.19 & 1.20 & 1.28 & 1.25 & 1.16 & 1.04 \\
\hline .484 .50 & 1.19 & 1.21 & 1.23 & 1.23 & 1.17 & 1.19 & $1: 22$ & 1.22 & 1.22 & 1.29 & 1.25 & 1.15 & 1.03 \\
\hline 489.50 & 1.21 & 1.24 & 1.26 & 1.27 & 1.22 & 1.24 & 1.27 & 1.25 & 1.25 & 1.30 & 1.25 & 1.14 & 1.02 \\
\hline 494.50 & 1.21 & 1.25 & 1.28 & 1.29 & 1.25 & 1.27 & 1.29 & 1.28 & 1.27 & 1.31 & 1.22 & 1.12 & 1.00 \\
\hline 499.50 & 1.21 & 1.26 & 1.29 & 1.32 & 1.35 & 1.37 & 1.38 & 1.35 & 1.32 & 1.27 & 1.19 & 1.09 & 0.98 \\
\hline 504.50 & 1.19 & 1.25 & 1.29 & 1.32 & 1.35 & 1.37 & 1.37 & 1.32 & 1.27 & 1.21 & 1.14 & 1.05 & 0.96 \\
\hline
\end{tabular}

${ }^{a}$ Average power density of element: $3.347 \mathrm{MW} / \mathrm{L}$. 


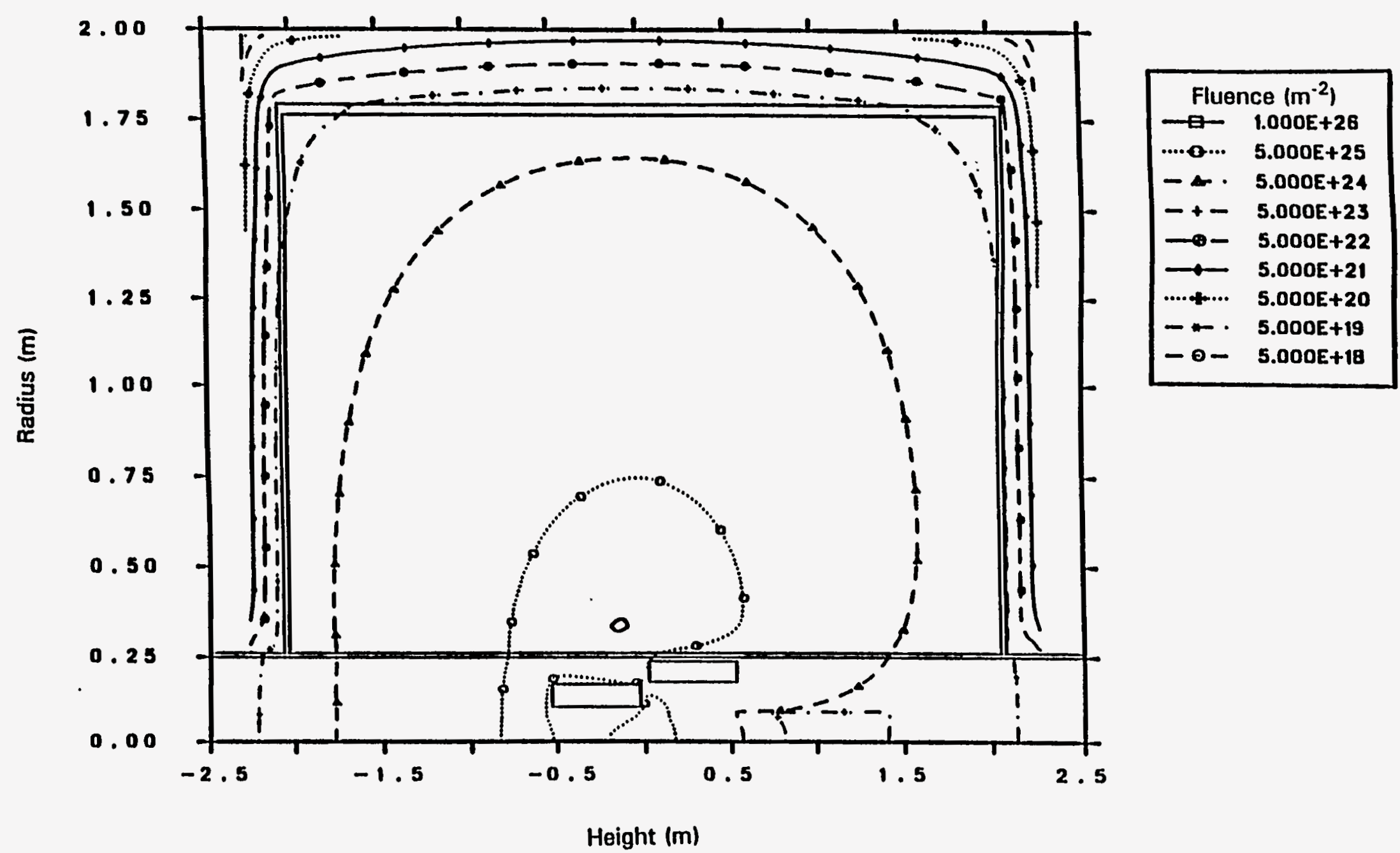

$\stackrel{N}{\stackrel{\leftrightarrow}{u}}$

Fig. 7.23. ANS total fluence per cycle. 
Table 7.7. Maximum ${ }^{28} \mathrm{Si}$ activation rates in CPBT

\begin{tabular}{cccccccc}
\hline \multirow{2}{*}{$\begin{array}{c}\text { Time } \\
(\mathrm{d})\end{array}$} & $\begin{array}{c}\text { Axial location } \\
\text { from midplane } \\
(\mathrm{mm})\end{array}$ & $\begin{array}{c}\text { Radial location } \\
\text { in CPBT }\end{array}$ & & \multicolumn{4}{c}{$\begin{array}{c}\text { Maximum activation rates } \\
\left.\text { (atoms }{ }^{28} \mathrm{Si} \mathrm{mL}^{-1} \cdot \mathrm{s}^{-1}\right)\end{array}$} \\
\cline { 5 - 8 } & & & Group 1 & Group 2 & Group 3 & Group 4 \\
\hline 0.0 & -233 & Inside & $1.462 \times 10^{10}$ & $5.985 \times 10^{11}$ & $1.206 \times 10^{12}$ & $4.349 \times 10^{13}$ & Total \\
& -233 & Middle & $1.384 \times 10^{10}$ & $5.754 \times 10^{11}$ & $1.193 \times 10^{12}$ & $4.365 \times 10^{13}$ & $4.531 \times 10^{13}$ \\
& -243 & Outside & $1.327 \times 10^{10}$ & $5.572 \times 10^{11}$ & $1.184 \times 10^{12}$ & $4.383 \times 10^{13}$ & $4.558 \times 10^{13}$ \\
8.5 & -172 & Inside & $1.201 \times 10^{10}$ & $5.399 \times 10^{11}$ & $1.171 \times 10^{12}$ & $4.776 \times 10^{13}$ & $4.948 \times 10^{13}$ \\
& -172 & Middle & $1.139 \times 10^{10}$ & $5.200 \times 10^{11}$ & $1.160 \times 10^{12}$ & $4.792 \times 10^{13}$ & $4.961 \times 10^{13}$ \\
& -172 & Outside & $1.080 \times 10^{10}$ & $5.007 \times 10^{11}$ & $1.149 \times 10^{12}$ & $4.809 \times 10^{13}$ & $4.975 \times 10^{13}$ \\
17.0 & -84 & Inside & $8.811 \times 10^{9}$ & $4.245 \times 10^{9}$ & $9.803 \times 10^{11}$ & $4.526 \times 10^{13}$ & $4.668 \times 10^{13}$ \\
& -78 & Middle & $8.809 \times 10^{9}$ & $4.211 \times 10^{11}$ & $9.866 \times 10^{11}$ & $4.534 \times 10^{13}$ & $4.676 \times 10^{13}$ \\
& -84 & Outside & $8.108 \times 10^{9}$ & $3.990 \times 10^{11}$ & $9.640 \times 10^{11}$ & $4.550 \times 10^{13}$ & $4.687 \times 10^{13}$ \\
\hline
\end{tabular}

Table 7.8. Maximum ${ }^{28}$ Si activation rates in reflector vessel

\begin{tabular}{cccccccc}
\hline \multirow{2}{*}{$\begin{array}{c}\text { Time } \\
(\mathrm{d})\end{array}$} & $\begin{array}{c}\text { Axial location } \\
\text { from midplane } \\
(\mathrm{mm})\end{array}$ & $\begin{array}{c}\text { Radial location } \\
\text { in vessel }\end{array}$ & & \multicolumn{5}{c}{$\begin{array}{c}\text { Maximum activation rates } \\
\left(\text { atoms }{ }^{28} \mathrm{Si} \mathrm{mL}^{-1} \cdot \mathrm{s}^{-1}\right)\end{array}$} \\
\cline { 4 - 8 } & & & Group 1 & Group 2 & Group 3 & Group 4 & Total \\
\hline 0.0 & -121 & Inside & $8.708 \times 10^{-4}$ & $2.111 \times 10^{2}$ & $3.470 \times 10^{8}$ & $1.560 \times 10^{12}$ & $1.560 \times 10^{12}$ \\
& -98 & Outside & $7.171 \times 10^{-4}$ & $1.805 \times 10^{2}$ & $3.069 \times 10^{8}$ & $1.515 \times 10^{12}$ & $1.515 \times 10^{12}$ \\
8.5 & -112 & Inside & $9.531 \times 10^{-4}$ & $2.278 \times 10^{2}$ & $3.829 \times 10^{8}$ & $1.721 \times 10^{12}$ & $1.721 \times 10^{12}$ \\
& -99 & Outside & $7.724 \times 10^{-4}$ & $1.932 \times 10^{2}$ & $3.387 \times 10^{8}$ & $1.672 \times 10^{12}$ & $1.672 \times 10^{12}$ \\
17.0 & +92 & Inside & $1.493 \times 10^{-3}$ & $3.015 \times 10^{2}$ & $3.996 \times 10^{8}$ & $1.796 \times 10^{12}$ & $1.796 \times 10^{12}$ \\
& +70 & Outside & $1.133 \times 10^{-3}$ & $2.461 \times 10^{2}$ & $3.532 \times 10^{8}$ & $1.745 \times 10^{12}$ & $1.745 \times 10^{12}$ \\
\hline
\end{tabular}


calculations did not include photoneutrons that would result in an increase in the group 1 activationrates (see Sect. 7.1). The axial location of the maximum ${ }^{28} \mathrm{Si}$ production rate in the CPBT moves axially upwards with increasing fuel cycle time.

Table 7.8 displays the maximum ${ }^{28} \mathrm{Si}$ production rates in the reflector vessel at $\mathrm{BOC}, \mathrm{MOC}$, and EOC at HFP operation.

Table 7.9 displays the maximum cumulative production of ${ }^{28} \mathrm{Si}$ after $17 \mathrm{~d}$ of operation at HFP of the ANS Core L7. At the location of maximum production, approximately $0.1 \%$ of the ${ }^{27} \mathrm{Al}$ atoms in the CPBT are replaced with ${ }^{28} \mathrm{Si}$ atoms during each $17-\mathrm{d}$ ANS fuel cycle.

Figure 7.24 shows the cumulative ${ }^{28} \mathrm{Si}$ production in the CPBT as a function of axial location after an irradiation of $17 \mathrm{~d}$ at HFP. Figure 7.25 shows the cumulative ${ }^{28} \mathrm{Si}$ production in the reflector vessel per cycle.

\subsection{BURNUP DATA}

The nuclide concentrations as a function of cycle time for all nuclides used in the VENTURE/BURNER fuel cycle analysis are listed in Table 7.10.

Table 7.9. Maximum cumulative production of ${ }^{28} \mathrm{Si}$ after $17 \mathrm{~d}$ at $330 \mathrm{MW}$,

\begin{tabular}{lcc}
\hline Component & $\begin{array}{c}\text { Axial location from midplane } \\
(\mathrm{mm})\end{array}$ & $\begin{array}{c}\text { Maximum cumulative production } \\
\text { (atoms }{ }^{28} \mathrm{Si} / \mathrm{mL} \text { ) }\end{array}$ \\
\hline CPBT & -159 & $6.901 \times 10^{19}$ \\
Reflector vessel & -50 & $2.488 \times 10^{18}$ \\
\hline
\end{tabular}




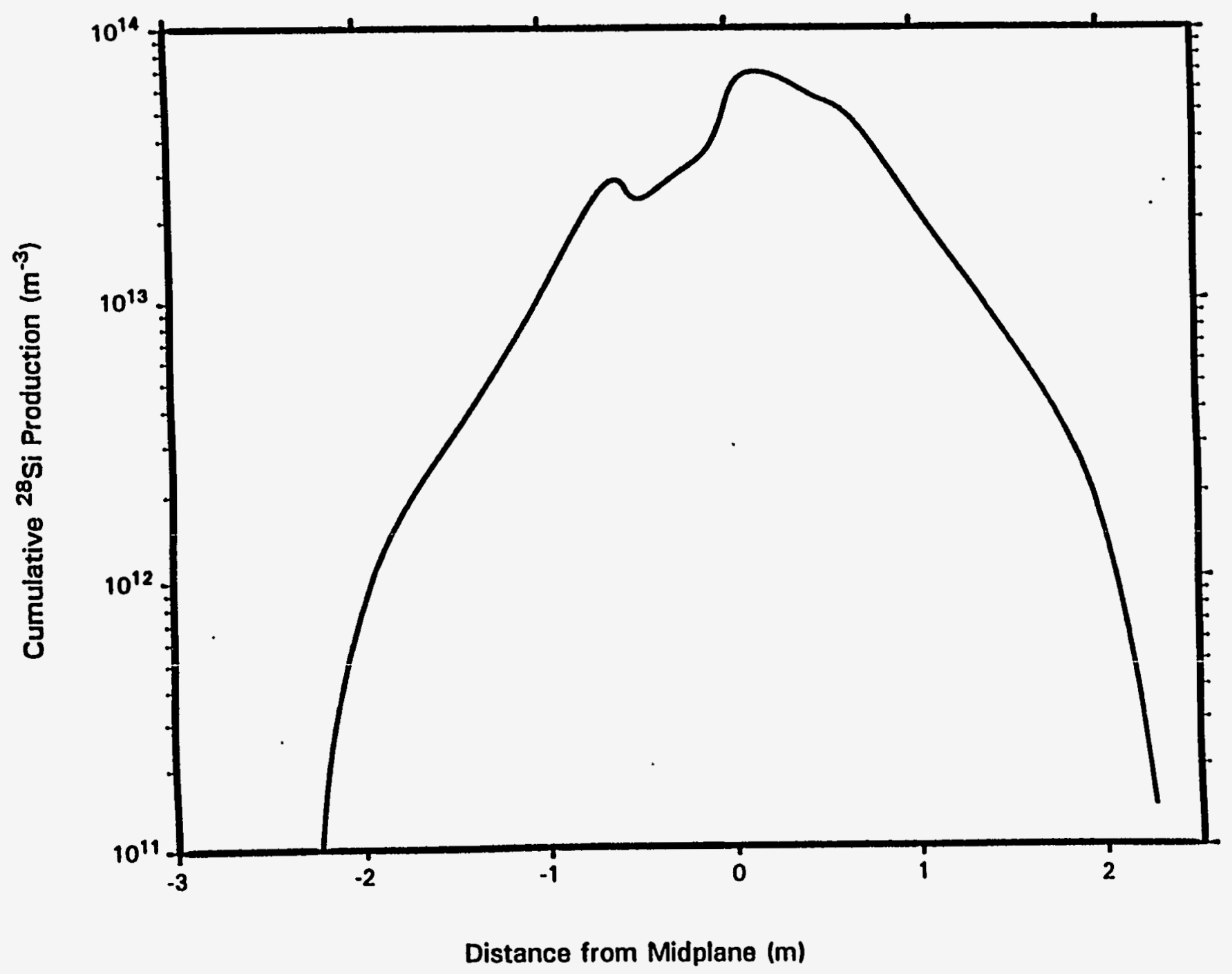

$\stackrel{+1}{\stackrel{1}{\omega}}$

Fig. 7.24. ANS ${ }^{28}$ Si production in the CPBT per cycle. 


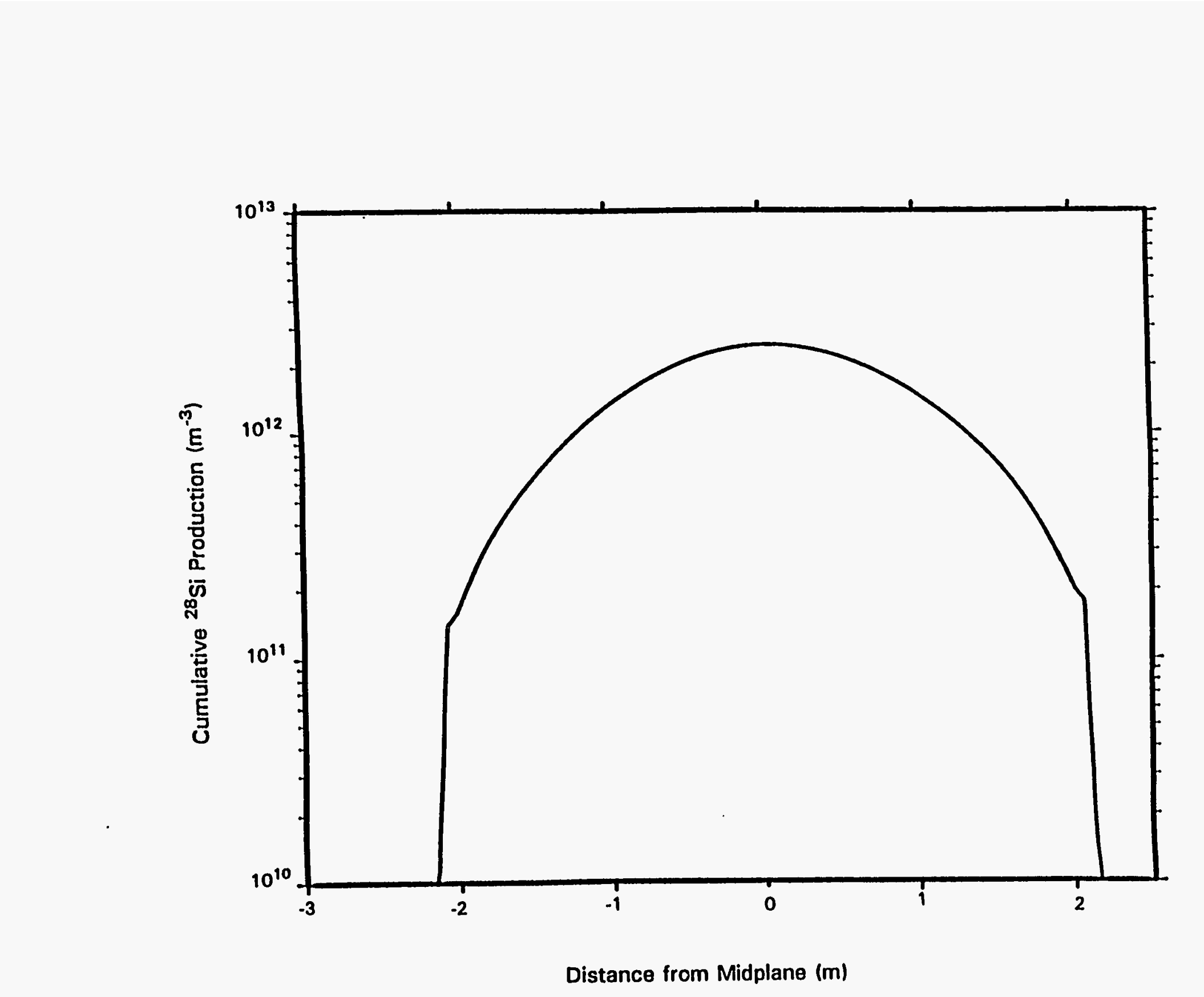


Table 7.10. Nuclide inventories (in $\mathrm{kg}$ ) as calculated by VENTURE

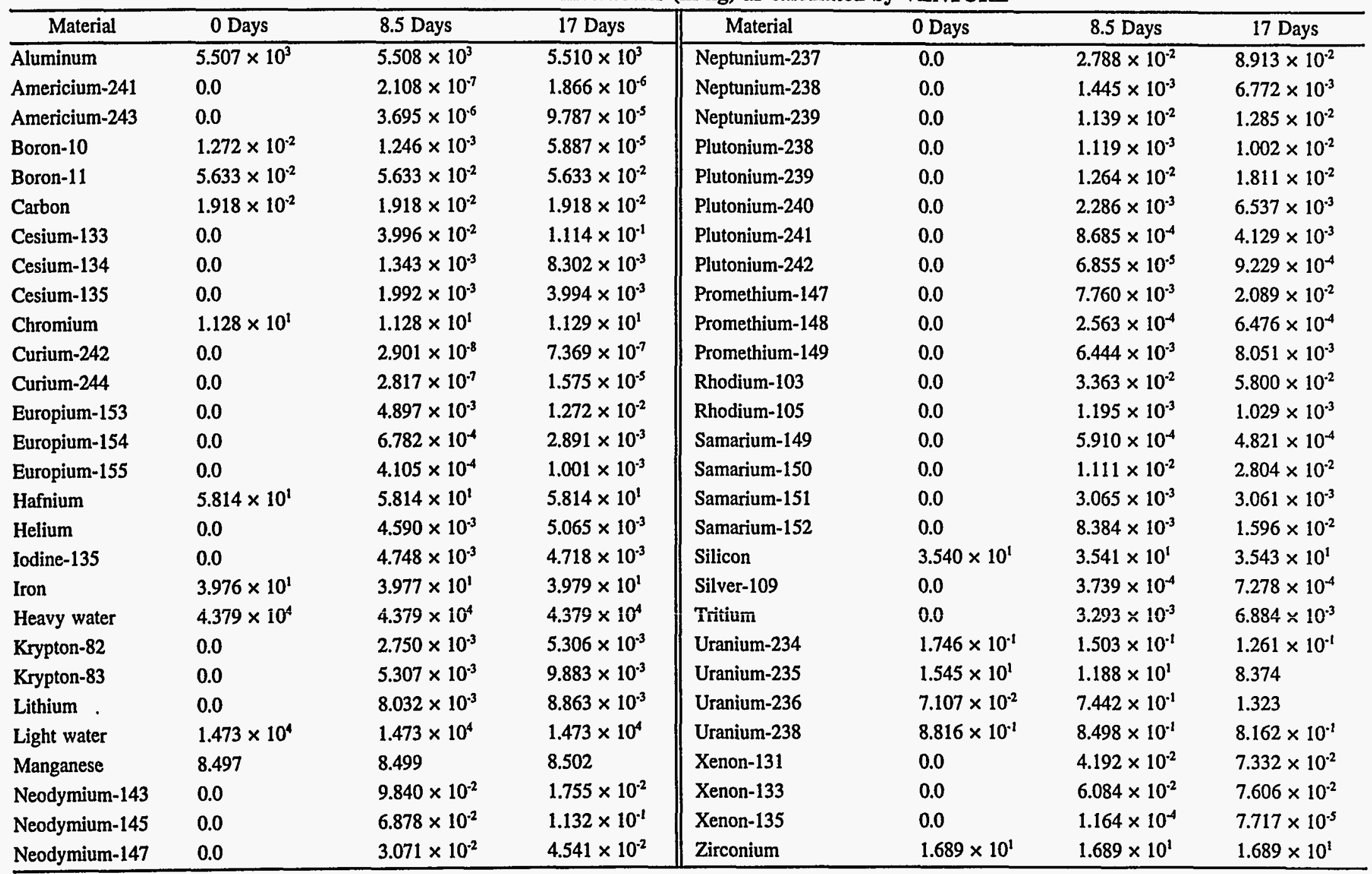




\section{COMPONENT REACTIVITIES}

This section discusses the variation and parametric studies performed with the MCNP model for the reflector components. The modeling techniques and options in these studies were discussed in Sect. 6.1. A summary of the component reactivity effects on the core eigenvalue are shown in

Table 8.1. Note that all of the reactivities presented in the report are calculated as $\ln \left(k_{\text {eff }} / k_{\text {eff }}^{o}\right)$ where $k_{e f f}^{o}$ is the reference effective multiplication factor.

Table 8.1. Reactivity impact of various reactor components ${ }^{q}$

\begin{tabular}{llc}
\hline Case & \multicolumn{1}{c}{ Reactor component } & $\begin{array}{c}\text { Reactivity worth } \\
\text { (pcm) }\end{array}$ \\
\hline ANS653 & Beam tubes, large slant beam tube, through-tube & $+3,820$ \\
ANS681 & Beam tubes flooded with heavy water & $+2,960$ \\
ANS681 & Beam tubes flooded with light water & $+2,940$ \\
ANS656 & Cold sources and all cold guides & +470 \\
ANS657 & Rabbit and hydraulic tubes & +850 \\
ANS658 & Slant tubes & $+1,300$ \\
ANS674 & Reflector isotope production facilities & +520 \\
ANS669 & Delayed neutrons & +730 \\
ANS670 & CPBT & $+5,150$ \\
ANS688 & Boron in fuel endplates & $+8,470$ \\
ANS671 & Potential reactivity of core (with boron) & $+17,590$ \\
\hline
\end{tabular}

${ }^{a}$ All cases with the three central control rods inserted to the core midplane, and with the eight short safety rods withdrawn $800 \mathrm{~mm}$ above the core midplane.

${ }^{b}$ Statistical uncertainty approximately $\pm 400 \mathrm{pcm}$ (percent mille).

\subsection{BEAM TUBE VARIATION STUDY}

The beam tube design has evolved significantly over the conceptual design phase. A series of MCNP cases was run to determine the effects of various changes in the beam tube design and location. The results of this study are shown in Table 8.2. The findings were that the beam tube shape and location on a local scale have negligible effects and that beam tube volume and number are much more important.

\subsection{COLD SOURCE VARIATION STUDIES}

At the time this analysis was performed, the reference cold source design was a two-phase deuterium system at a liquid volume fraction of $80 \%$. Two series of cases were run to examine the reactivity effects of the cold source design. The first series analyzed various off-normal scenarios involving the cold source and is summarized in Table 8.3. As can be seen from the accompanying results, the new 
Table 8.2. Reactivity effects of various beam tube shapes, dimensions, locations, and compositions for the conceptual core at BOC

\begin{tabular}{cllcccc}
\hline \multirow{2}{*}{ Number of tubes } & Cylinder shape & $\begin{array}{c}\text { Inner radius } \\
(\mathrm{mm})\end{array}$ & $\begin{array}{c}\text { Tube thickness } \\
(\mathrm{mm})\end{array}$ & \multicolumn{2}{c}{ Cross sectional area $\left(\mathrm{mm}^{2}\right)$} & $\begin{array}{c}\text { Reactivity change }^{a} \\
(\mathrm{pcm})\end{array}$ \\
\cline { 5 - 6 } & Circular & 74.2 & 2.5 & 17,296 & 1,282 & -500 \\
4 & Circular & 74.2 & 5.0 & 17,296 & 2,410 & -1700 \\
4 & Circular & 74.2 & 10.0 & 17,296 & 4,976 & -1500 \\
4 & Circular & 148.3 & 5.0 & 69,093 & 4,738 & -3500 \\
4 & Elliptical & $\mathrm{a}=50, \mathrm{~b}=75^{\mathrm{b}}$ & 5.0 & 11,781 & 2,042 & -800 \\
4 & Elliptical & $\mathrm{a}=50, \mathrm{~b}=150$ & 5.0 & 47,124 & 4,006 & -2200 \\
4 & Elliptical & $\mathrm{a}=50, \mathrm{~b}=110$ & 5.0 & 17,279 & 2,592 & -1500 \\
4 & Elliptical & $\mathrm{a}=100, \mathrm{~b}=220$ & 5.0 & 69,115 & 5,105 & -3200 \\
4 & Elliptical & $\mathrm{a}=50, \mathrm{~b}=110$ & 10.0 & 17,279 & 5,431 & -1300 \\
4 & Elliptical & $\mathrm{a}=50, \mathrm{~b}=110$ & 10.0 & $17,279^{\mathrm{c}}$ & 5,341 & $-2300^{c}$ \\
4 & Elliptical & $\mathrm{a}=50, \mathrm{~b}=110$ & 10.0 & $17,279^{d}$ & 5,341 & $-2400^{d}$ \\
8 & Elliptical & $\mathrm{a}=50, \mathrm{~b}=110$ & 10.0 & 34,558 & 10,682 & -3700 \\
7 & Elliptical & $\mathrm{a}=50, \mathrm{~b}=110$ & 10.0 & 30,238 & 9,347 & -3500 \\
7 & Elliptical & $\mathrm{a}=50, \mathrm{~b}=110$ & 10.0 & 30,238 & 9,347 & $-3400^{e}$ \\
\hline
\end{tabular}

${ }^{a}$ From a base case without any beam tubes. Statistical uncertainty in reactivity values is approximately $\pm 400 \mathrm{pcm}$.

$b a=$ radial axis (half of total beam void width), $b=$ axial axis (half of total beam void height).

Beam tubes are flooded with heavy water instead of void.

${ }_{B}$ Beam tubes are flooded with light water instead of void.

Beam tubes are moved $50 \mathrm{~mm}$ toward core.

Beam tubes are moved $50 \mathrm{~mm}$ away from core. 
single-phase cold source design is worth approximately $1 \%$ in core reactivity and has minimal effect on the peak flux values. The seemingly anomalous reactivity worths from cases ANS612 and ANS615 are because of the very small physical differences between the two cases. The small perturbations in the model resulting from these differences produce two models that are identical within statistics, and the tiny reactivity differences result only from MCNP statistics.

The second series of cases analyzed the effects of varying the cold source shell thickness. These model changes were very small and produced very little change in either the core reactivity or the peak thermal flux. As can be seen from the results summarized in Table 8.4, the deviations from the base case are, in general, not statistically significant.

\subsection{CORE PRESSURE BOUNDARY TUBE VARIATION STUDIES}

Several CPBT design variations were analyzed with PDQ-7 models to determine the effects on the core multiplication factor and peak thermal neutron flux. Descriptions of the perturbations along with their reactivity impact and corresponding peak thermal fluxes are presented in Table 8.5. Figure 8.1 shows the variation of the core multiplication factor with CPBT inner wall thickness.

The results from these cases are summarized in Table 8.5 and presented in Fig. 8.1.

The change in the peak flux relative to the core reactivity observed in case PVP001 results from a shift in the core power distribution. In the base case, the core power is nearly evenly distributed between the two fuel elements, and the peak thermal flux is in the reflector opposite the lower fuel element (LFE). In case PVP001, there is a 3\% shift in power towards the upper fuel element (UFE), which flattens the thermal flux distribution in the reflector. A similar event occurs for cases PVP009 and PVP010, which exhibit a smaller ( 0.3\%) drop in the peak flux because of a $0.3 \%$ shift in the power towards the UFE.

The results show that a $2.1-\mathrm{mm}$ change in the thickness of the CPBT produces a $1.0 \%$ change in the core reactivity and a $0.9 \%$ difference in the peak thermal flux. This effect is consistently demonstrated regardless of the CPBT design. It is also shown that thinner CPBTs result in higher peak fluxes and larger reactivities, agreeing with previous MCNP results. The extended outer-side-plate design for the UFE results in the highest core fluxes and reactivities.

The results also demonstrate that increasing the core loading by $1 \mathrm{~kg}$ of ${ }^{235} \mathrm{U}$ produces a $1.1 \%$ increase in the core reactivity and a $2.2 \%$ decrease in the peak thermal flux for a fixed power level. Because each additional kilogram of ${ }^{235} U$ provides approximately $0.4 \mathrm{~d}$ of full-power operation, this finding reveals a possible trade-off between cycle length (irradiation sample exposure time) and the CPBT design as well as peak thermal flux.

Figure 8.1 shows a compilation of the results of this series of CPBT design variation cases. It is apparent that the eigenvalue variation with CPBT thickness is linear to a very good approximation, providing a simple and accurate method for estimating the reactivity effect of a specific CPBT design. Also, the deviation in eigenvalue between the two series is very nearly constant, allowing the effects of other inner wall thicknesses to be estimated fairly well from these data. 
Table 8.3. MCNP analysis of the cold source for various accident scenarios at $P=362 \mathrm{MW}$, with the cold source re-entrant cavity always voided

\begin{tabular}{lcccc}
\hline \multicolumn{1}{c}{ Case } & $\mathrm{k}_{\text {eff }}$ & $\begin{array}{c}\text { Reactivity worth } \\
(\mathrm{pcm})\end{array}$ & $\begin{array}{c}\text { Peak thermal flux } \\
\left(10^{19} \mathrm{~m}^{-2} \cdot \mathrm{s}^{-1}\right)\end{array}$ & $\begin{array}{c}\mathrm{k}_{\text {eff }} \times \text { peak thermal flux } \\
\left(10^{19} \mathrm{~m}^{-2} \cdot \mathrm{s}^{-1}\right)\end{array}$ \\
\hline ANS611-Cold source as designed (base case) & $0.9433 \pm 0: 0030$ & & 8.1547 & 7.6923 \\
ANS612-Cold source removed or destroyed & $0.9514 \pm 0.0030$ & +860 & 8.0323 & 7.6419 \\
ANS613-Cold source fully voided & $0.9469 \pm 0.0027$ & +380 & 8.0160 & 7.5904 \\
ANS614-Cold source flooded with liquid $\mathrm{D}_{2}$ & $0.9477 \pm 0.0024$ & +460 & 7.8090 & 7.4006 \\
ANS615-Cold source flooded with $\mathrm{D}_{2} \mathrm{O}$ & $0.9526 \pm 0.0031$ & +980 & 7.8572 & 7.4848 \\
\hline
\end{tabular}

Table 8.4. MCNP analysis of varying the cold source $\mathrm{Al}-6061$ shell thickness at $P=362 \mathrm{MW}$, with the remainder of the cold source as designed

\begin{tabular}{lccccc}
\hline Case & $\begin{array}{c}\text { Shell thickness } \\
(\mathrm{mm})\end{array}$ & $\mathrm{k}_{\text {eff }}$ & $\begin{array}{c}\text { Reactivity worth } \\
(\mathrm{pcm})\end{array}$ & $\begin{array}{c}\text { Peak thermal flux } \\
\left(10^{19} \mathrm{~m}^{-2} \cdot \mathrm{s}^{-1}\right)\end{array}$ & $\begin{array}{c}\mathrm{k}_{\mathrm{eff}} \times \text { peak thermal flux } \\
\left(10^{19} \mathrm{~m}^{-2} \cdot \mathrm{s}^{-1}\right)\end{array}$ \\
\hline ANS617 & 1 & $0.9537 \pm 0.0031$ & +1090 & 7.7645 & 7.4050 \\
ANS616 & 2 & $0.9541 \pm 0.0032$ & +1140 & 7.9266 & 7.5628 \\
ANS611 (base) & 3 & $0.9433 \pm 0.0030$ & & 8.1547 & 7.6923 \\
ANS618 & 4 & $0.9421 \pm 0.0030$ & -130 & 7.6883 & 7.2431 \\
ANS619 & 6 & $0.9506 \pm 0.0027$ & +770 & 7.8568 & 7.4687 \\
ANS620 & 8 & $0.9465 \pm 0.0029$ & +340 & 7.7487 & 7.3341 \\
ANS621 & 10 & $0.9439 \pm 0.0028$ & +60 & 7.7609 & 7.3255 \\
\hline
\end{tabular}


Table 8.5. CPBT cases with PDQ-7 models at BOC control rods down to the core midplane

\begin{tabular}{|c|c|c|c|}
\hline Case & $\mathbf{k}_{\mathrm{efr}}$ & $\begin{array}{l}\text { Reactivity } \\
\text { difference } \\
\text { (pcm) }\end{array}$ & $\begin{array}{l}\text { Peak thermal flux } \\
\left(10^{19} \mathrm{~m}^{-2} \cdot \mathrm{s}^{-1}\right)\end{array}$ \\
\hline $\begin{array}{l}\text { 1. Base conceptual core, PDQ DD571 at reactor power of } 362 \mathrm{MW} \text {, and a core loading of } 15.041 \mathrm{~kg}^{235} \mathrm{U} \\
\text { (standard) }\end{array}$ & 1.0375 & 0 & 7.538 \\
\hline $\begin{array}{l}\text { 2. PVPOO1-like case } 1 \text { but with 5-mm-thick Al CPBT below top of the upper fuel element (UFE) and 9.1-mm- } \\
\text { thick Al CPBT with 5-mm-thick Al annual outer wall } 5 \mathrm{~mm} \text { outside CPBT }\end{array}$ & 1.0373 & -20 & 7.206 \\
\hline 3. PVP002-like case 2 but with $9.1-\mathrm{mm}$-thick Al CPBT and $5 \mathrm{~mm}$ thick outer wall extended to bottom of UFE & 1.0252 & -1190 & 7.414 \\
\hline $\begin{array}{l}\text { 4. PVPOO3-like case } 1 \text { but with 9.1-mm-thick Al CPBT and Al outer side plate of UFE extended as inner wall } \\
\text { of CPBT }\end{array}$ & 1.0325 & -480 & 7.371 \\
\hline 5. PVP004-like case 4 but with 7-mm-thick Al CPBT & 1.0428 & +510 & 7.432 \\
\hline $\begin{array}{l}\text { 6. Like case } 1 \text { but with } 9.1-\mathrm{mm} \text {-thick Al CPBT, Al UFE and outer side plate extended as inner wall of CPBT. } \\
\text { Inner wall is } 5 \mathrm{~mm} \text { thick, while side plate of UFE remains } 7 \mathrm{~mm} \text { thick. } \\
\text { PVP005-extension of plate lines up on outer edge } \\
\text { PVP005A-extension of plate lines up on inner edge }\end{array}$ & $\begin{array}{l}1.0387 \\
1.0389\end{array}$ & $\begin{array}{l}+120 \\
+140\end{array}$ & $\begin{array}{l}7.450 \\
7.456\end{array}$ \\
\hline $\begin{array}{l}\text { 7. Like case } 6 \text { but with 7-mm-thick Al CPBT } \\
\text { PVP006-same as PVP005 } \\
\text { PVP006A-same as PVP005A }\end{array}$ & $\begin{array}{l}1.0490 \\
1.0492\end{array}$ & $\begin{array}{l}+1100 \\
+1120\end{array}$ & $\begin{array}{l}7.516 \\
7.522\end{array}$ \\
\hline $\begin{array}{l}\text { 8. Like case } 6 \text { but at } 340 \mathrm{MW}_{\mathrm{f}} \text { and a loading of } 14 \mathrm{~kg}^{235} \mathrm{U} \\
\text { PVP007-same as PVP005 } \\
\text { PVP007A-same as PVP005A }\end{array}$ & $\begin{array}{l}1.0272 \\
1.0273\end{array}$ & $\begin{array}{r}-1000 \\
-990\end{array}$ & $\begin{array}{l}7.156 \\
7.162\end{array}$ \\
\hline $\begin{array}{l}\text { 9. Like case } 7 \text { but at } 340 \mathrm{MW}_{\mathrm{f}} \text { and a loading of } 14 \mathrm{~kg}^{235} \mathrm{U} \\
\text { PVP008-same as PVP006 } \\
\text { PVP008A-same as PVP006A }\end{array}$ & $\begin{array}{l}1.0376 \\
1.0377\end{array}$ & $\begin{array}{l}+10 \\
+20\end{array}$ & $\begin{array}{l}7.217 \\
7.222\end{array}$ \\
\hline 10. PVP009-same as PVP006A but with UFE outer side plate extended vertically downwards only & 1.0499 & +1190 & 7.499 \\
\hline 11. PVP010-like PVP008A but with UFE outer side plate extended vertically downwards only & 1.0385 & +100 & 7.200 \\
\hline $\begin{array}{l}\text { 12. PVPO11-like case } 1 \text { but with } 15 \text {-mm-thick Al CPBT and Al UFE outer side plate extended as inner wall of } \\
\text { CPBT. Inner wall is } 5 \mathrm{~mm} \text { thick, while side plate for UFE remains } 7 \mathrm{~mm} \text { thick. Extension lines up with the } \\
\text { inner edge of the side plate. }\end{array}$ & 1.0116 & -2530 & 7.287 \\
\hline 13. PVP012-like PVP011 but with 20-mm-thick Al CPBT & 0.9898 & -4710 & 7.179 \\
\hline 14. PVP013-like PVP011 but with 7-mm-thick inner wall & 1.0061 & -3070 & 7.221 \\
\hline 15. PVP014-like PVP013 but with 20-mm-thick Al CPBT & 0.9852 & -5170 & 7.144 \\
\hline
\end{tabular}




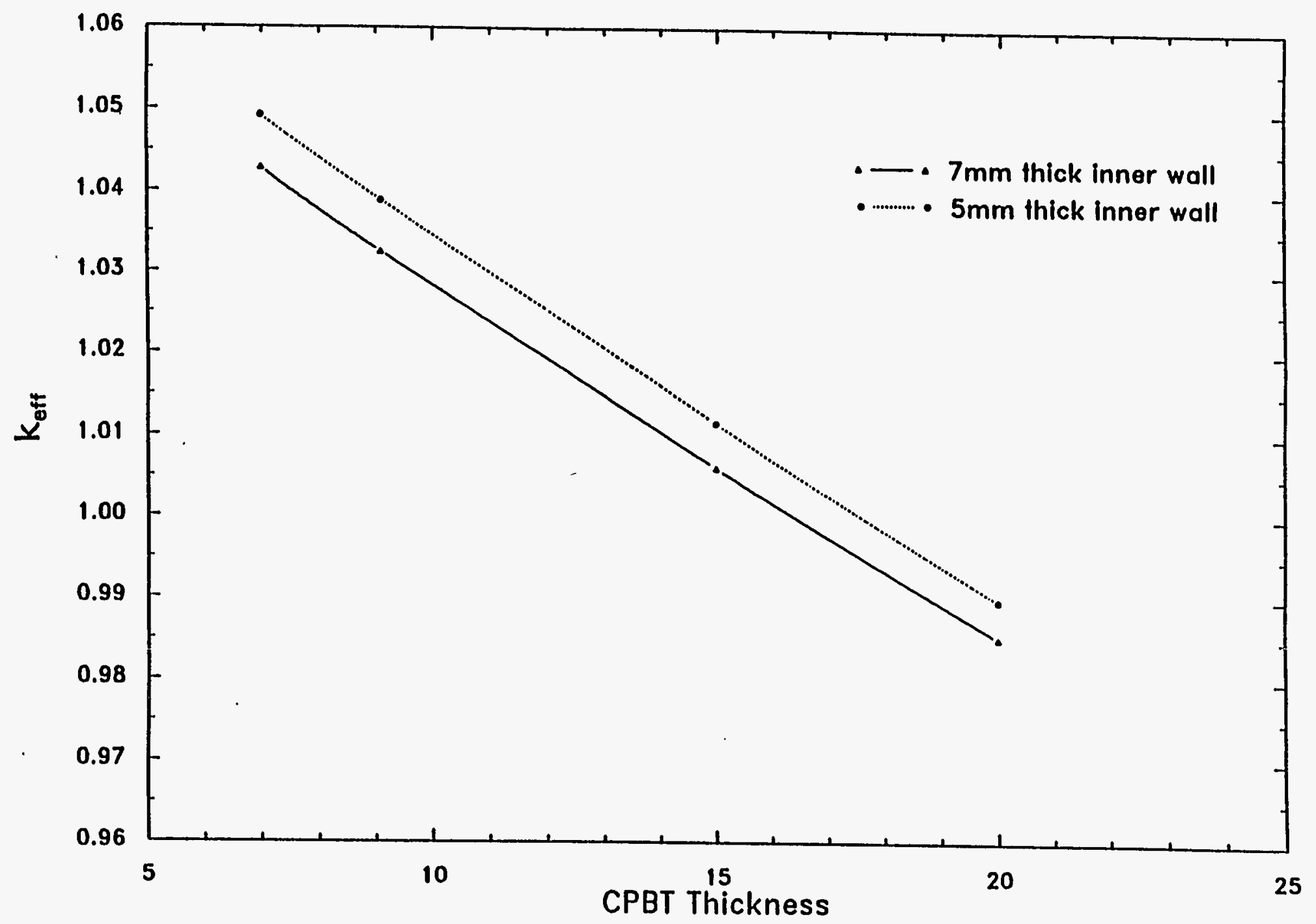

$\stackrel{\infty}{a}$

Fig. 8.1. Variation in multiplication factor with the CPBT inner wall thicknesses. 


\section{CONTROL ROD WORTHS}

\subsection{CENTRAL CONTROL ROD WORTHS}

The central control rod worths for the four- and three-control rod designs were computed using both MCNP and PDQ. The three-control rod differential bank worth as computed by MCNP at BOC is shown in Table 9.1 and Fig. 9.1. The control rod worths with one rod stuck fully withdrawn and the rod bank at operating position and in shutdown position are shown in Table 9.2. The control rod differential bank worths as computed by PDQ at beginning and end of cycle are shown in Figs. 9.2 and 9.3.

Table 9.1. Central control rod bank worth for the three-control rod design at BOC

\begin{tabular}{cccc}
\hline Case & $\begin{array}{c}\text { Rod tip position relative } \\
\text { to core midplane } \\
(\mathrm{mm})\end{array}$ & $\mathrm{k}_{\text {eff }}{ }^{a}$ & $\begin{array}{c}\text { Reactivity } \\
(\mathrm{pcm})\end{array}$ \\
\hline ANS659 & -600 & 0.8854 & $-12,170$ \\
ANS660 & -400 & 0.8938 & $-11,230$ \\
ANS686 & -300 & 0.9115 & $-9,270$ \\
ANS661 & -200 & 0.9369 & $-6,520$ \\
ANS687 & -100 & 0.9612 & $-3,960$ \\
ANS662 & 0 & 0.9881 & $-1,200$ \\
ANS663 & +100 & 0.9986 & -140 \\
ANS664 & +200 & 1.0173 & $+1,720$ \\
ANS665 & +300 & 1.0297 & $+2,930$ \\
ANS666 & +400 & 1.0543 & $+5,290$ \\
ANS667 & +500 & 1.0638 & $+6,180$ \\
ANS668 & +600 & 1.0763 & $+7,353$ \\
ANS673 & $+2,009$ & 1.0857 & $+8,220$ \\
\hline
\end{tabular}

${ }^{a}$ Statistical uncertainty approximately $\pm 0.3 \%$.

${ }^{b}$ Relative to $k_{\text {eff }}=1$. Statistical uncertainty approximately $\pm 400 \mathrm{pcm}$.

Various design studies for the central control rods were performed using the three- and four-rod models in MCNP. An analysis of the effects of varying the central control rod absorber thickness was conducted. Two methods were used to vary the hafnium thickness: holding the inner rod radius constant and holding the outer rod radius constant. The results of this analysis were discussed in Chap. 6 and are summarized in Figs. 6.1 and 6.2. This study demonstrated that little worth in terms of reactivity performance is gained by increasing the absorber thickness above $2 \mathrm{~mm}$. However, the reduction of absorber mass results in shorter in-core lifetimes for the control rods. The results of this study were used to set the hafnium thickness at $4 \mathrm{~mm}$.

Several off-normal scenarios were modeled with MCNP to test the shutdown capabilities of the three-control rod model. For these cases, the CPBT and safety rods were assumed to have been completely destroyed and removed by some external force and the control rods alone to have been left to shut the reactor down. The cases modeled the entire rod bank fully inserted, one rod stuck at the 


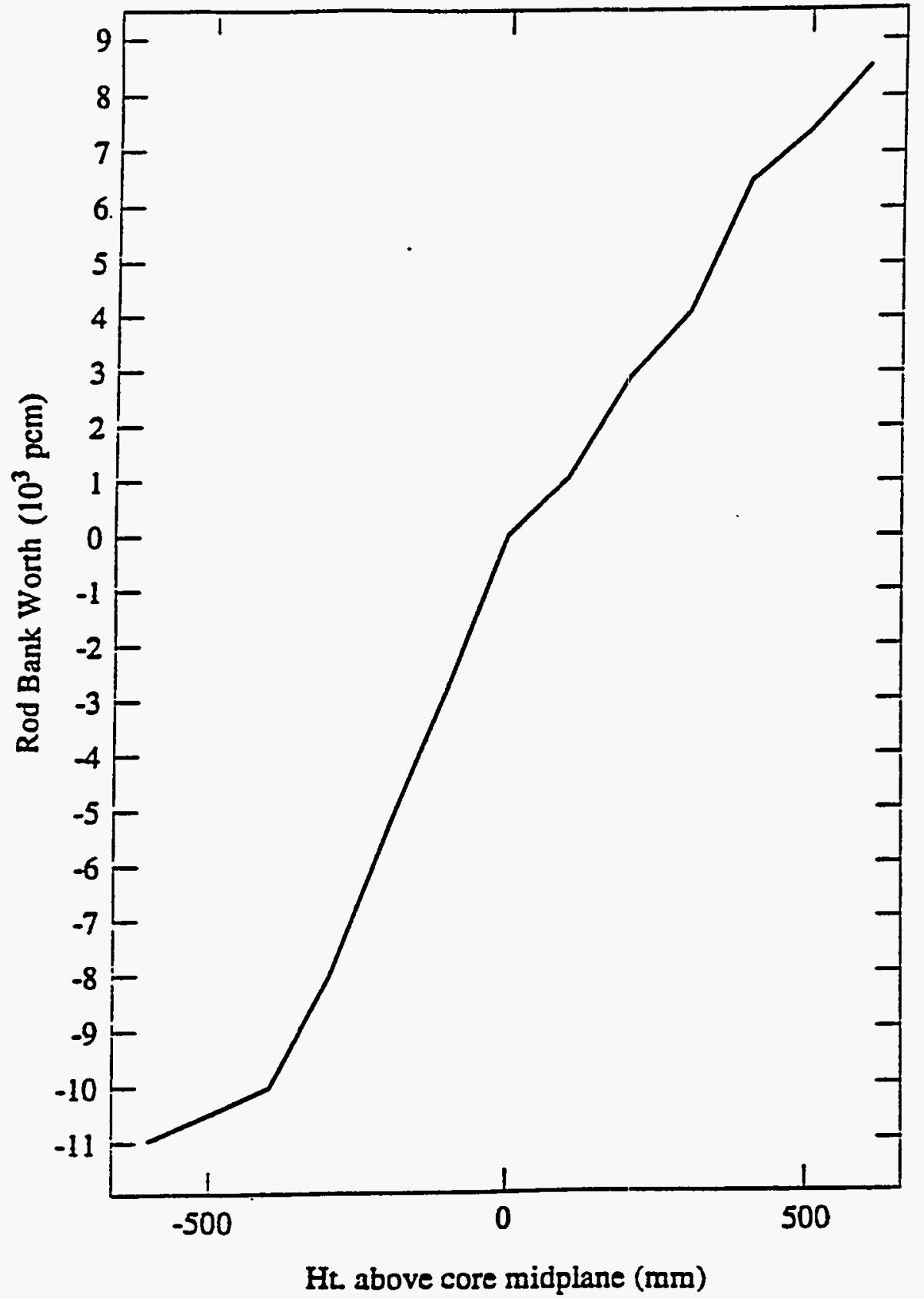

Fig. 9.1. MCNP-calculated central control rod bank worth at BOC. 
Table 9.2. Central control rod bank worths for single-rod-ejection scenarios. All cases are relative to all rods at core midplane (ANS662).

\begin{tabular}{ccccc}
\hline Case & $\begin{array}{c}\text { Rod tip position relative } \\
\text { to core midplane }\end{array}$ & $\begin{array}{c}\text { Identification number } \\
\text { of stuck rod }\end{array}$ & $\mathrm{k}_{\text {cff }}$ & $\begin{array}{c}\text { Reactivity } \\
\text { (pcm) }\end{array}$ \\
\hline ANS675 & -600 & 3 & 0.9186 & $-7,290$ \\
ANS676 & -600 & 2 & 0.9211 & $-7,020$ \\
ANS677 & -600 & 1 & 0.9173 & $-7,430$ \\
ANS678 & 0 & 3 & 0.9988 & $+1,080$ \\
ANS679 & 0 & 2 & 0.9936 & +560 \\
ANS680 & 0 & 1 & 1.0025 & $+1,450$ \\
\hline
\end{tabular}

Due to MCNP statistics, there is no real discernable reactivity difference among the three cases at a given insertion.

core midplane, and one rod stuck at the top of the upper fuel element. The results shown in Table 9.3 indicate clearly that, even under the described conditions, the reactor can still be shut down if the three inner control rods are inserted. However, it cannot be shut down at BOC if one of the three rods is ejected to the top of the UFE. For the case with one rod stuck at the core midplane, the results are not so clear. The eigenvalue difference is within the statistical errors of the cases, and thus there is some doubt as to whether safe shutdown could be achieved under this extreme condition.

It should be noted that the stuck control rod worths are substantially less than one-third of the total bank worth because of control rod "shadowing," whereby the presence of a control rod prevents the other rods from "seeing" a large portion of the flux impinging on the first rod. When one rod is removed, the other rods have ample absorber material and surface area to compensate. This effect explains the seemingly anomalous stuck-rod worths.

Table 9.3. Reactivity effects of CPBT failure. CPBT and safety shutdown rods are destroyed; central control rods are inserted as described. ${ }^{a}$

\begin{tabular}{clc}
\hline Case & \multicolumn{1}{c}{ Description } & $\begin{array}{c}\text { Reactivity } \\
\text { (pcm) }\end{array}$ \\
\hline ANS629 & $\begin{array}{l}\text { Base case-no damage, three control rods at midplane, safety rods } \\
\text { fully withdrawn }\end{array}$ & \\
ANS639 & $\begin{array}{l}\text { Off-normal case with three central control rods fully inserted } \\
\text { ANS640 }\end{array}$ & $\begin{array}{l}\text { Off-normal case with two central control rods fully inserted, most } \\
\text { reactive rod stuck at core midplane }\end{array}$ \\
ANS641 & $\begin{array}{l}\text { Off-normal case with two central control rods fully inserted, most } \\
\text { reactive rod ejected to top of upper fuel element }\end{array}$ & -2370 \\
\hline
\end{tabular}

${ }^{a}$ All cases contain three central control rods at BOC.

${ }^{b}$ Statistical uncertainty approximately $\pm 400 \mathrm{pcm}$. 


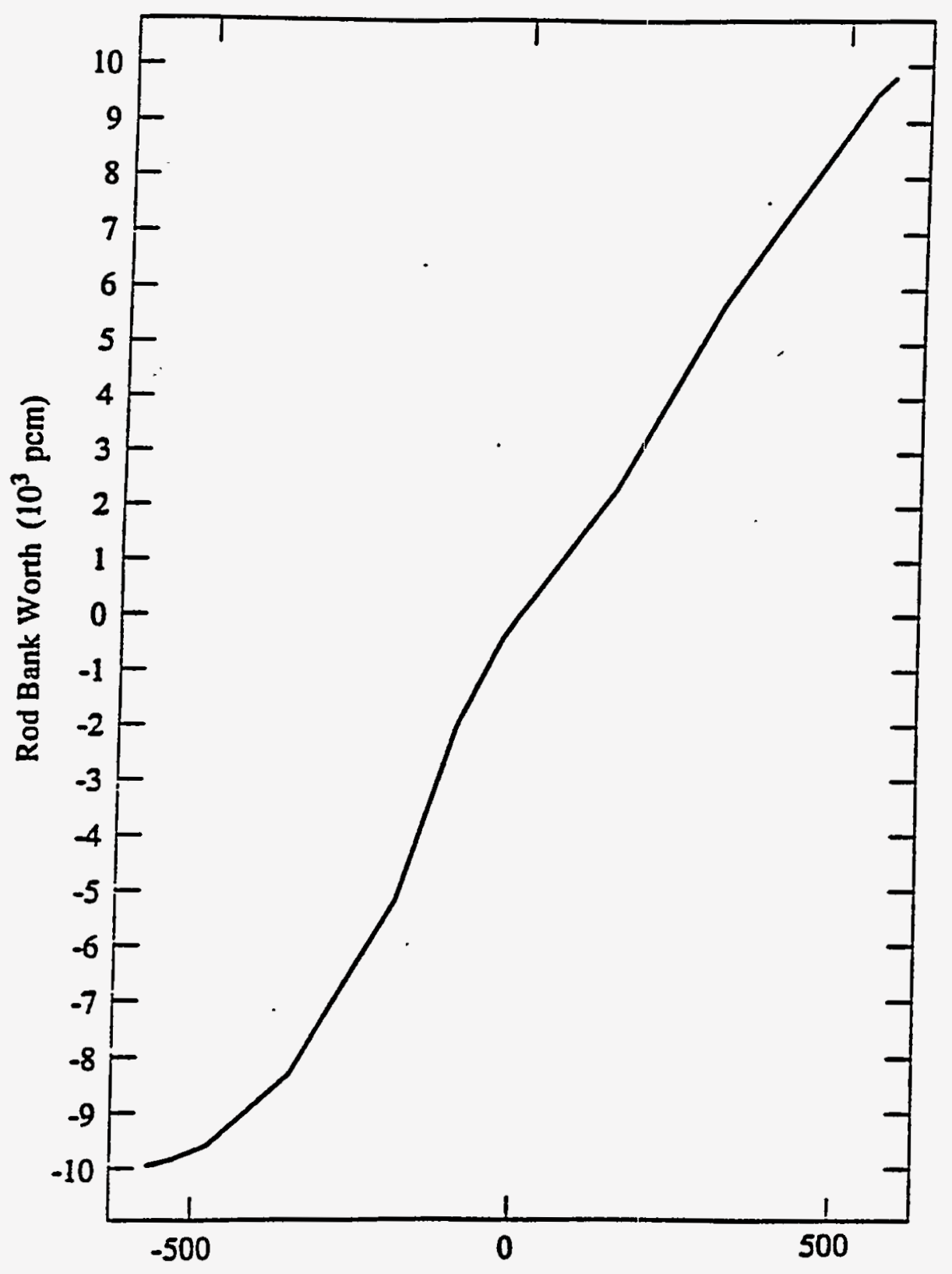

Hi above core midplane (mm)

Fig. 9.2. PDQ-calculated central control rod bank worth at BOC. 


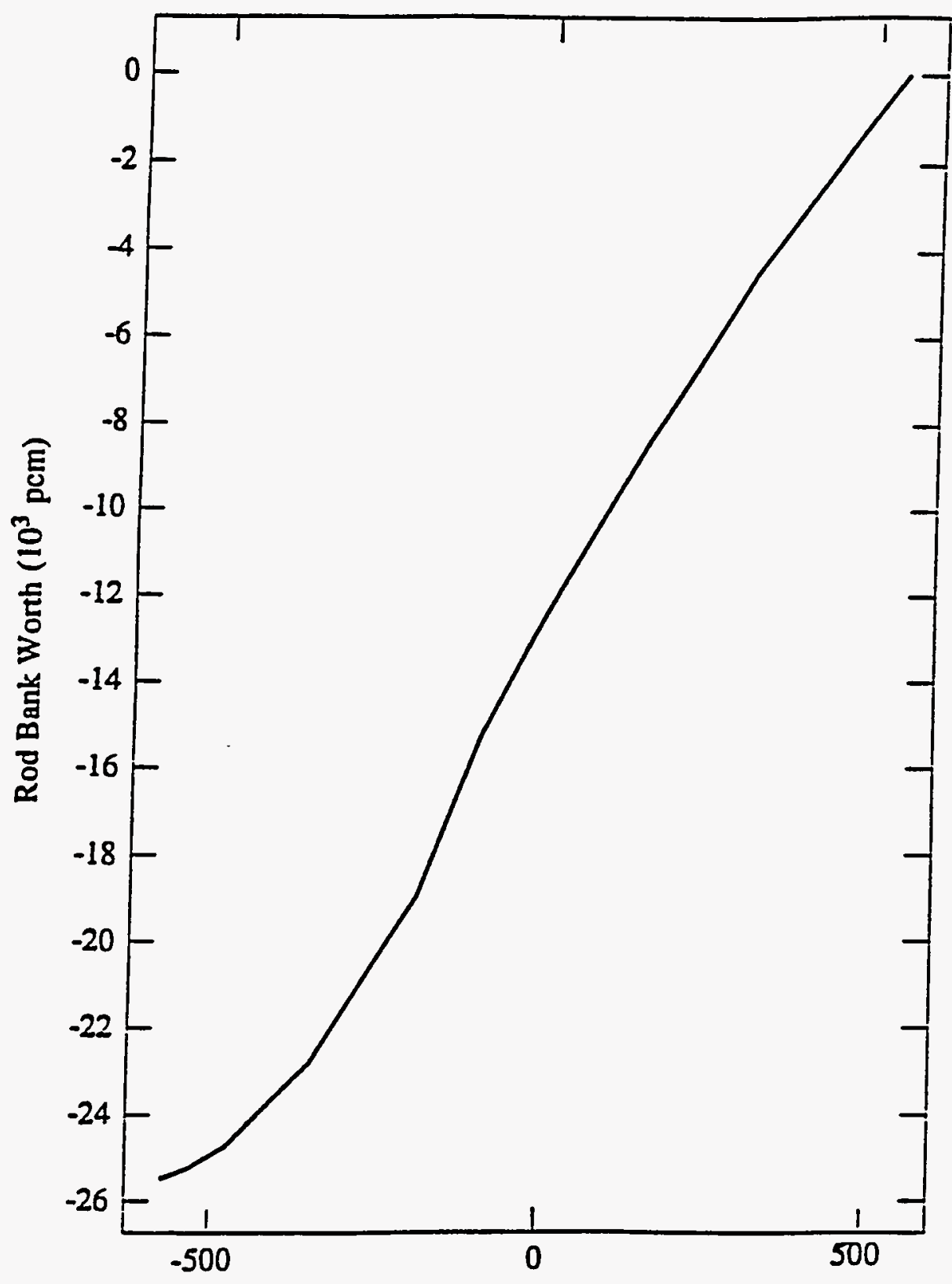

Ht above core midplane (mm)

Fig. 9.3. PDQ-calculated central control rod bank worth at EOC. 


\subsection{REFLECTOR SAFETY SHUTDOWN ROD WORTHS}

A number of options were considered for the reflector safety shutdown system, including the rapid expansion of the gas into vertical tubes. The reference concept chosen for the conceptual design was a set of eight absorber rods, parked above the core during normal operation. Evaluations performed to establish design features of these rods included the following: (1) searches were performed on the hafnium inner and outer radii to achieve optimal worth; (2) searches were performed on the poisoned section length and insertion direction (from above or below the core); (3) further, searches on the location of the eight rods to relative to the core centerline and the other components were made to optimize individual rod worths and to eliminate physical interferences during rod motion; and (4) finally, searches were made to obtain the optimal parked-rods positions, thus preserving the peak flux values in the reflector but retaining the required rod insertion rates. The final eight-rod configuration is given in Fig. 2.9 with the rod radii and locations as indicated in Table 9.4. The rod bank worth with the central control rods removed is given in Table 9.5.

Table 9.4. Final location of the short shutdown rods

\begin{tabular}{ccc}
\hline Shutdown rod identifier & $\begin{array}{c}\text { X-position } \\
(\mathrm{mm})\end{array}$ & $\begin{array}{c}\text { Y-position } \\
(\mathrm{mm})\end{array}$ \\
\hline A & 64.08 & 363.39 \\
B & -161.76 & 331.65 \\
C & -325.81 & 163.24 \\
D & -365.41 & -51.35 \\
E & -64.08 & -363.39 \\
F & 161.76 & -313.67 \\
G & 325.78 & -163.24 \\
H & 365.41 & 51.35 \\
\hline
\end{tabular}

${ }^{a}$ All rods have a 50 -mm-diam $\mathrm{D}_{2} \mathrm{O}$ hole in the center, a 7-mm-thick Al-6061 structure, and a 600-mm-long, 3-mm-thick hafnium poison parked at $800 \mathrm{~mm}$ above the core midplane.

Another variation examined was the substitution of alternative absorber materials in the safety rods. Two new safety shutdown absorber materials were examined to determine the potential shutdown worth of each. These models contained no central control rods but did model the reflector components. The first case used a 10-mm-thick shell of nickel as the poison material. The second used a 2 -mm-thick shell of $80 \%$ silver and $20 \%$ cadmium. Both cases preserved the outer diameter of the shutdown rods at $70 \mathrm{~mm}$. The results from these cases are displayed in Table 9.6. While both absorber materials provide sufficient negative reactivity for reactor shutdown, the $\mathrm{Ag}-\mathrm{Cd}$ mixture provides a shutdown margin $3 \%$ larger than that provided by the nickel and only $3 \%$ less than the margin for hafnium.

While both materials provide ample negative reactivity for shutdown, there are other considerations. The nickel control material is a significant source of high-energy photons, which would be deposited in the rod structural material and surrounding reflector components. This effect could present heat transfer problems for the shutdown rods, especially with the limited flow rates in the reflector. The Ag-Cd rods may require more frequent replacement because of the smaller control material volume and would have high activation levels after shutdown. 
Table 9.5. The multiplication factor for several short safety rod positions in ANS with central control rods removed

\begin{tabular}{clcc}
\hline Case & \multicolumn{1}{c}{ Description } & $k_{\text {eff }}$ & $\begin{array}{c}\text { Reactivity worth } \\
\text { (pcm) }\end{array}$ \\
\hline ANS704 & All eight short safety rods modeled & 0.9314 & 0 \\
ANS721 & All short safety rods modeled except A & 0.9629 & $+3,330$ \\
ANS722 & All short safety rods modeled except B & 0.9632 & $+3,560$ \\
ANS732 & All short safety rods modeled except C & 0.9698 & $+4,040$ \\
ANS730 & All short safety rods modeled except D & 0.9676 & $+3,810$ \\
ANS726 & All short safety rods modeled except E & 0.9654 & $+3,590$ \\
ANS733 & All short safety rods modeled except F & 0.9605 & $+3,080$ \\
ANS725 & All short safety rods modeled except G & 0.9585 & $+2,870$ \\
ANS731 & All short safety rods modeled except H & 0.9648 & $+3,520$ \\
ANS723 & All short safety rods modeled except A and E & 0.9771 & $+4,790$ \\
ANS724 & All short safety rods modeled except A, E, and G & 0.9884 & $+5,940$ \\
ANS727 & Only short safety rod C is modeled & 1.0547 & $+12,430$ \\
ANS728 & Only short safety rod B is modeled & 1.0580 & $+12,740$ \\
ANS729 & Only short safety rod A is modeled & 1.0656 & $+13,460$ \\
ANS705 & No safety rods modeled & 1.0857 & $+15,330$ \\
\hline
\end{tabular}

Table 9.6. Reactivity worth of alternative control materials in short (600-mm) safety shutdown rods

\begin{tabular}{llccc}
\hline Case & Poison material & $\begin{array}{c}\text { Thickness } \\
(\mathrm{mm})\end{array}$ & $\mathrm{k}_{\text {eff }}$ & $\begin{array}{c}\text { Reactivity } \\
(\mathrm{pcm})\end{array}$ \\
\hline ANS705 & Rod not modeled & & $1.0857 \pm 0.0020$ & 0 \\
ANS704 & Hf & 3 & $0.9314 \pm 0.0031$ & $-15,330$ \\
ANS654 & $\mathrm{Ni}$ & 10 & $0.9860 \pm 0.0023$ & $-9,630$ \\
ANS655 & $80 \%$ Ag-20\% Cd & 2 & $0.9587 \pm 0.0031$ & $-12,440$ \\
\hline
\end{tabular}

Several stuck safety rod cases were examined with the three control rods inserted and withdrawn. These results are shown in Tables 9.7 and 9.8. The two models display similar behavior for the stuck-rod worths, with both displaying the shadowing effect shown in the control rod ejection sequence. However, the effects are not as severe for the safety rods because they are not as large or closely packed as the control rods. A definite reactivity bias exists in the safety rod worths, with the rods not located near beam tubes worth about $35 \%$ more than the rods that are located near the beam tubes. This difference demonstrates that the safety rods absorb a significant number of the thermal neutrons returning from fairly deep within the reflector. 
Table 9.7. Short safety rod stuck rod worths for the ANS model with central control rods at core midplane. Stuck rods are at $+800 \mathrm{~mm}$.

\begin{tabular}{llcc}
\hline Case & Stuck rod & $k_{\text {eff }}$ & $\begin{array}{c}\text { Reactivity } \\
\text { (pcm) }\end{array}$ \\
\hline ANS806 & None & 0.8296 & 0 \\
ANS805 & C & 0.8379 & $+1,000$ \\
ANS824 & D & 0.8406 & $+1,320$ \\
ANS826 & E & 0.8428 & $+1,580$ \\
ANS825 & F & 0.8428 & $+1,580$ \\
ANS828 & H & 0.8425 & $+1,540$ \\
ANS807 & C, G & 0.8447 & $+1,800$ \\
ANS809 & A, C, G & 0.8502 & $+2,450$ \\
ANS813 & A, C, E, G & 0.8630 & $+3,950$ \\
ANS814 & A-C, E, G & 0.8716 & $+4,940$ \\
ANS815 & A-C, E-G & 0.8827 & $+6,200$ \\
ANS816 & A-G & 0.9008 & $+8,230$ \\
ANS818 & A-D & 0.8636 & $+4,020$ \\
ANS827 & E-H & 0.8782 & $+5,690$ \\
ANS808 & All & 0.9231 & $+10,680$ \\
\hline
\end{tabular}

Table 9.8. Short safety rod stuck rod worths for the ANS model with central control rods at $+600 \mathrm{~mm}$. Stuck rods are at $+800 \mathrm{~mm}$.

\begin{tabular}{cccc}
\hline Case & Stuck rod & $k_{\text {eff }}$ & $\begin{array}{c}\text { Reactivity } \\
\text { (pcm) }\end{array}$ \\
\hline ANS811 & None & 0.8778 & 0 \\
ANS810 & C & 0.8884 & $+1,200$ \\
ANS817 & C, G & 0.8966 & $+2,120$ \\
ANS812 & All & 1.0168 & $+14,700$ \\
\hline
\end{tabular}




\section{HEAT LOADS}

Component heat load computations utilized both the eigenvalue and fixed source modes of MCNP. An initial eigenvalue computation was made to calculate the fission, neutron, and prompt-photon heat loads and the fission and aluminum absorption rates in each component of the reactor. The aluminum absorption rates provided a source of photons from the decay of ${ }^{28} \mathrm{Al}$ to ${ }^{28} \mathrm{Si}$ for a fixed source mode computation and the local heat load resulting from the beta particles emitted in this decay. Data on the energetics of this decay were obtained from the 1984 Chart of the Nuclides. ${ }^{22}$ The fission rates yielded a source of photons from the decay of fission products and their daughters and also the local heat load from fission product decay beta particles. This source was evaluated using the code DKPOWR, which provided the energy split between the photon and beta decays associated with the fission products and daughters.

The original fission product decay energy division was obtained from the ORIGEN2 code by assuming that the difference between the total fission product decay energy and the fission product photon energy in ORIGEN2 yielded the fission product beta energy. However, the ORIGEN2 libraries are based on ENDF/B-IV data, and, while they do contain the correct decay reaction Q-values, they do not contain the complete photon spectrum for the fission product decay. Consequently, the total decay energy will be correct, but the division between photon and beta energy will not.

The code DKPOWR was obtained from Los Alamos National Laboratory to provide a new fission product photon spectrum. This code produces fission product decay power using an input fission rate history and pulse functions, with the fission product decay library obtained from ENDF/B-V, experimental data, and ANSI/ANS-5.1-1979 the American national standard for decay heat power in light water reactors. ${ }^{20}$ The code also generates a 19-group fission product photon decay spectrum, which is based on a more complete fission product photon library. A comparison of the fission product photon spectra from DKPOWR and ORIGEN2, as well as the actual photon release rates from each code, is shown in Figs. 10.1 and 10.2. Figure 10.1 shows that the spectrum from DKPOWR is significantly harder than that obtained from ORIGEN2. The release rate data in Fig. 10.2 show that the ORIGEN2 photon library is heavily biased towards the lower energies, with over $25 \%$ of the photons having energy $<15 \mathrm{keV}$, whereas the DKPOWR library is more biased towards the photons in the 200-800 keV range. The DKPOWR release rates also show a much larger proportion of photons in the 2-5 MeV range, resulting in a much larger average energy per photon for this spectrum. These differences combine to yield nearly twice the fission product photon energy for the new calculations.

A DKPOWR case was run using a fission rate history up to one day obtained from the previous ORIGEN2 calculation, and the resulting photon decay spectrum was input to MCNP as a fixed source. A fission product photon yield per fission was determined from the total fission photon yield rate (photons/s) and the total fission rate (fissions/s). This step was necessary to normalize the fission product energy deposition correctly. A new MCNP case was then run with the correct fission product photon spectrum to generate the energy deposition throughout the reactor. The corrected results of the total heat deposition in the ANS reactor are shown in Table 10.1. As seen from comparison with the table of fission energy release data given on Table 3-10 of Lamarsh (Ref. 36), the totals here conform closely to expectations. The fission product photon and beta energy deposition each account for about $3 \%$ of the total reactor power, agreeing very closely with the fission energy release data in the literature.

This process points out a shortcoming in the ORIGEN2 libraries. While the fission product decay reaction Q-values are indeed correct, the fission product photon spectrum is in error and will produce incorrect energy deposition distributions when coupled with other methods. Thus, total energy deposition values will be correct, but the distribution will be incorrect. While this is a conservative error for core cooling constraints, because the fission product beta energy will be deposited in the fuel, 


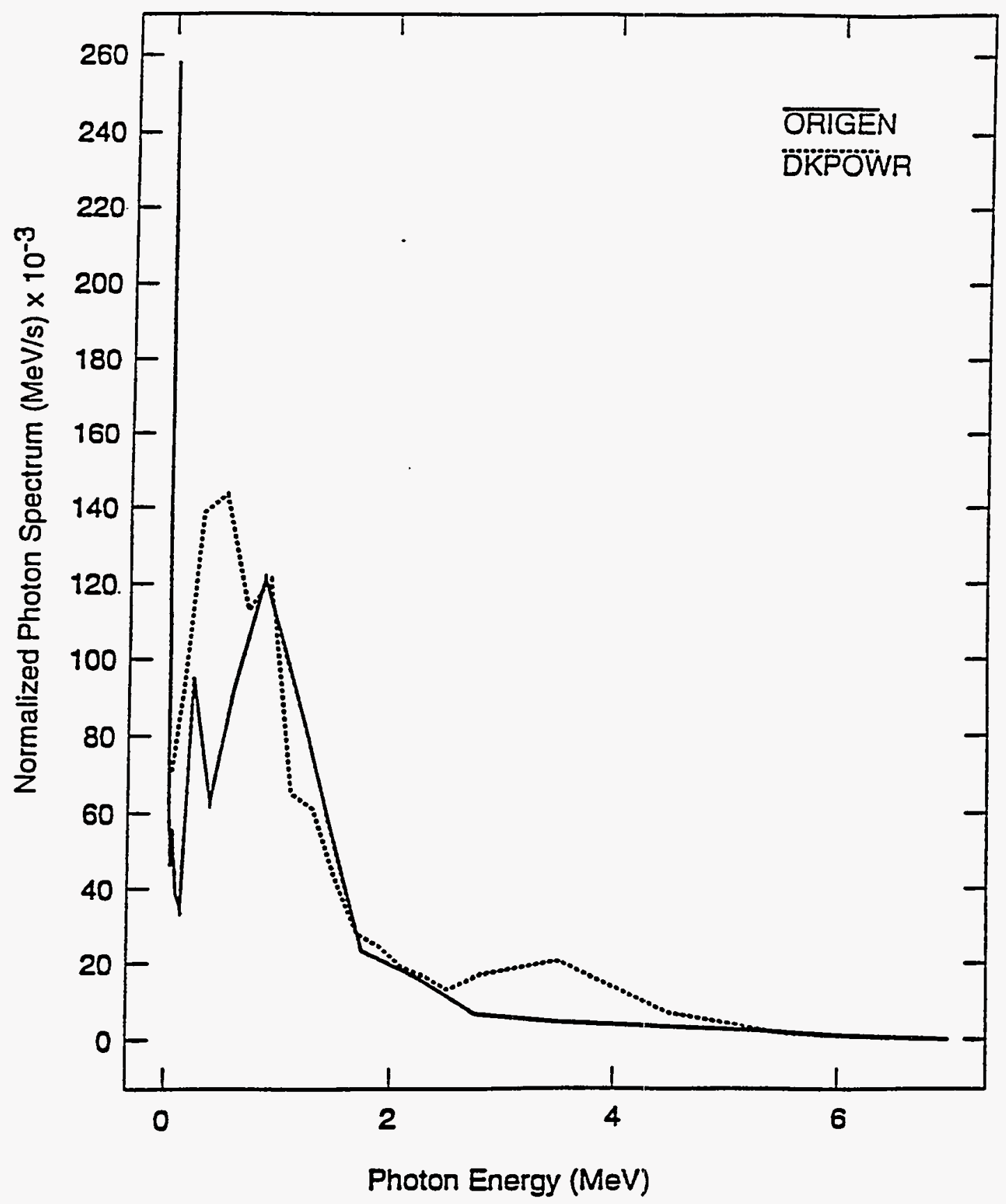

Fig. 10.1. Fission product photon release spectrum for the ANS reactor at 1-d exposure as calculated by DKPOWR and ORIGEN2. 


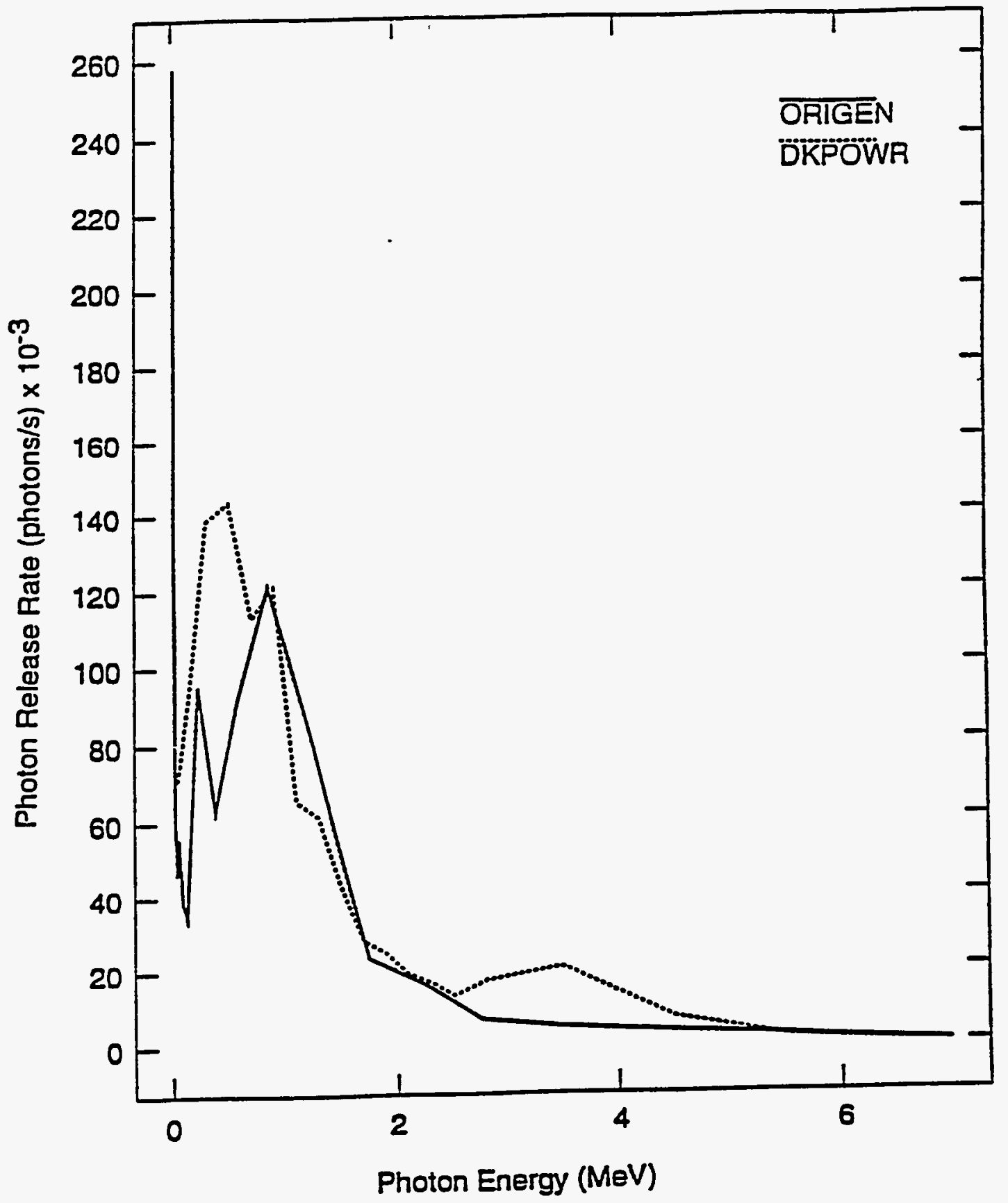

Fig. 10.2. Fission product photon yield for the ANS reactor at 1-d exposure as calculated by DKPOWR and ORIGEN2. 
Table 10.1. Heat loads for all elements in ANS design ANS643 (in $\mathrm{kW}$ ), normalized to $330 \mathrm{MW}_{\mathrm{f}} \mathrm{BOC}^{a}$

\begin{tabular}{|c|c|c|c|c|c|c|c|}
\hline \multirow{2}{*}{ Element } & \multirow{2}{*}{ Neutron } & \multirow{2}{*}{ Prompt photon } & \multicolumn{2}{|c|}{ Fission product } & \multicolumn{2}{|c|}{${ }^{28} \mathrm{Al}$ decay } & \multirow{2}{*}{ Totals } \\
\hline & & & Photon & Beta & $\overline{\text { Beta }}$ & Photon & \\
\hline Lower fuel element (LFE) & 156,828 & 3,768 & 2,472 & 5,356 & 32 & 33 & 168,489 \\
\hline Upper fuel element (UFE) & 122,945 & 2,924 & 1,837 & 4,199 & 22 & 98 & 132,025 \\
\hline Core pressure boundary tube (CPBT) & 43 & 1,114 & 458 & 0 & 251 & 96 & 1,962 \\
\hline Core support tube & 23 & 454 & 206 & 0 & 25 & 16 & 724 \\
\hline Fuel endcaps & 616 & 105 & 52 & 0 & 4 & 8 & 785 \\
\hline Outer side plate-LFE & 27 & 373 & 221 & 0 & 21 & 6 & 648 \\
\hline Inner side plate-UFE & 17 & 257 & 136 & 0 & 29 & 14 & 453 \\
\hline Outer side plate-UFE & 22 & 327 & 170 & 0 & 6 & 13 & 538 \\
\hline Central control rods (structure only) & 10 & 1,486 & 197 & 0 & 1 & 25 & 1,719 \\
\hline $\mathrm{D}_{2} \mathrm{O}$ inside $\mathrm{CPBT}$ & 3,112 & 3,526 & 1,597 & 0 & 0 & 207 & 8,442 \\
\hline Safety rods (structure only) & 0 & 640 & 17 & 0 & 2 & 17 & 676 \\
\hline Beam tubes (TH-5, TG-11, and TT-1-TT-7) & 1 & 341 & 45 & 0 & 228 & 54 & 669 \\
\hline Cold sources (spherical) & 1 & 17 & 3 & 0 & 30 & 2 & 53 \\
\hline Large slant-beam tube & 0 & 20 & 1 & 0 & 14 & 4 & 39 \\
\hline Cold source guides & 0 & 49 & 2 & 0 & 35 & 9 & 95 \\
\hline Hydraulic tubes & 1 & 48 & 7 & 0 & 29 & 9 & 94 \\
\hline Slant tube & 7 & 94 & 25 & 0 & 34 & 13 & 173 \\
\hline Isotope target facilities (VH-1-VH-4) & 0 & 5 & 1 & 0 & 4 & 4 & 14 \\
\hline Reflector vessel & 0 & 338 & 2 & 0 & 142 & 19 & 501 \\
\hline Reflector $\mathrm{D}_{2} \mathrm{O}$ & 1,714 & 9,813 & 2,400 & $\mathbf{0}$ & 0 & 728 & 14,655 \\
\hline Totals & 285,367 & 25,699 & 9,849 & 9,555 & 909 & $\overline{1,375}$ & 332,754 \\
\hline
\end{tabular}

\footnotetext{
${ }^{a} \mathrm{~A}$ total of $823 \mathrm{~kW}$ is lost by leakage out of the model.
} 


\section{$10-5$}

it represents a significant error for a reactor of the nature of ANS. The fission product photon energy represents a fraction of the fission product decay energy that is distributed much more widely than the beta energy. This fact will affect the energy deposition in the reflector components most and can result in a large error in the deposited energy if the fission product photon spectrum is incorrect. 
. 


\section{SHUTDOWN REACTIVITY MARGINS}

Because of the very high flux in the ANS fuel elements, the Xe poisoning after a trip is high and vanishes only after several days. During the shutdown time, the ${ }^{149} \mathrm{Sm}$ buildup from the ${ }^{149} \mathrm{Pm}$ decay continues uniformly, and by the time the Xe poisoning becomes small, the Sm poisoning may be too large to restart the reactor. To evaluate the capability for restart, calculations were performed in which the ANS L7 core was tripped after 1.0, 4.25, 8.50, 12.75, and 17.0 d of operation at HFP, and after each trip, the reactor $k_{\text {eff }}$ was followed. Within a few minutes after a reactor trip, the safety control rods were again completely withdrawn, and the regulating control rods were placed at the same position as just before the reactor trip. A synopsis of the results of these calculations is displayed in Table 11.1.

When the central control rods are repositioned as before the reactor trip, the reactor core cannot be restarted unless the regulating control rods are moved to add positive reactivity to the core. The table shows that, for a reactor trip at 1.0, 4.25, 8.50, and $12.75 \mathrm{~d}$ of operation, the reactor can be restarted after approximately $45 \mathrm{~h}$ for the 1-d trip and after approximately $64 \mathrm{~h}$ for the 12.75-d trip, when the central control rods are completely withdrawn from the core.

Table 11.1 also shows that the Sm poisoning at $96 \mathrm{~h}$ after shutdown increases with cycle length, since the flux (and thus the Sm poisoning after shutdown) increases with cycle time. (For constant power operation, fission product poisoning and fuel depletion increase with cycle time, and thus the flux increases with cycle time.)

An additional effect is that the power generated in the core shifts from the bottom element to the upper element because of the central control rod movement and the faster fuel depletion in the lower element in the first half of the cycle. At EOC there is less fuel in the lower element, and the power (and thus the flux) increases sharply in the upper element. This effect increases the Sm poisoning even more. In addition, at EOC no positive reactivity is held down by the regulating control rods because they are completely withdrawn.

Additional analyses for reactor trips at 8.5 and $14.85 \mathrm{~d}$ of HFP operation were performed. This evaluation addressed the issue of a possible reactivity decrease immediately after the reactor return to HFP with the regulating control rods fully withdrawn. As shown in Table 11.2, the $\mathrm{k}_{\text {eff }}$ increases with time in both cases immediately after a return to HFP. The positive reactivity effect of the burnup of the samarium is greater than the negative reactivity effect resulting from the buildup of the equilibrium xenon. This slow reactivity buildup effect is well within the range that can be compensated for by the reactor control system. With burnup of the samarium, the normal burnup pattern is restored, and a normal core life is obtained. 
Table 11.1 Core multiplication factor $\left(k_{\mathrm{eff}}\right)$ after shutdown as a function of cycle time at which reactor trip occurs

\begin{tabular}{|c|c|c|c|c|c|c|c|c|c|c|}
\hline \multirow{3}{*}{$\begin{array}{l}\text { Time after } \\
\text { trip (h) }\end{array}$} & \multicolumn{10}{|c|}{ Cycle time at which trip occurs } \\
\hline & \multicolumn{2}{|c|}{$1.0 \mathrm{~d}$} & \multicolumn{2}{|c|}{$4.25 \mathrm{~d}$} & \multicolumn{2}{|c|}{$8.50 \mathrm{~d}$} & \multicolumn{2}{|c|}{$12.75 \mathrm{~d}$} & \multicolumn{2}{|c|}{$17.0 \mathrm{~d}$} \\
\hline & $\begin{array}{l}\text { Same control } \\
\text { rod position }\end{array}$ & $\begin{array}{l}\text { Control rods } \\
\text { withdrawn }\end{array}$ & $\begin{array}{l}\text { Same control } \\
\text { rod position }\end{array}$ & $\begin{array}{l}\text { Control rods } \\
\text { withdrawn }\end{array}$ & $\begin{array}{l}\text { Same control } \\
\text { rod position }\end{array}$ & $\begin{array}{l}\text { Control rods } \\
\text { withdrawn }\end{array}$ & $\begin{array}{l}\text { Same control } \\
\text { rod position }\end{array}$ & $\begin{array}{l}\text { Control rods } \\
\text { withdrawn }\end{array}$ & $\begin{array}{l}\text { Same control } \\
\text { rod position }\end{array}$ & $\begin{array}{l}\text { Control rods } \\
\text { withdrawn }\end{array}$ \\
\hline 0 & 1.0000 & & 1.0000 & & 1.0000 & & 1.0000 & & 1.0000 & \\
\hline 2 & 0.7856 & & 0.7536 & & 0.7230 & & 0.7016 & & 0.6864 & \\
\hline 4 & 0.6995 & & 0.6609 & & 0.6256 & & 0.6021 & & 0.5832 & \\
\hline 6 & 0.6582 & & 0.6177 & & 0.5811 & & 0.5573 & & 0.5373 & \\
\hline 12 & 0.6314 & & 0.5897 & & 0.5525 & & 0.5286 & & 0.5078 & \\
\hline 18 & 0.6601 & & 0.6184 & & 0.5811 & & 0.5569 & & 0.5366 & \\
\hline 24 & 0.7103 & & 0.6696 & & 0.6328 & & 0.6084 & & 0.5892 & \\
\hline 30 & 0.7687 & & 0.7302 & & 0.6949 & & 0.6707 & & 0.6531 & \\
\hline 36 & 0.8268 & & 0.7916 & & 0.7587 & & 0.7352 & & 0.7195 & \\
\hline \multirow[t]{2}{*}{42} & 0.8788 & 0.9840 & 0.8472 & 0.9545 & 0.8174 & & 0.7952 & & 0.7814 & \\
\hline & & CRITICAL & & CRITICAL & & & & & & \\
\hline \multirow[t]{2}{*}{48} & 0.9217 & 1.0269 & 0.8934 & 1.0007 & 0.8667 & 0.9707 & 0.8460 & & 0.8339 & \\
\hline & & & & & & CRITICAL & & & & \\
\hline 54 & 0.9546 & & 0.9290 & & 0.9049 & 1.0089 & 0.8856 & & 0.8747 & \\
\hline \multirow[t]{2}{*}{60} & 0.9785 & & 0.9548 & & 0.9325 & & 0.9142 & 0.9855 & 0.9043 & \\
\hline & & & & & & & & CRITICAL & & \\
\hline \multirow[t]{2}{*}{66} & 0.9952 & & 0.9742 & & 0.9514 & & 0.9476 & 1.0188 & 0.9243 & \\
\hline & CRITICAL & & & & & & & & & \\
\hline 72 & 1.0064 & & 0.9840 & & 0.9636 & & 0.9462 & & 0.9370 & \\
\hline 78 & & & 0.9912 & & 0.9710 & & 0.9537 & & 0.9445 & \\
\hline 84 & & & 0.9954 & & 0.9752 & & 0.9578 & & 0.9485 & \\
\hline 90 & & & 0.9978 & & 0.9773 & & 0.9597 & & 0.9501 & \\
\hline 96 & & & 0.9988 & & 0.9780 & & 0.9602 & & 0.9504 & $\begin{array}{c}\text { NOT } \\
\text { CRITICAL }\end{array}$ \\
\hline
\end{tabular}

${ }^{\circ}$ Central control rods are at the same position as when the trip occurred.

${ }^{b} \mathrm{Central}$ control rods are completely withdrawn.

Reactor becomes critical $\left(k_{\mathrm{eff}}=1\right)$ in indicated time interval. 
Table 11.2 Core multiplication factor $\left(k_{\mathrm{eff}}\right)$ after restart from reactor trip, demonstrating the ${ }^{149} \mathrm{Sm}$ burnup

\begin{tabular}{ccc}
\hline $\begin{array}{c}\text { Operation time at } \\
\text { full power }\end{array}$ & \multicolumn{2}{c}{ Cycle time at which reactor trip occurs } \\
\cline { 2 - 3 }$(\mathrm{h})$ & $8.5 \mathrm{~d}$ & $14.85 \mathrm{~d}$ \\
\hline $0^{a}$ & 1.0047 & 0.9991 \\
2 & 1.1099 & 1.0273 \\
4 & 1.1130 & 1.0410 \\
6 & 1.1137 & 1.0474 \\
\hline
\end{tabular}

${ }^{a}$ Operation time of $0 \mathrm{~h}$ corresponds to $53 \mathrm{~h}$ after trip occurring at $8.5 \mathrm{~d}$ and $96 \mathrm{~h}$ after trip occurring at $14.85 \mathrm{~d}$. 
- 


\section{REACTIVITY COEFFICIENTS}

\subsection{REACTIVITY EFFECTS OF LIGHT WATER CONTAMINATION}

MCNP and PDQ studies of light water contamination were performed. The MCNP studies were for BOC configurations with three positions of the control rods: fully inserted, inserted to midplane, and fully withdrawn. Further, because of the statistical nature of the Monte Carlo calculations, the studies in MCNP were made for large $(>5 \%)$ contamination in $\mathrm{D}_{2} \mathrm{O}$. The PDQ studies were for BOC and $\mathrm{EOC}$ and for small $(<5 \%)$ contaminations in $\mathrm{D}_{2} \mathrm{O}$.

\subsubsection{Light Water Contamination Studies with MCNP}

Four sets of MCNP studies of light water contamination at BOC have been completed. These are for uniformly distributed light water contamination in (1) the central hole inside the inner tube (IT), (2) the fueled flow region inside the CPBT but outside the IT, (3) the CPBT and the IT, and (4) the reflector. Note that these are scoping calculations; there is no mechanism by which such contamination could be limited to the individual regions only. In each of the four sets, the control rods were positioned such that the leading tips were at the core midplane, at the top of the UFE, and at the bottom of the LFE. Thus, 12 subsets of calculations were performed.

\section{Light Water Contamination in Central Hole}

Figure 12.1 gives the reactivity worth as only the central hole $\mathrm{D}_{2} \mathrm{O}$ is contaminated with light water for the control rod configuration where the leading tips are at the core midplane. The initial light water contamination has a positive worth that peaks between 10 and $25 \% \mathrm{H}_{2} \mathrm{O}$ with a net worth of $-2000 \mathrm{pcm}$. As the contamination increases, the parasitic absorption in hydrogen overcomes its moderating advantage over deuterium, yielding a net negative reactivity insertion. At $100 \%$ contamination, the maximum negative reactivity insertion is $-7600 \mathrm{pcm}$.

Figure 12.2 is a plot of the reactivity worth as evaluated against the percentage of light water contamination for the control rod leading tips at the top of the UFE case. Here the positive reactivity peak is less than $1000 \mathrm{pcm}$, and the peak occurs at a smaller percentage of light water contamination $(10 \%)$.

Table 12.1 shows that light water contamination in the central hole has a negligible worth when the control rod leading tips are inserted to the bottom of the LFE. The variation in the eigenvalue from the base case (ANS307a) is of the order of magnitude of the sum of the statistical errors in these values; hence the eigenvalue is not plotted as in the previous two cases. In all the degrees of light water contamination in the central hole, the reactor remains subcritical with the control rods fully inserted.

\section{Light Water Contamination Between CPBT and Inner Tube}

Figure 12.3 shows that, with the control rod leading tips at core midplane, there is about $1000 \mathrm{pcm}$ in $\mathrm{k}_{\text {eff }}$ positive reactivity insertion at about $5 \%$ light water contamination. This trend becomes negative and reaches a maximum negative worth of $-6600 \mathrm{pcm}$ at full $(100 \%)$ light water contamination.

Figure 12.4 shows that there is no initial positive reactivity insertion when the control rod leading tips are withdrawn to the top of the UFE. The effect of $\mathrm{H}_{2} \mathrm{O}$ contamination monotonically decreases in reactivity, with a maximum negative reactivity worth of nearly $14,000 \mathrm{pcm}$ at full $(100 \%) \mathrm{H}_{2} \mathrm{O}$ contamination. The worth of contamination under $10 \%$ is less than $-1000 \mathrm{pcm}$. 


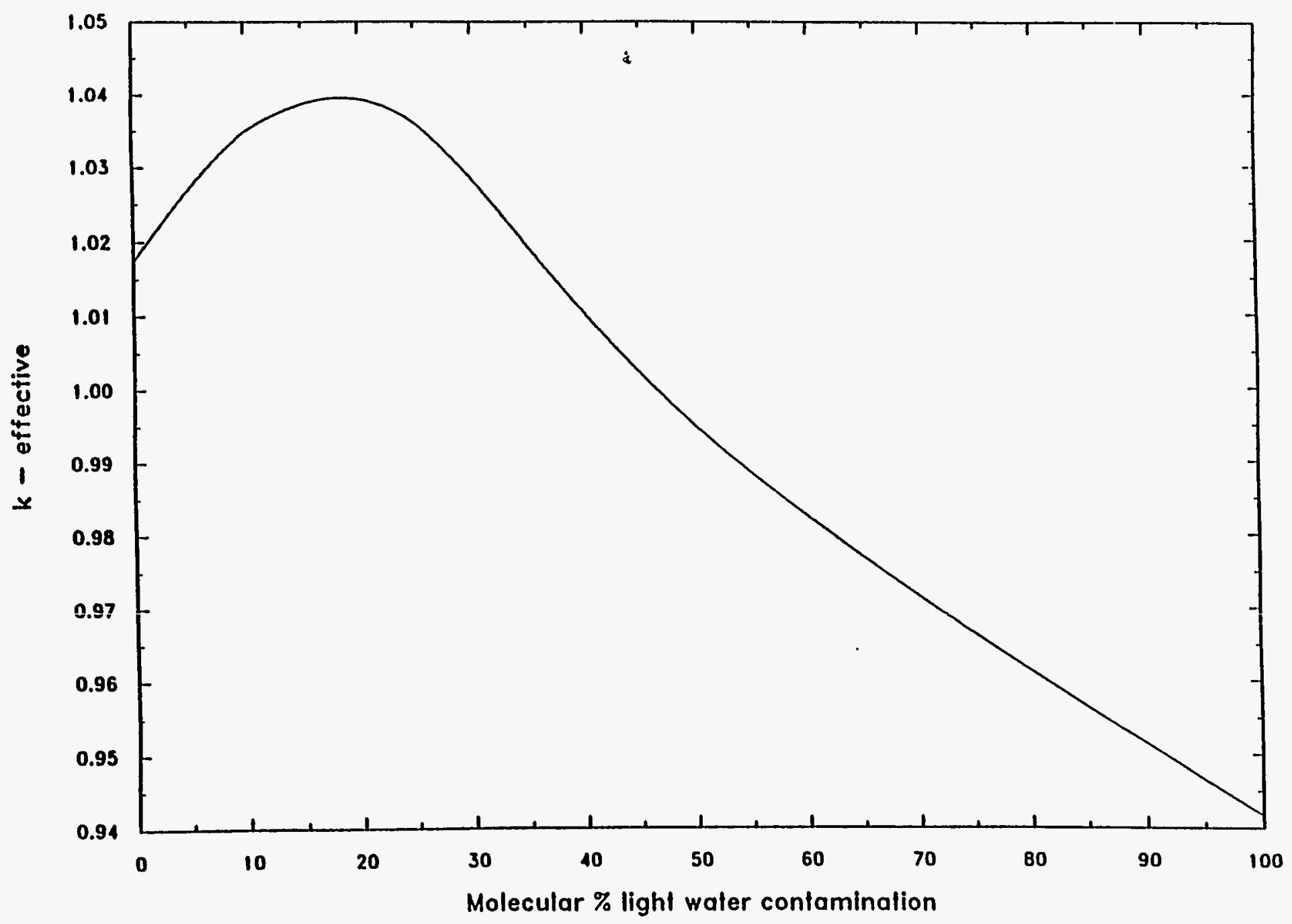

Fig. 12.1. Core multiplication factor at BOC with control rod leading tips at core midplane as a function of molecular percent light water contamination in the central hole $\mathrm{D}_{\mathbf{2}} \mathrm{O}$. 


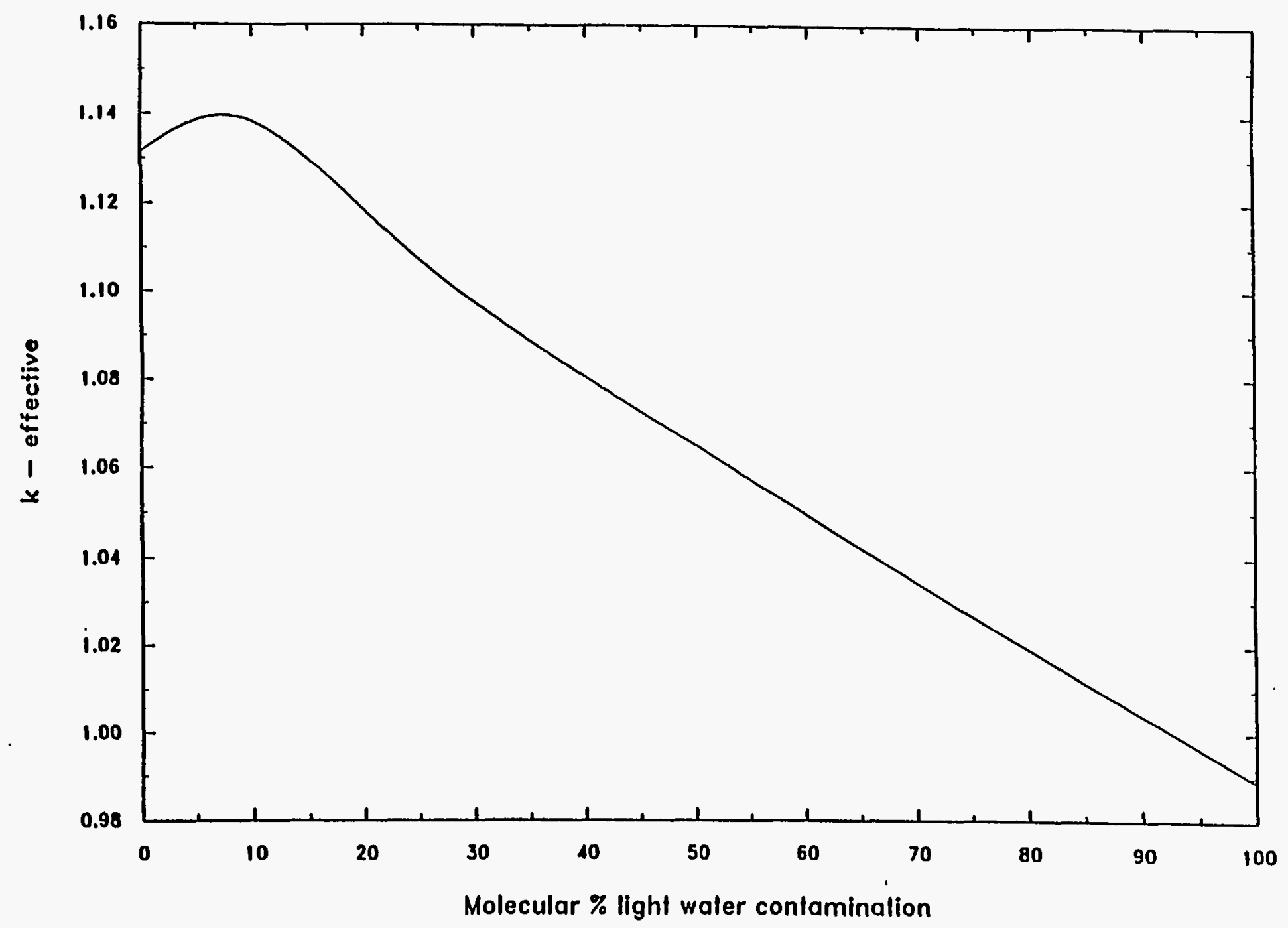

$\vec{\omega}$

Fig. 12.2. Core multiplication factor at BOC with control rod leading tips at the top of UFE as a function of molecular percent light water contamination in the central hole $\mathrm{D}_{2} \mathrm{O}$. 
Table 12.1. Reactivity worth of light water contamination in the central hole at BOC with the control rods at the bottom of LFE

\begin{tabular}{cccc}
\hline Run identifier & $\begin{array}{c}\mathrm{H}_{2} \mathrm{O} \text { contamination } \\
(\%)\end{array}$ & $\mathrm{k}_{\text {eff }}$ & $\begin{array}{c}\text { Reactivity worth } \\
(\mathrm{pcm})\end{array}$ \\
\hline ANS307a & 0 & $0.8977 \pm 0.0026$ & 0 \\
ANS509 & 10 & $0.8951 \pm 0.0026$ & -290 \\
ANS508 & 25 & $0.8978 \pm 0.0030$ & 0 \\
ANS507 & 50 & $0.8898 \pm 0.0027$ & -880 \\
ANS510 & 75 & $0.8881 \pm 0.0033$ & -1080 \\
ANS476 & 100 & $0.8901 \pm 0.0029$ & -850 \\
\hline
\end{tabular}

Figure 12.5 shows that, with the control rod leading tips inserted to the bottom of the LFE, the reactivity worth monotonically increases with $\mathrm{H}_{2} \mathrm{O}$ contamination to over $50 \%$. There is a fairly mild peak between approximately 30 and $50 \%$ contamination. The reactor remains subcritical for all levels of contamination.

\section{Light Water Contamination Inside the CPBT and Inner Tube}

Figure 12.6 shows that, with the control rod leading tips at core midplane, the reactivity worth of light water contamination in the entire region inside the CPBT has the expected trend of initial positive reactivity worth and then increasingLY negative reactivity worth.

Figure 12.7 shows that, with the control rod leading tips withdrawn to the top of the UFE, the light water contamination in the entire region inside the CPBT results in a negative reactivity insertion of a few thousand percent mille at $<20 \% \mathrm{H}_{2} \mathrm{O}$ contamination, increasing rapidly thereafter to reach $-20,000$ pcm at $100 \%$ contamination.

Figure 12.8 shows that, with the control rod leading tips inserted to the bottom of the LFE, the reactivity worth inside the CPBT monotonically increases until $-30 \%$ contamination and slowly decreases thereafter to $100 \%$ contamination, where the net positive reactivity insertion is $2300 \mathrm{pcm}$. The reactor remains subcritical for all levels of contamination.

From the above nine cases, some general conclusions can be made. There is a strong trade-off between the relative blackness in hafnium as the neutron energy changes and the spectral effects resulting from hydrogen moderation and absorption in the various contaminated regions.

First, low-level light water contamination is a positive reactivity insertion. At greater contaminations, the reversal in this trend is because of the relative moderation to absorption effects in hydrogen as compared to deuterium. This effect is most apparent in the contamination in the central hole alone. Second, the relative reactivity insertion peak positions along the contamination scale are affected by the control rod bank position. Thus, the peak is between 10 and $25 \%$ contamination when the control rods are at core midplane, but it is pushed to $<10 \%$ contamination when the control rod leading tips are at the top of the UFE and to $\geq 30 \%$ contamination when the control rod leading tips are at the bottom of the LFE. 


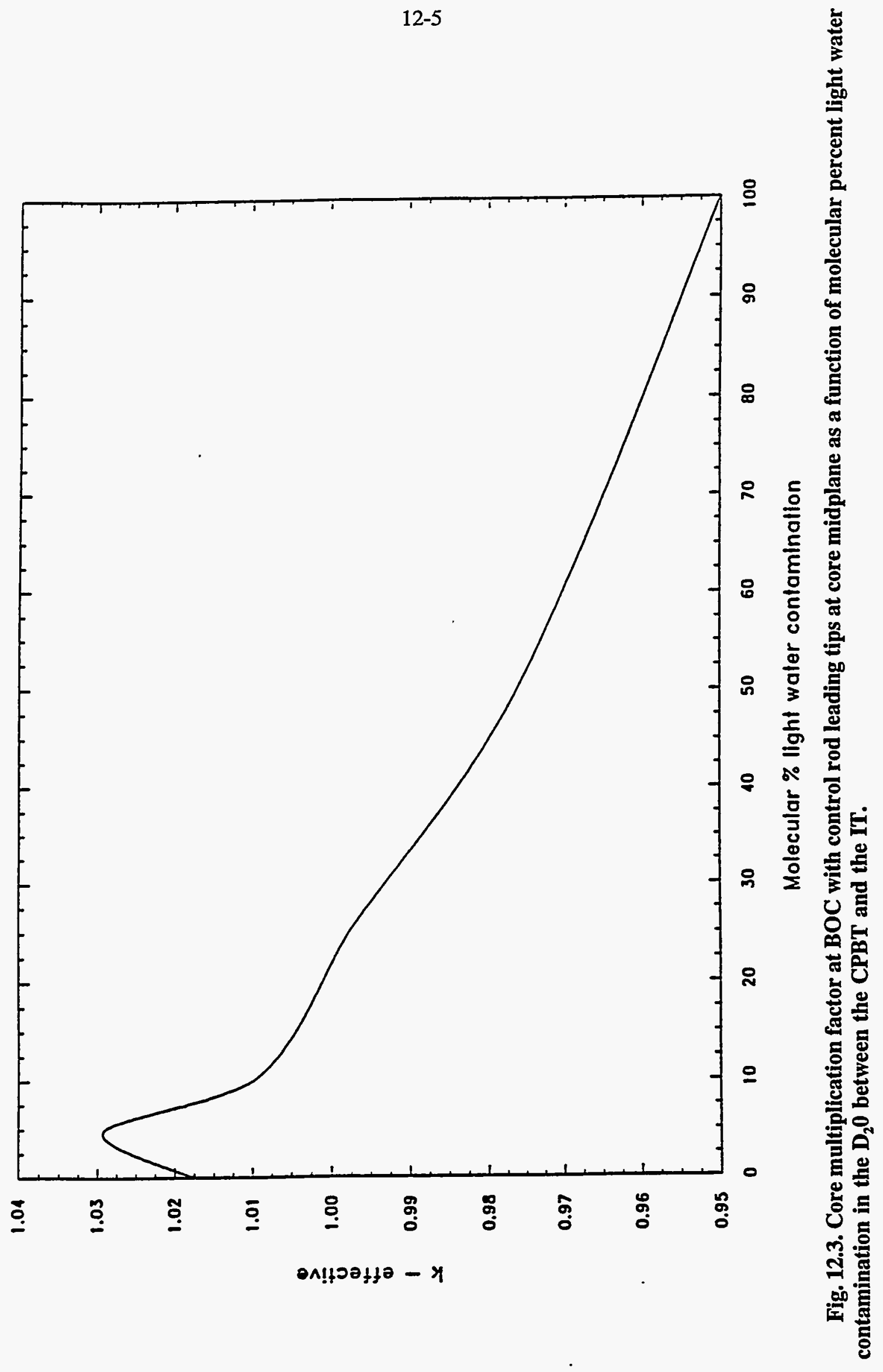




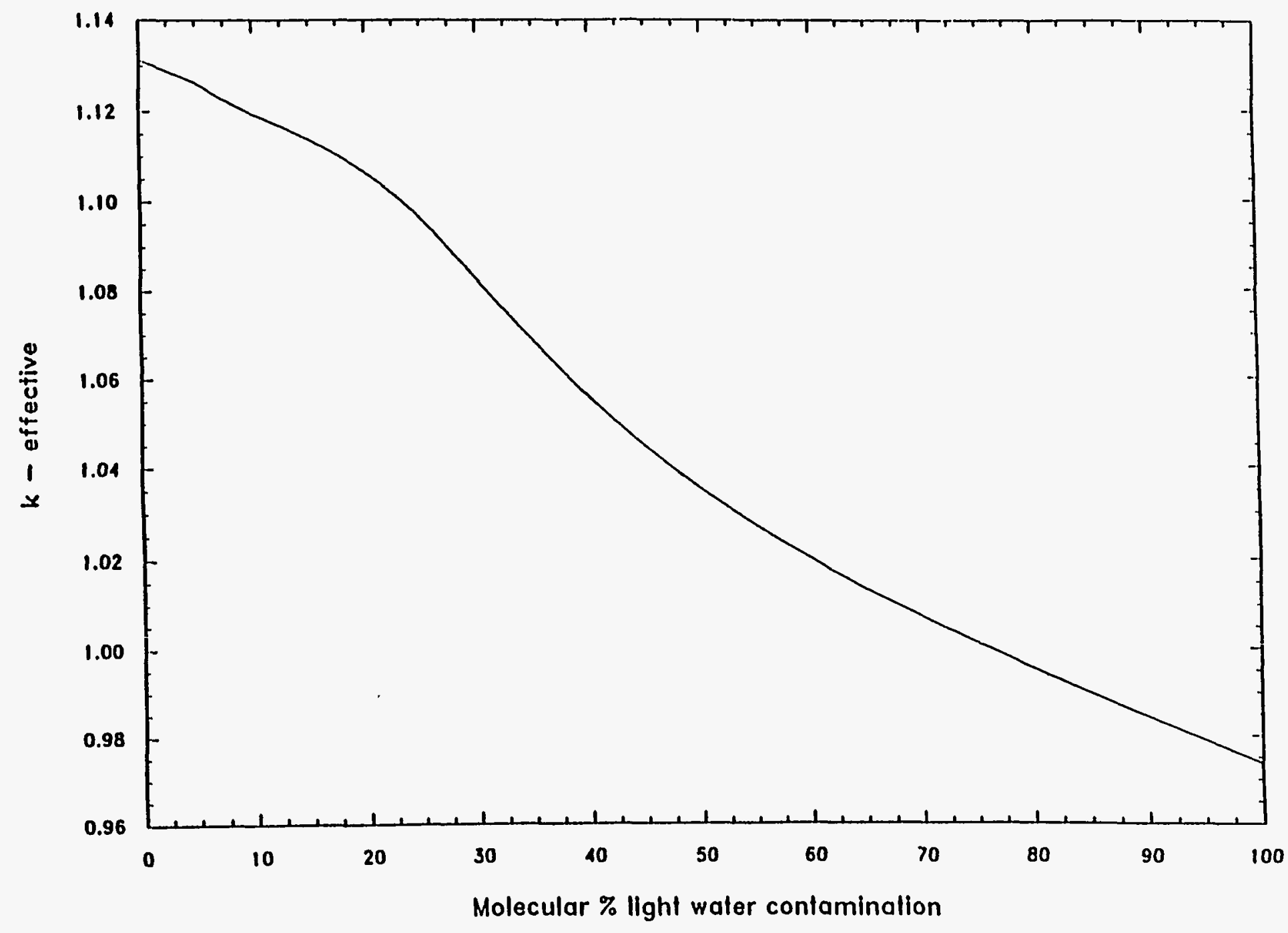

Fig. 12.4. Core multiplication factor at BOC with control rod leading tips at the top of the UFE as a function of molecular percent light water contamination in the $D_{2} 0$ between the CPBT and the IT. 

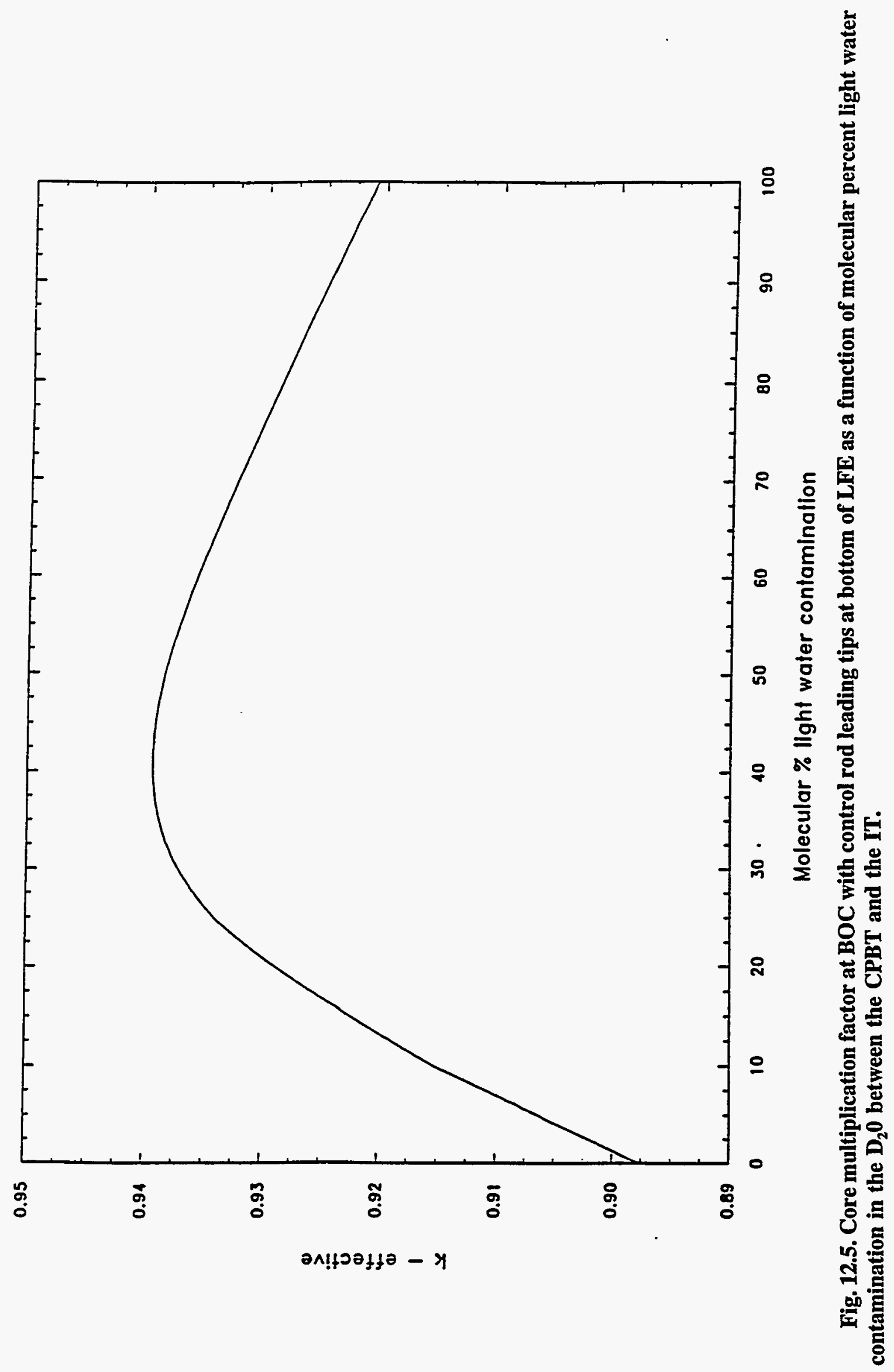


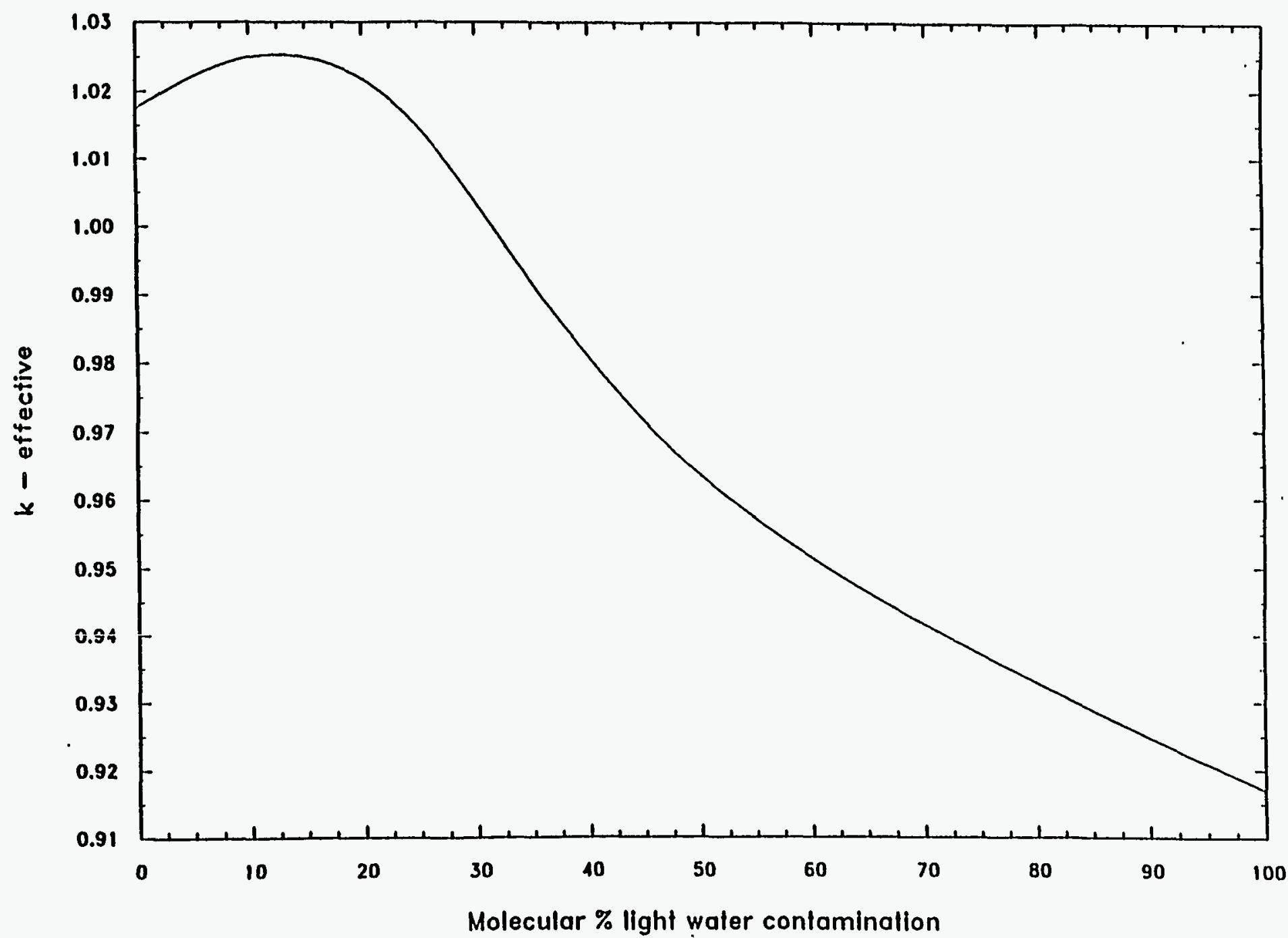

$\underset{\infty}{\infty}$

Fig. 12.6. Core multiplication factor at BOC with control rod leading tips at the core midplane as a function of molecular percent light water contamination in the $\mathrm{D}_{2} 0$ inside the CPBT. 
$12-9$

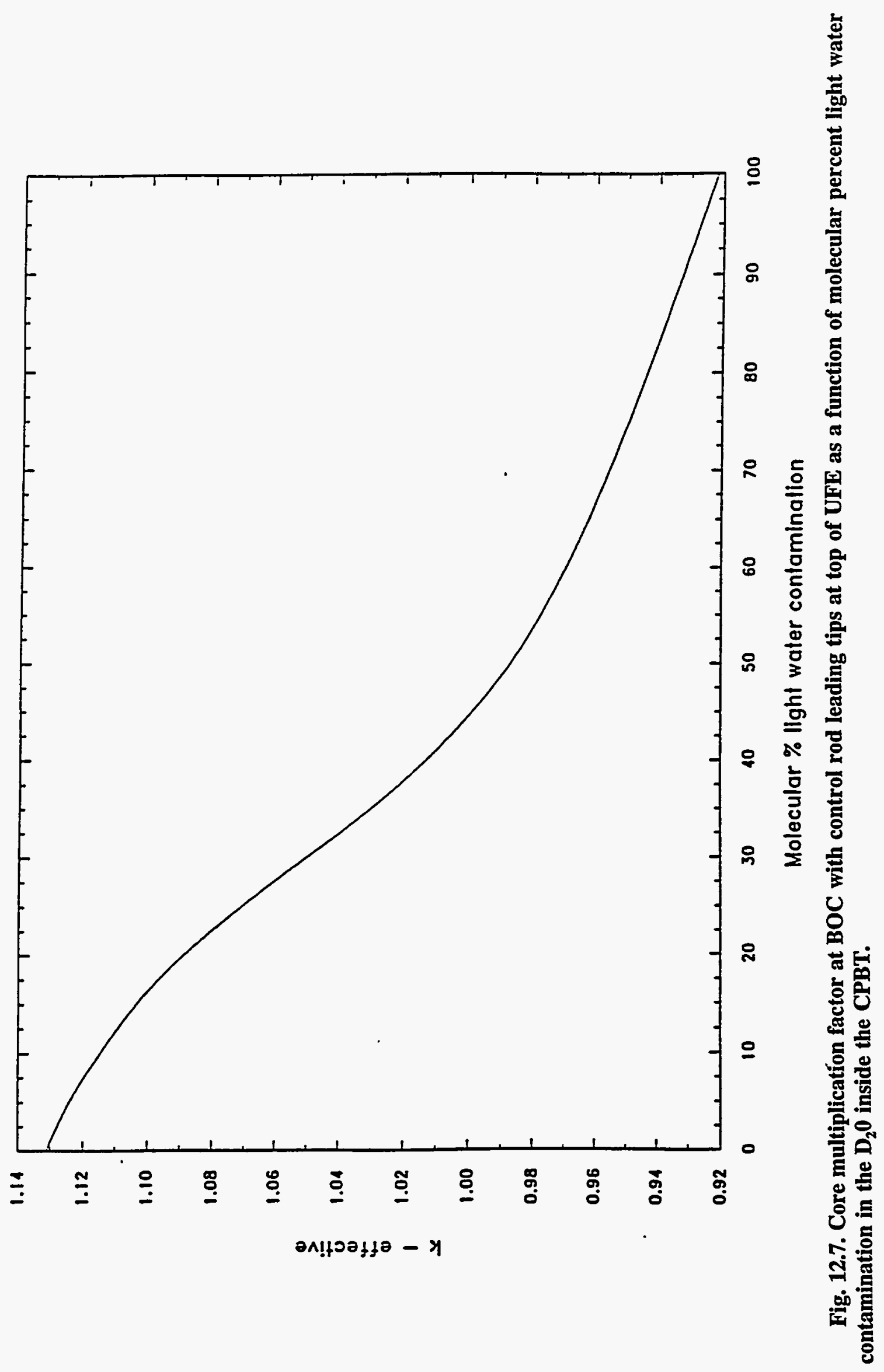




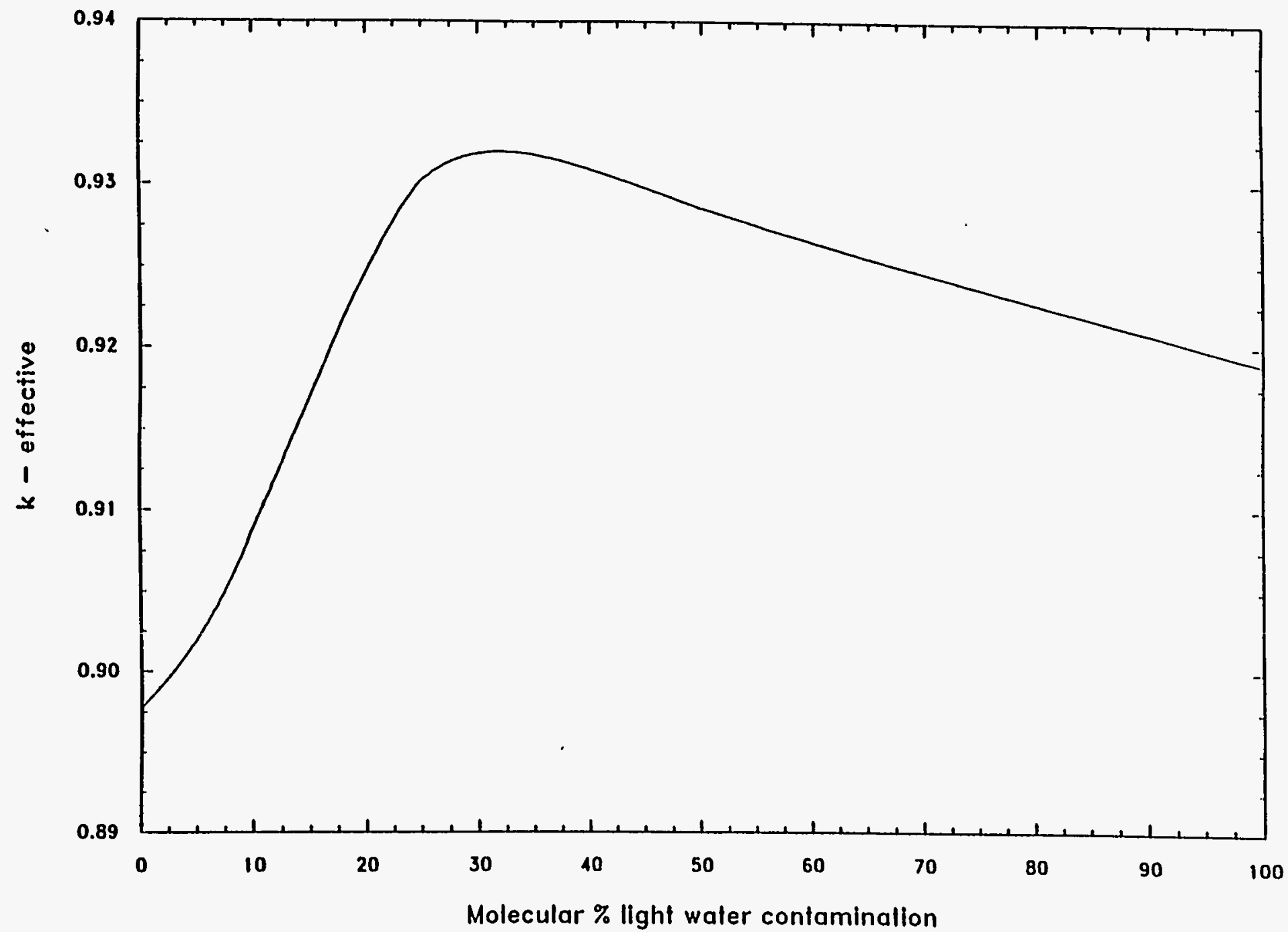

Fig. 12.8. Core multiplication factor at BOC with control rod leading tips at bottom of $\mathrm{LFE}$ as a function of molecular percent light water contamination in the $\mathrm{D}_{\mathbf{2}} \mathrm{O}$ inside the CPBT. 
This trend with the control rods results from decreasing reactivity insertion for the rod tips at the top of the UFE (i.e., peak is at zero contamination) and fairly flat peaks when the rod tips are at the bottom of the LFE. The full-contamination worth is generally a net positive insertion in the latter cases. However, the reactor is always subcritical when the rod tips are at the bottom of the LFE.

Finally, at any value of contamination, the combined region contamination is not equal to the sum of the individual region's contaminations. For example, compare Figs. 12.1, 12.3, and 12.6 at $10 \%$ contamination. For this case, the combined region contamination worth is less than that of either region alone. Clearly, there are complicated spectral and relative hafnium blackness effects at play here.

\section{Light Water Contamination in the Reflector}

Figure 12.9 shows the results of light water contamination in the reflector at BOC when the control rod leading tips are at the core midplane. The light water contamination has a negative worth that grows continuously with contamination. At $100 \%$ contamination, the maximum negative reactivity insertion is $-30,000 \mathrm{pcm}$.

In Fig. 12.10, the reactivity worth is evaluated against the percentage of light water contamination in the reflector with the control rod leading tips at the top of the UFE. The negative reactivity worth of the contamination also monotonically increases with contamination.

In Fig. 12.11 the reactivity worth is evaluated against the percentage of light water contamination in the reflector with the control rods almost fully inserted (leading tips at bottom of LFE). The reactivity worth of the light water contamination is negative and monotonically decreases with contamination. In all the degrees of light water contamination in the reflector with the control rods fully inserted, the reactor remains subcritical.

The reactivity effect of light water contamination in the reflector is negative for all cases considered. The values at $10 \%$ contamination are approximately $-12,000 \mathrm{pcm}$ in relative worth, indicating that the contamination probably reduces reactivity worth even for contamination levels that are too small to resolve in the MCNP statistics. This conclusion is supported by the PDQ studies presented below.

\subsubsection{Light Water Contamination Studies with PDQ}

\section{PDQ Study of Very Small Light Water Contamination Effects in the Reflector at BOC}

Figures 12.12 and 12.13 give the results of $P D Q-7$ runs for $C C D$, showing the effects on reactivity and the peak thermal flux of very small amounts of light water contamination in the reflector at BOC. The location of the peak thermal neutron flux did not vary significantly from case to case. The absolute accuracy in the eigenvalue prediction in PDQ is not claimed to be to four decimal places. However, for this fine incremental change in the reflector light water contamination, the incremental change in eigenvalue can be extracted.

\section{PDQ Evaluation of Light Water Contamination at BOC and EOC}

Results of light water contamination inside the CPBT at BOC and EOC for concentrations of 0 to $40 \% \mathrm{H}_{2} \mathrm{O}$ are shown in Fig. 12.14.

Results of $\mathrm{H}_{2} \mathrm{O}$ contamination in the reflector and in both the reflector and the CPBT at EOC are shown in Fig. 12.15. The effect of the reflector on the eigenvalue should be noted because only a small amount of light water contamination results in a very large decrease in the eigenvalue. This effect from the reflector overrides the increase in eigenvalue previously observed for the CPBT ingress study, although the increase is apparent in the reflector plus CPBT cases. The reflector studies were 


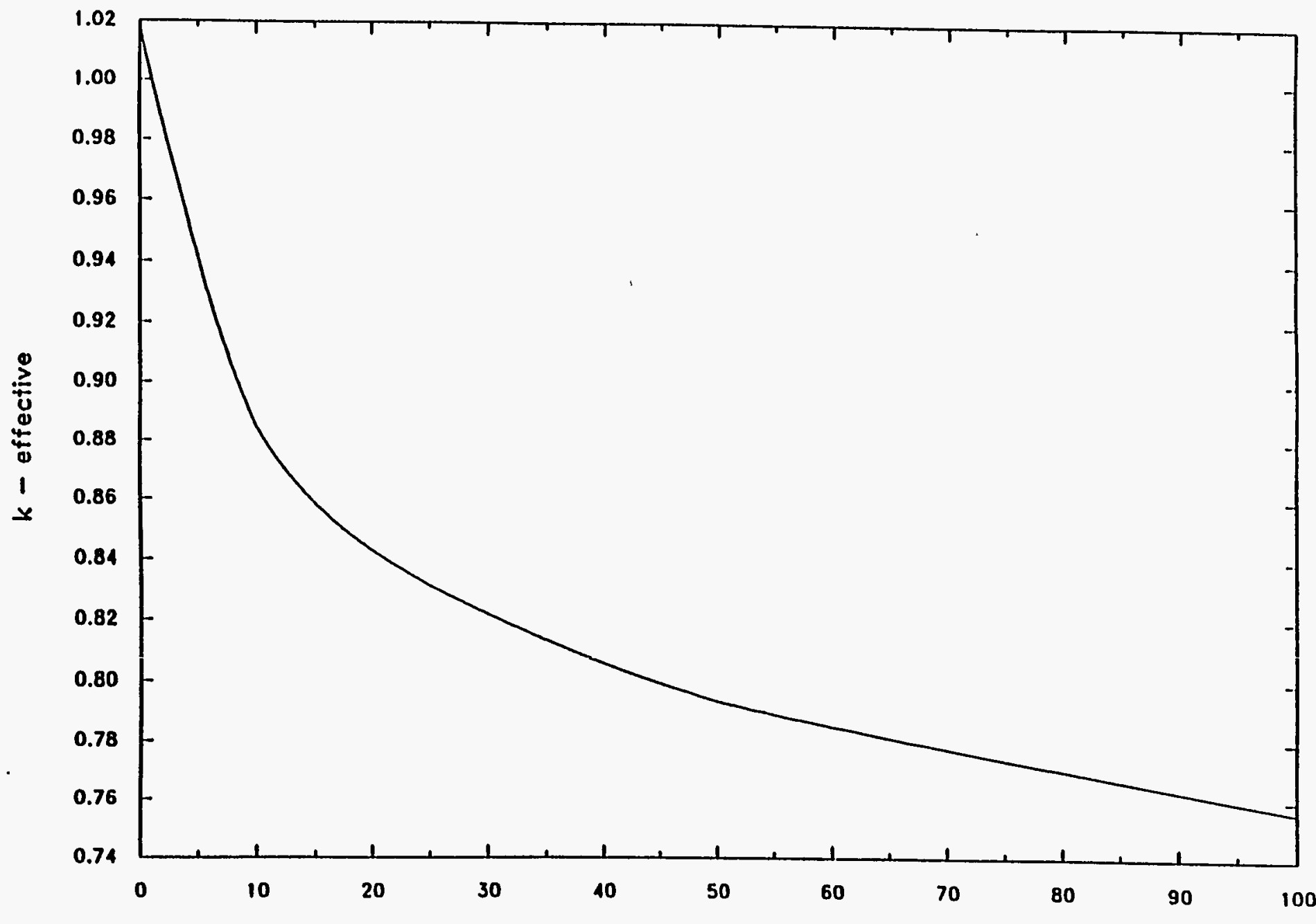

Fig. 12.9. Core multiplication factor at BOC with control rod leading tips at core midplane as a function of molecular percent light water contamination in the $\mathrm{D}_{2} \mathrm{O}$ reflector. 


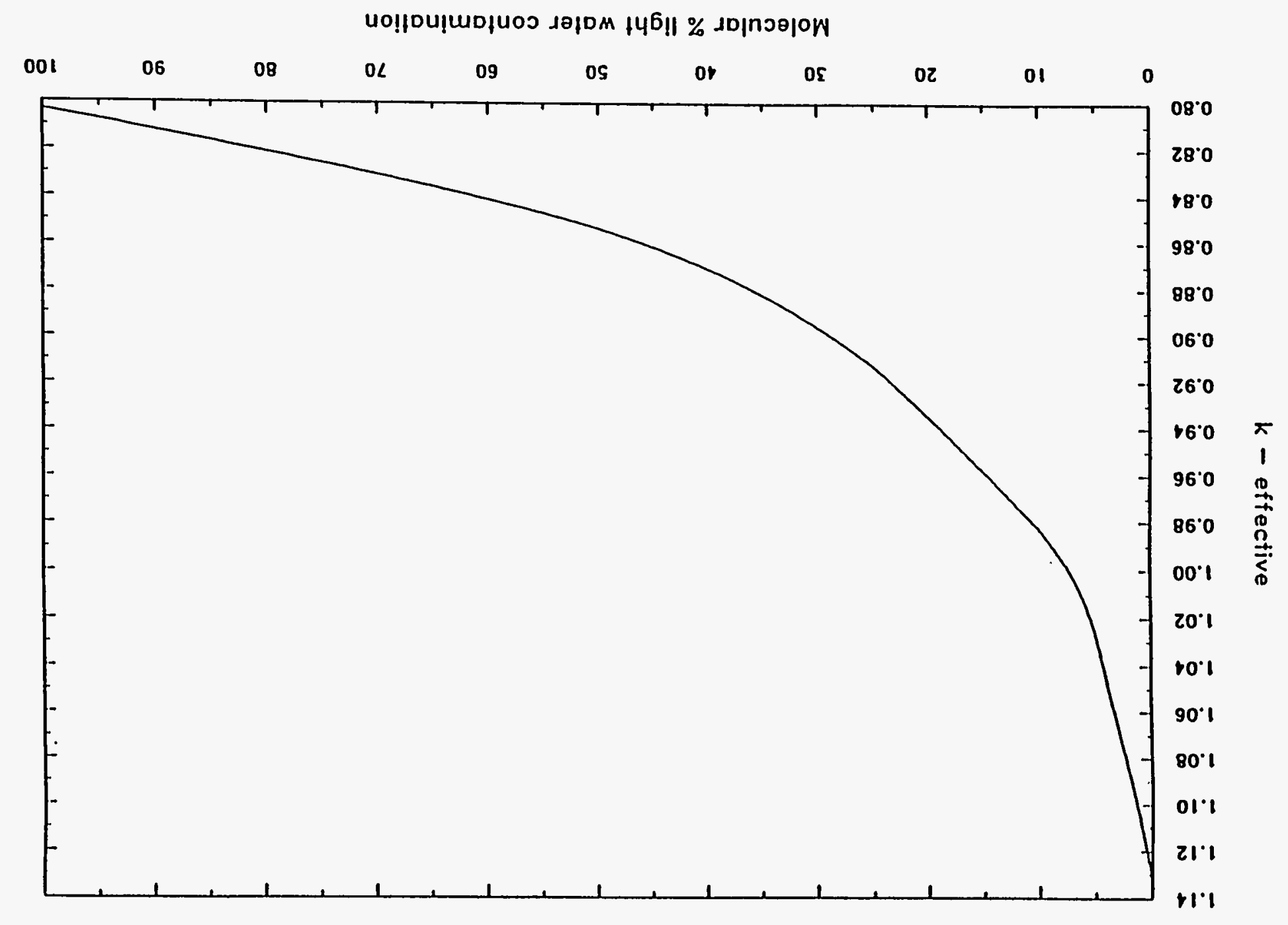

Fig. 12.10. Core multiplication factor at BOC with control rod leading tips at top of UFE as a function of molecular percent light water contamination in the $\mathrm{D}_{\mathbf{2}} \mathrm{O}$ reflector. 


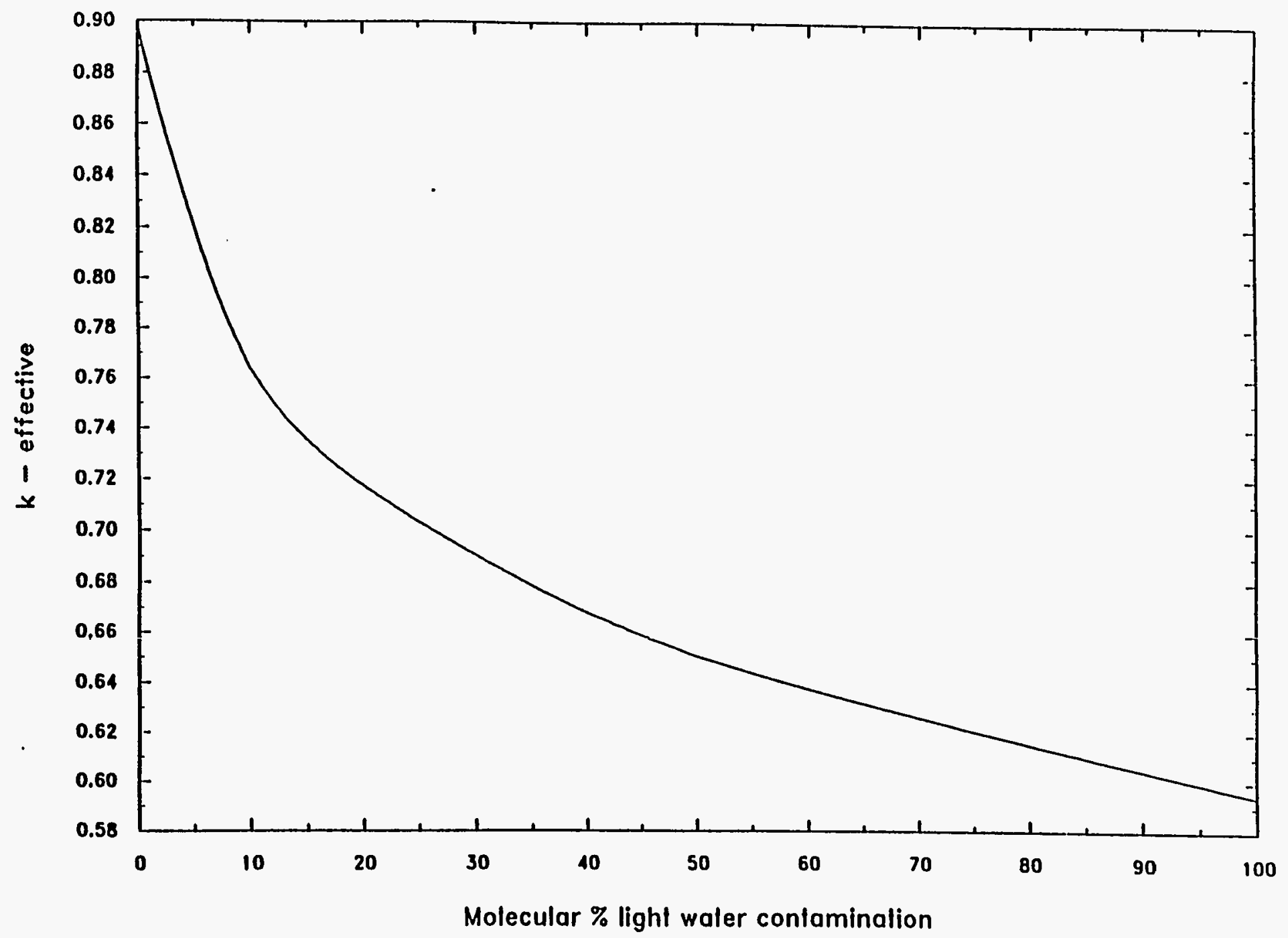

$\stackrel{\vec{N}}{\stackrel{1}{A}}$

Fig. 12.11. Core multiplication factor at BOC with control rod leading tips at bottom of LFE as a function of molecular percent light water contamination in the $\mathbf{D}_{2} 0$ reflector. 
$12-15$

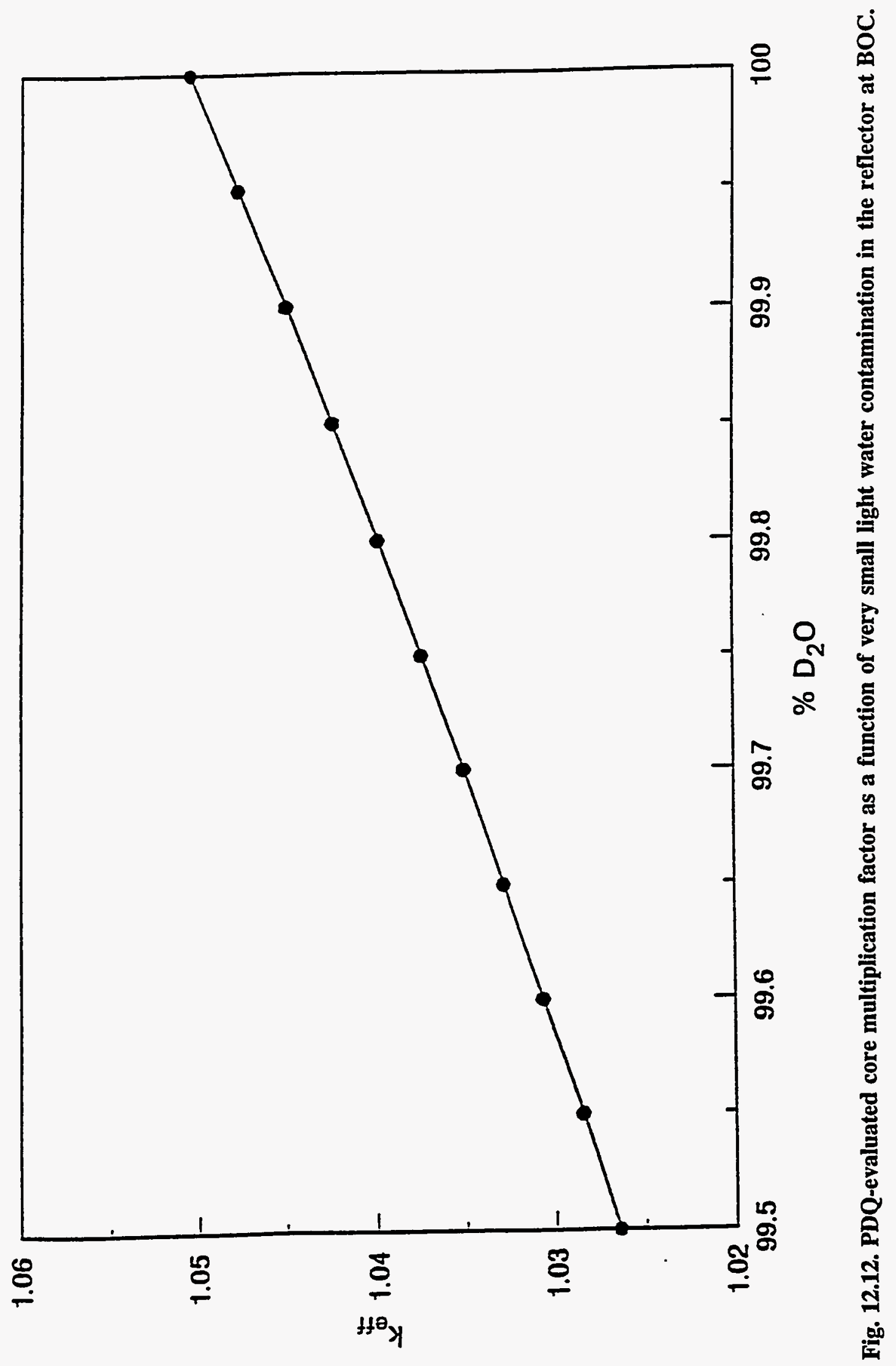


12-16

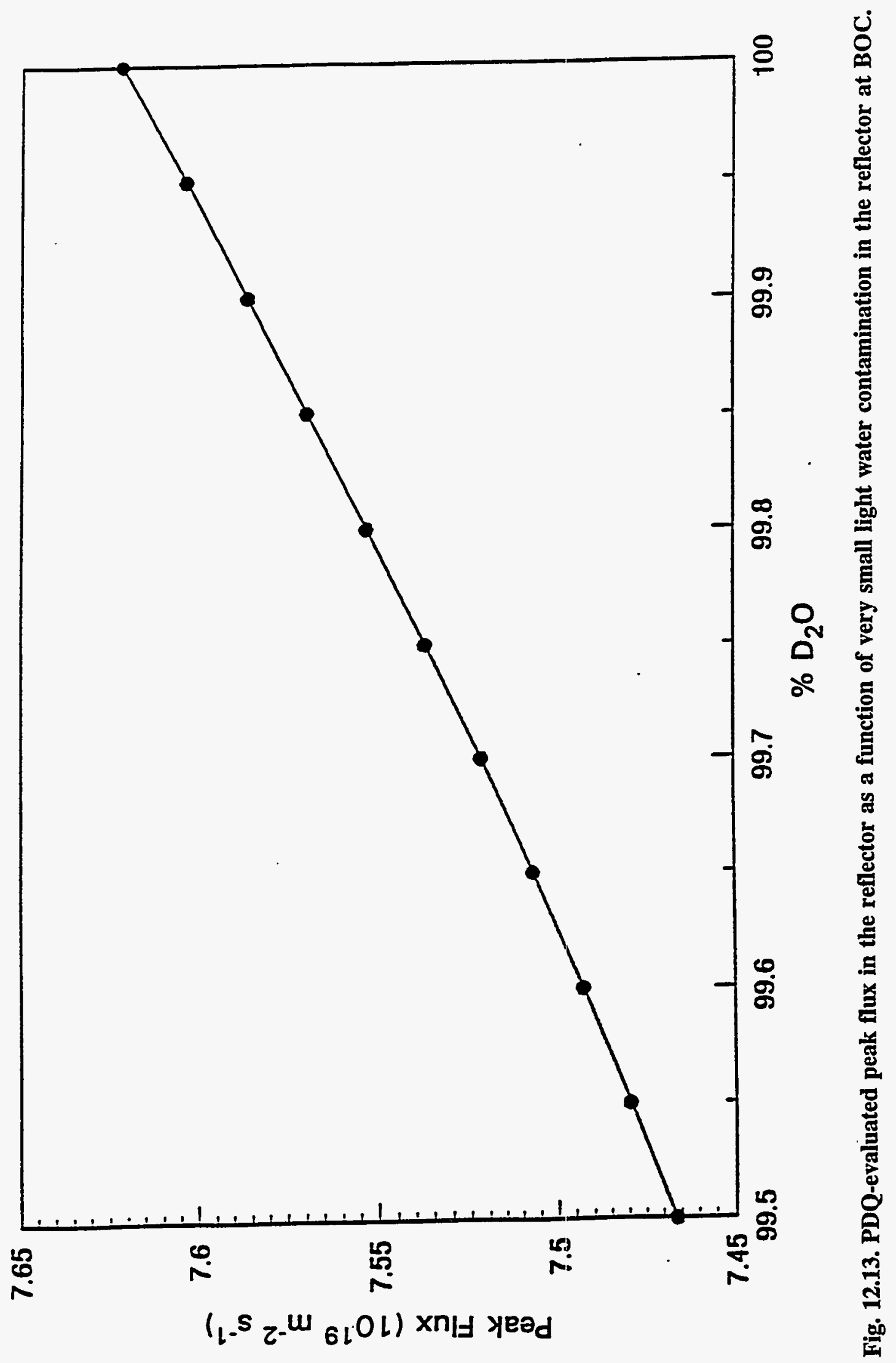




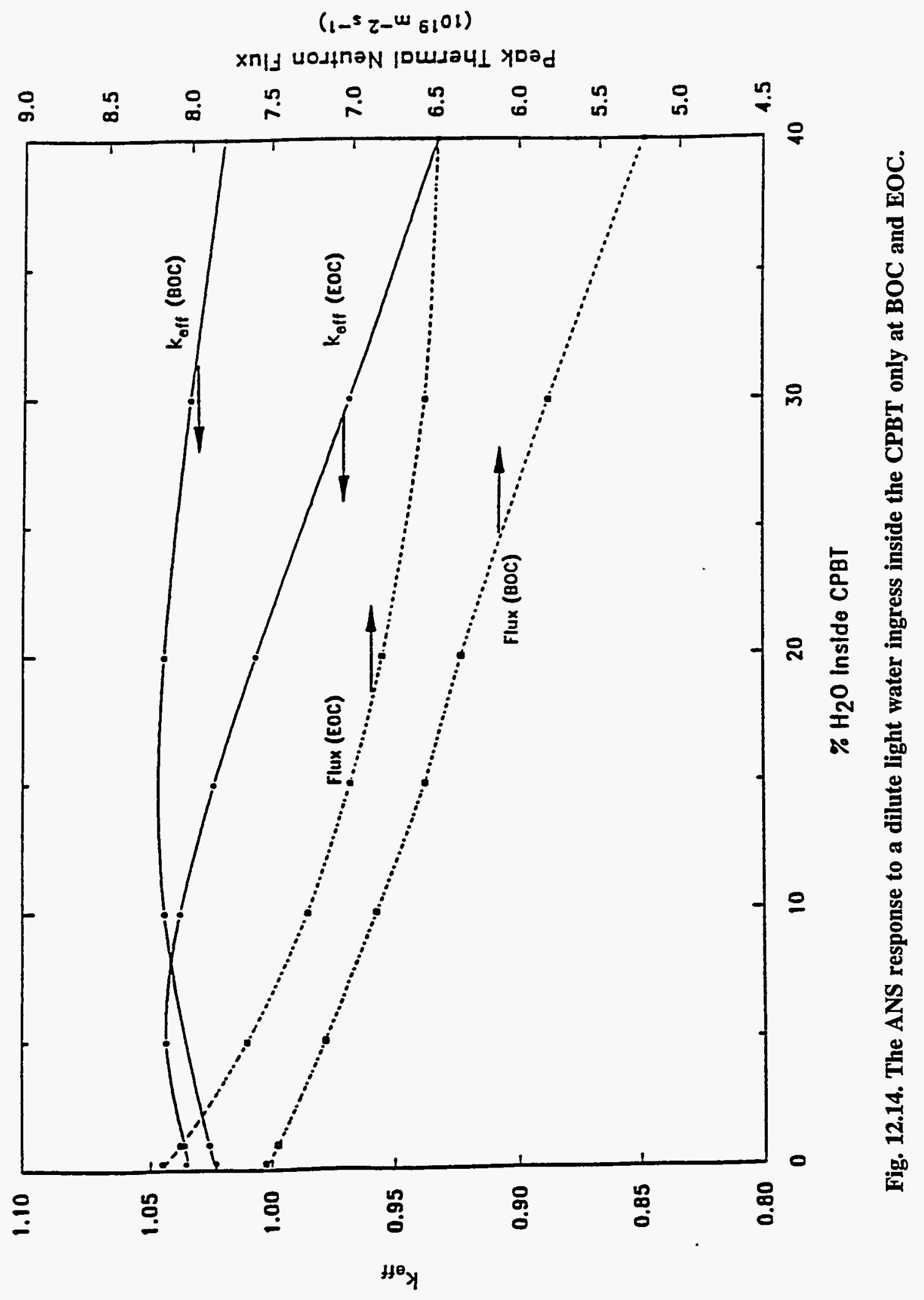




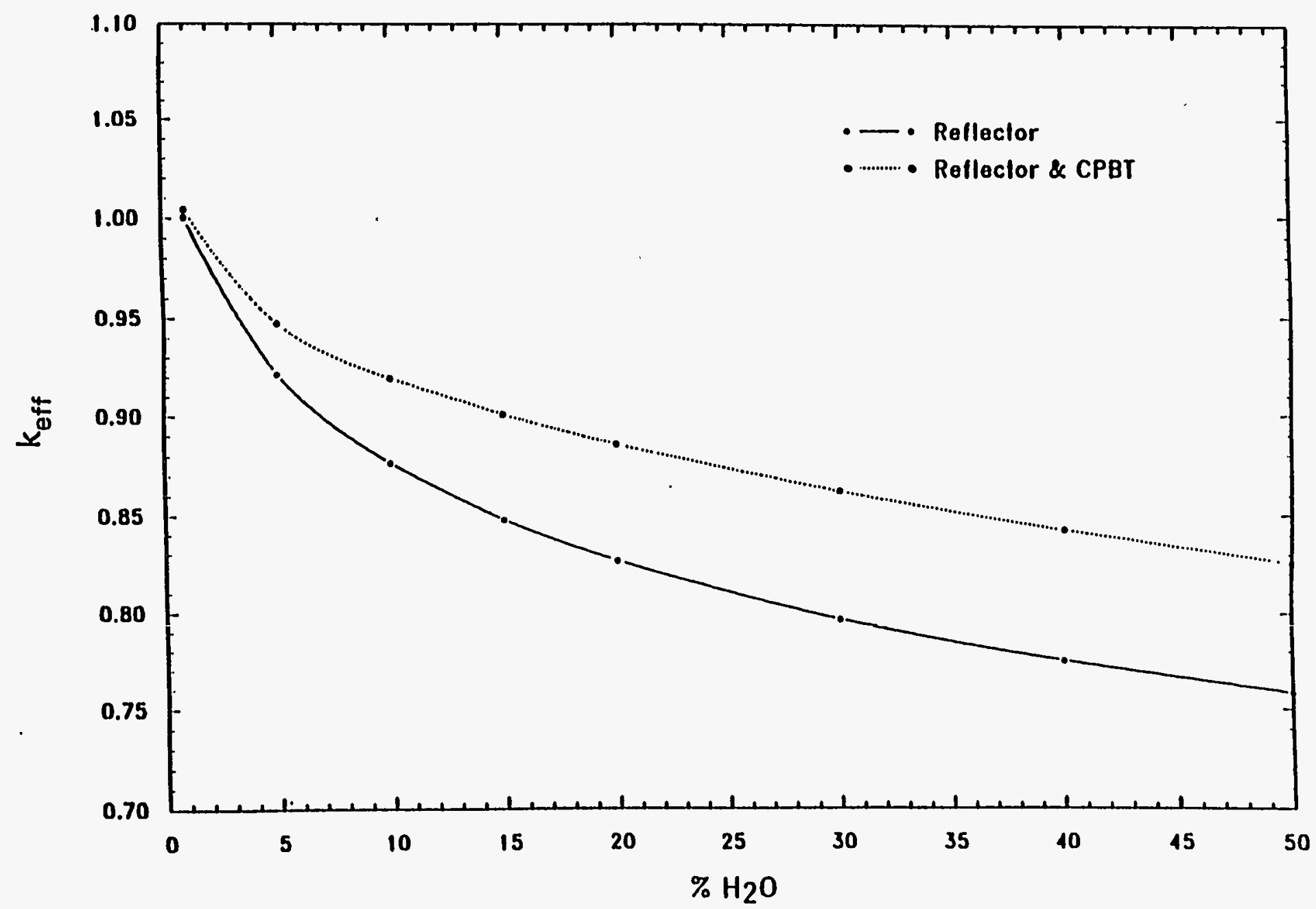

Fig. 12.15. The ANS response to a dilute light water ingress into the reflector only and into the reflector and the CPBT at EOC. 
terminated at 50\% light water incursion because the configuration was extremely subcritical, with the eigenvalue decreasing monotonically, and further introduction of light water would not alter this progression. These results emphasize the importance of maintaining a high priority of $\mathrm{D}_{2} \mathrm{O}$ throughout the system.

It should also be noted that the peak thermal neutron fluxes are not included in these results because the eigenvalues are far below critical and the resulting fluxes are unrealistically normalized. The flux results are physically unrealizable and thus are ignored for these cases.

The light water contamination results from MCNP and PDQ are consistent in all areas where similar cases are evaluated.

\subsection{REACTIVITY EFFECTS OF HEAVY WATER VOIDING}

MCNP and PDQ were used to determine the reactivity effects of heavy water voiding. MCNP was used to evaluate large changes in $\mathrm{D}_{2} \mathrm{O}$ concentrations. However, statistics made it impractical to use MCNP for small reactivity changes, and it was thus necessary to use the two-dimensional PDQ model to examine small changes, near normal conditions. The evaluations were made for individual regions in the core, the reflector, and the central hole.

\subsubsection{MCNP Analysis of Heavy Water Voiding}

In all regions, heavy water voiding decreases reactivity. Voiding the coolant channels results in a negative reactivity insertion because the fuel elements are very undermoderated. Voiding at the coolant exit in the upper plenum also decreases reactivity, even with control rods inserted to core midplane, because the flux spectrum does not shift enough to reduce the worth of the control rods significantly. This effect may be partly the result of using a hafnium absorber that has high epithermal resonance absorption.

Table 12.2 shows the reactivity effect of uniformly reducing the heavy water theoretical density in the reflector from 100 to $0 \%$. As indicated, the core reactivity continues to drop over the entire range. Table 12.3 shows the reactivity effect as the reflector tank is drained. The core reactivity drops as the heavy water level goes down.

Table 12.2. Reactivity effect at $\mathrm{BOC}$ of uniform variation in the $\mathrm{D}_{2} \mathrm{O}$ density in the reflector

\begin{tabular}{cccc}
\hline $\begin{array}{c}\text { Theoretical } \\
\mathrm{D}_{2} \mathrm{O} \text { density } \\
(\%)\end{array}$ & $\mathrm{k}_{\text {eff }}$ & $\begin{array}{c}\text { Reactivity change } \\
(\mathrm{pcm})\end{array}$ & $\begin{array}{c}\text { Void coefficient } \\
\text { (pcm/\% decrease in density) }\end{array}$ \\
\hline 100.00 & 1.0182 & 0 & 0 \\
90.00 & 0.9986 & $-1,940$ & -194 \\
75.00 & 0.9556 & $-6,350$ & -293 \\
50.00 & 0.8652 & $-16,280$ & -397 \\
25.00 & 0.6973 & $-37,860$ & -863 \\
0.00 & 0.4910 & $-72,930$ & -1403 \\
\hline
\end{tabular}

${ }^{a}$ Based on difference with numbers in row immediately above. Statistical uncertainty is less than $60 \mathrm{pcm} / \%$. 
Table 12.3. Reactivity effect at $\mathrm{BOC}$ of decreasing the $\mathrm{D}_{2} \mathrm{O}$ level in the reflector

\begin{tabular}{ccccc}
\hline $\begin{array}{c}\mathrm{D}_{2} \mathrm{O} \text { level } \\
(\mathrm{m} \text { above } \\
\text { vessel bottom })\end{array}$ & $\begin{array}{c}\text { Volume of } \\
\text { reflector } \\
\text { voided }\left(\mathrm{m}^{3}\right)\end{array}$ & $\mathrm{k}_{\text {eff }}$ & \multicolumn{2}{c}{ Reactivity change } \\
\hline 4.018 & 0.00 & 1.0182 & 0 & $\begin{array}{c}\text { (pcm/m of } \\
\text { level drop) }\end{array}$ \\
2.909 & 10.55 & 1.0041 & $-1,400$ & 0 \\
2.541 & 14.05 & 0.9980 & $-2,000$ & $-1,260$ \\
0 & 38.23 & 0.4910 & $-72,930$ & $-1,660$ \\
\hline
\end{tabular}

${ }^{\circ} \mathrm{Based}$ on difference with numbers in row immediately above. Statistical uncertainty is less than $500 \mathrm{pcm} / \mathrm{m}$.

Table 12.4 shows the reactivity effect of uniformly reducing the heavy water effective density inside the central hole, and Fig. 12.16 is a plot of these results. The core reactivity decreases with voiding. Table 12.5 gives the reactivity effect of heavy water voiding at $\mathrm{BOC}$ when the control rods are fully inserted, positioned at core midplane, and totally withdrawn. Voiding effects are most significant when the control rods are positioned at core midplane.

Table 12.4. Reactivity effect at $\mathrm{BOC}$ of uniform variation in the $\mathrm{D}_{2} \mathrm{O}$ density in the central hole with the central rods inserted down to core midplane

\begin{tabular}{rlcc}
\hline $\begin{array}{c}\mathrm{D}_{2} \mathrm{O} \text { lost } \\
(\%)\end{array}$ & $\mathrm{k}_{\text {eff }}$ & $\begin{array}{c}\text { Reactivity change } \\
(\mathrm{pcm})\end{array}$ & $\begin{array}{c}\text { Void coefficient }^{a} \\
\text { (pcm/\% decrease in density) }\end{array}$ \\
\hline 0 & 1.0182 & & \\
40 & 0.9892 & -2890 & -72.2 \\
70 & 0.9644 & -5430 & -84.6 \\
85 & 0.9577 & -6130 & -46.5 \\
100 & 0.9480 & -7140 & -67.9 \\
\hline
\end{tabular}

${ }^{a}$ Based on difference from numbers in row immediately above.

One scenario for the departure from nucleate boiling (DNB) was postulated, and the value of the multiplication factors evaluated. A DNB was assumed to start on the outer surface of the CPBT between the core midplane and the top of the UFE. After some extended time, this phenomenon could be modeled as a void cylinder $30 \mathrm{~mm}$ thick and $600 \mathrm{~mm}$ high, starting at the core midplane. Further, as this situation progresses, the 30-mm-thick cylinder can expand upward and outward. The void cylinder was conservatively modeled as extending only upward to the top of the reflector. The evaluated multiplication factors shown in Table 12.6 indicate a negligible negative reactivity feedback. Thus, DNB on the wall of the CPBT would not decrease the multiplication factor significantly, and hence the local power generation may continue without heat removal. In summary, it cannot be assumed that voiding because of DNB on the outer CPBT surface will return the reactor to a normal 


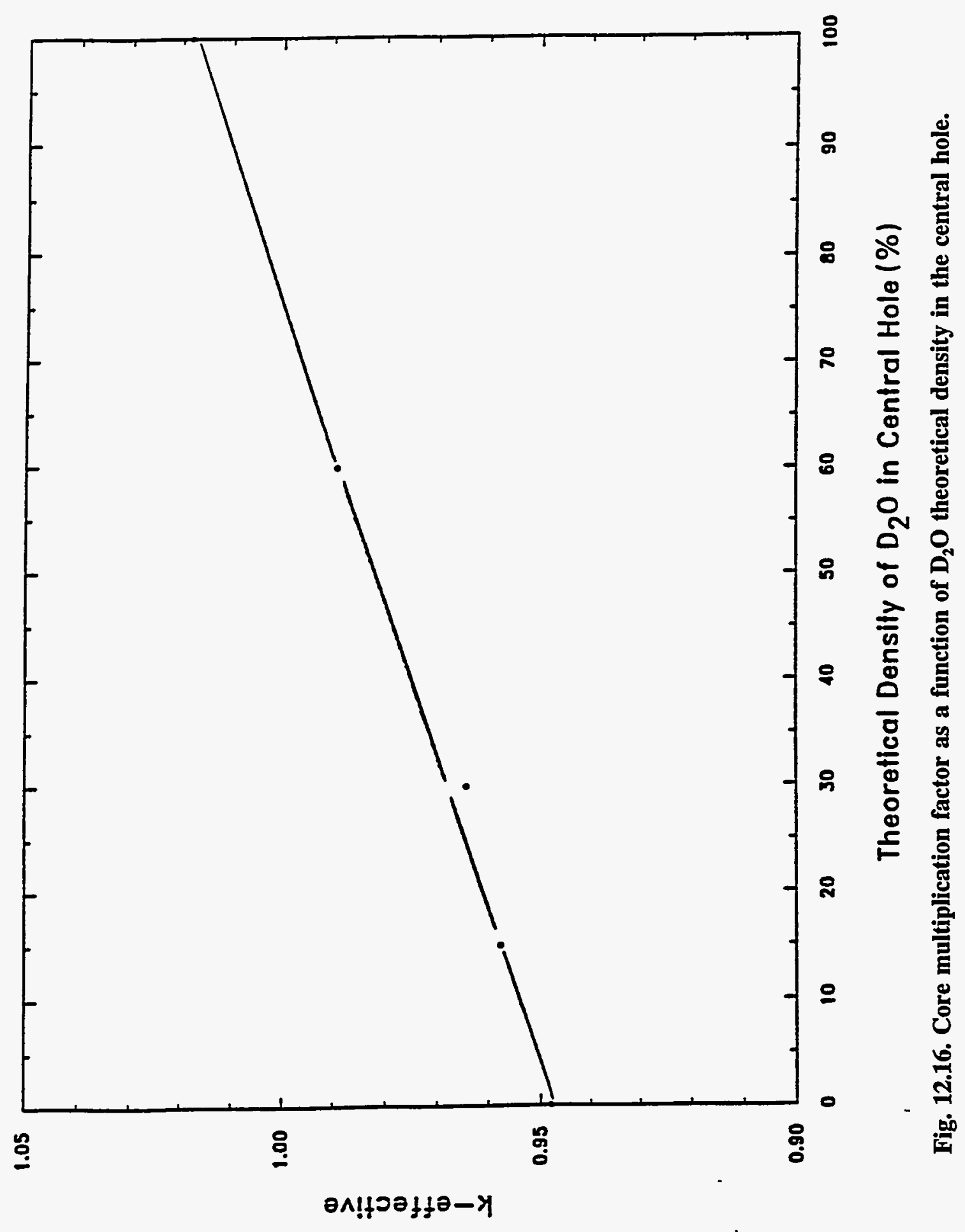


Table 12.5. MCNP-evaluated reactivity as a function of $\mathrm{D}_{2} \mathrm{O}$ voiding in the central hole at $\mathrm{BOC}$

\begin{tabular}{cccc}
\hline $\begin{array}{c}\text { Material inside } \\
\text { control rods }\end{array}$ & $\begin{array}{c}\text { Material outside } \\
\text { control rods }\end{array}$ & $\mathrm{k}_{\text {eff }}$ & $\begin{array}{c}\text { Reactivity } \\
\text { change (pcm) }\end{array}$ \\
\hline \multicolumn{4}{c}{ Control rods full inserted } \\
$\mathrm{D}_{2} \mathrm{O}$ & $\mathrm{D}_{2} \mathrm{O}$ & 0.8962 & 0 \\
Void & $\mathrm{D}_{2} \mathrm{O}$ & 0.9067 & +1160 \\
$\mathrm{D}_{2} \mathrm{O}$ & $\mathrm{Void}$ & 0.8881 & -910 \\
Void & Void & 0.8972 & +110 \\
& Control rods inserted to core midplane & \\
$\mathrm{D}_{2} \mathrm{O}$ & $\mathrm{D}_{2} \mathrm{O}$ & 1.0182 & 0 \\
Void & $\mathrm{D}_{2} \mathrm{O}$ & 1.0176 & -60 \\
$\mathrm{D}_{2} \mathrm{O}$ & Void & 0.9495 & -6990 \\
Void & Void & 0.9480 & -7140 \\
& Control rods fully inserted & \\
& $\mathrm{D}_{2} \mathrm{O}$ & 1.1457 & 0 \\
& Void & 1.0862 & -5330 \\
\hline
\end{tabular}

Table 12.6. Reactivity effect of cylindrical voids just outside the CPBT

\begin{tabular}{lcc}
\hline \multicolumn{1}{c}{ Description } & $\mathrm{k}_{\text {eff }}$ & $\begin{array}{c}\text { Reactivity } \\
\text { difference } \\
\text { (pcm) }\end{array}$ \\
\hline Base case & 1.0182 & \\
$\begin{array}{l}\text { 30-mm void cylinder around CPBT from midplane } \\
\text { to top of UFE }\end{array}$ & 1.0170 & -120 \\
$\begin{array}{l}\text { 30-mm void cylinder around CPBT from midplane } \\
\text { to top of reflector }\end{array}$ & 1.0138 & -430 \\
\hline
\end{tabular}

flow regime. Other active mechanisms of preventing DNB on the outer surface of the CPBT, such as flow mixers or directed jets or scramming the reactor, are necessary. The onset of DNB and the inability of the present design to return automatically to a normal flow regime will not be changed by substitution of CPBT material only.

A void reactivity worth study for uniform voiding of the $\mathrm{D}_{2} \mathrm{O}$ in all components inside the CPBT was made. This condition reflects reduction in $\mathrm{D}_{2} \mathrm{O}$ density in components such as homogenized fuel regions. The results are summarized in Table 12.7 . Voiding reduces the core reactivity. Below $50 \%$ $\mathrm{D}_{2} \mathrm{O}$ inside the CPBT, core reactivity is controlled by the heavy water in the reflector. 
Table 12.7. Evaluation of reactivity worth of uniform reduction of $\mathrm{D}_{2} \mathrm{O}$ density in all components inside the CPBT

\begin{tabular}{cccc}
\hline $\begin{array}{c}\mathrm{D}_{2} \mathrm{O} \text { in CPBT } \\
\text { components } \\
(\%)\end{array}$ & $\mathrm{k}_{\text {eff }}$ & $\begin{array}{c}\text { Reactivity change } \\
(\mathrm{pcm})\end{array}$ & $\begin{array}{c}\text { Void coefficient } \\
\text { (pcm/\% density decrease) }\end{array}$ \\
\hline 100 & 1.0182 & & \\
75 & 0.9683 & $-5,020$ & -200 \\
40 & 0.9015 & $-12,170$ & -200 \\
0 & 0.9091 & $-11,330$ & +20 \\
\hline
\end{tabular}

${ }^{\circ}$ Based on difference from numbers in row immediately above.

The effects of heavy water voiding (or drying out) because of boiling in the fuel regions and in the regions near the fuel inside the CPBT were also evaluated. Table 12.8 presents some of these results, and Fig. 12.17 gives the corresponding regions. The region volumes in Fig. 12.17 are given in Table 12.9. For all cases, the core reactivity drops with voiding.

Table 12.8. Evaluation of $\mathrm{D}_{2} \mathrm{O}$ voiding in the fuel and regions near the fuel inside the CPBT at BOC with the central control rods inserted down to core midplane

\begin{tabular}{lcc}
\hline \multicolumn{1}{c}{ Region voided } & $\mathrm{k}_{\mathrm{eff}}$ & $\begin{array}{c}\text { Reactivity worth } \\
\text { (pcm) }\end{array}$ \\
\hline $\begin{array}{l}\text { None (base case) } \\
\text { UFE dried up }\end{array}$ & 1.0182 & 0 \\
$\begin{array}{l}\text { UFE and UFE endplate dried up, cell 163 voided (cylindrical region of } 342 \mathrm{~mm} \\
\text { above UFE) }\end{array}$ & 1.0040 & $-1,400$ \\
$\begin{array}{l}\text { LFE dried up } \\
\text { LFE and LFE endplate dried up, cells 401 and 301 voided (cylindrical region }\end{array}$ & 0.9993 & $-1,870$ \\
$\begin{array}{l}\text { above LFE to level of bottom of LFE) } \\
\text { LFE and LFE endplate dried up; cells 201, 301, and 401 voided (cylindrical }\end{array}$ & 0.9724 & $-4,600$ \\
$\begin{array}{l}\text { region above LFE endplate to level of top of LFE) } \\
\text { LFE, UFE, and fuel endplates dried up; all regions above fuel voided to 884 } \\
\text { mm above core midplane (cells 161, 162, 163, 164, 201, 301, and 401) }\end{array}$ & 0.9753 & $-4,300^{n}$ \\
$\begin{array}{l}\text { Void regions in the preceding case extended to top of reflector and expanded to } \\
\text { include all } \mathrm{D}_{2} \mathrm{O} \text { regions above UFE endplate and within CPBT }\end{array}$ & 0.9490 & $-7,040$ \\
\hline
\end{tabular}

${ }^{a}$ Should have a lower value of $k_{e r r}$ than preceding case. The discrepancy is well within the sum of the combined statistical uncertainties.

This MCNP analysis at BOC was confirmed with PDQ-7 at different points in the cycle and for different control rod positions. In all cases, even for small voids, the reactivity was found to decrease with voiding. 


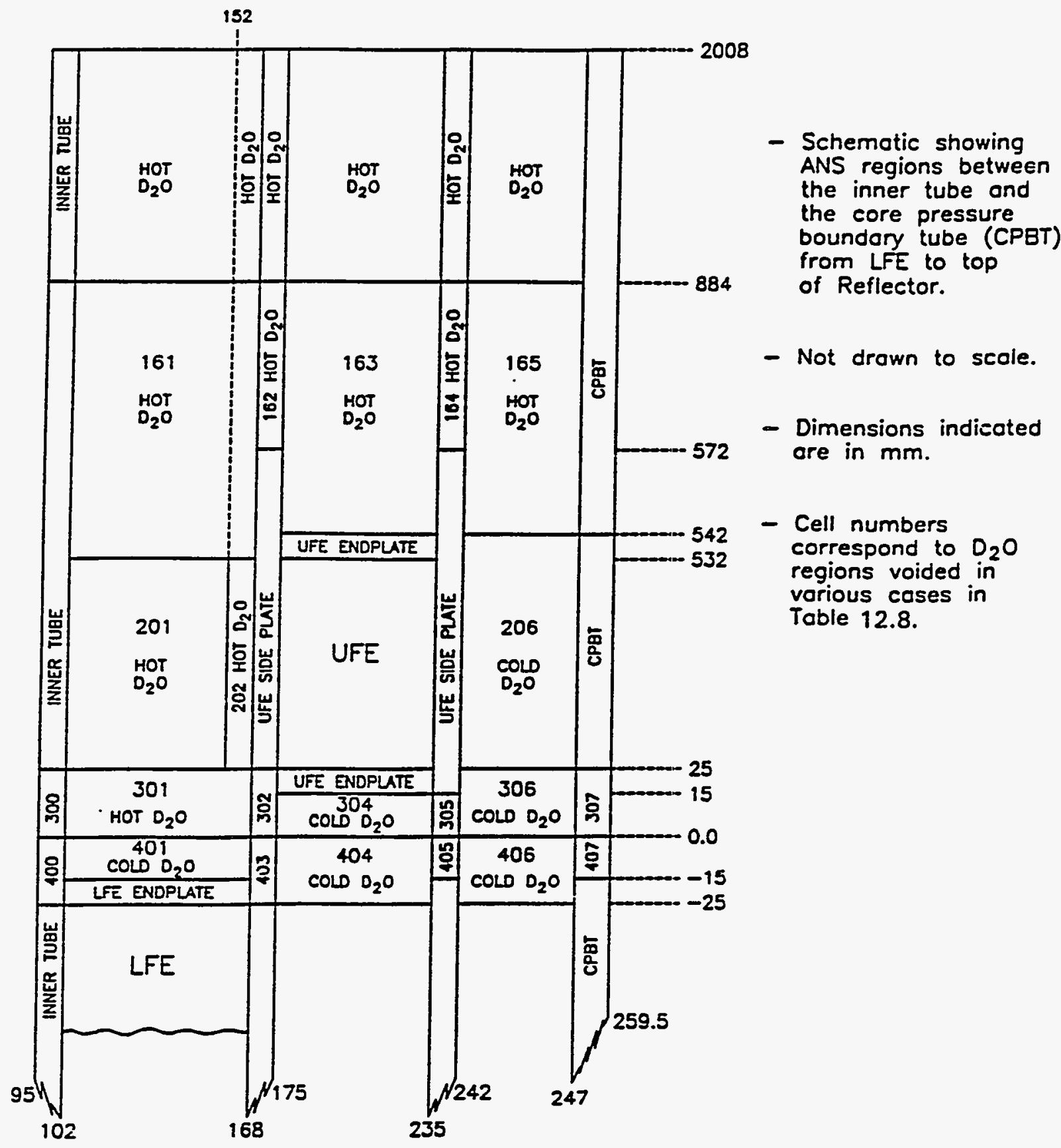

Fig. 12.17. Schematic diagram of fuel near fuel regions dried up or voided of $D_{2} 0$ in the various cases of Table $\mathbf{1 2 . 8}$. 
Table 12.9. Volumes of cells given in Fig. 12.17

\begin{tabular}{|c|c|}
\hline Cell identifier & $\begin{array}{l}\text { Volume } \\
\text { (L) }\end{array}$ \\
\hline 161 & 19.71 \\
\hline 162 & 2.35 \\
\hline 163 & 26.43 \\
\hline 164 & 3.27 \\
\hline 165 & .16 .52 \\
\hline 201 & 20.23 \\
\hline 202 & 8.16 \\
\hline UFE (fuel, aluminum, and $\mathrm{D}_{2} \mathrm{O}$ without sideplate or end plates) & 39.18 \\
\hline 206 & 3.97 \\
\hline 301 & 1.40 \\
\hline 302 & 0.19 \\
\hline UFE upper or lower endplate including $\mathrm{D}_{2} \mathrm{O}$ & 0.88 \\
\hline 304 & 1.16 \\
\hline 306 & 0.21 \\
\hline 401 & 0.92 \\
\hline 404 & 1.93 \\
\hline 405 & 0.16 \\
\hline 406 & 0.19 \\
\hline
\end{tabular}

\subsubsection{PDQ Analysis of Heavy Water Voiding Effects on the Core}

A series of PDQ cases was run to determine when in the 17-d cycle voiding in the central hole would present the greatest limitations on design. For each time step, the central hole was voided by 0 , $1,5,10,15$, and $20 \%$. Table 12.10 lists the results from this series of voiding cases (VOI019-VOI024). Figure 12.18 reflects the information from the table. The results show that the eigenvalue varies nearly linearly with increasing void fraction, as does the reactivity worth. The effects of voiding are more severe at BOC, when reactivity drops as much as $2300 \mathrm{pcm}$. These void cases were run using unvoided group constants in PDQ. The quantitative results may be questioned for the high-void cases because the spectral-hardening effect caused by the voiding is not accounted for in the group constants. 
Table 12.10 PDQ calculations of reactivity worth (in pcm) of voiding the central hole at various times in the cycle

\begin{tabular}{ccccccc}
\hline & & \multicolumn{5}{c}{ Central hole voiding } \\
\cline { 3 - 7 } Case & $\begin{array}{c}\text { Time } \\
\text { (d) }\end{array}$ & $1 \%$ & $5 \%$ & $10 \%$ & $15 \%$ & $20 \%$ \\
\hline v01019 & $0-1$ & -100 & -610 & -1220 & -1830 & -2340 \\
v01020 & $1-4$ & -200 & -610 & -1220 & -1730 & -2340 \\
v01021 & $4-7$ & -100 & -490 & -990 & -1490 & -2090 \\
V01022 & $7-10$ & -100 & -480 & -970 & -1460 & -1950 \\
v01023 & $10-14$ & -100 & -490 & -970 & -1460 & -1960 \\
v01024 & $14-17$ & 0 & -420 & -950 & -1380 & -1910 \\
\hline
\end{tabular}

\subsubsection{Effects of Heavy Water Voiding on Core Reactivity}

A series of PDQ-7 runs for the ANS reactor were carried out to evaluate the effects on the core multiplication factor of uniform voiding within the CPBT. Three different BOC scenarios were used: control rods at midplane, control rods fully withdrawn, and control rods fully inserted. Within each scenario, the regions inside the CPBT were voided by $0,1,5,10,15$, and $20 \%$. This model includes all regions except where the control rods are located because these are smeared out in the PDQ r- $\mathrm{z}$ model. However, this approximation is reasonably good. Complete voiding around control rods is worth only $1200 \mathrm{pcm}$ reactivity. The results here have a maximum voiding of $20 \%$, so the secondary effect of voiding around control rods can be accounted for by multiplying the reactivity worth values in Table 12.11 by -1.1 .

In Table 12.11, the reactivity worths are evaluated for the three control rod positions. The results from Table 12.11 are plotted in Figs. 12.19-12.21. The results show that the core reactivity decreases linearly as the percentage of voiding increases.

In all these void studies, the increase in void from 0 to $20 \%$ inside the CPBT results in a linear decrease in the core multiplication factor. Some errors inherent in this calculation increase as $\mathrm{D}_{2} \mathrm{O}$ density decreases because (1) the cross sections are evaluated at a fuel spectrum reflecting $0 \%$ void, and, (2) as the void increases, PDQ, which is a diffusion-theory code, becomes less capable of handling a reactor model. However, these errors are not expected to affect the general trends presented by this analysis. 


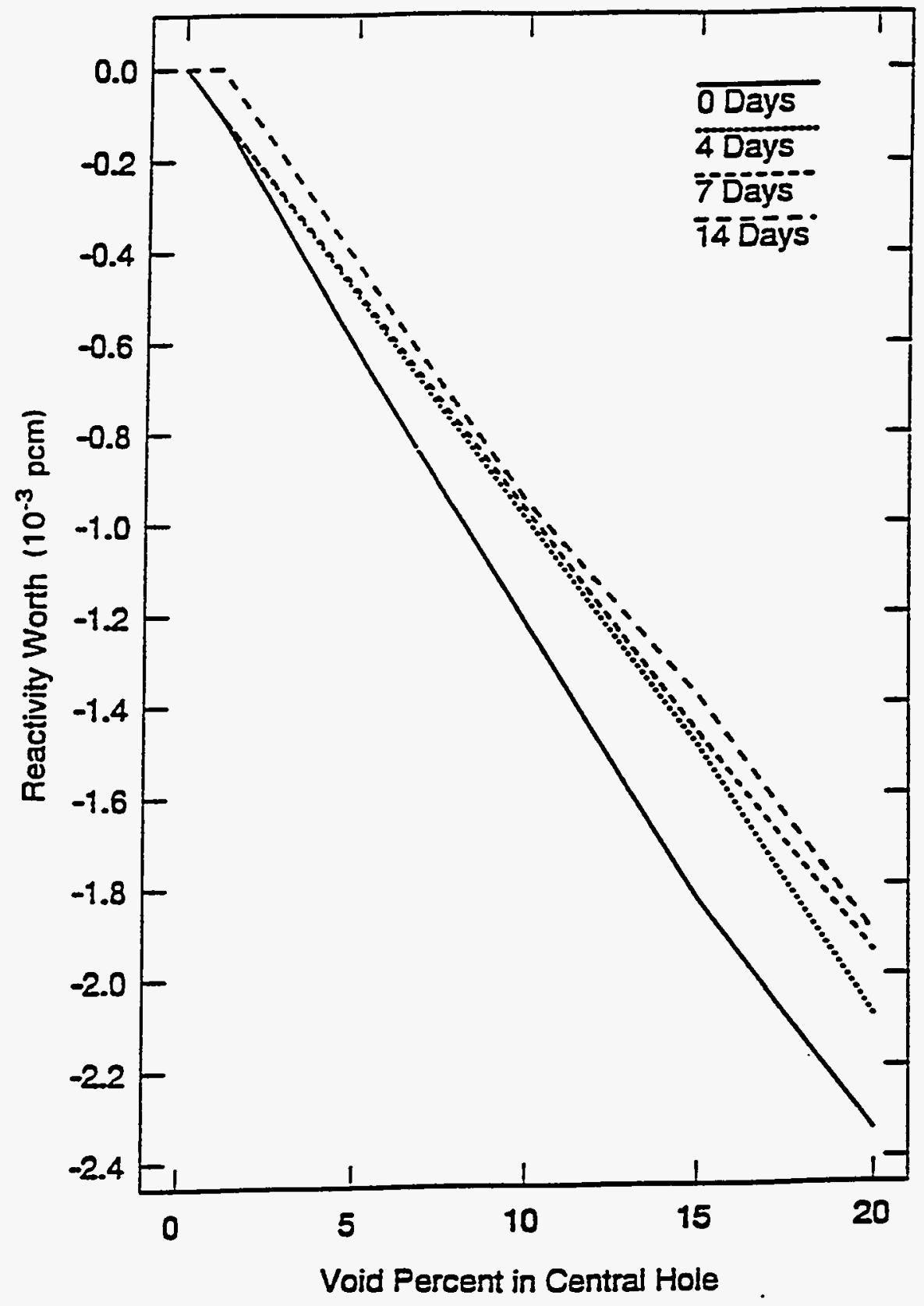

Fig. 12.18. Void reactivity worth at several time steps in PDQ models V01019-V01024. 
Table 12.11. Effects of heavy water voiding inside the CPBT on core reactivity at BOC

\begin{tabular}{|c|c|c|c|}
\hline Run & $\begin{array}{l}\mathrm{D}_{2} \mathrm{O} \text { voiding } \\
(\%)\end{array}$ & $\mathrm{k}_{\mathrm{erI}}$ & $\begin{array}{l}\text { Reactivity worth } \\
\text { (pcm) }\end{array}$ \\
\hline \multicolumn{4}{|c|}{ Control rods at midplane } \\
\hline v01006 & 0 & 1.0375 & 0 \\
\hline v01001 & 1 & 1.0358 & -160 \\
\hline v01002 & 5 & 1.0312 & -610 \\
\hline v01003 & 10 & 1.0249 & -1220 \\
\hline V01004 & 15 & 1.0186 & -1840 \\
\hline v01005 & 20 & 1.0126 & -2430 \\
\hline \multicolumn{4}{|c|}{ Control rods fully withdrawn } \\
\hline V01007 & 0 & 1.1638 & 0 \\
\hline V01008 & 1 & 1.1627 & -90 \\
\hline V01009 & 5 & 1.1592 & -400 \\
\hline V01010 & 10 & 1.1545 & -800 \\
\hline V01011 & 15 & 1.1497 & -1220 \\
\hline V01012 & 20 & 1.1448 & -1650 \\
\hline \multicolumn{4}{|c|}{ Control rods fully inserted } \\
\hline V01013 & 0 & 0.9392 & 0 \\
\hline V01014 & 1 & 0.9384 & -90 \\
\hline V01015 & 5 & 0.9356 & -380 \\
\hline V01016 & 10 & 0.9321 & -760 \\
\hline V01017 & 15 & 0.9285 & -1150 \\
\hline V0I018 & 20 & 0.9248 & -1550 \\
\hline
\end{tabular}




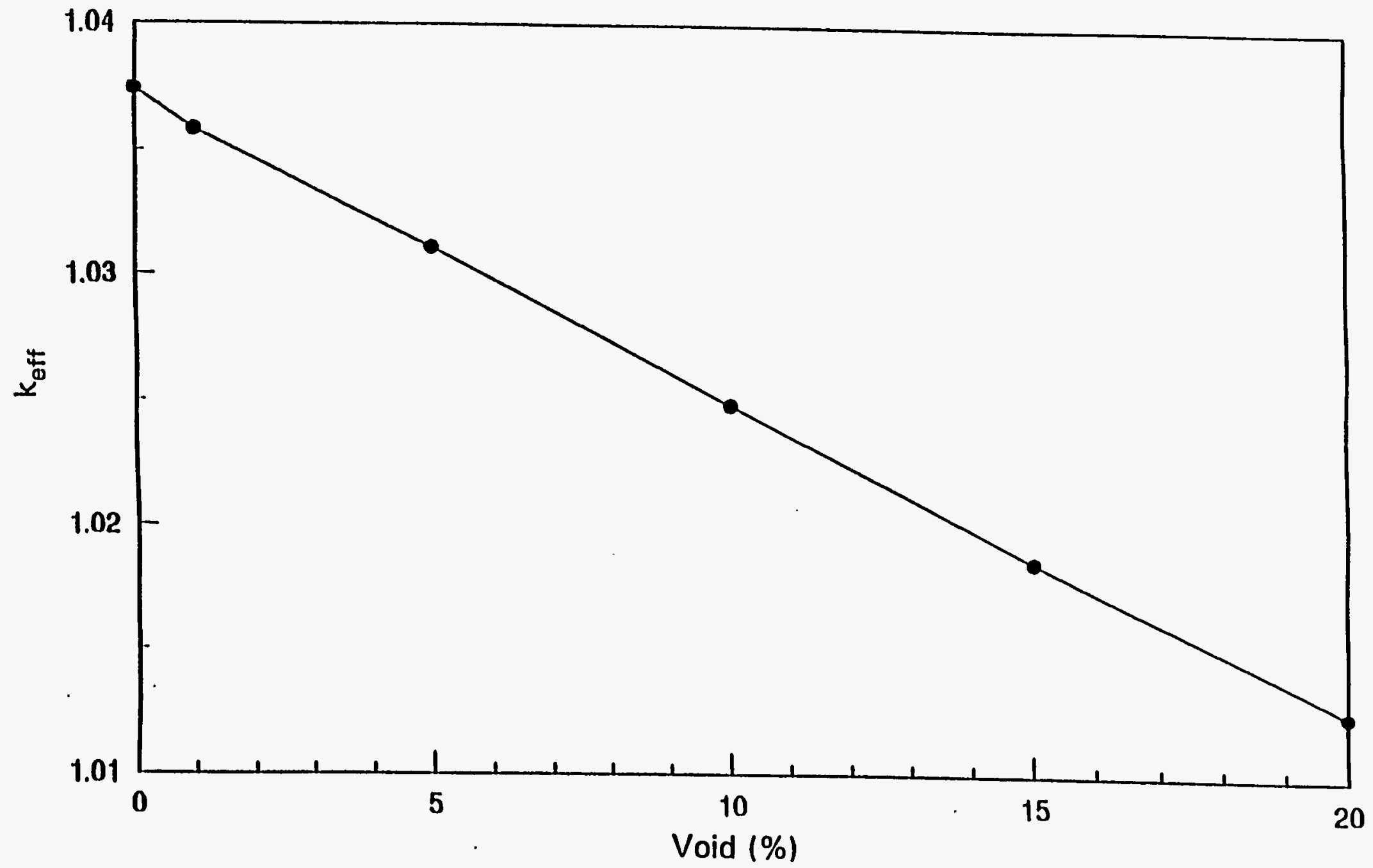

Fig. 12.19. PDQ-evaluated core multiplication factor as a function of uniform heavy water voiding inside the CPBT with the control rods at core midplane at BOC. 


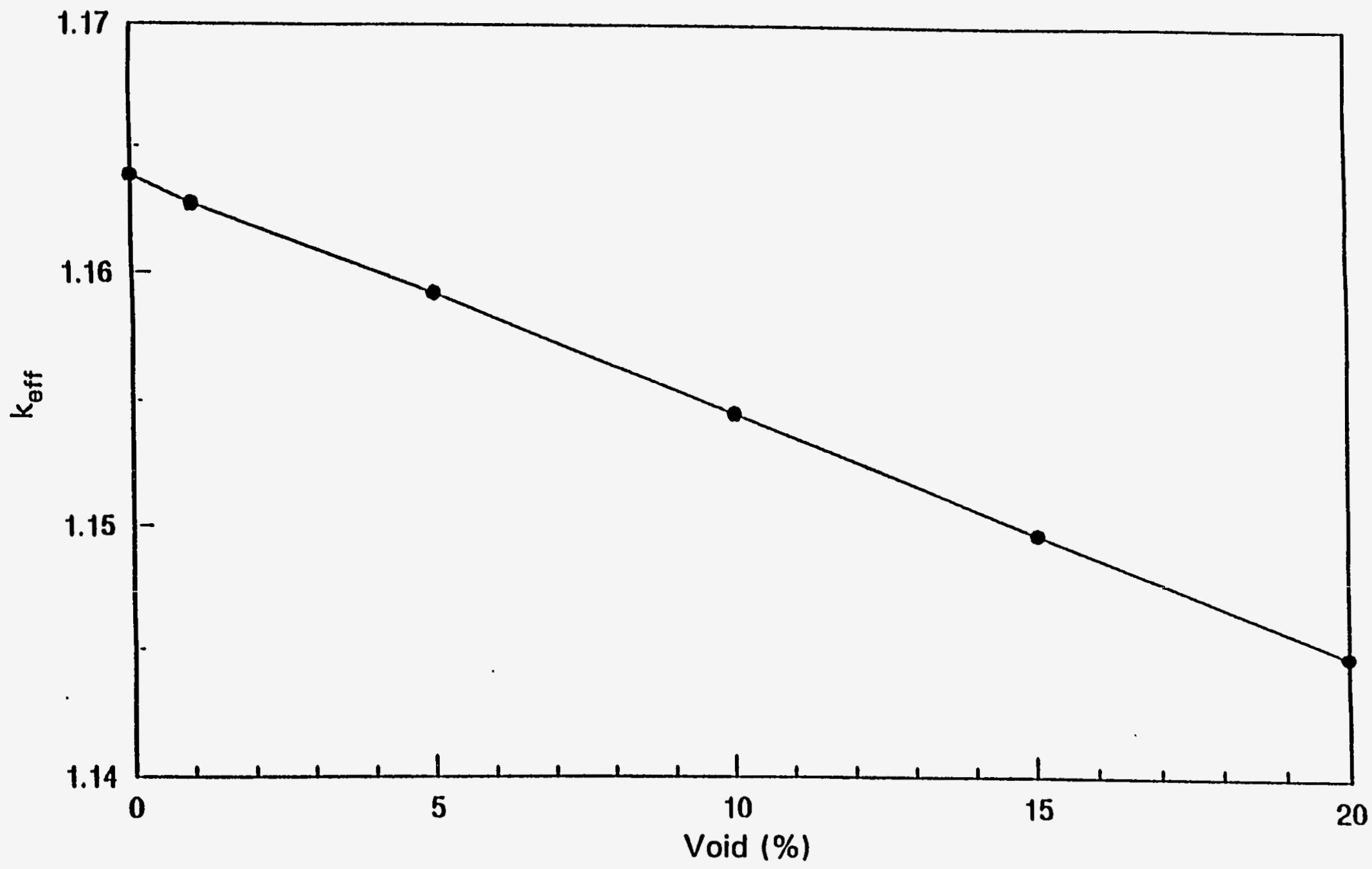

Fig. 12.20. PDQ-evaluated core multiplication factor as a function of uniform heavy water voiding inside the CPBT with the control rods fully withdrawn at BOC. 


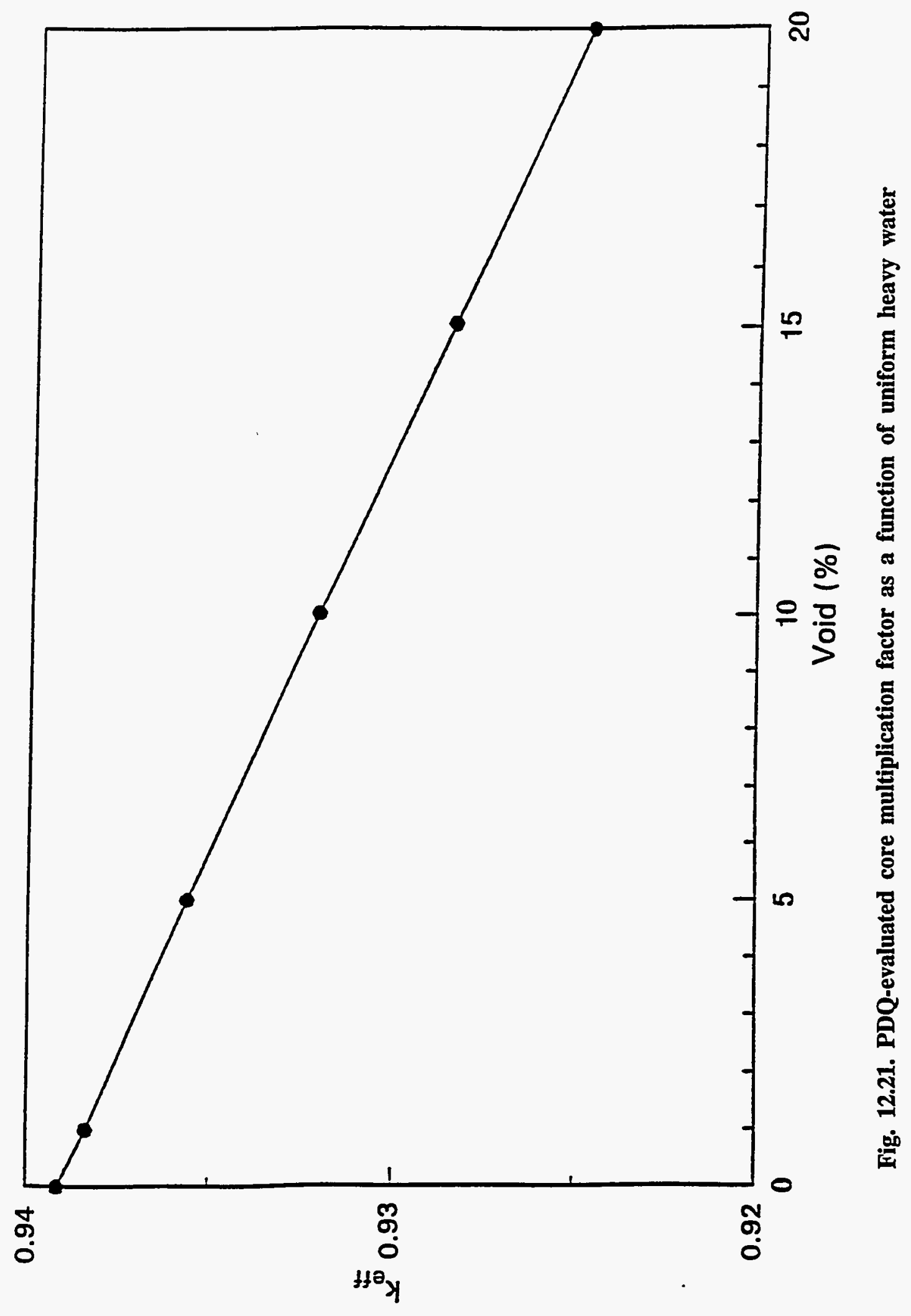




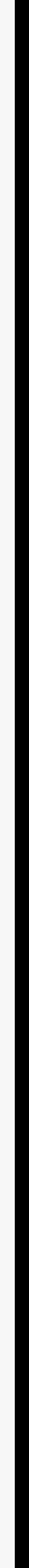




\section{MATERIALS IRRADIATION AND ISOTOPE PRODUCTION}

\subsection{MATERIALS IRRADIATION}

Space and facilities have been provided in the core central hole region for performing fast-neutron irradiation experiments on various materials. Irradiation specimens placed in these facilities can affect the core reactivity and the power distribution. Therefore, the impact of potential irradiation material targets on the core was analyzed.

Nickel and hafnium were determined to represent the worst potential specimens for impact on the core reactivity. Nickel has the highest absorption cross section among target materials likely to be tested in the in-core materials irradiation facilities. Hafnium, which also has a very high absorption cross section, may be considered as a thermal neutron shield around some of the targets to provide spectrum modification. Three extreme cases were examined: (1) nickel in all targets, (2) hafnium in one small and one large target, and (3) hafnium in one small and one large target with nickel in the other eight targets.

The four-group diffusion-theory code PDQ-7 was used to compute the core multiplication factors for these targets. The targets were smeared into an r-z ring that almost ensures an overestimate of the target impact on core reactivity. The results are listed in Table 13.1. Nickel, and hence most other materials that might be irradiated in the in-core irradiation facilities, reduces the core reactivity less than $1000 \mathrm{pcm}$ at BOC. However, because the hafnium was smeared in the two-dimensional model, the reactivity impact of the hafnium is greatly overestimated. Therefore, the maximum expected target loading (two hafnium targets and eight nickel targets) is likely to reduce the core reactivity by less than $2000 \mathrm{pcm}$ at BOC.

Table 13.1. The impact of fast flux irradiation targets on core reactivity from a base case without targets

\begin{tabular}{lccc}
\hline \multirow{2}{*}{ Case } & \multicolumn{3}{c}{$\begin{array}{c}\text { Reactivity change } \\
\text { (pcm) }\end{array}$} \\
\cline { 2 - 4 } & Rods at midplane & No rods & Partial rods at day 10 \\
\hline Nickel in all capsules & -750 & -2090 & -2240 \\
$\begin{array}{l}\text { Hafnium in one large and one small } \\
\text { capsule }\end{array}$ & -1480 & -4360 & \\
$\begin{array}{l}\text { Hafnium in one large and one small } \\
\text { capsule, nickel in eight others }\end{array}$ & -1850 & -5480 & \\
\hline
\end{tabular}

The impact on core reactivity at EOC can be approximated by using the PDQ-7 model at BOC without control rods. The impact of targets on core reactivity is twice as great at EOC as it is at BOC. As the control rods are withdrawn near the EOC, a softer spectrum is introduced in the fast flux target region, which allows the targets to absorb more neutrons. If deemed necessary, enough ${ }^{235} U$ could be loaded at BOC to compensate for this reactivity drop. However, no changes have been made at present, and the reactivity worth of the hafnium targets will be determined more accurately through more detailed analyses as part of the advanced conceptual design activities. Findings from these analyses could lead to a limitation on the maximum permitted reactivity worth of an irradiation experiment. 


\subsection{ISOTOPE PRODUCTION}

To improve the description of the transplutonium production model, a series of PDQ-7 cases was run using time-dependent group constants for key isotopes in the burnup chains to evaluate their impact on the total californium and einsteinium production. Two different PDQ models of ANS were used to perform this analysis. Both models contained no reflector components, a single control rod neutronically equivalent to the four-control rod design, and a reactor power of $330 \mathrm{MW}_{\mathrm{f}}$. The first model used a 14-full-power-day cycle with a 3-d decay time, and the second used a 17-full-power-day cycle with a 4-d decay time.

Burnup-dependent multigroup cross sections were computed using COMBINE, which collapsed cross sections from a 72-group fast-cross section set over the energy range $0.414 \mathrm{eV}$ to $16.9 \mathrm{MeV}$ and a 101-group thermal-cross section set over the energy range $0.001-2.38 \mathrm{eV}$. Because of the importance of incoherent scattering on heavy water to the solution, the thermal cross sections were used in the energy overlap region. Burnup-dependent atom densities for the transplutonium rods at 34 , 68,102 , and 119-d were obtained from previous PDQ results. A core spectrum was generated for a representative fuel composition, and the core leakage spectrum was then used to weight the fine-group cross sections in the transplutonium rods at each time. Thermal disadvantage factors were computed using the $\mathrm{ABH}$ method. ${ }^{37} \mathrm{~A}$ third-order polynomial fit in time was used to interpolate between the points for each isotope.

These time-dependent cross sections were then applied to the PDQ model discussed above, and the transplutonium rods were then depleted over several cycles. The results are shown in Tables 13.2 and 13.3 for the 14-full-power-day cycle and in Tables 13.4 and 13.5 for the 17 full-power-day cycle. The results for the 17-full-power-day cycle show a marginal increase in californium production over that for the shorter cycle, but also exhibit an additional $8 \%$ drop in the total einsteinium production.

Table 13.2. Production of ${ }^{252} \mathrm{Cf}$ at $330 \mathrm{MW}$ in the epithermal and fast regions with exposure-dependent cross sections in the rods. Cycle length is $17 \mathrm{~d}$ (14 full-power days $+3-\mathrm{d}$ refueling period).

\begin{tabular}{ccc}
\hline \multirow{2}{*}{$\begin{array}{c}\text { Cycle ending } \\
(\mathrm{d})\end{array}$} & \multicolumn{2}{c}{$\begin{array}{c}\text { Production } \\
(\mathrm{g})\end{array}$} \\
\cline { 2 - 3 } & Epithermal region & Fast region \\
\hline 17 & 0.093 & 0.047 \\
34 & 0.198 & 0.122 \\
51 & 0.284 & 0.190 \\
68 & 0.357 & 0.249 \\
85 & 0.417 & 0.301 \\
102 & 0.468 & 0.346 \\
119 & 0.509 & 0.385 \\
\hline
\end{tabular}


Table 13.3. Production of ${ }^{254} \mathrm{Es}$ at $330 \mathrm{MW}$ in the epithermal and fast regions with exposure-dependent cross sections in the rods. Cycle length is $17 \mathrm{~d}$ (14 full-power days $+3-\mathrm{d}$ refueling period).

\begin{tabular}{ccc}
\hline \multirow{2}{*}{$\begin{array}{c}\text { Cycle ending } \\
(\mathrm{d})\end{array}$} & \multicolumn{2}{c}{ Production $(\mu \mathrm{g})$} \\
\cline { 2 - 3 } 17 & Epithermal region & Fast region \\
34 & 0.820 & 0.263 \\
51. & 4.420 & 3.353 \\
68 & 8.199 & 8.940 \\
85 & 11.400 & 14.935 \\
102 & 14.083 & 20.483 \\
119 & 16.327 & 25.420 \\
\hline
\end{tabular}

Table 13.4. Production of ${ }^{252} \mathrm{Cf}$ at $330 \mathrm{MW}_{\mathrm{f}}$ in the epithermal and fast regions with exposure-dependent cross sections in the rods. Cycle length is $21 \mathrm{~d}$ (17 full-power days $+4-\mathrm{d}$ refueling period)

Production

\begin{tabular}{ccc} 
Cycle ending & \multicolumn{2}{c}{$(\mathrm{g})$} \\
\cline { 2 - 3 }$(\mathrm{d})$ & Epithermal region & Fast region \\
\hline 21 & 0.113 & 0.074 \\
42 & 0.230 & 0.167 \\
63 & 0.323 & 0.246 \\
84 & 0.399 & 0.311 \\
105 & 0.459 & 0.366 \\
126 & 0.507 & 0.412 \\
\hline
\end{tabular}


Table 13.5. Production of ${ }^{254} \mathrm{Es}$ at $330 \mathrm{MW}$ in the epithermal and fast regions with exposure-dependent cross sections in the rods.

Cycle length is $21 \mathrm{~d}$ (17 full-power days + 4-d refueling period).

\begin{tabular}{ccc}
\hline \multirow{2}{*}{$\begin{array}{c}\text { Cycle ending } \\
(\mathrm{d})\end{array}$} & \multicolumn{2}{c}{$\begin{array}{c}\text { Production } \\
(\mu \mathrm{g})\end{array}$} \\
\cline { 2 - 3 } & Epithermal region & Fast region \\
\hline 21 & 1.338 & 0.739 \\
42 & 5.713 & 5.580 \\
63 & 9.718 & 11.842 \\
84 & 12.967 & 17.521 \\
105 & 15.597 & 22.363 \\
126 & 17.702 & 26.443 \\
\hline
\end{tabular}




\section{REFLECTOR FAST FLUX EXPERIMENTAL FACHITY}

Several irradiation experiments require a lower gamma heating rate than is found in the in-core irradiation facility positions. An investigation was made of the characteristics of a potential fast flux converter located in the $\mathrm{D}_{2} \mathrm{O}$ reflector of ANS that might produce high fast flux levels with relatively low heat loads.

In the analysis, the centerline of the converter was located $1 \mathrm{~m}$ from the CPBT. The converter consisted of an inner $\mathrm{D}_{2} 0$ region $56.4 \mathrm{~mm}$ in diameter, surrounded by a cylindrical ring of an ANStype fuel region. The fuel region of the converter consisted of involute ANS plates of the same dimensions, coolant spacing, and "average" fuel loading as the 330-MW ANS L7 upper fuel element. Three different designs were investigated: 10-, 20-, and 30-mm-thick fuel regions. No burnable poison was used in the converter. The height of the converter was $507 \mathrm{~mm}$, centered at the core midplane.

The results of the three-dimensional calculations are shown in Table 14.1. The 10-mm-thick fuel region design is shown as converter \#1, the 20 -mm-thick as \#2, and the 30 -mm-thick as \#3. Note that these calculations do not include photoneutrons, which would substantially increase the fast flux for the no-converter case (see Sect. 7.1). However, the fast flux would still be rather small.

The fast flux at the center (converter centerline and core midplane) at BOC (no Xe) is $4.7 \times$ $10^{18} \mathrm{~m}^{-2} \cdot \mathrm{s}^{-1}$ for converter $\# 1,7.4 \times 10^{18} \mathrm{~m}^{-2} \cdot \mathrm{s}^{-1}$ for converter $\# 2$, and $9.3 \times 10^{18} \mathrm{~m}^{-2} \cdot \mathrm{s}^{-1}$ for converter \#3. At BOC (with Xe), the fast flux increases to $4.9 \times 10^{18} \mathrm{~m}^{-2} \cdot \mathrm{s}^{-1}$ for converter \#1, $7.7 \times$ $10^{18} \mathrm{~m}^{-2} \cdot \mathrm{s}^{-1}$ for $\# 2$, and $9.3 \times 10^{18} \mathrm{~m}^{-2} \cdot \mathrm{s}^{-1}$ for $\# 3$.

The converter boost ratio of the fast flux at BOC (no Xe) is $1.8 \times 10^{9}$ for \#1, $2.9 \times 10^{9}$ for \#2, and $3.6 \times 10^{9}$ for \#3. At BOC (with Xe), the boost ratio is $1.8 \times 10^{9}$ for $\# 1,2.8 \times 10^{9}$ for $\# 2$, and $3.5 \times 10^{9}$ for \#3. The ratio of the fast-to-thermal flux at the center of each converter is 1.025 (BOC, no $\mathrm{Xe}$ ) and 1.057 (BOC, with $\mathrm{Xe}$ ) for \#1; 1.903 (BOC, no Xe), and 1.975 (BOC, with Xe) for \#2; and 2.303 (BOC, no Xe) and 2.523 (BOC, with $\mathrm{Xe}$ ) for \#3.

Table 14.1 also shows that the increase in reactivity is small, even including equilibrium xenon: approximately $90 \mathrm{pcm}$ for converter \#1, $200 \mathrm{pcm}$ for \#2, and $350 \mathrm{pcm}$ for \#3.

At $\mathrm{BOC}$ (no Xe), the converter conversion ratio is 0.511 for \#1, 0.813 for converter \#2 and 1.017 for \#3. 
Table 14.1. Neutronic results for the fast flux irradiation converter at $\mathrm{BOC}^{a}$

\begin{tabular}{|c|c|c|c|c|c|c|}
\hline Case & $\begin{array}{l}\text { Reactivity } \\
\text { change } \\
\text { (pcm) }\end{array}$ & $\begin{array}{l}\text { Fast flux at core } \\
\text { midplane } \\
\left(\mathrm{m}^{-2} \cdot \mathrm{s}^{-1}\right)\end{array}$ & $\begin{array}{l}\text { Thermal flux at core } \\
\text { midplane } \\
\left(\mathrm{m}^{-2} \cdot \mathrm{s}^{-1}\right)\end{array}$ & $\begin{array}{l}\text { Fast-to-thermal flux } \\
\text { ratio }\end{array}$ & $\begin{array}{l}\text { Converter boost in } \\
\text { flux ratio }\end{array}$ & $\begin{array}{c}\text { Converter } \\
\text { conversion ratio } \\
\text { fast/thermal }\end{array}$ \\
\hline \multicolumn{7}{|c|}{ No xenon } \\
\hline In-core irradiation region ${ }^{b}$ & & $1.455 \times 10^{19}$ & $1.515 \times 10^{19}$ & 0.960 & & \\
\hline $\begin{array}{l}\text { Converter position } \\
\text { No converter } \\
\text { Converter \#1 } \\
\text { Converter \#2 } \\
\text { Converter \#3 }\end{array}$ & $\begin{array}{c}0^{d} \\
86 \\
196 \\
243\end{array}$ & $\begin{array}{l}2.590 \times 10^{90}(9) \\
4.673 \times 10^{18} \\
7.435 \times 10^{18} \\
9.279 \times 10^{18}\end{array}$ & $\begin{array}{l}9.145 \times 10^{18} \\
4.560 \times 10^{18} \\
3.906 \times 10^{18} \\
3.875 \times 10^{18}\end{array}$ & $\begin{array}{l}2.832 \times 10^{-10} \\
1.025 \\
1.903 \\
2.305\end{array}$ & $\begin{array}{l}1.804 \times 10^{9} \\
2.871 \times 10^{9} \\
3.583 \times 10^{9}\end{array}$ & $\begin{array}{l}0.511 \\
0.813 \\
1.017\end{array}$ \\
\hline \multicolumn{7}{|c|}{ Equilibrium xenon } \\
\hline In-core irradiation region ${ }^{b}$ & & $1.601 \times 10^{19}$ & $3.608 \times 10^{19}$ & 0.887 & & \\
\hline $\begin{array}{l}\text { Converter position } \\
\text { No converter } \\
\text { Converter \#1 } \\
\text { Converter \#2 } \\
\text { Converter \#3 }\end{array}$ & $\begin{array}{c}0^{e} \\
92 \\
207 \\
349\end{array}$ & $\begin{array}{l}2.748 \times 10^{9}(1) \\
4.949 \times 10^{18} \\
7.745 \times 10^{18} \\
9.269 \times 10^{18}\end{array}$ & $\begin{array}{l}1.003 \times 10^{19} \\
4.684 \times 10^{18} \\
3.921 \times 10^{18} \\
3.815 \times 10^{18}\end{array}$ & $\begin{array}{l}2.742 \times 10^{-10} \\
1.057 \\
1.975 \\
2.523\end{array}$ & $\begin{array}{l}1.801 \times 10^{9} \\
2.828 \times 10^{9} \\
3.503 \times 10^{9}\end{array}$ & $\begin{array}{l}0.494 \\
0.773 \\
1.028\end{array}$ \\
\hline
\end{tabular}

aphotoneutrons not included.

'Location inside of upper element at core midplane.

Location at center of converter, $1 \mathrm{~m}$ from CPBT and at core midplane. Converter \#1: 10-mm-thick fuel region; converter \#2: 20-mm-thick fuel region; converter \#3: 30-mm-thick fuel region.

${ }^{d}$ Reference $\mathrm{k}_{\mathrm{eff}}=1.070$.

Reference $\mathrm{k}_{\text {eff }}=1.017$.

These values are on the order of $1 \times 10^{14} \mathrm{~m}^{-2} \cdot \mathrm{s}^{-1}$ when photoneutrons are included. 


\section{REFUELING CRITICALITY ANALYSIS}

\subsection{MCNP REFUELING CRITICALITY ANALYSIS}

The refueling analysis simulates the required movement of fresh fuel elements through the refueling canal to their location inside the CPBT at start of operation.

The analysis is made for movement of both fuel elements together in their in-core configuration, for movement of each of the fuel elements alone, and for movement of the fuel elements when auxiliary neutron poisons are incorporated. These auxiliary poisons may be an external poison, such as dissolved $\mathrm{Gd}_{2} \mathrm{NO}_{3}$ in the reflector, a poison-bearing fuel casket, or poison(boron)-impregnated plates integrated with the fuel element during transfer. The cases of fuel transfer without auxiliary neutron poisons were also analyzed. In all these cases, the two unirradiated fuel elements are represented in their in-core configuration. All cases are modeled at $300 \mathrm{~K}$.

The first analyzed case, MCNP run ANS576, represents the two fresh fuel elements during transfer in the canal and is shown in Fig. 15.1. The tank and canal walls are 20-mm-thick Al-6061. The resultant multiplication factor is 1.20 .

The second analyzed case, MCNP run ANS577, represents the same configuration as the first, but with 20-mm-thick SS-316 tank walls. The resultant multiplication factor is 1.19 . The SS-316 is quite thick in this model, and it provides a very small decrease in reactivity. Thus, when considering the multiplication factors of the two fuel elements immersed in an infinite $\mathrm{H}_{2} \mathrm{O}$ medium $\left(\mathrm{k}_{\mathrm{eff}}<0.9\right)$ and immersed in an infinite $\mathrm{D}_{2} \mathrm{O}$ medium $\left(\mathrm{k}_{\mathrm{eff}}>1.0\right)$, the multiplication factor for the two fuel elements in these cases is large enough to seem as if they were immersed in an infinite $\mathrm{D}_{2} \mathrm{O}$ reflector. No amount of poison in the canal walls would reduce the multiplication factor as much as desired.

This fact leads to the case in MCNP run ANS580, where the canal transfer region around the fuel is reduced from $1.422 \mathrm{~m}$ to $0.711 \mathrm{~m}$. This configuration is identical to the first except for this dimension. Again, the multiplication factor is above critical, 1.0782. Figure 15.2 gives the side view change in the geometry used for this case.

The next step, MCNP run ANS582, was to examine the previous case condition but with only the UFE being transferred. Further, this element is modeled such that it is $0.5 \mathrm{~m}$ above the canal floor and centered in the $0.711-\mathrm{m}$ canal. The multiplication factor for this case is 0.9963 , which is subcritical but with a very low level of confidence.

MCNP run ANS583 is a further improvisation on the above case where the Al-6061 liner is replaced with a stainless steel of the same thickness. This gives an additional decrease in $\mathrm{k}_{\mathrm{eff}}$ of approximately $4 \%$ to 0.9594 .

MCNP run ANS581 is a representation of the two fuel elements in transit through the long refueling shaft. As expected from the above arguments about the canal $\mathrm{D}_{2} \mathrm{O}$ region seeming infinite around the fuel, the multiplication factor is well above critical (1.1778). Figure 15.3 shows planar and elevation views of this case.

MCNP run ANS584 represents the two fresh fuel elements raised to the top of the reflector tank while the control and shutdown rods are in their inserted configuration. Figure 15.4 illustrates this case. The multiplication factor is 1.1027. A variation of this case, MCNP run ANS579, where only the UFE is modeled in this state, also yields a multiplication factor above 1.0 (1.0406). The overall reflector vessel height transmitted in the hand drawings from ORNL for this case is $4324 \mathrm{~mm}$, whereas in all the MCNP models to date the reflector tank height is only $4018 \mathrm{~mm}$. This is a discrepancy of a few millimeters at the bottom and about $280 \mathrm{~mm}$ at the top. The above modeling runs continued to use the 4018-mm height. If the 4324-mm height were employed, there would be a larger $\mathrm{D}_{2} \mathrm{O}$ region around the fuel element(s) during transfer, and the values of the multiplication factors obtained would be even higher. 
a. Front view volo

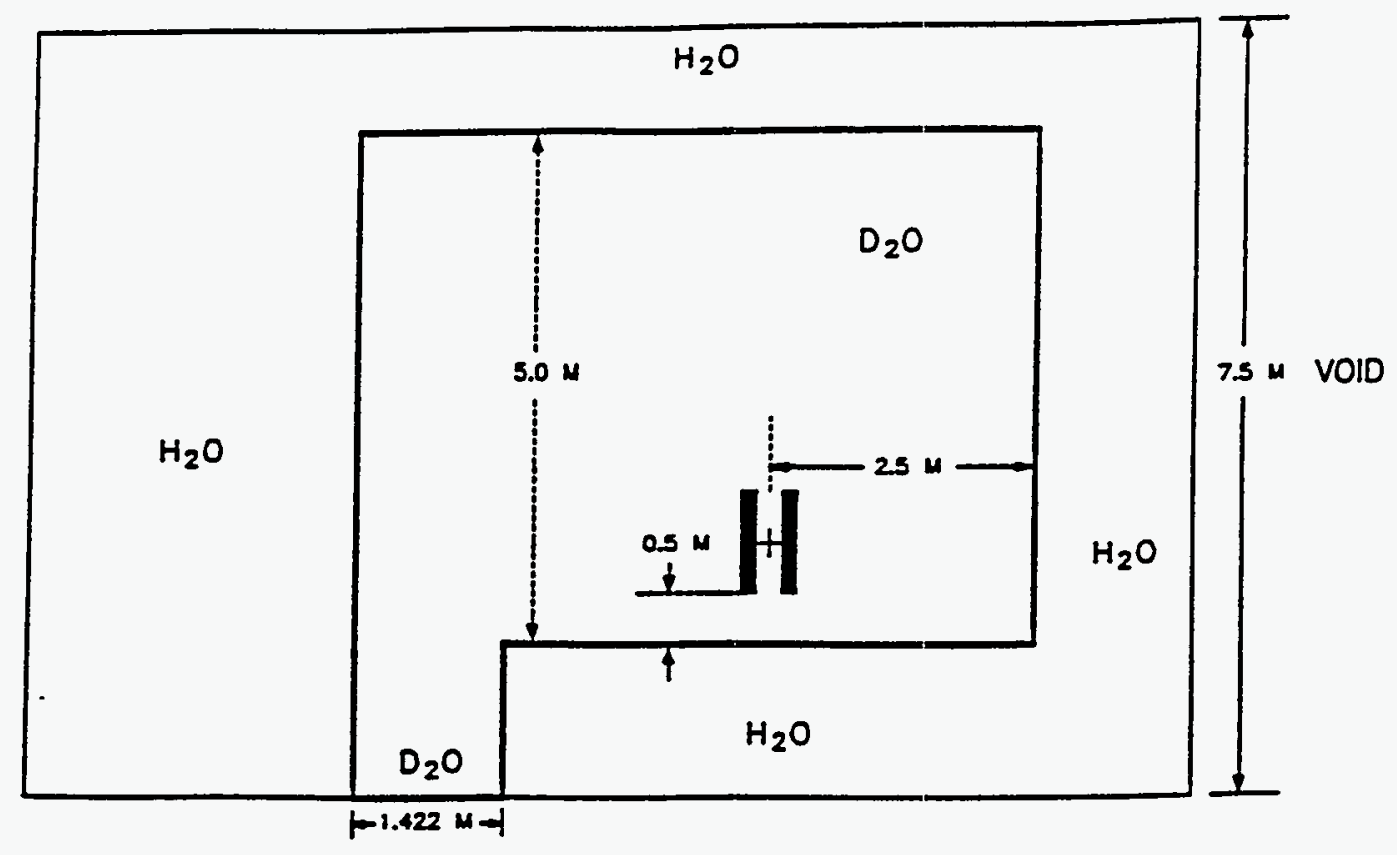

b. Side view

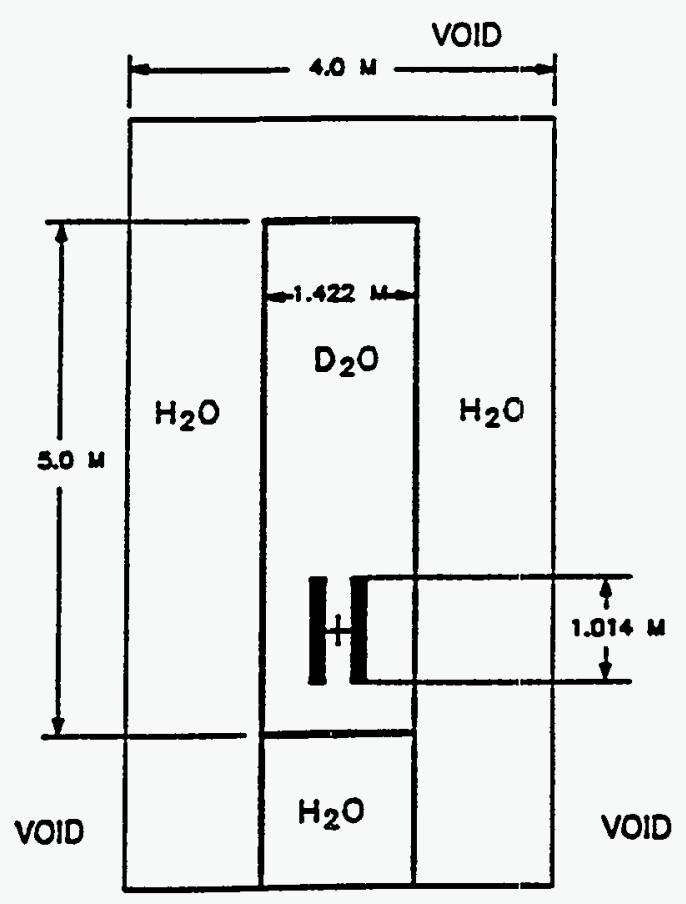

Fig. 15.1. Front and side views of the two fuel elements in the transfer canal base case. 
a. Front view vold

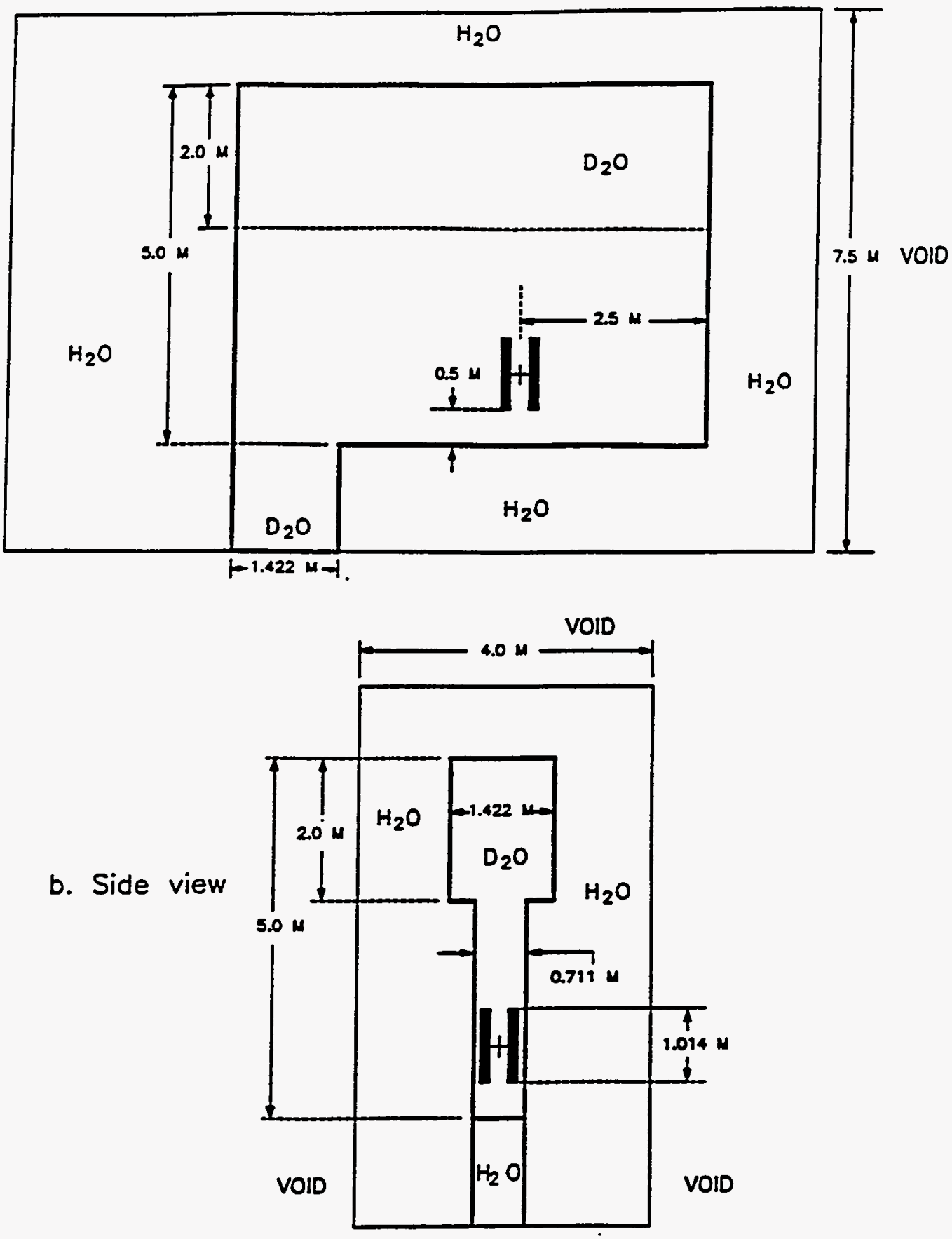

Fig. 15.2. Front and side views of the two fuel elements in the transfer canal reduced to a width of $0.7 \mathrm{~m}$. 
o. Top view
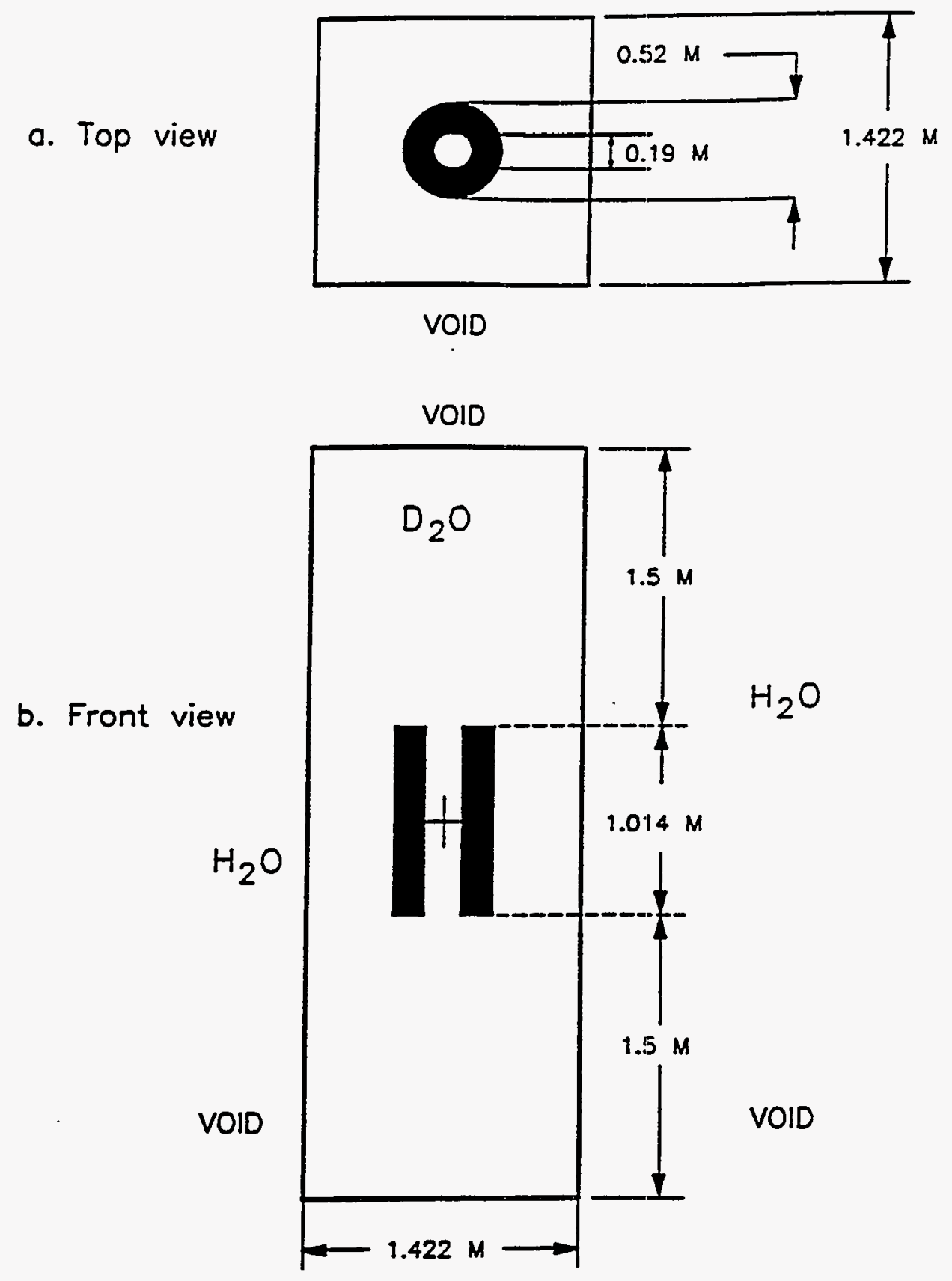

Fig. 15.3. Top and front views of the two fuel elements during transfer in the long leg of the canal. 


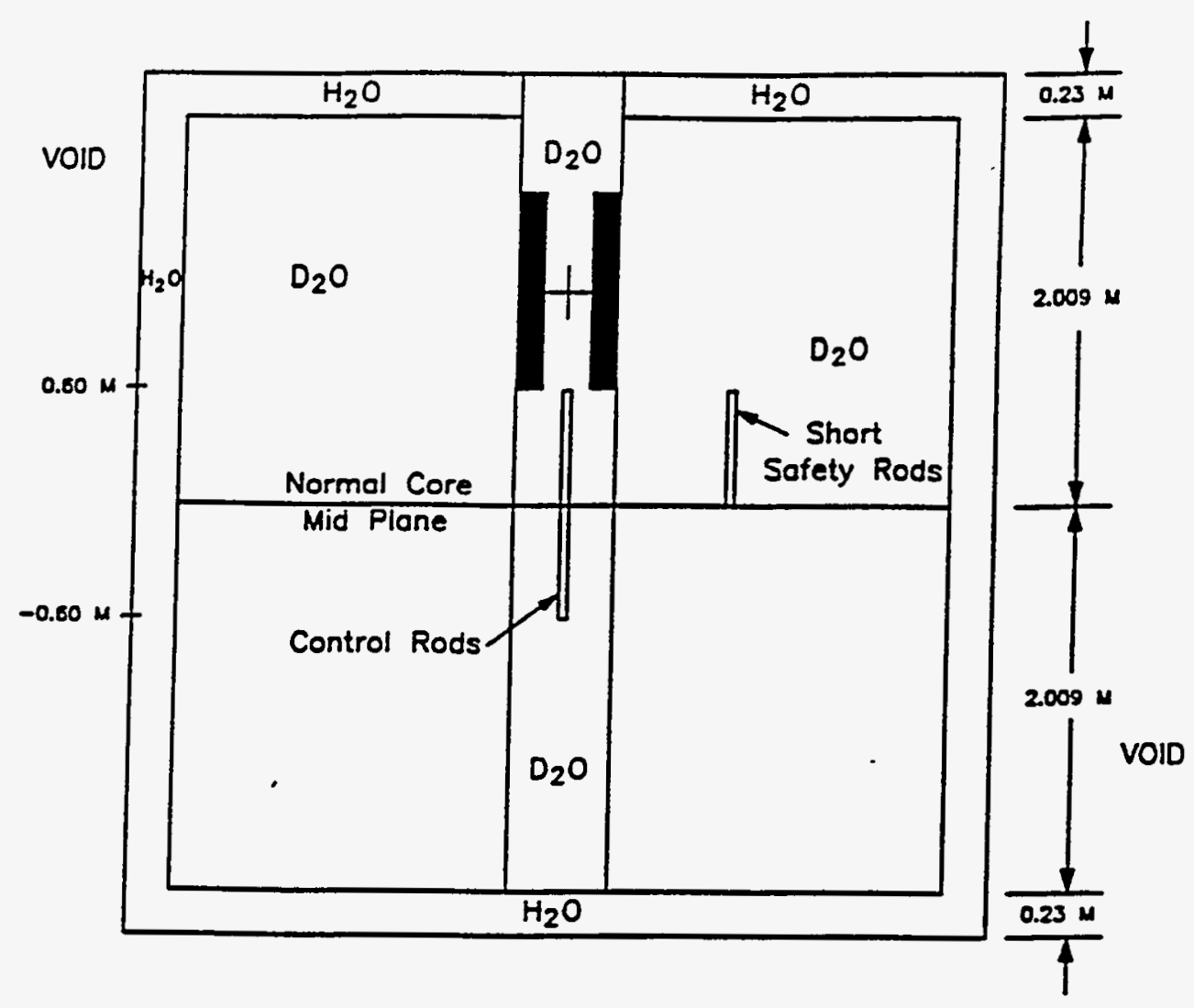

Fig. 15.4. Two fuel elements moved near the top of the reflector tank while control and shutdown rods are in the fully inserted position.

The above analysis indicates that the cumbersome effort to transfer the two fuel elements separately will not on its own yield a total solution to this fuel transfer problem. All the cases run to date are summarized in Table 15.1. The basic difficulty lies in the 200 - to 300 -mm thick $\mathrm{D}_{2} \mathrm{O}$ reflector layer around the fuel, which appears in one aspect or another during the fuel transfer. This means the fuel transfer has to consider auxiliary poisons as mentioned above. The fuel transfer can be performed satisfactorily by placing a boron-impregnated inner cylinder inside the inner fuel plate, as shown in the analysis by ORNL discussed below.

\subsection{VENTURE AND KENO REFUELING CRITICALITY ANALYSIS}

Scoping analysis of the criticality of the upper and lower fuel elements surrounded by $\mathrm{D}_{2} \mathrm{O}$ was also performed using VENTURE. The BOC fuel loading of the ANS L7 core was used. An upper and lower $\mathrm{D}_{2} \mathrm{O}$ reflector of $2.0 \mathrm{~m}$ was modeled, and the criticality as a function of $\mathrm{D}_{2} \mathrm{O}$ radial reflector thickness was calculated for each element separately and for both elements attached together. The results are listed in Table 15.2. Also listed in Table 15.2 is the criticality for inclusion of various absorbers.

The space available for attaching absorbers to each element is shown schematically in Fig. 15.5. A selection of absorbers that could be inserted into the available spaces for each element was made, and the criticality of each fuel element in "infinite" $\mathrm{D}_{2} \mathrm{O}$ was calculated using KENO with 99 energy 
Table 15.1. MCNP-evaluated effective multiplication factors of various fuel transfer cases

\begin{tabular}{|c|c|c|}
\hline Case & Description & $\mathrm{k}_{\mathrm{eff}}$ \\
\hline ANS576 & Base case & $1.2012 \pm 0.0022$ \\
\hline ANS577 & $\begin{array}{l}\text { Same as above but canal has } 20 \text {-mm-thick SS- } 316 \\
\text { walls }\end{array}$ & $1.1865 \pm 0.0022$ \\
\hline ANS580 & $\begin{array}{l}\text { Similar to above except lower section of canal is } \\
0.7 \mathrm{~m} \text { wide }\end{array}$ & $1.0782 \pm 0.0027$ \\
\hline ANS582 & $\begin{array}{l}\text { Similar to above except UFE alone in canal (Base of } \\
\text { upper fuel is } 0.5 \mathrm{~mm} \text { above floor.) }\end{array}$ & $0.9963 \pm 0.0021$ \\
\hline ANS583 & Same as above but with SS-316 liner & $0.9594 \pm 0.0030$ \\
\hline ANS581 & $\begin{array}{l}\text { Two fuel elements are modeled in lower section of } \\
\text { canal }\end{array}$ & $1.1778 \pm 0.0030$ \\
\hline ANS584 & $\begin{array}{l}\text { Two fresh fuel elements raised to top of reflector } \\
\text { tank, control rods fully inserted, short safety rods } \\
\text { fully inserted }\end{array}$ & $1.1027 \pm 0.0028$ \\
\hline ANS579 & Same as ANS576 but UFE only & $1.0406 \pm 0.0023$ \\
\hline
\end{tabular}

groups. The results are shown in Table 15.3. The numbers without error bars are from the four-group VENTURE calculations; those with error bars represent the KENO results. Without absorbers, each element is critical; with any of the absorbers evaluated, even $\mathrm{Al}$, each element alone is subcritical below 0.95 multiplication factor. For both elements together, an absorber placed inside the upper element alone is not sufficient, and an additional absorber inside the lower element is necessary. Note that a single, full-length absorber inside the lower element alone cloes not decrease the multiplication factor below 0.95 . 
Table 15.2. Criticality $\left(k_{e f f}\right)$ of ANS fuel elements ${ }^{a}$

\begin{tabular}{|c|c|c|c|c|c|c|}
\hline & \multicolumn{6}{|c|}{$\mathrm{D}_{2} \mathrm{O}$ radial reflector thickness } \\
\hline & $0.0 \mathrm{~m}$ & $0.1 \mathrm{~m}$ & $0.25 \mathrm{~m}$ & $0.5 \mathrm{~m}$ & $1.0 \mathrm{~m}$ & $1.5 \mathrm{~m}$ \\
\hline \multicolumn{7}{|c|}{ UFE at BOC } \\
\hline $\begin{array}{l}\text { No absorber } \\
\text { Ideal absorber inside } \\
\text { 4-mm Hf }\end{array}$ & 0.3704 & 0.7329 & 0.9890 & 1.1185 & $\begin{array}{l}1.1817 \\
0.4760 \\
0.7192\end{array}$ & $\begin{array}{l}1.1959 \\
0.7192 \\
0.7192\end{array}$ \\
\hline \multicolumn{7}{|c|}{ UFE at EOC ( 25 h) } \\
\hline $\begin{array}{l}\text { No absorber } \\
\text { Ideal absorber inside } \\
\text { 4-mm Hf }\end{array}$ & 0.2278 & 0.4316 & 0.5616 & 0.6273 & 0.6603 & $\begin{array}{l}0.6604 \\
0.2497 \\
0.3930\end{array}$ \\
\hline \multicolumn{7}{|c|}{$\mathrm{LFE}$ at BOC } \\
\hline $\begin{array}{l}\text { No absorber } \\
\text { Ideal absorber inside } \\
\text { 4-mm Hf inside } \\
\text { Ideal absorber outside } \\
\text { 4-mm Hf outside }\end{array}$ & 0.2432 & 0.5764 & 0.8395 & 0.9725 & 1.0364 & $\begin{array}{l}1.0509 \\
0.5099 \\
0.7296 \\
0.2552 \\
0.4364\end{array}$ \\
\hline \multicolumn{7}{|c|}{ Both elements at BOC } \\
\hline $\begin{array}{l}\text { No control } \\
\text { Ideal absorber inside upper element } \\
\text { 4-mm Hf cylinder inside upper element } \\
\text { Ideal absorber inside both } \\
\text { Two 4-mm Hf cylinders, just inside } \\
\text { each element } \\
\text { One 4-mm Hf cylinder, } 180 \mathrm{~mm} \mathrm{ID}\end{array}$ & 0.5208 & 0.7929 & 1.0331 & 1.1696 & 1.2439 & $\begin{array}{l}1.2633 \\
1.0376 \\
1.0971 \\
0.5525 \\
0.8105 \\
0.9561\end{array}$ \\
\hline
\end{tabular}

${ }^{a}$ All cases assume $2.0 \mathrm{~m}$ of $\mathrm{D}_{2} \mathrm{O}$ above and below the element. The $\mathrm{L} 7$ fuel loadings are used in all cases. Calculations performed using VENTURE with four-group cross sections. 
$-\mathrm{D}_{2} \mathrm{O} \rightarrow$
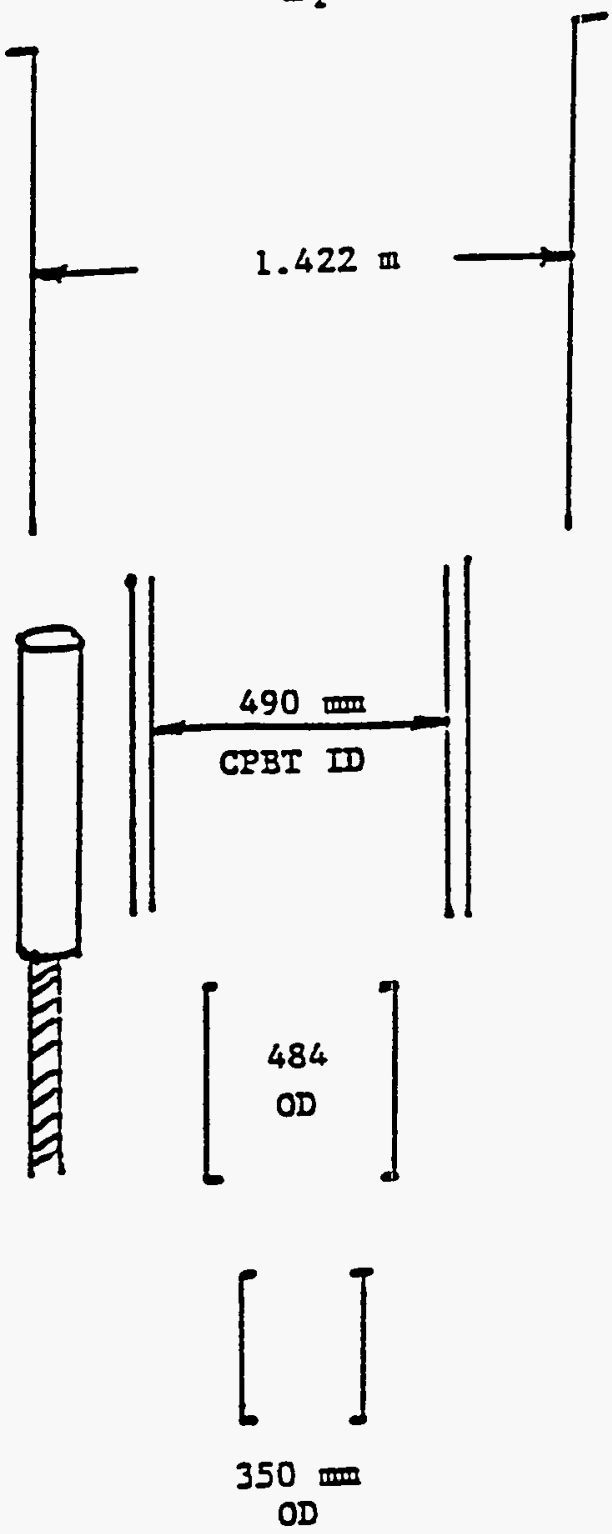

Refueling Shaft

\section{Upper Element}

- No clearance on outsicie until refueiting shart.

- $\quad-80 \mathrm{~mm}$ clearance on inside at all times.

\section{Lower Element}

- $\quad-70 \mathrm{~mm}$ clearance on outside at all times.

- $\quad 10 \mathrm{~mm}$ clearance on insicie at all times.

Fig. 15.5. Schematic of space available for adding absorbers to the upper and lower fuel elements. 
Table 15.3. Fuel element criticality $\left(k_{e f f}\right)$ for fresh-fueled elements with BOC burnable poison for fuel loadings for $L 7$ core

Upper element in infinite heavy water

No absorber $1.1959^{a}$

4-mm Hf inside

$0.7192^{a}$

25-mm SS inside

$0.935 \pm 0.003^{b}$

127-mm Al outside

$0.945 \pm 0.002^{b}$

$\mathrm{SS}$ and $\mathrm{Al}$

$0.653 \pm 0.002^{b}$

Lower element in infinite heavy water

No absorber

$1.0509^{a}$

4-mm Hf inside

$0.7296^{a}$

4-mm Hf outside

$0.4364^{a}$

25-mm SS inside

$0.936 \pm 0.004^{b}$

57-mm Al outside

$0.948 \pm 0.002^{b}$

$\mathrm{SS}$ and $\mathrm{Al}$

$0.769 \pm 0.002^{b}$

Both elements in infinite heavy water

No absorber

$1.2633^{a}$

4-mm Hf inside upper

$1.0971^{a}$

4-mm Hf inside both

$0.8105^{a}$

4-mm Hf inside lower, full height

$0.9561^{a}$

"VENTURE calculations using 4-group cross sections.

${ }^{b} \mathrm{KENO}$ calculations using 99-group cross sections. 


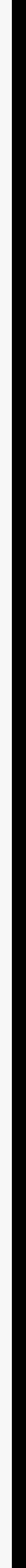




\section{REACTOR KINETICS ANALYSIS}

\subsection{INTRODUCTION}

The use of the point-kinetics method requires the accurate knowledge of the point-kinetics parameters, including the reactivity, prompt-neutron lifetime, and effective delayed-neutron fractions. The most crucial parameter is the reactivity, which is commonly obtained by performing static calculations (referred to as the adiabatic method). The prompt-neutron lifetime and the delayed-neutron fractions generally change much more slowly and, for most cases, can be assumed to be constant.

The prompt-neutron lifetime and the effective delayed-neutron fractions have been evaluated for ANS. The calculations are based upon a diffusion-theory model, and the effect of photoneutron production in $\mathrm{D}_{2} \mathrm{O}$ is considered. An approximation for the transport of the gamma rays is used until a more rigorous transport calculation can be performed. The prompt-neutron lifetime and effective delayed-neutron fractions are also computed at each depletion step throughout the cycle.

\subsection{POINT-KINETICS EQUATIONS WITH DELAYED PHOTONEUTRONS}

The point-kinetics equations are obtained by factoring the time-dependent neutron flux into an amplitude function and a shape function

$$
\phi(r, E, t)=T(t) S(r, E, t)
$$

where

$$
\begin{aligned}
& T(t) \equiv \int d E \int d r \phi_{o}^{*}(r, E) \frac{1}{v(E)} \Phi(r, E, t), \\
& S(r, E, t) \equiv \frac{1}{T(t)} \phi(r, E, t),
\end{aligned}
$$

$v(E)=$ neutron velocity at energy $E$,

$\phi_{o}^{*}(r, E)=$ adjoint flux, used as a weight function.

Substituting this factorization into the time-dependent diffusion equation, weighting with the adjoint and integrating over energy and space results in the following definitions for the point-kinetics parameters:

$$
\begin{aligned}
\rho(t) & \equiv \frac{1}{F(t)} \int d E \int d r \phi_{o}^{*}(r, E)\left\{\nabla \cdot D(r, E, t) \nabla S(r, E, t)-\Sigma_{t}(r, E, t) S(r, E, t)\right. \\
& +\int d E^{\prime}\left[(1-\beta) \chi_{p}(E) \vee \Sigma_{f}\left(r, E^{\prime}, t\right) s\left(r, E^{\prime}, t\right)\right. \\
& \left.+\sum_{i=1}^{t+J} \beta_{i} \chi_{t}(E) \int d \boldsymbol{r}^{\prime} K_{i}\left(\boldsymbol{r}^{\prime}, r\right) \vee \Sigma_{t}(r, E, t) s\left(\boldsymbol{r}^{\prime}, E^{\prime}, t\right)\right] \\
& \left.+\int d E^{\prime} \Sigma_{s}\left(r, E^{\prime} \rightarrow E, t\right) S\left(r, E^{\prime}, t\right)\right\} .
\end{aligned}
$$




$$
\begin{gathered}
\Lambda(t) \equiv \frac{1}{F(t)} \int d E \int d r \phi_{o}^{*}(r, E) \frac{1}{v(E)} S(r, E, t) \\
\beta_{i}(t) \equiv \frac{1}{F(t)} \int d E \int d r \phi_{o}^{*}(r, E) \beta_{i} \chi_{i}(E) \int d E^{\prime} \int d \boldsymbol{r}^{\prime} K_{i}\left(\boldsymbol{r}^{\prime}, \boldsymbol{r}\right) \vee \Sigma_{f}\left(\boldsymbol{r}^{\prime}, E^{\prime}, t\right) S\left(\boldsymbol{r}^{\prime}, E^{\prime}, t\right) . \\
F(t) \equiv \int d E \int d \boldsymbol{r} \phi_{o}^{*}(\boldsymbol{r}, E) \int d E^{\prime}\left\{(1-\beta) \chi_{p}(E) \vee \Sigma_{f}\left(r, E^{\prime}, t\right) S\left(\boldsymbol{r}, E^{\prime}, t\right)\right. \\
\left.+\sum_{r=1}^{I+J} \beta_{i} \chi_{i}(E) \int d \boldsymbol{r}^{\prime} K_{i}\left(\boldsymbol{r}^{\prime}, \boldsymbol{r}\right) \vee \Sigma_{f}\left(\boldsymbol{r}^{\prime}, E^{\prime}, t\right) S\left(\boldsymbol{r}, E^{\prime}, t\right)\right\} .
\end{gathered}
$$

The effective precursor concentrations are given by

$$
C_{i}(t) \equiv \frac{\int d E \int d r \phi_{o}^{*}(r, E) \chi_{i}(E) \int d r^{\prime} K_{i}\left(r^{\prime}, r\right) c_{i}\left(r^{\prime}, t\right)}{\int d E \int d r \phi_{o}^{*}(r, E) \frac{1}{v(E)} S(r, E, t)}
$$

In the above equations there are $I$ regular delayed-neutron precursor groups and $J$ delayed-photoneutron groups. The kernel $K_{i}\left(r^{\prime}, r\right)$ accounts for the gamma-ray transport from the point of fission to the point at which the $\gamma, n$ reaction occurs. For the regular delayed-neutron groups $(i=1,2, \ldots, I)$, this kernel is taken to be a delta function (i.e., neutrons appear at the fission site). The resulting point-kinetics equations are

$$
\begin{gathered}
\frac{d}{d t} T(t)=\frac{\rho(t)-\beta(t)}{\Lambda(t)} T(t)+\sum_{i=1}^{I+J} \lambda_{i} C_{i}(t) . \\
\frac{d}{d t} C_{i}(t)=\frac{\beta_{i}(t)}{\Lambda(t)} T(t)-\lambda_{i} C_{i}(t) .
\end{gathered}
$$

Note that all of the parameters are time dependent. If the shape function does not change much, the prompt-neutron lifetime and the effective delayed-neutron fractions will be nearly constant. Note, however, that because of shape changes resulting from rod motions and fuel depletion, these parameters may change throughout the fuel cycle. Furthermore, the parameters may experience changes resulting from large shape changes during severe transients.

\subsection{BASIC DATA}

The computation of the point-kinetics parameters requires the knowledge of the shape function, adjoint weight function, cross sections, group speeds, and delayed-neutron parameters in Eqs. (4-7). A 
four-group, fine-mesh VENTURE model is used to compute the shape function and the adjoint weight function at each depletion step throughout the fuel cycle. The remainder of the input data is specified below.

\subsubsection{Delayed-Neutron Fractions and Decay Constants}

The total number of delayed neutrons that are emitted after a fission event was obtained from ENDF/B-VI and is $\bar{v}_{d}=0.0167$ for the thermal fission of ${ }^{235} \mathrm{U}$. The average number of neutrons released per fission was also obtained from ENDF/B-VI for thermal fission $\bar{v}=2.432$. Thus, the total delayed-neutron fraction is $\beta=\bar{v}_{d} / \bar{v}=0.00687$. This value compares favorably with that recommended by Tuttle, ${ }^{38} \beta=0.00680$, and is slightly larger than Keepin's value, ${ }^{39} \beta=0.0065$. Note. that because of the hard spectrum in the fuel elements, a significant fraction of the fissions are fast. Fortunately, the delayed-neutron fractions do not vary significantly with neutron energy.

The relative delayed-neutron fractions and decay constants, using six delayed groups, were obtained from a recent evaluation by Brady and England. ${ }^{40}$ The values are presented in Table 16.1 along with the values of Tuttle and Keepin, for comparison.

Table 16.1. Relative delayed-neutron fractions and decay constants for thermal fission of ${ }^{235} \mathrm{U}$

\begin{tabular}{ccccccc}
\hline \multirow{2}{*}{$\begin{array}{c}\text { Precursor } \\
\text { group } i\end{array}$} & \multicolumn{2}{c}{ England and Brady } & \multicolumn{2}{c}{ Tuttle } & \multicolumn{2}{c}{ Keepin } \\
\cline { 2 - 7 } & $B / B$ & $\begin{array}{c}\lambda_{i} \\
\left(\mathrm{~s}^{-1}\right)\end{array}$ & $B / B$ & $\begin{array}{c}\lambda_{i} \\
\left(\mathrm{~s}^{-1}\right)\end{array}$ & $B_{i} / B$ & $\begin{array}{c}\lambda_{i} \\
\left(\mathrm{~s}^{-1}\right)\end{array}$ \\
\hline 1 & 0.0138 & 0.0133 & 0.038 & 0.0127 & 0.033 & 0.0124 \\
2 & 0.1918 & 0.0325 & 0.213 & 0.0317 & 0.219 & 0.0305 \\
3 & 0.1638 & 0.1219 & 0.188 & 0.115 & 0.196 & 0.111 \\
4 & 0.3431 & 0.3169 & 0.407 & 0.311 & 0.395 & 0.301 \\
5 & 0.1744 & 0.9886 & 0.128 & 1.40 & 0.115 & 1.14 \\
6 & 0.0889 & 2.9544 & 0.026 & 3.87 & 0.042 & 3.01 \\
\hline
\end{tabular}

\subsubsection{Photoneutron Yields}

The yield of delayed photoneutrons, as represented by nine delayed groups, are taken from Ref. 39 and are given in Table 16.2 for a saturation of fission products. For non-saturation conditions, these values must be multiplied by $\left(1-e^{\lambda_{i} \tau}\right)$ where $\tau$ is the effective radiation time. In all following calculations, we assume a saturated fission-product inventory. Note that these yields are only for the photoneutrons from prompt-fission gamma rays and fission-product gamma rays. The effect of capture gamma rays is yet to be evaluated.

\subsubsection{Group Speeds and Energy Boundaries}

The spectrum-weighted group speeds are obtained during the cross-section processing and are averaged over the entire core region. These group speeds and the energy-group boundaries are presented in Table 16.3. The calculation of region-dependent group speeds, to account for spectral differences throughout the core, is planned. 
Table 16.2. Delayed-neutron yields and delay constants for photoneutron production

\begin{tabular}{|c|c|c|}
\hline Photoneutron group $i$ & $\begin{array}{c}B_{i} \\
\left(\times 10^{5}\right)\end{array}$ & $\begin{array}{c}\lambda_{i} \\
\left(\mathrm{~s}^{-1}\right)\end{array}$ \\
\hline 7 & 0.05 & $6.26 \times 10^{-7}$ \\
\hline 8 & 0.103 & $3.63 \times 10^{-6}$ \\
\hline 9 & 0.323 & $4.37 \times 10^{-5}$ \\
\hline 10 & 2.34 & $1.17 \times 10^{-4}$ \\
\hline 11 & 2.07 & $4.28 \times 10^{-4}$ \\
\hline 12 & 3.36 & $1.50 \times 10^{-3}$ \\
\hline 13 & 7.00 & $4.81 \times 10^{-3}$ \\
\hline 14 & 20.4 & $1.69 \times 10^{-2}$ \\
\hline 15 & 65.1 & $2.77 \times 10^{-1}$ \\
\hline Total & 100.75 & \\
\hline
\end{tabular}

Table 16.3. Spectrum-averaged group speeds and energy-group boundaries

\begin{tabular}{ccc}
\hline $\begin{array}{c}\text { Energy } \\
\text { group } g\end{array}$ & $\begin{array}{c}\mathrm{v}_{g} \\
(\mathrm{~m} / \mathrm{s})\end{array}$ & $\begin{array}{c}\mathrm{E}_{g}^{\max } \\
(\mathrm{eV})\end{array}$ \\
\hline 1 & $1.163 \times 10^{7}$ & $2.0 \times 10^{7}$ \\
2 & $5.644 \times 10^{5}$ & $1.5 \times 10^{7}$ \\
3 & $3.123 \times 10^{4}$ & $1.0 \times 10^{2}$ \\
4 & $2.687 \times 10^{3}$ & $6.5 \times 10^{-3}$ \\
\hline
\end{tabular}

\subsubsection{Delayed-Neutron Spectra}

A recent experimental analysis of the delayed-neutron spectra for the six precursor groups (consistent with the Brady and England data) were performed at the University of Lowell. ${ }^{41}$ The collapsed values for the four-group structure are shown in Table 16.4. The photoneutrons are assumed to appear in group 1 because the $(\gamma, n)$ reaction is a threshold reaction with a threshold gamma-ray energy of $2.23 \mathrm{MeV}$. Note that the delayed neutrons appear at a significantly lower energy than the prompt neutrons (compare to the fission spectrum in Table 16.4). Also note that precursor groups 2-6 have nearly identical spectra. 
Table 16.4. Energy spectra of delayed-precursor groups

\begin{tabular}{ccccccccc}
\hline \multirow{2}{*}{$\begin{array}{c}\text { Energy } \\
\text { group } g\end{array}$} & 1 & 2 & 3 & 4 & 5 & 6 & $\begin{array}{c}\text { Photoneutron } \\
\text { groups }\end{array}$ & $\begin{array}{c}\text { Prompt } \\
\text { fission } \\
\text { spectra }\end{array}$ \\
\hline 1 & 0.7591 & 0.8356 & 0.8150 & 0.8330 & 0.8393 & 0.8110 & 1.0 & 0.976 \\
2 & 0.2409 & 0.1644 & 0.1850 & 0.1670 & 0.1602 & 0.1890 & 0.0 & 0.024 \\
3 & 0.0 & 0.0 & 0.0 & 0.0 & 0.0 & 0.0 & 0.0 & 0.0 \\
4 & 0.0 & 0.0 & 0.0 & 0.0 & 0.0 & 0.0 & 0.0 & 0.0 \\
\hline
\end{tabular}

\subsection{RESULTS}

The shape function and adjoint weight function were obtained throughout the cycle using four-energy-group VENTURE calculations. Routines from the CONQUEST nodal kinetics code were used to evaluate the point-kinetics parameters using discretized forms of Eqs. (4-7).

Considering only the first six precursor groups (i.e., no photoneutron contribution), the prompt-neutron lifetime and delayed-neutron functions were computed at $\mathrm{BOC}$ to be

$$
\begin{aligned}
& \Lambda=1.30459 \mathrm{~ms}, \\
& \beta=0.00693 .
\end{aligned}
$$

Thus, it is seen that the delayed neutrons have an average effectiveness of $\beta / \beta=1.0094$ resulting from their appearance at lower energies. The relative delayed-neutron fractions are given in Table 16.5

The calculation of the parameters that include the effects of the photoneutrons requires the specification of the transport kernel $K\left(r^{\prime}, r\right)$. A rigorous treatment would require a coupled neutron/photon transport calculation to obtain the $(\gamma, n)$ reaction rates accurately. A DORT model (39 neutron groups, 44 gamma-ray groups) is presently being developed for just such a calculation.

An approximate treatment of the gamma-ray transport can be obtained by making the assumption that once a gamma ray has had an interaction, it falls below the $(\gamma, n)$ threshold energy $(2.23 \mathrm{MeV})$. As a result, we are required to calculate only the uncollided gamma-ray flux to obtain the $(\gamma, n)$ reaction rate, a calculation that can be performed using a diffusion-theory model. A one-group VENTURE fixed-source calculation using the same mesh as for the neutron flux and adjoint flux calculations was performed. The gamma-ray source in each fuel element was assumed to be proportional to the fission rate. The resulting flux distribution was normalized to give $K_{l}\left(\boldsymbol{r}^{\prime}, r\right)$. The prompt-neutron lifetime and effective delayed-neutron fractions at BOC including the effects of photoneutrons are

$$
\begin{aligned}
& \Lambda=1.30481 \mathrm{~ms}, \\
& \beta=0.00774 .
\end{aligned}
$$


Table 16.5. Relative effective delayed-neutron fractions for calculations without photoneutrons at BOC

Precursor group, $i$

$\beta / \beta$

\begin{tabular}{ll}
\hline 1 & 0.038163 \\
2 & 0.191695 \\
3 & 0.163925 \\
4 & 0.342968 \\
5 & 0.174258 \\
6 & 0.088990 \\
\hline
\end{tabular}

As can be seen from Table 16.6, the photoneutrons result in a significant contribution to the fraction of delayed neutrons.

Calculations were also performed at each VENTURE depletion step to obtain the prompt-neutron lifetime and delayed-neutron fractions throughout the entire cycle. The results are presented in Figure 16.1. The quantities show only minor variations throughout the cycle.

While the methodology of the calculation of the point-kinetics parameters is complete, a more precise determination of the gamma-ray transport kernel $K_{i}\left(\boldsymbol{r}^{\prime}, \boldsymbol{r}\right)$ is required. After performing a neutron/photon DORT calculation, the production of photoneutrons and their distribution throughout the core can be obtained. In addition, the resulting neutron flux can be used to verify the use of the four-group diffusion-theory calculation of the point-kinetics parameters.

Table 16.6. Relative effective delayed-neutron fractions for calculations with photoneutrons at BOC

\begin{tabular}{cc||cc}
\hline & & & \\
Precursor group $i$ & $\beta / \beta$ & Precursor group $i$ & $\beta / \beta$ \\
& & & \\
\hline 1 & $3.4227 \times 10^{-2}$ & 9 & $3.3206 \times 10^{-4}$ \\
2 & $1.7214 \times 10^{-1}$ & 10 & $2.4057 \times 10^{-4}$ \\
3 & $1.4720 \times 10^{-1}$ & 11 & $2.1281 \times 10^{-3}$ \\
4 & $3.0797 \times 10^{-1}$ & 12 & $3.4543 \times 10^{-3}$ \\
5 & $1.5648 \times 10^{-1}$ & 13 & $7.8274 \times 10^{-3}$ \\
6 & $7.9909 \times 10^{-2}$ & 14 & $2.0972 \times 10^{-2}$ \\
7 & $5.1408 \times 10^{-5}$ & 15 & $6.6926 \times 10^{-2}$ \\
8 & $1.0588 \times 10^{-4}$ & & \\
\hline
\end{tabular}




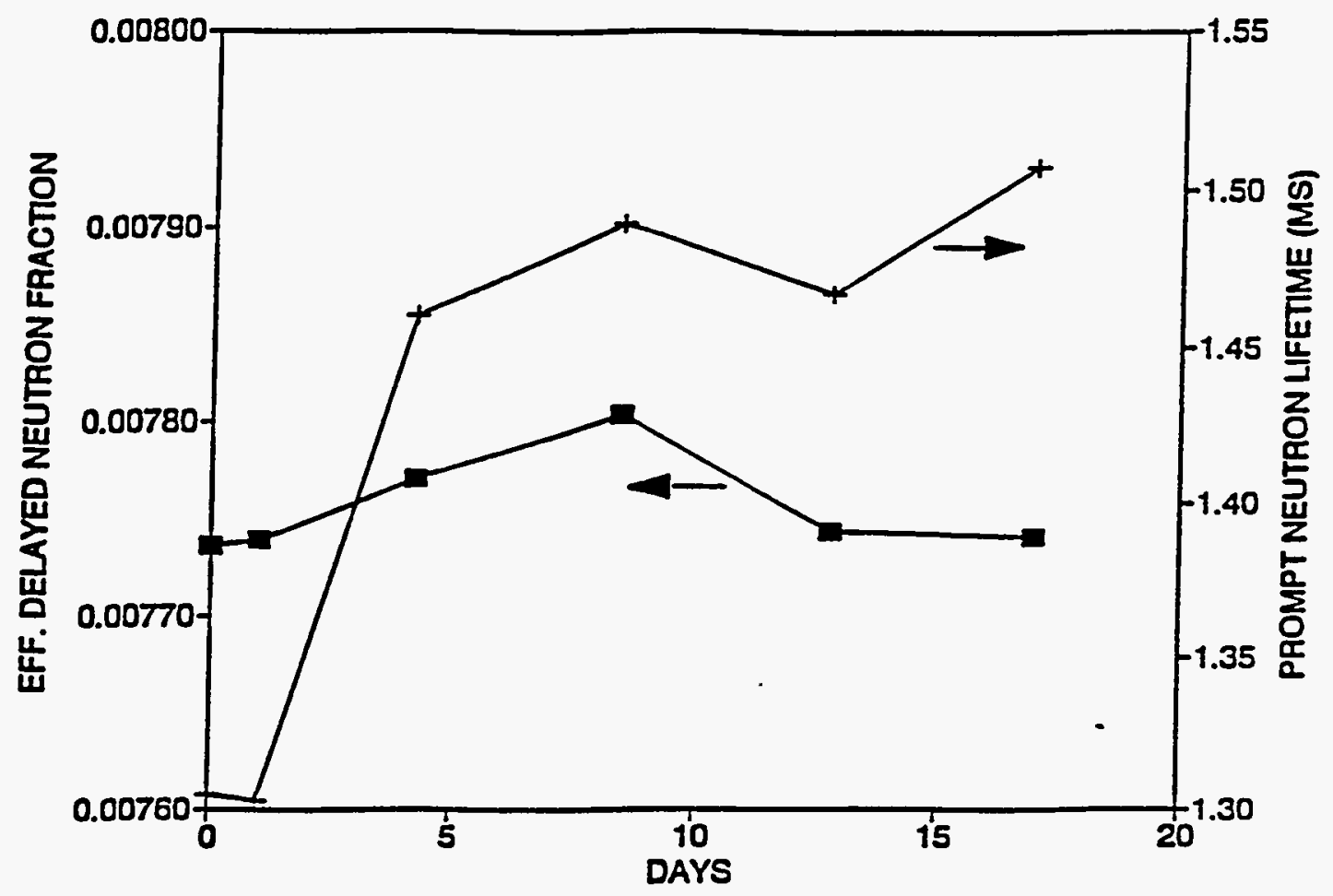

Fig. 16.1. The prompt-neutron lifetime and effective delayed neutron fraction (including photoneutrons) during the ANS fuel cycle. 


\section{REFERENCES}

1. J. M. Ryskamp, D. L. Selby, and R. T. Primm, III, "Reactor Design of the Advanced Neutron Source," Nucl. Technol. 93, 330 (1991).

2. Reference Core Selection Committee: Notes for the Record, Vols. 1 and 2, ORNL/ANS/INT-15, Martin Marietta Energy Systems, Inc., Oak Ridge Natl. Lab., March 1989.

3. Reference Conceptual Core Design Selection Committee: Notes for the Record, ORNL/ANS/INT-24, Martin Marietta Energy Systems, Inc., Oak Ridge Natl. Lab., May 1990.

4. R. Kinsey, ed., ENDF/B Summary Documentation, BNL-NCS-17541 (ENDF-201), 3d ed., Brookhaven National Laboratory, Upton, N.Y., 1979.

5. ANSL-V: ENDF/B-V Based Multigroup Cross-Section Libraries for Advanced Neutron Source (ANS) Reactor Studies, ORNL-6618, Martin Marietta Energy Systems, Inc., Oak Ridge Natl: Lab., September 1990.

6. SCALE: A Modular Code System for Performing Standardized Computer Analysis for Licensing and Evaluation, NUREG/CR-0200, Rev. 4 (ORNL/NUREG/CSD-2), Martin Marietta Energy Systems, Inc., Oak Ridge Natl. Lab., April 1992.

7. N. M. Greene, et al., AMPX-A Modular Code System to Generate Coupled Multigroup Neutron-Gamma Cross Sections from ENDF/B, ORNL/TM-3706, Union Carbide Corp., Oak Ridge Natl. Lab., March 1976.

8. I. I. Bondarenko, ed., Group Constants for Nuclear Reactor Calculations, Consultants Bureau, New York, 1964.

9. L. W. Nordheim, "The Theory of Resonance Absorption," Proc. Symp. Appl. Math. 11, 58 (1961).

10. D. R. Vondy, T. B. Fowler, and G. W. Cunningham, VENTURE: A Code Block for Solving Multigroup Neutronics Problems Applying the Finite-Difference Diffusion-Theory Approximation to Neutron Transport, Version III, ORNL-5062/R1, Union Carbide Corp., Oak Ridge Natl. Lab., November 1977.

11. D. R. Vondy and T. B. Fowler, Reference Test Problems for the VENTURE Neutronics and Related Computer Codes, ORNL/TM-5887, Union Carbide Corp., Oak Ridge Natl. Lab., August 1977.

12. D. R. Vondy and G. W. Cunningham, Exposure Calculation Code Module for Reactor Core Analysis: BURNER, ORNL-5180, Union Carbide Corp., Oak Ridge Natl. Lab., February 1979.

13. C. J. Pfeifer, $P D Q-7$ Reference Manual II, WAPD-TM-947, Bettis Atomic Power Laboratory, Pittsburgh, 1976. 
14. R. A. Grimesey, D. W. Nigg, and R. L. Curtis, COMBINE/PC - A Portable ENDF/B Version 5 Neutron Spectrum and Cross-Section Generation Program, EGG-2589, Rev. 1, Idaho National Engineering Laboratory, Idaho Falls, Idaho, 1991.

15. J. L. Judd, SCRABL-5-An ENDF/B Version 5 Computer Code for Cross Section Collapsing, EGG-NE-9904, Idaho National Engineering Laboratory, Idaho Falls, Idaho, 1991.

16. J. M. Ryskamp et al., Reactivity Studies on the Final Preconceptual Reference Design of the Advanced Neutron Source, EGG-NE-8940, Idaho National Engineering Laboratory, Idaho Falls, Idaho, 1990.

17. J. F. Briemester, ed., MCNP-A General Monte Carlo Code from Neutron and Photon Transport Version 3A, LA-7396-M, Rev. 2, Los Alamos National Laboratory, Los Alamos, N.M., September 1986.

18. E. L. Redmond II and J. M. Ryskamp, "Monte Carlo Methods, Models, and Applications to the Advanced Neutron Source," Nucl. Technol. 95, 282 (September 1991).

19. W. B. Wilson et al., DKPOWR: A Code for Calculating Decay Power, Energy, Activity, and $\beta$ and $\gamma$ Spectra in LWR Fuel Using Fission Pulse Functions, LA-UR-85-157, Los Alamos National Laboratory, Los Alamos, N.M., December 1984.

20. American National Standard for Decay Heat Power in Light Water Reactors, ANSI/ANS-5.11979, American Nuclear Society, La Grange Park, Ill., 1979.

21. A. G. Croff, ORIGEN2 Isotope Generation and Depletion Code - Matrix Exponential Method, ORNL/TM-7175, Union Carbide Corp., Oak Ridge Natl. Lab., July 1980.

22. Chart of the Nuclides, 13th ed., GET-6504, General Electric Company, San Jose, Calif. 1984.

23. W. A. Rhoades and R. L. Childs, "The DORT Two-Dimensional Discrete Ordinates Transport Code," Nucl. Sci. Eng. 99, 88 (1988).

24. W. A. Rhoades and R. L. Childs, An Updated Version of the DOT One-and Two-Dimensional Neutron/Photon Transport Code, ORNL-5851, Union Carbide Corp., Oak Ridge Natl. Lab., July 1982.

25. J. C. Gehin, “A Quasi-Static Polynomial Nodal Method for Nuclear Reactor Analysis,” Ph.D. thesis, Massachusetts Institute of Technology, Cambridge, 1992.

26. J. R. White, The Depth Charge Static and Time-Dependent Perturbation/Sensitivity System for Nuclear Reactor Core Analysis, ORNL/CSD-78/R1, Martin Marietta Energy Systems, Inc., Oak Ridge Natl. Lab., April 1985.

27. R. E. MacFarlane, D. W. Muir, and R. M. Boicourt, The NJOY Nuclear Processing System, LA-9303-M (ENDF-324), Los Alamos National Laboratory, Los Alamos, N.M., 1982. 
28. R. A. Grimesey, G. L. Singer, and D. A. Milsap, ETOP-14-A FORTRAN Code to Process ENDF/B Data into the 68-Group PHROG Library Format, ANCR-1322 (UC-34a), Idaho National Engineering Laboratory, Idaho Falls, Idaho, July 1976.

29. H. C. Honeck and D. R. Finch, FLANGE-II-A Code to Process Thermal Neutron Data from an ENDF/B Tape, DP-1278 (ENDF-152), Savannah River Laboratory, Aiken, S.C. October 1971.

30. H. Reutler and A. Stroemlich, "Research Reactor Design Methods and Some Benchmarks," Advanced Neutron Source Project Lecture Series, Oak Ridge Nat. Lab., Oak Ridge, Tenn. Oct. 23-25, 1989.

31. A. M Ougouag et al., MCNP Analysis of the FOEHN Critical Experiment, ORNL/TM-12466, Martin Marietta Energy Systems, Inc., Oak Ridge Natl. Lab., January 1993.

32. Y. Y. Azmy and F. C. Difilippo, "Comparison of the Diffusion and Transport Calculations for the Advanced Neutron Source Reactor," in Proceedings of the International Reactor Physics Conference, American Nuclear Society, La Grange Park, Ill., 1988, Vol. II, p. 183.

33. R. T. Primm III, Reactor Physics Input to the Safety Analysis Report for the High Flux Isotope Reactor, ORNL/TM-11956, Martin Marietta Energy Systems, Inc., Oak Ridge Natl. Lab., March 1992.

34. R. T. Primm III and N. M. Greene, "Generation of Lumped Fission Product Cross Sections for High-Burnup, Highly Enriched Uranium Fuel," Trans. Am. Nucl. Soc. 56, 592 (June 1988).

35. L. A. Smith and J. P. Renier, Implementation of CTRLPOS, A VENTURE Module for Control Rod Position Criticality Searches, Control Rod Work Curve Calculations, and General Criticality Searches, ORNL/TM-12746, Martin Marietta Energy Systems, Inc., Oak Ridge Natl. Lab., June 1994.

36. J. R. Lamarsh, Introduction to Nuclear Reactor Theory, Addison-Wesley, Reading, Mass. 1966.

37. A. Amouyal, P. Benoist, and J. Horowitz, "Nouvelle methode de Determination du Facteur D'Utilisation Thermique D’Une Cellule," J. Nucl. Energy 6, 79-98, 1957.

38. R. J. Tuttle, "Delayed-Neutron Data for Reactor-Physics Analysis," Nucl. Sci. Eng. 56, 37-71 (1975).

39. G. R. Keepin, Physics of Nuclear Kinetics, Addison-Wesley, Reading, Mass., 1965.

40. M. C. Brady and T. R. England, "Delayed Neutron Data and Group Parameters for 43 Fissioning Systems," Nucl. Sci. Eng. 103, 129-149 (1989).

41. M. F. Villani et. al., "Six-Group Decomposition of Composite Delayed Neutron Spectra from ${ }^{235} \mathrm{U}$ Fission," Nucl. Sci. Eng. 111, 422-432 (1992). 



\section{INTERNAL DISTRIBUTION}

1. B. R. Appleton

2-3. J. H. Campbell

4. J. E. Cleaves

5. F. X. Gallmeier

6-10. J. C. Gehin

11. R. M. Harrington

12. D. T. Ingersoll

13. R. A. Lillie

14. T. J. McManamy

15-19. J. P. Renier
20. R. B. Rothrock

21. D. L. Selby

22. C. D. West

23-27. B. A. Worley

28. G. L. Yoder

29. CPED Reports Office

30. ORNL Patent Office

31. Central Research Library

32-33. Laboratory Records Dept.

34. Laboratory Records, ORNL-RC

\section{EXTERNAL DISTRIBUTION}

35. J. M. Ryskamp, Idaho National Engineering Laboratory, P.O. Box 1625, Idaho Falls, ID 83415.

36. C. A. Wemple, Idaho National Engineering Laboratory, P.O. Box 1625, Idaho Falls, ID 83415.

37. ANS Project Office, U.S. Department of Energy, Oak Ridge Field Office, P.O. Box 2009, FEDC, MS-8218, Oak Ridge, TN 37831-8218.

38. Office of Assistant Manager for Energy Research and Development, Department of Energy, Oak Ridge Field Office, P.O. Box 2001, Oak Ridge, TN 37831-2001.

39-40. Office of Scientific and Technical Info., P.O. Box 62, Oak Ridge, TN 37831 
